EMÍLIO CARLOS NELLI SILVA

\title{
MODELAGEM VIBRACIONAL DE TRANSDUTORES DE ULTRA-SOM PIEZOELÉTRICOS PELO MÉTODO DE ELEMENTOS FINITOS
}

Dissertação apresentada à Escola Politécnica da Universidade de São Paulo para obtenção do título de Mestre em Engenharia.

São Paulo

1993 
EMÍLIO CARLOS NELLI SILVA

MODELAGEM VIBRACIONAL DE TRANSDUTORES DE ULTRA-SOM PIEZOELÉTRICOS PELO MÉTODO DE ELEMENTOS FINITOS

Dissertação apresentada à Escola Politécnica da Universidade de São Paulo para obtenção do título de Mestre em Engenharia.

Área de Concentração:

Engenharia Mecânica

Orientador:

Paulo Eigi Miyagi

São Paulo

1993 


\section{Dedicatória}

Dedico esse trabalho aos meus pais por me apoiarem e darem todas as condições para que pudesse chegar até aqui.

Dedico também ao Prof. Dr. Julio Cezar Adamowski pela sua iniciativa, capacidade de coordenação e liderança, incentivando a mim e meus amigos Cláudio Simon e Flávio Buiochi a montar o laboratório de ultra-som e estabelecer linhas de pesquisa, o que permitiu definir nossos objetivos futuros. 


\section{Agradecimentos}

Agradeço ao Prof. Dr. Paulo Eigi Miyagi e ao Prof. Dr. Julio Cezar Adamowski pela orientação durante loda execução desse trabalho.

Agradeço aos caríssimos colegas e amigos Cláudio Simon e Flávio Buiochi com os quais tive proveitosas discussões.

Ao pessoal do CAETEC (Prof. Marcelo Masserani, Prof. Dr. Paulo Kaminsky e Prof. Dr. Ronaldo de Breyne Salvagni) que gentilmente cederàm a estação de trabalho "Sylicon Graphics" onde se encontra instalado o software ANSYS, sem o qual não seria possível a realização desse trabalho. À SMI Software e Marketing International, representante da "Swanson Analysis System", pela assessoria prestada no software ANSYS ao longo do trabalho. Ao pessoal do Laboratório de Engenharia Biomédica (LEB) da UNICAMP, em especial ao Prof. Dr. Eduardo T. Costa, que colocou seus equipamentos a minha disposição. Ao Instituto de Pesquisas Tecnológicas (IPT), em especial ao Engenheiro Mario, por ter doado as cerâmicas piezoelétricas, o que permitiu realizar as experiências. Ao Departamento de Física da USP (IFUSP), em especial ao Prof. Dr. Mykia Muramatsu e o Físico Gélio M. Ferreira, que realizaram as experiências de interferometria laser (permitindo visualizar os modos de vibrar da cerâmica), contribuindo para enriquecer esse trabalho.

Agradeço ainda aos demais colegas do Departamento de Engenharia Mecânica, em especial o pessoal do grupo de Automação e Sistemas - a Mecatrônica. Sem citar nomes em particular para não incorrer num erro de omissão, muito obrigado a todos vocês.

Aos meus pais, aos quais dedico grande parte do mérito desse trabalho, me apoiando e dando todas as condições para que pudesse chegar até aqui. À minha namorada Viviane, pela sua paciência e compreensão durante os fins de semana e feriados que dediquei a esse mestrado.

Por fim agradeço ao CNPQ (Conselho Nacional de Pesquisa e Desenvolvimento) pela bolsa de mestrado concedida para realização desse trabalho. 


\section{Conteúdo}

1 Introdução 1

1.1 Projeto de Transdutores ...................... 1

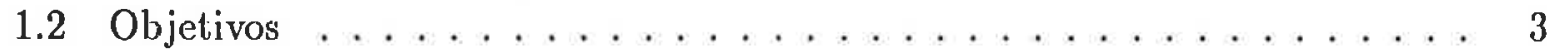

1.3 Por que utilizar o método de elementos finitos? . . . . . . . . . . . . 5

1.4 A Técnica de Apodização . . . . . . . . . . . . . . . 6

2 Revisão Bibliográfica $\quad 8$

3 Transdutores Piezoelétricos de Ultra-Som 12

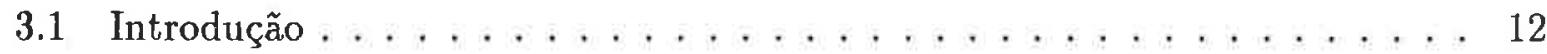

3.1.1 Características Vibracionais dos Transdutores Piezoelétricos ................. 14

3.2 Campo Acústico de um Transdutor . . . . . . . . . . . . . . 15

3.2.1 Campo Acústico de um Transdutor Operando em Onda Contínua

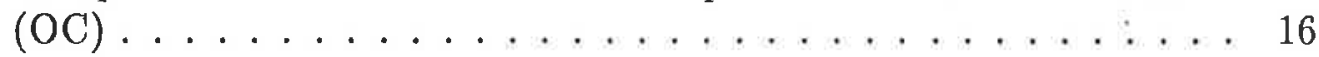

3.2 .2 Campo Acústico Transiente . . . . . . . . . . . . . . . . 19

3.2 .3 Apodização . . . . . . . . . . . . . . . . . 22

3.3 Piezoeletricidade . . . . . . . . . . . . . . . . . . 24

3.3.1 Teoria Piezoelétrica . . . . . . . . . . . . . . . . 24

3.3.2 Equações do Meio Piezoelétrico . . . . . . . . . . . . . . . . . 27

3.3.3 Materiais Piezoelétricos ................... 28

3.3.4 Equações do Meio Piezoelétrico na Forma Tensorial . . . . . . . . . 31 
3.3.5 Propagação de Onda em Materiais Piezoelétricos . . . . . . . . 35

4 MEF aplicado à Piezoeletricidade $\quad 37$

4.1 Introdução . . . . . . . . . . . . . . . . . 37

4.2 Teoria de Elementos Finitos Piezoelétricos . . . . . . . . . . . . . . 38

4.2.1 Amortecimento . . . . . . . . . . . . . . . . 41

4.2.2 Freqüências de Ressonância e Anti-ressonância . . . . . . . . . . . . 42

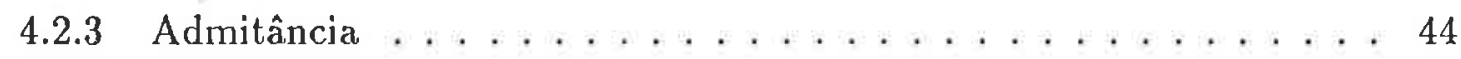

4.2.4 Coeficiente de Acoplamento Eletromecânico $(K) \ldots \ldots$. . . . . . 45

4.3 Método de Elementos Finitos aplicado à Propagação de Ondas Acústicas

(Acoplamento Fluido-Estrutura) . . . . . . . . . . . 47

5 Aplicação do Método de Elementos Finitos 50

5.1 O Elemento Piezoelétrico . . . . . . . . . . . . . . . 50

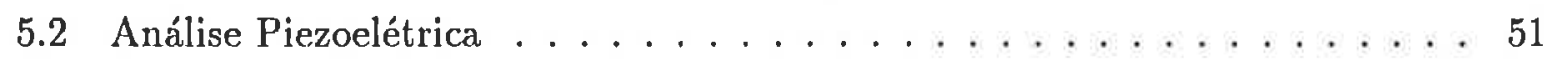

A) Estrutura Piezoelétrica Isolada . . . . . . . . . . . . . . . . . 52

B) Acoplamento Fluido-Estrutura . . . . . . . . . . . . . . . 57

5.3 Descrição dos Modelos Empregados ................. 61

A) Disco Piezoelétrico . . . . . . . . . . . . . . . 6 6 6

B) Acoplamento Fluido-Estrutura . . . . . . . . . . . . . . 65

5.4 Parte Experimental . . . . . . . . . . . . . . . 70

5.4 .1 Curva de Admitância . . . . . . . . . . . . . 70

5.4.2 Visualização dos Modos de Vibrar . . . . . . . . . . . . 70

6 Resultados e Discussões $\quad 73$

6.1 Características Vibracionais .................. 73

6.2 Apodização . . . . . . . . . . . . . . . . . 77

6.3 Análise Transiente . . . . . . . . . . . . . . . . 78

6.4 Acoplamento Fluido-Estrutura . . . . . . . . . . . . . . . 80 
6.5 Análise Transiente Acústica . . . . . . . . . . . . . . 81

7 Conclusões 102

8 Bibliografia $\quad 104$

Apêndice A

O Software ANSYS

Apêndice B

Seqüência para a execução das análises harmônica, modal e transiente no ANSYS.

Apêndice C

C.1 Constantes do Material PZT5A (formato ANSYS)

C.2 Constantes do Material P160 (formato ANSYS)

\section{Apêndice D}

Listagem das rotinas MACRO implementadas no ANSYS. 


\section{Lista de Figuras}

1.1 Resoluçâo Lateral. . . . . . . . . . . . . . . . . . . . . . . . 2

1.2 Transdutor representado por um elemento com três terminais. . . . . . . . 5

1.3 Modelo de Mason. . . . . . . . . . . . . . . . . . . 5

3.1 Transdutor piezoelétrico comum. . . . . . . . . . . . . . . 12

3.2 Transdutor multi-elemento. . . . . . . . . . . . . . 13

3.3 Ondas Plana e de Borda. . . . . . . . . . . . . . . . . . 17

3.4 Pistão Plano. . . . . . . . . . . . . . . . . . . . . . 18

3.5 Amplitude de pressão no eixo $(a / \lambda=5) \ldots \ldots \ldots \ldots$

3.6 Campo Acústico (OC) . . . . . . . . . . . . . . . . . . . . 19

3.7 Resposta Impulsiva no eixo axial. . . . . . . . . . . . . . . . . 21

3.8 Resposta Impulsiva fora do eixo axial. . . . . . . . . . . . . . . . . . . . 21

3.9 Resposta Impulsiva fora da região do pistão. . . . . . . . . . . . . . . . . 22

3.10 Campo acústico $(\mathrm{OC})$ do transdutor gaussiano. . . . . . . . . . . 23

3.11 Campo acústico $(\mathrm{OC})$ de um transdutor linear. . . . . . . . . . . 23

3.12 Transdutor SOB. . . . . . . . . . . . . . . . . . 24

3.13 Campo acústico (OC) de um transdutor SOB. . . . . . . . . . . . 24

3.14 Célula unitária deformada. . . . . . . . . . . . . . . . 26

3.15 Célula unitária genérica. . . . . . . . . . . . . . . . . . 29

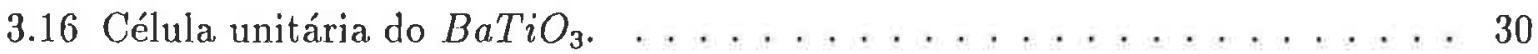

3.17 Domínio. . . . . . . . . . . . . . . . . . . . 30 
4.1 Aplicação do MEF. . . . . . . . . . . . . . . . . . . 38

4.2 Barra paralelepipidica de cerâmica piezoelétrica. . . . . . . . . . . 39

4.3 Condições de contorno, mecânica e elétrica. . . . . . . . . . . . . 43

4.4 Curva do módulo de impedância. . . . . . . . . . . . . . . . . 44

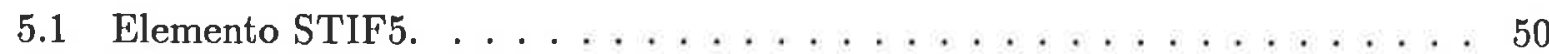

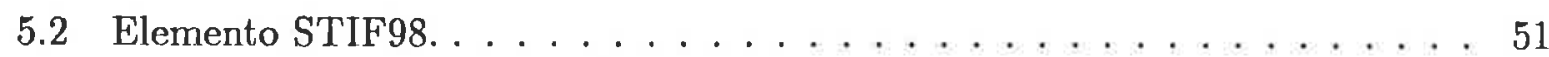

5.3 Passos de carga e incrementos de tempo. . . . . . . . . . . . . 57

5.4 Elemento STIF30. . . . . . . . . . . . . . . . 58

5.5 Modelo gerado e condições de contorno. . . . . . . . . . . . . 63

5.6 Pulso de banda limitada. . . . . . . . . . . . . . . . . . . 64

5.7 Modelo de um pistão plano. . . . . . . . . . . . . . 66

5.8 Modelos do transdutor acoplado com fluido - TCP1 e TCP2. . . . . . . 66

5.9 Modelo incluindo camadas de casamento e retaguarda - TCPMB . . . . 68

5.10 Pulso de excitação. . . . . . . . . . . . . . . . . . . . . 69

5.11 Montagem para a obtenção da curva de admitância. . . . . . . . . . 70

5.12 Montagem para visualização dos modos. . . . . . . . . . . . 71

6.1 Pulso de excitação. . . . . . . . . . . . . . . . . . 79

6.2 Amplitude de pressão ao longo do eixo do pistão para relaçôes $a / \lambda=1 \mathrm{e}$ $a / \lambda=2$ - expressão analítica. ................. 81

6.3 e $6.4,1^{\circ}$ e $2^{\circ}$ modos de ressonância (PZT5A - D/H=2,5), e respectivas visualizações por interferometria laser. . . . . . . . . . . 82

6.5 à $6.7,3^{\circ}, 4^{\circ}$ e $5^{\circ}$ modos de ressonância ( $\left.\mathrm{PZT} 5 \mathrm{~A}-\mathrm{D} / \mathrm{H}=2,5\right)$, e respectivas visualizações por interferometria laser. . . . . . . . . . . . 83

$6.81^{\circ}$ modo de ressonância (PZT5A - D/H=4), e respectiva visualização por interferometria laser. . . . . . . . . . . . . . . 84

6.9 e $6.10,2^{\circ}$ e $3^{\circ}$ modos de ressonância (PZT5A - D/H=4), e respectivas visualizações por interferometria laser. . . . . . . . . . . . . 85

6.11 Modos de vibrar na ressonância $($ PZT5A - D/H=4) . . . . . . . . 86 
6.12 e 6.13, Campo de potencial elétrico no interior da cerâmica. . . . . . . . 86

6.14 e 6.15, Curvas de admitância (PZT5A - D/H=4). . . . . . . . . 87

6.16 Curvas de admitância (PZT5A - D/H=2,5) . . . . . . . . 88

6.17 Modos de vibrar na ressonância (cerâmica apodizada) . . . . . . . . . . . . 89

6.18 Curva de admitância (cerâmica apodizada) . . . . . . . . . . . . 89

6.19 e 6.20, Deformação da cerâmica PZT5A - D/H=10) ao longo do tempo. . . 90

6.21 e 6.22, (deformação $X$ tempo) para alguns nós da face. . . . . . . . . . . . 91

6.23 à 6.28 , Campo acústico e distribuição de velocidades para o pistão plano

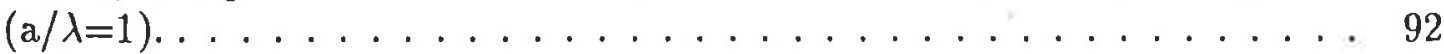

6.29 Gráficos de amplitude de pressão para o pistão plano a/ $\lambda=2$ ). . . . . . . 95

6.30 à 6.34, Campo acústico e distribuição de velocidades para o transdutor

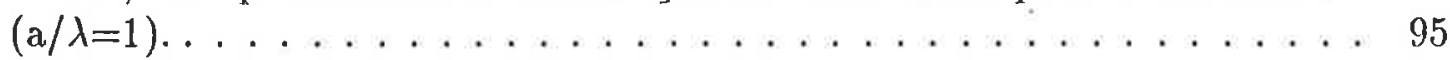

6.35 Campo acústico do transdutor com as camadas de casamento e retaguarda $(\mathrm{a} / \lambda=1,31) \ldots \ldots \ldots \ldots \ldots \ldots \ldots$

6.36 à 6.40, Campo acústico e distribuição de velocidades $(\mathrm{a} / \lambda=1,5)$. . . . . . 98

6.41 Campo acústico transiente. . . . . . . . . . . . . . . . . 101

6.40 à 6.42 , Gráficos de amplitude de pressão para pontos situados ao longo do eixo do pistão. . . . . . . . . . . . . . . . . . . . . . . 100

B.1 Seqüência para a execução das análises harmônica e modal no ANSYS. . . 112

B.2 Seqüência para a execução da análise transiente. . . . . . . . . . . . . 113 


\section{Lista de Tabelas}

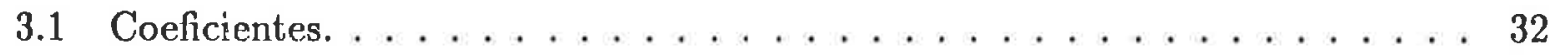

6.1 Comparação das freqüências de ressonância $(\mathrm{kHz})$ para a cerâmica PZT5A $(D / H=20)$ obtidas pelo ANSYS e pela referência [Guo 91] - RDIV=48; HDIV $=2 \ldots \ldots \ldots \ldots \ldots \ldots \ldots \ldots$. . . . . . . . . . . . . . . .

6.2 Comparação das freqüências de ressonância $(\mathrm{kHz})$ para a cerâmica P160 $(D / H=25)$ obtidas pelo ANSYS e pela referência [Lanceleur 92] - RDIV=48; $\mathrm{HDIV}=2 \ldots \ldots \ldots \ldots \ldots \ldots \ldots \ldots$

6.3 Freqüências de ressonância $\left(\omega_{r}\right)$ e anti-ressonância $\left(\omega_{a}\right)(\mathrm{kHz})$, e coeficiente piezoelétrico $(K)$ - Cerâmica PZT5A $(D / H=4) R D I V=16$ e $H D I V=8.75$

6.4 Comparação đas freqüências de ressonância $\left(\omega_{r}\right)$ com os valores experimentais $\left(\omega_{r}^{e x p .}\right)$, para a cerâmica PZT5A $(D / H=4) R D I V=16$ e $H D I V=8 . \quad 76$

6.5 Freqüências de ressonância $\left(\omega_{r}\right)$ e anti-ressonância $\left(\omega_{a}\right)(\mathrm{kHz})$, e coeficjente piezoelétrico $(K)$. As freqüências $\left(\omega_{\tau}\right)$ são comparadas com os valores experimentais - Cerâmica PZT5A $(D / H=2,5) R D I V=12$ e $H D I V=12.76$

6.6 Freqüências de ressonância $\left(\omega_{\tau}\right)$ e anti-ressonância $\left(\omega_{a}\right)(\mathrm{kHz})$, e coeficiente piezoelétrico $(K)$ - Cerâmica PZT5A $(D / H=4) R D I V=16$ e $H D I V=$ 8; apodizada segundo uma função decrescente ao longo do rajo. . . . . . . 78

6.7 Freqüências de ressonância $\left(\omega_{r}\right)$ e anti-ressonância $\left(\omega_{a}\right)(\mathrm{kHz})$, e coeficiente piezoelétrico $(K)$ - Cerâmica PZT5A $(D / H=4) R D I V=16$ e $H D I V=$ 8 ; apodizada segundo uma função ao longo do raio. . . . . . . . . . . 79 


\title{
Lista de Abreviaturas
}

\author{
END _..... Ensaios Não Destrutivos \\ FREQ ….. Freqüência \\ MEF ...... Método de Elementos Finitos \\ SOP ...... Somente Onda Plana \\ SOB $\quad$...... Somente Onda de Borda
}




\section{Lista de Símbolos}

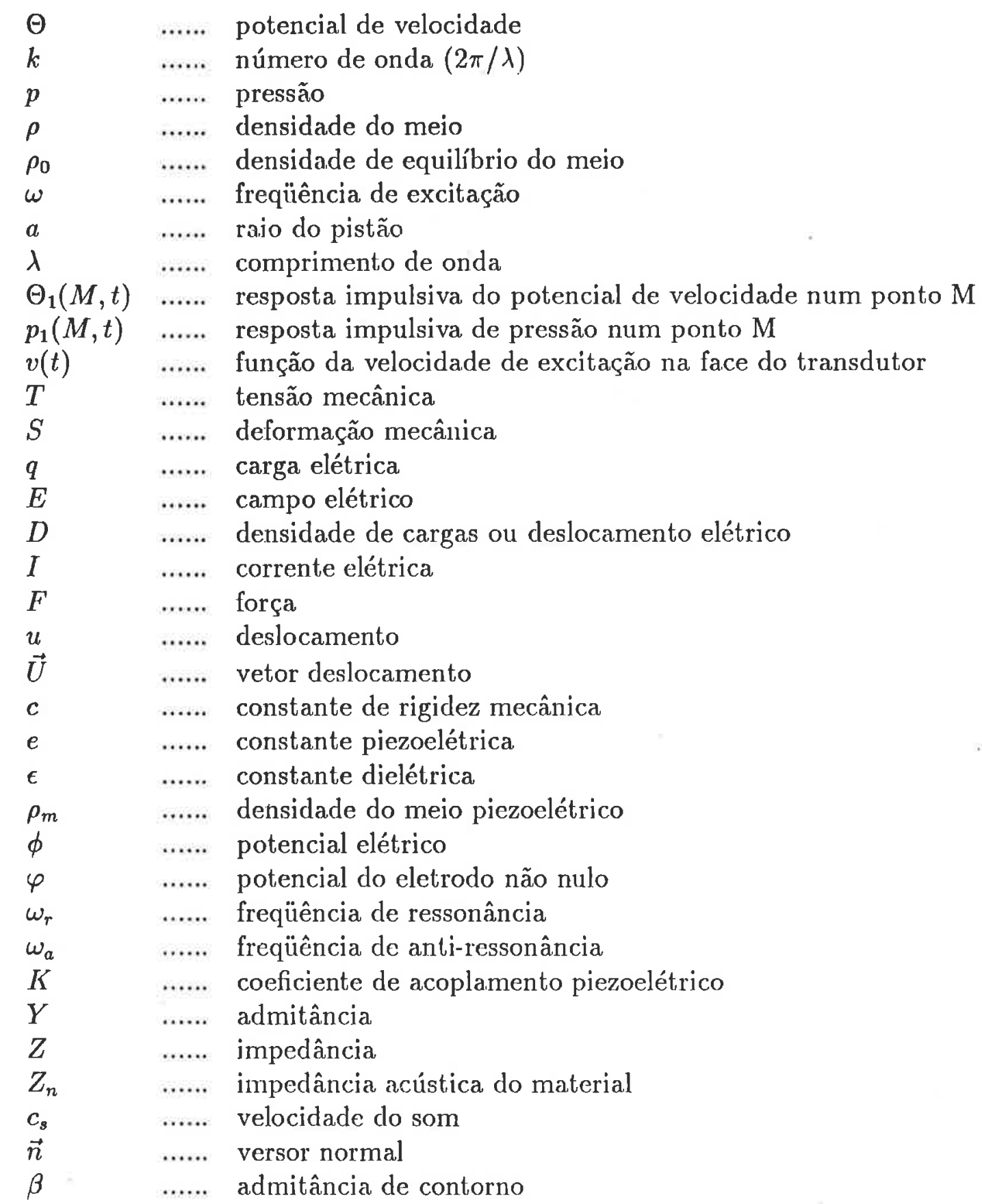




\section{Resumo}

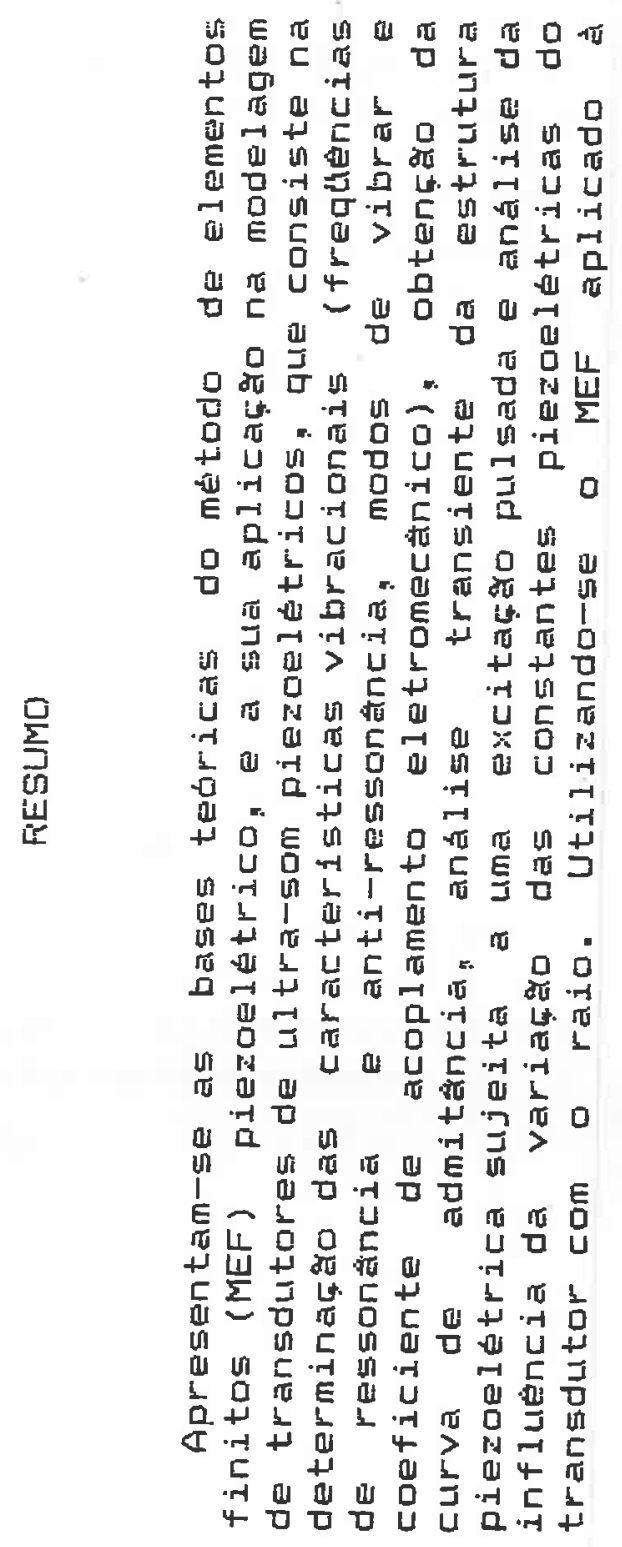




\section{Abstract}

The theoretical basis of piezoelectric finite element method (FEM), and its application in piezoelectric ultrasonic transducer modelling is presented. Among these aplications we have the calculation of resonance and antiresonance frequencies, vibration modes, piezoelectric coupling coefficient, admittance curve and transient analysis of piezoelectric structure excited by a short pulse.

By means of piezoelectric FEM, the influence of variation of a piezoelectric constant with radius is analysed. It is cliscussed three kind of functions (linear, cosinoidal and gaussian). This technique is called apodization.

The acoustic field generated by the transducer operating in continuous wave (CW) was calculated by using FEM applied to acoustics, considering the fluid-structure coupling.

The study of wave propagation in liquids is started by using FEM, analysing the waves generated by a plane piston in contact with the fluid, excited by a short pulse.

For each case discussed above, all boundary conditions and hypothesis assumed in the construction of finite element models are discussed. Although the models considered are circular transducers, the concepts acquired can be expanded to other geometries.

The vibrational modes were visualized by means of a laser interferometry technique (ESPI), and the admittance curves were measured by using an impedometer. These results were compared with the FEM results, and the models precision was discussed. 


\section{Capítulo 1}

\section{Introdução}

\subsection{Projeto de Transdutores}

Transdutores de ultra-som construídos com materiais piezoelétricos, transformam sinais elétricos (energia elétrica) em deformações estruturais (energia mecânica) que excitam o meio, gerando a onda ultrassônica. Estes transdutores são utilizados na obtenção de imagens médicas e em ensaios não destrutivos de materiais (END). A qualidade da imagem por ultra-som, bem como da análise END, depende em grande parte do desempenho do transdutor utilizado.

Atualmente a evolução dos aparelhos de ultra-som está relacionada basicamente com o desenvolvimento dos seus transdutores. No projeto de um transdutor desejam-se obter determinadas características de acordo com a sua aplicação específica. Assim por exemplo, um transdutor destinado à obtenção de imagens necessita apresentar altas resoluções lateral e axial e alta profundidade de foco. A resolução axial está relacionada com a banda de freqüências de operação do transdutor. Quanto mais larga essa banda, menor o número de ciclos do pulso emitido e menor o seu comprimento. Assim transdutores usados na obtenção de imagem caracterizam-se por serem banda larga. A largura da banda por sua vez está relacionada com a intensidade de resposta dos diferentes modos de vibrar, dependendo portanto das características vibracionais do transdutor. A resolução lateral está relacionada com a diretividade do lóbulo principal, ou seja, com a distribuição da intensidade das pressões geradas no meio. Quanto mais concentrada estiver essa distribuição no eixo geométrico do transdutor maior será a diretividade do transdutor e a sua resolução lateral, ou seja, a distinção entre dois pontos próximos (fig. 1.1). A profundidade de foco é o comprimento no qual essa concentração é máxima. A diretividade depende entre outros fatores, da razão entre o raio do transdutor e o comprimento de onda correspondente à freqüência central do pulso emitido, sendo maior quanto maior essa razão. Assim, no caso de um transdutor circular deve-se escolher um raio e espessura que atendam às exigências acima.

Já no caso de alguns transdutores destinados à recepção (hidrofones) deseja-se, por 


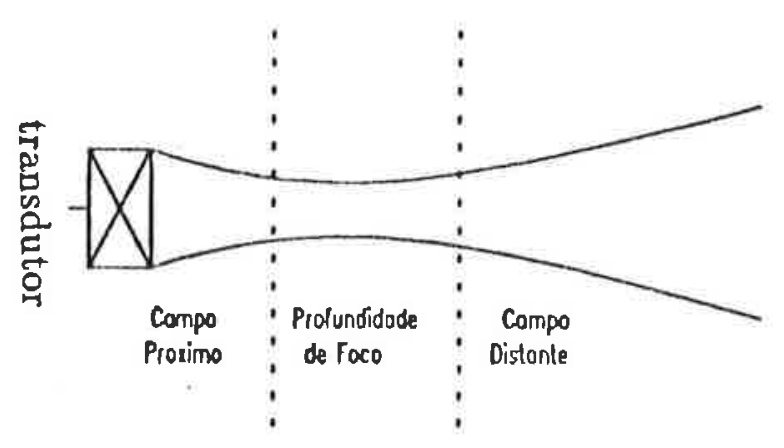

Figura 1.1: Resolução Lateral.

exemplo, que o transdutor tenha um lóbulo aberto (baixa diretividade), captando o sinal com a mesma intensidade de qualquer direção, além de apresentar uma larga banda de freqüências de operação. Nesse caso verifica-se que o transdutor deve ter um pequeno diâmetro (ex.: hidrofone tipo agulha) e características vibracionais que proporcionem uma banda larga.

Nos exemplos acima percebe-se a necessidade de se realizar simulações que permitam variar os diferentes parâmetros de projeto. Existem muitos fatores que podem influenciar o comportamento de um transdutor, entre eles a escolha do material, construção mecânica e condições externas de cargas mecânicas e elétricas. Dessas, a construção mecânica é em geral o fator que mais influencia diretamente o desempenho, através de parâmetros como área da superfície de radiação, amortecimento mecânico, encapsulamento e outras variáveis de construção física.

Além de atender as características exigidas, tem-se como objetivo principal projetar transdutores que enviem de maneira eficiente ondas acústicas para um meio adjacente, o que está relacionado principalmente com o projeto do elemento piezoelétrico. No caso de transdutores circulares, este objetivo é melhor atingido quando o elemento (disco) opera como um pistão plano, ou seja, todos os pontos da superfície oscilam com a mesma amplitude e fase (deformação uniforme), se comportando de forma unidimensional. Entretanto isto é difícil de ser conseguido, devido ao complicado espectro dos ìnodos vibracionais exibidos por um disco piezoelétrico comum. Entre esses modos, o que envia ondas acústicas com major eficiência é o modo conhecido como modo da espessura, que apresenta um deslocamento médio positivo na superfície do transdutor, além de possuir um alto acoplamento com a excitação elétrica (fortemente excitado). Na maioria das aplicações, a freqüência de operação e a dimensão do lóbulo acústico desejado ditam a escolha da espessura e o diâmetro do disco, respectivamente, como mostrado nos exemplos iniciais. Ao fazer essa escolha, é geralmente assumido que o disco piezoelétrico exibirá o comportamento de pistão rígido, com o modo da espessura (ver 3.1.1) contribuindo predominantemente para o comportamento do transdutor na freqüência de operação desejada. Em transdutores que possuern uma grande razão diâmetro/espessura $(D / H>20)$, isto é geralmente conseguido. Embora exista um enorme espectro de modos vibracionais próximos da ressonância do modo de espessura nestes casos $(D / H>20)$, a maior parte 
deles é fracamente acoplada com o campo elétrico excitante, de forma que o modo de espessura fortemente excitado predomina. Com a diminuição de $D / H$, o acoplamento com outros modos vibracionais (modos radiais) torna-se mais pronunciado afastando-se consideravelmente do pistão plano. Para razóes $D / H$ muito pequenas $(D / H<4)$, o modo de espessura deixa de existir, degenerando-se em modos de vibração complicados que são fortemente dependentes de $D / H$. Nesses casos os deslocamentos na superfície do disco diferem significativamente daquele de um pistão uniforme, e uma simples análise unidimensional não é mais aplicável, dificultando o projeto de transdutores precisos.

O desempenho do transdutor é avaliado através da determinação das suas características vibracionais, que por sua vez estão relacionadas com a geometria e as caracteristicas do material do elemento piezoelétrico.

Assim é especialmente importante poder determinar os modos vibracionais e as demais características de ressonância do elemento piezoelétrico a ser utilizado, bem como a influência de fatores como a presença das camadas de casamento e retaguarda (item 3.1), e do meio externo sobre essas características, de forma que o diâmetro e a espessura do elemento possam ser propriamente escolhidos, otimizando o desempenho do transdutor. Há necessidade portanto de se prever com precisão o comportamento dinâmico dos transdutores, o que só é possível atualmente, através de simulações computacionais.

No passado, o desenvolvimento de transclutores piezoelétricos era normalmente baseado na tentativa e erro, a qual consome tempo, apresenta um alto custo e não fornece resultados precisos. Este tipo de desenvolvimento não é consistente com a prática moderna de engenharia industrial, a qual se utiliza de simulações computacionais na previsão teórica das propriedades que se espera resultarem para um dado projeto de transdutor. Através da simulação computacional é possível utilizar um método numérico geral que permite obter as características vibracionais para diferentes geometrias e materiais de transdutores. Dessa forma pode-se determinar os parâmetros de construção do transdutor (diâmetro, espessura, etc ...) que forneçam características vibracionais desejadas de acordo com um tipo específico de aplicação. Dessa forma a simulação computacional constitui uma ferramenta moderna de grande potencial para melhorar o projeto de transdutores. Os principais objetivos das simulações computacionais no desenvolvimento de transdutores são [Lerch 90]:

- Otimização do projeto de transdutores

- Avaliação de novos materiais na construção de transdutores

- Maior profundidade no estudo de propagação de ondas em sólidos piezoelétricos

\subsection{Objetivos}

Este trabalho trata da modelagem de estruturas piezoelétricas através do método de elementos finitos (MEF) e procura mostrar a sua utilização como uma ferramenta importante 
na análise de transdutores de ultra-som piezoelétricos que permite obter as características vibracionajis do transdutor, bem como o campo acústico gerado pelo mesmo. Para isso foram estabelecidas as seguintes etapas:

- Determinar utilizando o MEF, as características vibracionais da estrutura piezoelétrica, importantes para a realização de um projeto otimizado do transdutor de ultra-som piezoelétrico, através de análises e modelos que permitam simular o comportamento dinâmico da estrutura piezoelétrica. Incluem-se entre as análises: análise modal, harmônica (resposta a uma excitação harmônica) e transiente (resposta a uma excitação transiente) (itein 5.2).

- Utilizando a teoria do MEF aplicada à acústica, obter o campo acústico num meio fluido gerado pelo transdutor sujeito a uma excitação harmônica, identificando as suas principais caracteristicas.

- Mostrar o potencial do MEF no estudo da influência da variação de algumas propriedades piezoelétricas na direção radial de um transdutor circular (técnica de apodização - item 3.2 .3 ), sobre suas características vibracionais.

São considerados nas simulações transdutores circulares, por serem muito utilizados, e portanto apresentarem vasto material sobre suas características na literatura científica. Dessa forma foi possivel realizar um estudo comparativo, verificando se as hipóteses adotadas na modelagem do transdutor são razoáveis. Para as demais geometrias os conceitos adquiridos continuam válidos.

Devido às aplicações em que são utilizados (obtenção de imagens médicas, END, etc ...), os transdutores estudados são excitados com baixa potência $(\sim 20 W)$, de maneira que o material piezoelétrico opera na sua região linear.

Os falores que influenciam as características vibracionais do transdutor são inúmeros (entre eles as características do circuito elétrico de excitação ou recepção do transdutor, camadas de retaguarda e casamento, etc...) sendo que para cada aplicação somente alguns são levados em consideração no projeto. Nesse trabalho é mostrada a influência da variação de algumas propriedades piezoelétricas na direção radial do transdutor (apodização) e da presença de um meio fluido externo nas características vibracionais, com o objetivo de mostrar a potencialidade do método de elemcintos finitos como uma ferramenta no projeto do transdutorcs piczoslétricos.

A técnica de apodização vem sendo utilizada recentemente na otimização de transdutores, não se encontrando por isso publicações de autores que tenham utilizado elementos finitos para o estudo desse tema. Dessa forma devido a sua importância atual, realizou-se um estudo preliminar da técnica de apodização, mostrando o potencial do uso do MEF aplicado à piezoeletricidade no seu estudo, despertando interesse para pesquisas futuras. Para isso variou-se uma das propriedades piezoelétricas do transdutor ao longo do raio. 


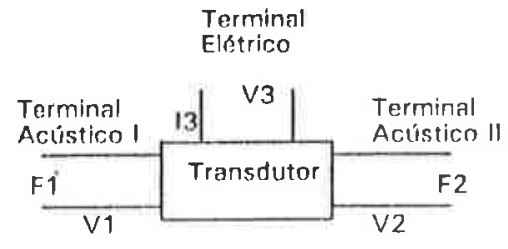

Figura 1.2: Transdutor representado por um elemento com três terminais [Kino 87].

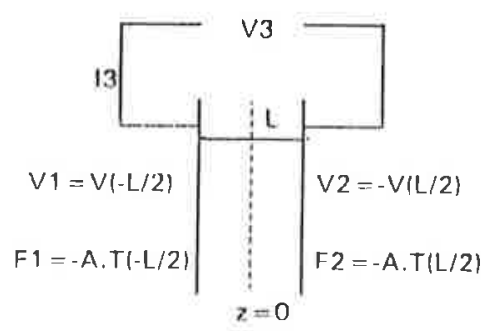

Figura 1.3: Modelo de Mason [Kino 87].

\subsection{Por que utilizar o método de elementos finitos?}

Os modelos comumente usados para simular o comportamento mecânico e elétrico dos transdutores piezoelétricos geralmente introduzem hipóteses simplificadoras, que nem sempre são válidas para as situações reais. Entre esses modelos, os majs comuns são os que se utilizam de circuitos elétricos eqüivalentes para representar o transdutor, considerando um comportamento unidimensional, ou seja, as dimensões da secção do transdutor são muito maiores que a sua espessura, de maneira que não haverá movimento transversal, somente longitudinal (pistão rígido - a vibração é expressa como uma única variável).

Consiste em considerar o transdutor como sendo um elemento com três terminais (dois mecânicos e um elétrico). Define-se então a força na superfície do transdutor como sendo tensão elétrica no circuito elétrico, e a velocidade da partícula como sendo corrente, como mostrado na fig. 1.2. Utilizando-se a notação da fig. 1.2 para a representação do transdutor e a mostrada na fig. 1.3 para o transdutor físico, pode-se determinar um circuito elétrico eqüivalente para essa representação.

A força externa aplicada na superfície do transdutor vale $F=-A * T$ onde $A$ é a área do transdutor e ' $T$ ' as tensões mecânicas internas. Portanto as definições dos circuitos equiivalentes usadas na teoria piezoclétrica de transdutores são baseadas na idéia de que a velocidade da partícula é eqüivalente à corrente, e a tensão mecânica à tensão elétrica. Assim, uma vez obtido o circuito, utiliza-se as teorias de linhas de transmissão e circuitos elétricos para determinar o comportamento unidimensional do transdutor.

Esse tipo de modelo é muito prático quando se tem um transdutor com várias camadas, sendo cada uma modelada através de um circuito, que posteriormente é colocado em 
série (ou em paralelo conforme o modelo) com os demais. Entre os principais circuitos utilizados tem-se o de Mason, o de Redwood e o KLM, que utilizam linhas de transmissão na modelagem do transdutor [Kino 87].

Entretanto as geometrias dos transdutores utilizados na prática são normalmente bi (2-D) ou tridimensionais (3-D), o que faz com que as hipóteses unidimensionais adotadas pelos modelos de circuito elétrico estejam distantes da realidade. Para a simulação (2D) e (3-D) do meio piezoelétrico um conjunto completo de equações fundamentais que governam esse meio devem ser resolvidas. $\mathrm{Na}$ literatura encontram-se muitos autores que resolveram essas equações analiticamente para casos particulares (geometrias simples), chegando a soluções aproximadas através de métodos numéricos.

O método de elementos finitos apresenta-se como uma boa opção, pois é suficientemente geral para resolver essas equações diferenciais e permite manipular geometrias complexas em 2-D e 3-D, constituindo um método geral de análise aplicável a qualquer configuração de transdutor. Assim, a utilização do método de elementos finitos aplicado à piezoeletricidade permite uma simulação rápida do transdutor com uma alta precisão, sendo utilizado com freqüência no projeto de diferentes tipos de transdutores piezoelétricos [Kagawa 76,Lerch 90].

É importante ressaltar que outros métodos numéricos, tão gerais quanto o de elementos finitos, também podem ser utilizados nesse tipo de problema, podendo-se discutir as vantagens e desvantagens de cada um. Porém o método de elementos finitos além de ser um método preciso (em relação por exemplo ao método de diferenças finitas), vem sendo bastante utilizado atualmente graças à evolução computacional, extendendo-se sua aplicação para as diversas áreas de engenharia (cálculo de campo elétrico, magnético, escoamento de fluidos, etc ...). O objetivo desse trabalho, no entanto, foi estudar uma ferramenta geral que possa ser utilizada no projeto de transdutores, e não realizar um estudo comparativo dos métodos numéricos existentes para isso.

\subsection{A Técnica de Apodização}

Os efeitos de difração (ondas plana e de borda) (item 3.2.2) limitam a resolução lateral para um dado transdutor piezoelétrico, e geralmente introduzem uma variação espacial no perfil do pulso emitido e recebido. Isto é acentuado pelo fato do disco piezoelétrico não vibrar como um pistão rígido. Diversos modos de vibração contribuem para a distorção, que em geral, é difícil de medir ou prever segundo uma base teórica. Estes efeitos distorcem as imagens dos aparelhos de ultra-som. Os efeitos de difração são particularmente evidentes no campo próximo dos transdutores e em conseqüência, torna difícil a detecção de pequeno corpo (p. ex.: trinca numa peça) situado nessa região, pela dificuldade de relacionar o eco com as características do corpo. Além disso é igualmente difícil projetar e implementar estratégias inversas de processamento de sinais (por exemplo deconvolução) que sejam válidas ao longo do campo acústico, pois as técnicas de correlação e filtragem inversa usadas para o aumento da resolıção e caracterização, estão restritas geralmente ao campo 
muito distante onde alguma consistência no perfil do pulso é encontrada [Hayward 91].

O problema de projetar discos piezoelétricos que gerem características desejadas no campo acústico tem sido investigado por muitos pesquisadores. Existem técnicas propostas, conhecidas como apodização, em que variando-se uma certa características do transdutor ao longo do raio, procura-se reduzir o efeito das ondas de borda ou das ondas planas, gerando um campo acústico uniforme ou estritamente diretivo, sendo o segundo caso excelente para a obtenção de imagens. Assim por exemplo, Claus et al. [Claus 83] propoem uma distribuição de amplitudes Gaussiana ao longo do raio que reduz a um mínimo a contribuição das ondas de borda proporcionando um campo uniforme. 


\section{Capítulo 2}

\section{Revisão Bibliográfica}

A necessidade de se projetar $11 \mathrm{~m}$ transdutor com um alto coeficiente eletromecânico, e que envie de maneira eficiente ondas de compressão para um meio, exige um modelo que represente o transdutor de forma precisa levando em conta todos os efeitos que influenciam no seu funcionamento. Como já visto (Capítulo 1), os modelos unidimensionais que se utilizam de circuitos elétricos eqüivalentes para representar o transdutor (modelos de MASON e KLM [Kino 87]), consideram hipóteses simplificadoras que muitas vezes estão fora da realidade, gerando resultados inconsistentes. É o que ocorre quando a relação $D / H$ do transdutor circular diminui, aparecendo modos de vibrar complexos, que se afastam do modelo unidimensional.

$\mathrm{Na}$ tentativa de entender o comportamento vibracional dos materiais piezoelétricos, Shaw [Shaw 56] realizou um dos primeiros estudos experimentais dos modos vibracionais de um disco de cerâmica piezoelétrica $\left(\mathrm{BaTiO}_{3}\right.$ - Ticanato de bário). Shaw visualizou os doze primeiros modos de discos cerâmicos com relação diâmetro/espessura $(D / H)$ variando entre 1 e 6,6, utilizando técnicas de interferometria laser para mapear os deslocamentos na face do disco a cada freqüĉncia de ressonância, além de obter os coeficientes de acoplamento piezoelétrico em cada modo. Embora nenhum modelo teórico tenha sido apresentado, Shaw tentou explicar a possível origem física de suas observações utilizando modelos unidimensionais. Gazis e Mindlim [Gazis 60] tentaram interpretar os resultados de Shaw modelando os modos vibracionais de um disco isotrópico não-piezoelétrico com uma razão de Poisson isotrópica escolhida de maneira a se ajustar os resultados às observações experimentais de Shaw. Obtiveram uma boa concordância qualitativa com os resultados de Shaw, mas a omissão da anisotropia e piezoeletricidade no modelo limitou sua precisão. Ikegami et al. [Ikegami 74] realizou experiências semelhantes às de Shaw com o titanato de chumbo modificado, um material de grande interesse devido ao seu baixo coeficiente de acoplamento radial. Mediram-se as freqüências de ressonância e o coeficiente de acoplamento eletromecânico numa série de discos com a relação $D / H$ variando entre 5 e 30 . Examinando-se os resultados os autores classificaram os modos piezoelétricos de vibração dos discos de grande relação $D / H$ em cinco tipos: três tipos de modo de espessura (modos $\mathrm{T}$, modos $\mathrm{TE}$ e modos $\mathrm{E}$ ) e dois tipos de modos radiais (modo 
$\mathrm{R}$ e modo A). Uma razoável aproximação teórica foi obtida para os resultados utilizando o modelo do disco isotrópico de Gazis e Mindlim com uma razão de Poisson isotrópica de 0,18. Dessa forma era necessário um método geral capaz de levar em conta a anisotropia, a piezoeletricidade e a geometria do problema, como é o caso do método de elementos finitos.

Se o estudo variacional de estruturas elásticas foi desenvolvido na década de 40 , foi necessário esperar até a década de 60 quando Holland e Eer Nisse [EerNisse 67], e Tiersten [Tiersten 67] desenvolveram a formulação variacional para estruturas eletro-acústicas. Eer Nisse aplicou essa formulação variacional para o problema do disco piezoelétrico de $\mathrm{BaTiO}_{3}$, calculando as freqüências e modos de ressonância. Os resultados foram comparados com as experiências de Shaw obtendo uma boa concordância. A aplicação do MEF iniciou-se na década de $70 \mathrm{com}$ o desenvolvimento de um sonar e alguns transdutores utilizados na obtenção de imagens médicas por Smith et al. [Smith 73] e Allik et al. [Allik 74]. Posteriormente outros autores passaram a utilizar o MEF para dimensionar estruturas piezoelétricas. Kagawa e Yamabushi [Kagawa 76] analisaram transdutores circulares com várias relações $D / H$, determinando os três primeiros modos e freqüências de ressonância, entretanto não determinando os coeficientes de acoplamento eletromecânico. Já Boucher et al. [Boucher 81] analisou estruturas piezoelétricas de forma cúbica, determinando suas freqüências de ressonância e anti-ressonância e os coeficientes de acoplamento piezoelétrico. No cálculo das freqüências de anti-ressonância utilizou-se o método das perturbações (item 4.2.4), o que reduziu o tempo computacional.

Outros autores encontraram grande aplicação do MEF no desenvolvimento de transdutores multi-elemento (item 3.1). Assim Sato et al. [Sato 79] estudaram os dois primeiros modos de pequenas barras de cerâmica com relações largura/espessura variando entre 0,2 e 2, utilizadas em transdutores multi-elemento. Determinou-se a geometria que maximiza o coeficiente de acoplamento piezoelétrico do menor modo. Naillon et al. [Naillon 83] apresentam um texto completo sobre a teoria de elementos finitos aplicado à piezoeletricidade, analisando, como exemplo de aplicação, os seis primeiros modos de pequenas barras de cerâmica paralelepipidicas com relações largura/espessura também variando entre 0,2 e 2, utilizadas em transdutores multi-elemento. Determinou-se as curvas de impedância, bem como a geometria que maximiza o coeficiente de acoplamento eletromecânico. Os resultados obtidos foram comparados com os resultados experimentais, obtendo-se boa concordância. Lerch [Lerch 90] também estudou a otimização da geometria para o coeficiente piezoelétrico dessas barras de cerâmica. Obteve as curvas de impedância para diferentes formas (relação largura/espessura variando entre 0,2 a 3), além de analisar o acoplamento mecânico entre essas barras para diferentes montagens de camadas de casamento e de retaguarda no transdutor multi-elemento. Entretanto os transdutores mais comuns são os circulares, sendo de grande importância um estudo majs detalhado sobre os mesmos. Dessa forma Kunkel et al. [Kunkel 90] fazem uma análise completa dos modos de vibrar, freqüências de ressonância e anti-ressonância, e coeficiente de acoplamento piezoelétrico para transdutores circulares de material cerâmico $\mathrm{PZT} 5 \mathrm{H}$, com relação $D / H$ entre 0,2 e 10 . O espectro de freqüência obtido pelos autores fornece importantes informaçôes sobre o comportamento dos discos cerâmicos a medida que se varia a relação $D / H$, discutindo-se através da teoria de propagação de ondas em materiais piezoelétricos 
o aparecimento do modo extensional de espessura (ou modo de espessura).

A análise piezoelétrica é implementada num software comercial no fim da década de 80, com Ostergaard e Pawlak [Ostergaard 86] analisando transdutores circulares e cúbicos através do MEF piezoelétrico recém-implementado no software ANSYS, comparando os resultados obtidos com os de Shaw e Boucher. Além disso apresentam um estudo sobre a utilização de graus mestres (Redução de Guyan) (apêndice A) em estruturas piezoelétricas. Entre outras aplicações destacam-se os sonares, como Dubus et al. [Dubus 91] que estudam o desenvolvimento de sonares através do MEF, realizando análises de tensões mecânicas e resistência à fadiga (alta potência de operação).

Entretanto devido à alta freqüência de operação (da ordem de $\mathrm{MHz}$ ) os transdutores piezoelétricos encontram-se emitindo num meio fluido (em geral água), onde a atenuação é baixa. Isso fez com que se passasse a levar em conta a presença do fluido. Na determinação do campo acústico foram desenvolvidos vários equacionamentos do $\mathrm{MEF}$, todos baseados nas hipóteses da equação de onda (item 4.3). Smith et al. [Smith 73] realizaram esse tipo de análise para três tipos de estruturas eletro-acústicas utilizadas na construção de sonares, caracterizando-se como um dos primeiros trabalhos na área. Kagawa e Yamabushi [Kagawa 79] determinaram o campo acústico gerado por um transdutor piezoelétrico circular montado em diferentes configurações. Varadan et al. [Varadan 90] apresentam um MEF híbrido para simulação numérica de barras de material composto (polímero e cerâmica) oscilando num meio fluido. Já Lanceleur et al. [Lanceleur 92] estuda a variação da freqüência de ressonância em transdutores circulares de alta relação $D / H$ $(20,15$ e 25), considerando três tipos de meios fluidos: água, um fluido de alta densidade e um fluido de densidade intermediária.

Na maior parte das aplicações, principalmente em END, os transdutores piezoelétricos são excitados com um pulso banda larga, fazendo com que o estudo do comportamento transiente do transdutor assuma grande importância. Entretanto poucos trabalhos foram publicados até agora. Guo e Cawley [Guo 91] realizando uma análise por superposição modal, estudaram a influência dos diversos modos de vibrar na deformação de transdutores circulares com relação $D / H$ igual à 10 e 20 , sujeitos a uma excitação impulsiva e de um ciclo de senóide de $1 \mathrm{MHz}$. Lanceleur et al. [Lanceleur 92] simulam a deformação de transdutores circulares sujeitos a uma excitação impulsiva e na presença de três tipos diferentes de fluido (já comentados). Além disso os autores realizam um estudo do comportamento transiente do disco piezoelétrico analisando a propagação de ondas na face do mesmo. Entretanto o modelo utilizado no acoplamento fluido-estrutura não permite representar o transdutor por inteiro, obtendo somente a deformação na sua face.

\section{A Técnica de Apodização}

A técnica de apodização em transdutores vem sendo sugerida com o intuito de se obter um campo acústico melhor comportado. Existem diversas técnicas propostas atualmente para se realizar a apodização. Hayward et al. [Hayward 91] propoem uma técnica que permite obter uma variação de tensão elétrica logarítmica ao longo do eletrodo. Já Weight 
[Weight 84b] sugere a construção de um transdutor com perfil de velocidades decrescente ao longo do raio (somente onda plana - SOP) e outro com perfil de velocidades crescente (somente onda de borda - SOB) (item 3.2.3), que apresenta um campo altamente diretivo, excelente para aplicações em END. Claus et al. [Claus 83] apresentam o projeto e construção de um transdutor com distribuição de potencial elétrico gaussiano ao longo do raio, obtendo um campo acústico uniforme. Entretanto não há conhecimento da utilização do MEF piezoelétrico no estudo da técnica de apodização. 


\section{Capítulo 3}

\section{Transdutores Piezoelétricos de Ultra-Som}

\subsection{Introdução}

Um transdutor piezoelétrico é constituído basicamente por um material piezoelétrico, a camada de casamento e a camada de retaguarda (fig. 3.1). O material piezoelétrico é o elemento ativo no transdutor, transformando pulsos elétricos (energia elétrica) em deformações estruturais (energia mecânica) e vice-versa. Essas deformações excitam o meio gerando as ondas ultrassônicas. A camada de casamento é destinada ao casamento de impedância do material piezoelétrico com o meio externo (líquido), diminuindo a reflexão de ondas nessa interface. A camada de retaguarda atua como um amortecedor das vibrações do material piezoclétrico, quando o mesmo é excitado por um pulso (elétrico ou mecânico), e como um refletor no caso cm que consiste de uma camada de ar, direcionando a energia emitida pelo transdutor para um único sentido. $O$ contato elétrico com o elemento piezoelétrico é conseguido através de eletrodos de metais.

O material piezoelétrico do transdutor pode apresentar diferentes formas, sendo a mais comumente utilizada a forma circular ou cilíndrica. Já em transdutores do tipo multi-elemento, muito utilizados na obtenção de imagens médicas, o material piezoelétrico apresenta a forma de barras paralelepipidicas montadas de forma intercalada sobre uma

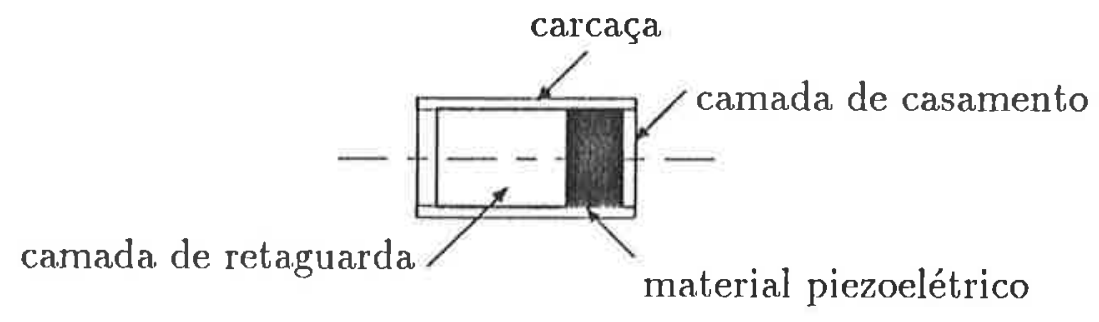

Figura 3.1: Transdutor piezoelétrico comum. 


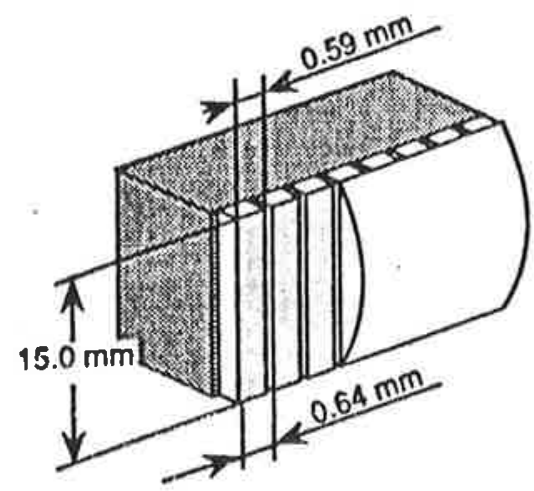

Figura 3.2: Transdutor multi-elemento [Kino 87].

mesma estrutura (camadas de retaguarda e de casamento) (fig. 3.2).

Além dos transdutores de ultra-som piezoelétricos, existem também os transdutores eletromagnéticos (que podem operar em altas temperaturas e numa ampla faixa de freqüências), os magneto-estrictivos e os capacitivos. Um que merece destaque é o transdutor eletrostático (capacitivo), utilizado para emissão no ar, operando na faixa de $\mathrm{kHz}$ [Asher 83].

Os transdutores de ultra-som piezoelétricos são utilizados na área médica para a obtenção de imagens, em sonares, sensores de robótica, atuadores eletromecânicos, ensaios não destrutivos de materiais (END), aparelhos de medição de vazão, etc..., sendo que os avanços tecnológicos dos aparelhos disponíveis comercialmente para essas aplicações estão relacionados basicamente com o desenvolvimento dos transdutores piezoelétricos. Em geral, na obtenção de imagens e em END, os transdutores operam em freqüências da ordem de $\mathrm{MHz}$. Dessa forma, pelo fato da atenuação ser muito alta no ar nessa faixa de freqüências, estes transdutores devem operar em meios líquidos e sólidos, onde o efeito da atenuação em altas freqüências é bem menor.

Os materiais piezoelétricos utilizados nos transdutores devem possuir várias qualidades, entre elas: alto coeficiente e acoplamento eletromecânico $(K)$, para uma boa conversão entre energia elétrica e mecânica; uma impedância acústica $(Z)$ próxima do meio propagante, para evitar reflexões de ondas na interface meio-transdutor; uma alta constante dielétrica $(\epsilon)$, para garantir um bom acoplamento elétrico com os circuitos elétricos de excitação e recepção; e baixas perdas elétricas e mecânicas, para uma alta sensibilidade. Entre os materiais piezoelétricos mais utilizados tem-se as cerâmicas e os polímeros. As cerâmicas apresentam um alto acoplamento ( $K \cong 0.4-0.5)$, larga faixa de constantes dielétricas $(\epsilon \cong 100-2500)$ e baixas perdas, entretanto apresentam uma alta impedância acústica $(Z \cong 20-30 \mathrm{Mrayl})$, sendo necessária a camada de casamento já descrita. No caso do transdutor ser usado em meios sólidos (como é o caso em END), é necessário ainda utilizar um gel que realize o casamento de impedância entre a camada de casamento e o meio sólido. Já os polímeros piezoelétricos (PVDF) apresentam uma baixa impedância acústica $(Z \cong 4 \mathrm{Mrayl}$ ), mas possuem a sensibilidade limitada devido a.o baixo fator de acoplamento eletromecânico $(K<0.3)$ e altas perdas elétricas. Assim, como ambos os 
materiais não satisfazem as características desejadas, está se desenvolvendo atualmente os chamados compostos piezoelétricos que reúnem as melhores propriedades das cerâmicas e dos polímeros, ou seja alta fator de acoplamento eletromecânico ( $K \cong 0.6-0.75)$, baixa impedância acústica $(Z<7.5 \mathrm{Mrayl})$, larga faixa de constantes dielétricas $(\epsilon \cong 10-1000)$ e baixas perdas mecânicas e elétricas [Challande 90,Ristic 83]. Consistem em pequenos elementos de cerâmica com o mesmo formato, inseridos num polímero formando uma matriz.

A forma de onda de ultra-som emitido pelo transdutor pode ser basicamente de três tipos: onda contínua (OC), "burst" (pulso com vários ciclos) e pulsos curtos de alguns ciclos. No caso de operação em onda contínua (OC) utiliza-se um transdutor para emissão e outro para recepção das ondas (hidrofone), mas no caso de ser emitido um "burst" ou um pulso curto de ultra-som, um único transdutor pode ser usado como emissor e receptor (modo pulso-eco).

O acoplamento eletromecânico (ver adiante) do elemento piezoelétrico e o acoplamento elétrico com o circuito elétrico de excitação ou recepção dependem da aplicação específica. As aplicações em geral constituem basicamente duas categorias, conforme a banda de freqüências do sinal emitido: banda larga e banda estreita [O'Donnell 81].

Nas aplicações banda estreita o transdutor emite um sinal harmônico ou de caráter periódico (sinal com alguns ciclos). Um exemplo de aplicação é a medição da atenuação ultrassônica de um material numa certa freqüência, em que o transdutor piezoelétrico faz parte de um composto ressonante constituído do transdutor mais o material a ser analisado.

Já transdlutores banda larga são utilizados em aplicações onde se deseja pulsos curtos, como por exemplo, obtenção de imagens por ultra-som, medição rápida da velocidade de fase e da atenuação sobre uma faixa de freqüências, entre outras.

A obtenção de um transdutor banda larga ou estreita pode ser conseguida, além dos métodos convencionais [Kino 87,0'Donnell 81], através da alteração da intensidade de resposta dos diversos modos de transdutor. Dessa forma pode-se obter um transdutor banda estreita construindo um espectro com uma dada freqüência de ressonância apresentando uma resposta intensa, e as demais bem próximas desta, com respostas de baixa intensidade. Isso pode ser feito alterando-se os coeficientes de acoplamento piezoelétricos $(K)$ de cada modo, cujos valores são conseguidos através de simulações computacionais.

\subsubsection{Características Vibracionais dos Transdutores Piezoelétricos}

As características vibracionais dependem do material piezoelétrico utilizado e da configuração geométrica do transdutor, influenciando na distribuição da intensidade do campo acústico, bem como na eficiência com que o transdutor transforma energia elétrica em mecânica (deformação da estrutura piezoelétrica). Entre as características vibracionais 
tem-se as freqüências de ressonância e anti-ressonância, modos de vibrar e coeficiente de acoplamento piezoelétrico.

- Freqüências de ressonância e anti-ressonância: Ambas as freqüências podem ser associadas com o conceito de impedância elétrica do transdutor. Assim a freqüência de ressonância é definida como a freqüência em que o módulo da admitância é máximo ( $\left.\left.Y\right|_{\text {máx }}\right)$, enquanto que a freqüência de anti-ressonância, a freqüência em que o módulo da admitância é mínimo $\left(|Y|_{\min }\right)$ [Standard 78]. No cap.4 estas freqüências serão apresentadas com maior detalhe.

- Coeficiente de acoplamento piezoelétrico $(K)$ : Indica a eficiência com que num dado modo de vibrar, a energia elétrica é transformada em energia mecânica, mostrando assim a significância desse modo em relação aos demais. Se o $K$ de um certo modo é cerca de $50 \%$ ou mais, esse modo será fortemente excitado. Ele indica o acoplamento que existe entre a excitação elétrica (em geral um campo elétrico aplicado ao longo da espessura) e o modo de vibrar. O cálculo desse coeficiente é apresentado com detalhe no cap.4.

- Modos de vibrar: A cada freqüência de ressonância e anti-ressonância estão associados modos de vibrar. No caso de um disco piezoelétrico identificam-se os modos radiais, que apresentam uma grande variação dos deslocamentos axiais do disco com o raio. Quanto maior a relação $D / H$ do disco, mais os modos de vibrar do mesmo se aproximam dos modos do modelo unidimensional (placa infinita), que podem ser considerados modos puros, ou seja, desacoplados. A medida que a relação $D / H$ diminui a presença das bordas do disco se faz sentir, provocando um acoplamento entre os modos puros, afastando-se do modelo unidimensional. Esse acoplamento pode dar origem a outros modos, como é o caso do modo de expansão de comprimento que surge para relações $D / H<0,5$. Num disco piezoelétrico, os modos que apresentam os mais altos coeficientes piezoelétricos são os primeiros modos (modos radiais), e também o modo extensional de espessura (ou modo de espessura), que resulta da propagação de uma onda longitudinal na direção da espessura (ver item 3.3.5). Por ser um modo de alta freqüência e alto coeficiente piezoelétrico o modo de espessura assume grande importância no projeto de transdutores [Kunkel 90].

\subsection{Campo Acústico de um Transdutor}

O campo acústico de um transdutor é a característica que limita o desempenho de um dado sistema uma vez que se seu comportamento é desconhecido, a tarefa de recuperar informações correspondente ao meio sob investigação torna-se difícil [Hutchins 90]. Neste item será descrito o campo acústico de um transdutor de ultra-som circular irradiando num fluido, sujeito a excitações harmônicas e pulsadas. Apesar da teoria ser apresentada para transdutores circulares, a mesma pode ser expandida para transdutores de geometria arbitrária. 
A extensão dessas aproximações teóricas para o estudo de campo acústico em um meio sólido é também possível, embora devido à presença de ondas adicionais de cisalhamento, a análise é mais complicada.

As teorias que serão descritas foram originalmente desenvolvidas considerando um transdutor ideal, ou seja, um transdutor que se comporte como um pistão plano (amplitudes e fases de vibração são constantes ao longo da superfície do transdutor), o qual tem sido assunto de muito estudo teórico.

\subsubsection{Campo Acústico de um Transdutor Operando em Onda Contínua (OC)}

Quando um transdutor é excitado numa única frequiência, diz-se que está sob excitação de onda contínua. Na maior parte dos casos, este tipo de excitação é aproximado por um sinal harmônico com somente alguns ciclos. Este tipo de excitação é usado em várias aplicações, como processamento de materiais em alta potência, limpadores ultrassônicos, sonares e em certas aplicações médicas de ultra-som como medição de temperatura. Em todas essas aplicações, é importante conhecer com detalhes a distribuição da energia ultrassônica através do campo acústico.

\section{Modelo do Pistão Plano}

Várias aproximações teóricas para excitação em OC têm sido apresentadas para o caso de transdutores circulares e retangulares. Em todas elas, o ponto de início é encontrar uma solução para a integral de Rayleigh, apresentada abaixo:

$$
\Theta=\iint_{S} \frac{V_{0} e^{j \omega\left(t-\frac{r^{\prime}}{c_{s}}\right)}}{2 \pi r^{\prime}} d S
$$

onde $r^{\prime}$ é a distância de um ponto do campo em relação a um elemento de área da superfície $(d S)$ do disco e $V_{0}$ a amplitude da velocidade normal à face do pistão. Trata-se de uma integral de superfície válida para superfícies planas, onde o potencial de velocidade final num dado ponto do campo resulta da contribuição de uma série de fontes pontuais na superfície do transdutor (Princípio de Huygens), ou seja, supõe-se que cada ponto radiante contribue para o campo total numa dada posição do campo do transdutor. A pressão será dada por [Kinsler 82]:

$$
p=-\rho \frac{d \Theta(x, z)}{d t}=-j \omega \rho \Theta(x, z)
$$

onde $\omega$ é a freqüência de excitação. Assim as variações em $p$ são eqüivalentes ao do potencial de velocidade.

Uma solução para o problema foi obtida, demonstrando-se que o campo acústico pode ser entendido como sendo resultado da soma de dois tipos de onda: onda plana e 

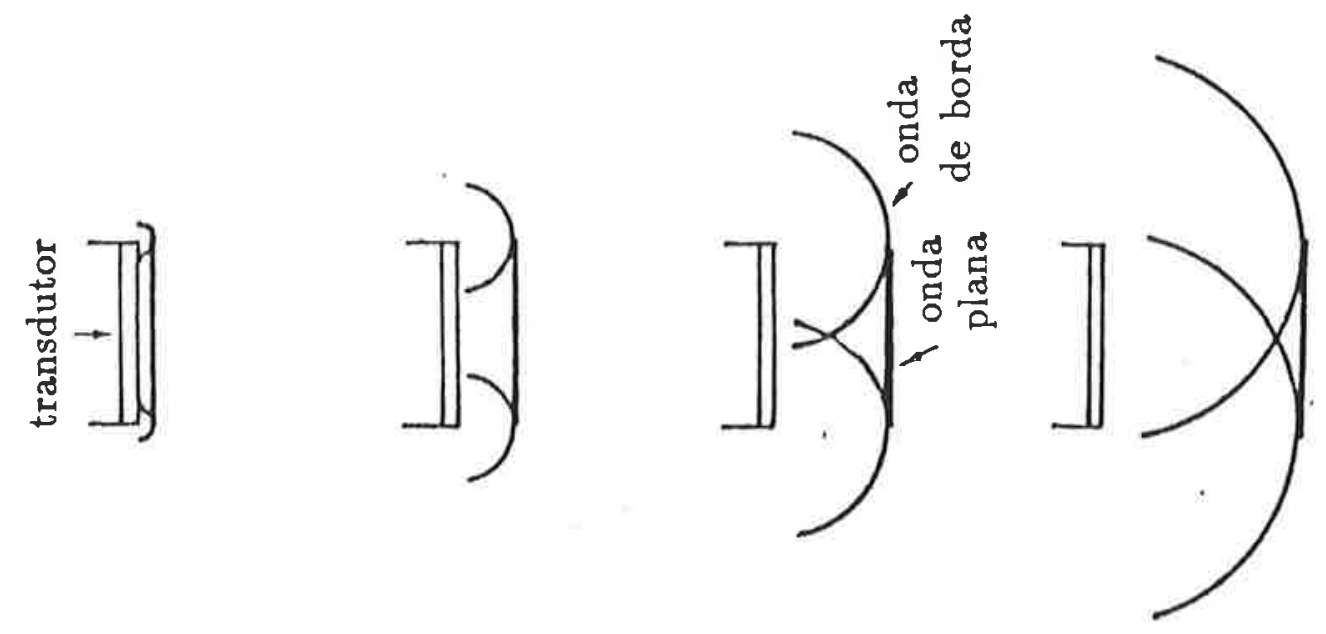

Figura 3.3: Ondas Plana e de Borda [Weight 84a].

onda de borda, muito úteis na análise do campo de transdutores. Essas ondas podem ser visualizadas no estudo do campo acústico transiente, quando um pulso emitido pelo pistão propaga-se através do campo. A primeira (onda plana) consiste numa onda plana emitida pela face plana do pistão e restrita na área correspondente à essa face, já a segunda (onda de borda) trata-se de uma onda de formato toroidal emitida pela borda do pistão, como mostrado na fig. 3.3 [Stepanishen 71, Weight 84a].

Apesar da integral de Rayleigh ser muito complicada, uma solução analítica foi obtida sobre o eixo axial de um pistão plano, circundado por um refletor perfeito infinito, como mostra a fig. 3.4. O gráfico resultante das amplitudes de pressão ao longo do eixo exibiu vários pontos de máximo e mínimo, que ocorrem em posições $z$ dadas por [Hutchins 90]:

$$
z_{n}=\frac{\left(4 a^{2}-(n \lambda)^{2}\right)}{(4 n \lambda)}
$$

onde $n$ é ímpar para o máximo e par para o mínimo. O último máximo é considerado a fronteira entre o chamado campo próximo e o campo distante do transdutor, sendo dado por:

$$
n=1 \Rightarrow z=\frac{\left(4 a^{2}-\lambda^{2}\right)}{4 \lambda}
$$

O número total de máximos e mínimos na amplitude de pressão na região do campo próximo aumenta com a razão $a / \lambda$. Na fig. 3.5 tem-se um exemplo para $a=5 \lambda$. Nota-se que no campo distante a amplitude da pressão diminui continuamente com a distância $z$. Estes máximos e mínimos podem ser previstos considerando-se as ondas plana e de borda. $\mathrm{Na}$ posição axial em que as ondas estão em fase ocorre o máximo devido à interferência construtiva, enquanto os zeros ocorrem devido à interferência destrutiva (oposição de fase).

Um exemplo de variação espacial de amplitudes de pressão é mostrada na fig. 3.6 para $a=5 \lambda$. Observa-se na fig. 3.6 uma região com altas amplitudes de pressão em torno 


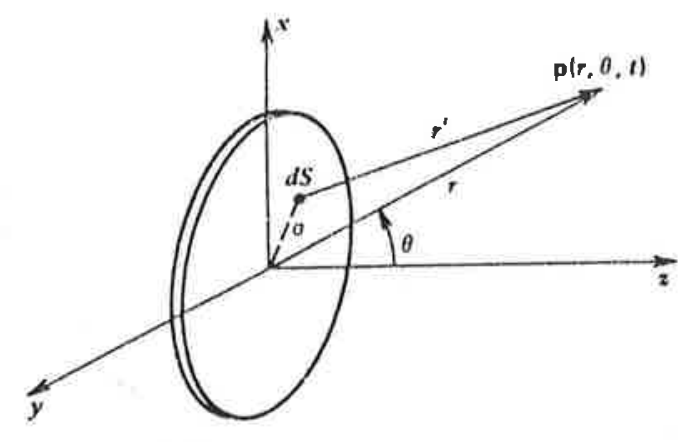

Figura 3.4: Pistão Plano [Kinsler 82].

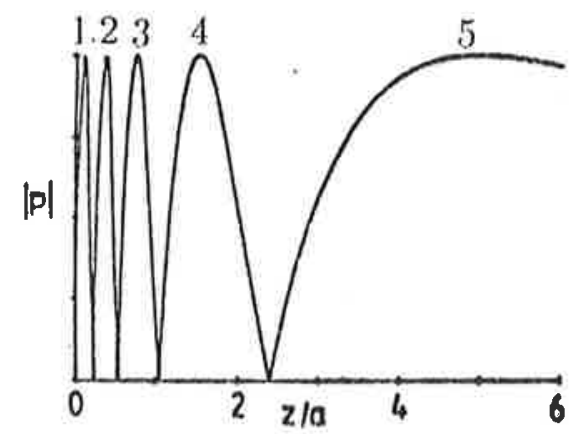

Figura 3.5: Amplitude de pressão no eixo $(a / \lambda=5)$ [Hutchins 90]. 


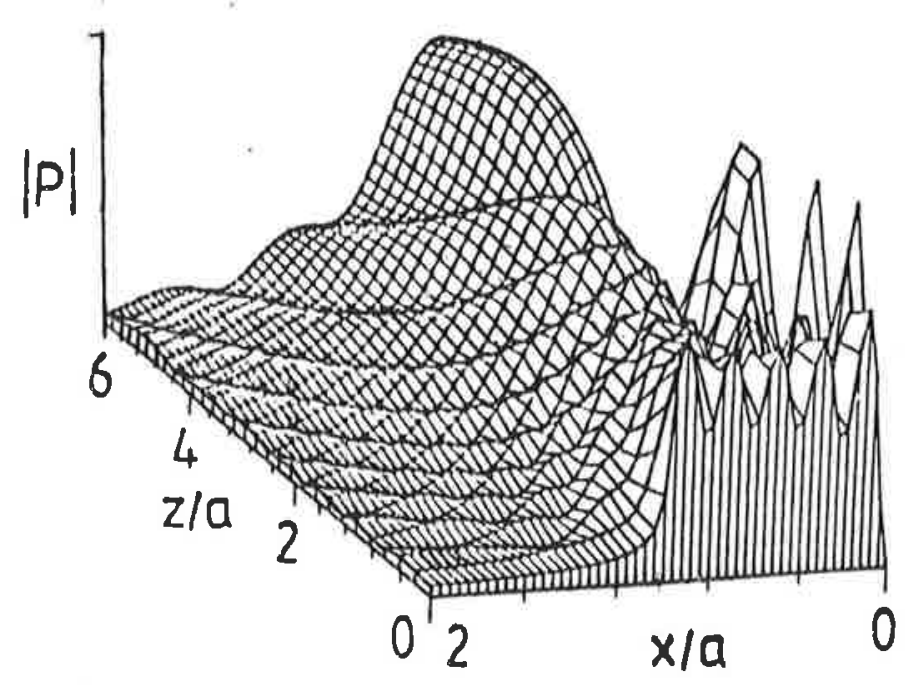

Figura 3.6: Campo Acústico (OC) [Hutchins 90].

do eixo do transdutor formando o chamado lóbulo principal. Próximo ao lóbulo principal encontram-se regiões menores de amplitudes altas, denominadas lóbulos laterais. Quanto menor for o ângulo compreendido pelo lóbulo principal, maior será a concentração das amplitudes de pressão em torno do eixo, e em geral maior será a chamada diretividade do transdutor. O lugar em que ocorre um estreitamento dessa distribuição de amplitudes é denominado foco, e o comprimento desse estreitamento, profundidade de foco [Kinsler 82].

No caso de um transdutor real (principalmente os de cerâmica piezoelétrica), o mesmo não se comporta como um pistão plano, pois como visto, o mesmo apresenta modos de vibrar radiais, que geram as chamadas "head waves" (ver 3.2.3), alterando as características do campo acústico, diferindo do obtido com o modelo do pistão plano. O modo de espessura (ver item 3.1.1) é um modo desacoplado que mais se aproxima do modelo unidimensional, sendo por isso preferido para a excitação do transdutor. Entretanto esse modo é muito difícil de se excitar, pois é muito sensivel a pequenas variações na freqüência de excitação. Mesmo assim, a superfície do transdutor não permanece totalmente plana nesse modo. Já em transdutores de PVDF, em que a relação $D / H$ é extremamente alta $(D / H \cong 1000)$, o comportamento é bem próximo do modelo de pistão rígido [Hutchins 90 ].

\subsubsection{Campo Acústico Transiente}

Muitas aplicações de ultra-som envolvem excitação pulsada do transdutor piezoelétrico. Entre elas tem-se, caracterização de materiais, ensaio não destrutivo (END), imagens médicas, análise de tecido humano, e sistemas de posicionamento e medição. Nestes casos um transdutor mecanicamente amortecido (através da camada de retaguarda) (fig. 3.1) é estimulado por meio da aplicação de um pulso elétrico. O pulso de pressão resultante é banda larga, compreendendo um ou dois ciclos no comprimento de onda fundamental. 
As características do campo acústico transiente são funções diretas da natureza de construção do transdutor, do circuito clétrico de recepção e excitação e da forma do transdutor. São bem diferentes da situação OC, onde as características do campo acústico dependem somente da razão (raio do pistão)/(comprimento de onda).

Assim como em outros problemas de engenharia, a análise de campo transiente pode ser convenientemente tratada por meio da aproximação de um sistema linear baseada na resposta espacial impulsiva do transdutor. Esta, descreve as variações espaciais do campo em termos do potencial de velocidade produzido pelo movimento impulsivo da face do transdutor. $O$ potencial de velocidade resultante em cada ponto do espaço é então obtido por meio da convolução [Hutchins 90]:

$$
\Theta(M, t)=\Theta_{1}(M, t) * v(t)
$$

onde $\Theta_{1}(M, t)$ é a resposta impulsiva do potencial de velocidade que relaciona a estrutura do campo acústico com a geometria da fonte irradiante. A pressão num ponto arbitrário $M$ do campo é dada por:

$$
p(M, t)=v(t) * p_{1}(M, t) \quad \text { e: } \quad p_{1}(M, t)=\rho_{0} \frac{\delta \Theta_{1}(M, t)}{\delta t}
$$

onde $p_{1}(M, t)$ é a resposta impulsiva de pressão num ponto arbitrário $\mathrm{M}$ do campo.

\section{Resposta Impulsiva de um Pistão Plano (Ondas Plana e de Borda)}

Considere um pistẽo plano de forma arbitrária, circundado num refletor rígido, plano e infinito, irradiando num meio isotrópico através do qual o som tem velocidade constante. O objetivo é determinar a resposta impulsiva do potencial de velocidade. Como no item anterior, o ponto inicial para a obtenção da resposta impulsiva é a integral de Rayleigh. A análise dessa resposta pode ser feita diretamente no domínio do tempo [Stepanishen 71, Hutchins 90].

O conceito de uma onda plana, que viaja paralela à face do pistão, e uma onda de borda resultante do movimento das bordas, que se propaga num formato de onda toroidal, pode ser usado para descrever a estrutura do campo transiente. Para isso deve-se dividir o campo do transdutor em três regiões distintas: interior do pistão, bordas do pistão e região exterior ao pistão.

Nas figuras adiante, os tempos $t_{0}, t_{1}$ e $t_{2}$ estão relacionados com os tempos de chegada das ondas plana e de borda. No caso de um ponto $M$ estar situado no eixo, o mesmo é atingido nos instantes $t_{0}$ por uma onda plana, seguida no instante $t^{\prime}=t_{1}=t_{2}$ por uma onda de borda de igual amplitude e sinal negativo, resultando no gráfico de resposta impulsiva do potencial de velocidade da fig. 3.7, de duração $t^{\prime}-t_{0}$. Para um ponto $M$ fora do eixo, mas dentro da região do pistão, a função $\Theta(t)$ é constante até o tempo $t_{1}$ (devido à onda plana), decrescendo a partir do momento que a primeira onda de borda 

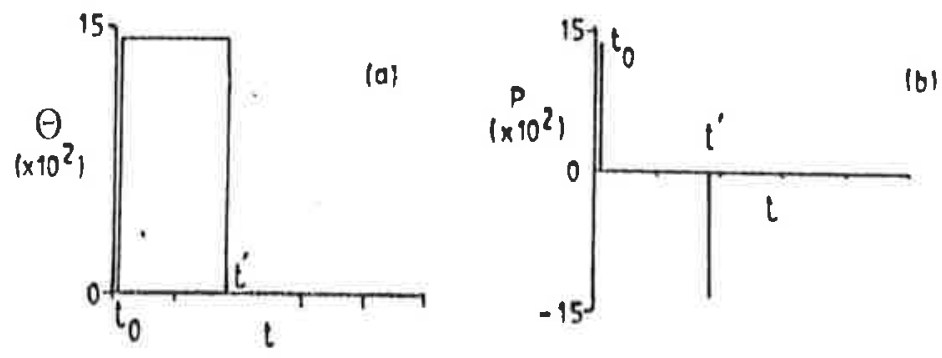

Figura 3.7: Resposta Impulsiva no eixo axial [Hutchins 90]; (a) - potencial de velocidade $(\Theta) ;(b)$ - pressão $(p)$.
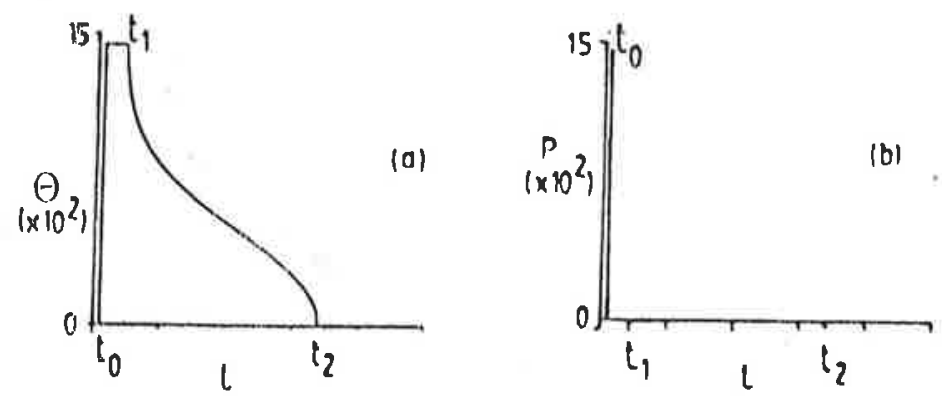

Figura 3.8: Resposta Impulsiva fora do eixo axial [Hutchins 90]; (a) - potencial de velocidade $(\Theta) ;(b)$ - pressão $(p)$.

atinge o ponto, e se anulando quando a segunda onda de borda proveniente da borda mais distante se aproxima até o instantc $t_{2}$ (fig. 3.8). Nota-se que como as ondas de borda não chegam ao ponto em fase, suas contribuições são suavizadas no tempo. Quando o ponto $M$ se situa diretamente sobre a projeção das bordas do pistão, a amplitude da onda plana é reduzida à. metade, chegando no tempo $t=t_{0}=t_{1}$ juntamente com a onda de borda da borda mais próxima, e sendo suavizada pela aproximação da onda de borda da borda mais distante no intervalo $t_{1}<t<t_{2}$. No caso de um ponto fora da região do pistão, o mesmo só será atingido por ondas de borda nos tempos $t_{1}$ e $t_{2}$, não havendo ondas planas, dando origem a uma função como mostra a fig. 3.9 [Weight 84a].

Uma visualização dessas ondas através do efeito Schlieren encontra-se em [Weight 84a], comprovando essa teoria.

Combinando-se os resultados devido às ondas planas e de borda chega-se às expressões para as respostas impulsivas de pressão e potencial de velocidade para um pistão plano circular [Hutchins 90]. 

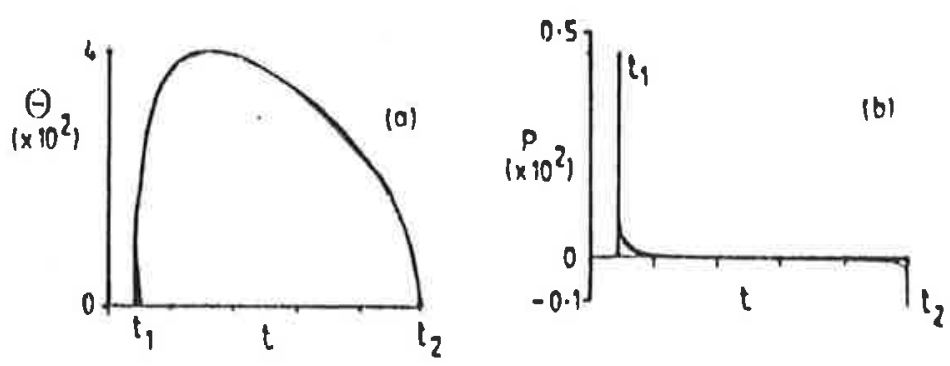

Figura 3.9: Resposta Impulsiva fora da região do pistão [Hutchins 90]; (a) - potencial de velocidade $(\Theta)$; (b) - pressão.

\subsubsection{Apodização}

Na determinação do campo acústico emitido por um transdutor, supõe-se que a sua superfície vibra como um pistão plano com a velocidade das partículas constantes em fase e amplitude ao longo da área do pistão. Entretanto, como já comentado, poucos transdutores operam de uma maneira unimodal, apresentando os chamados modos de vibrar radiais que ocasionam desvios em relação ao comportamento de pistão. Esses modos consistem na propagação de ondas na direção radial no interior do elemento piezoelétrico, dando origem às denominadas "head waves" no campo acústico. As "head waves" se interagem iniciando o efeito de foco axial do transdutor, ou seja, ocasionam o aumento da pressão acústica numa pequena região sobre o eixo axial do transdutor. Assim para se obter um campo acústico mais uniforme, e que possa ser previsto teoricamente, a atividade dos modos radiais deve ser eliminada. Isso é conseguido utilizando-se um material piezoelétrico com um baixo acoplamento radial (como por exemplo, o metaniobato de chumbo) ou alterando a forma de excitação ao longo do raio do transdutor (amplitude e fase) usando uma técnica conhecida como apodização. Além disso, muitas vezes conforme o tipo de aplicação do transdutor, deseja-se também alterar algumas características do campo acústico (tanto na excitação pulsada como em $\mathrm{OC}$ ) como por exemplo, reduzir a presença de lóbulos laterais, obter um campo mais focalizado ou um campo próximo mais uniforme.

Um exemplo de transdutor que possui características desejáveis no campo acústico é o transdutor Gaussiano [Claus 83], assim chamado por apresentar uma variação de amplitudes gaussiana ao longo do raio, quando excitado. Nesse transdutor as oscilações do campo próximo e a presença de lóbulos laterais são minimizadas. Isto acontece pelo fato de não haver movimentos na borda, o que minimiza a geração da onda de borda, deixando somente a onda plana com variação de amplitude gaussiana. Entretanto reduzse o diâmetro efetivo do transdutor (superfície que está efetivamente emitindo energia), em comparação com um pistão plano de dimensões idênticas, resultando numa redução das amplitudes de pressão no campo acústico, e conseqüentemente a sensibilidade do transdutor. A fig. 3.10 mostra o campo acústico de um transdutor gaussiano excitado em onda contínua, onde nota-se a uniformidade do campo. 


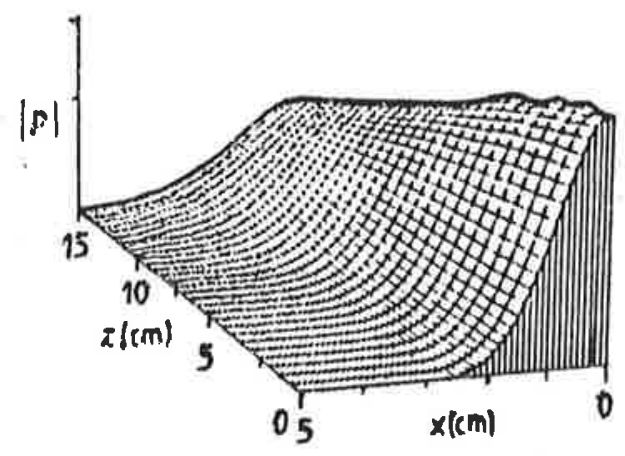

Figura 3.10: Campo acústico (OC) do transdutor gaussiano [Hutchins 90].

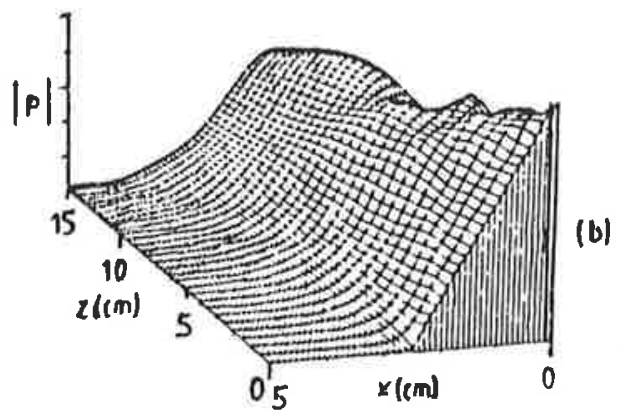

Figura 3.11: Campo acústico (OC) de um transdutor linear [Hutchins 90].

Estes transdutores têm aplicação na caracterização de materiais, onde é desejado uma invariância espacial das características de resposta do transdutor, para o processamento inverso de sinais. Entretanto a construção na prática de um transdutor gaussiano é complicada, exigindo algumas aproximações. Dessa forma determinou-se que qualquer função que faça decrescer a amplitude de vibração do transclutor de uma maneira contínua do centro para a borda, irá proporcionar uma melhora na característica do campo acústico. O objetivo principal ć remover as descontinuidades de amplitude, que são responsáveis por gerar a onda de borda. Como exemplo na fig. 3.11 tem-se o campo acústico de um transdutor linear (variação linear da amplitude).

Assim, se a função espacial de amplitude apresentar alguma descontinuidade provocará a geração da onda de borda, alterando as características axiais e de uniformidade do campo acústico.

Ao invés de se minimizar o efeito da onda de borda, obtendo o chamado transdutor somente onda plana (SOP), pode-se minimizar a geração de onda plana obtendo o transdutor somente onda de borda (SOB) [Weight 84a], que apresenta a função amplitude decrescendo das bordas para o centro (fig. 3.12). Devido à interferência da onda de borda ao longo do eixo axial, esse tipo de transdutor apresenta um alto foco axial, sendo de grande aplicação na obtenção de imagens por ultra-som. A fig. 3.13 mostra o 


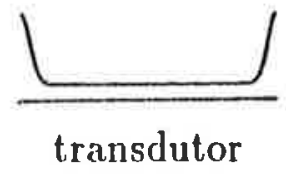

Figura 3.12: Transdutor SOB [Weight 84b].

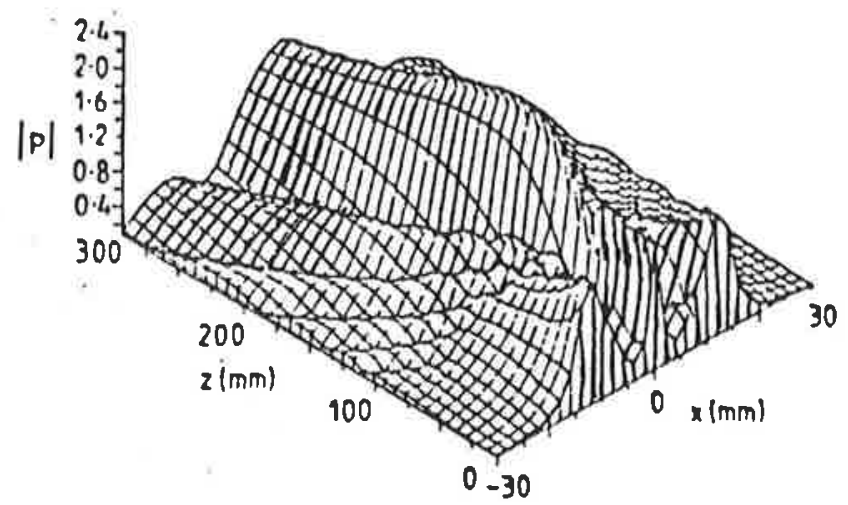

Figura 3.13: Campo acústico (OC) de um transdutor SOB [Hutchins 90].

campo acústico de um transdutor SOB excitado em onda contínua (OC). Observa-se que o campo acústico não é uniforme. É importante ressaltar que um resultado semelhante não seria obtido com um transdutor anular (coroa circular), devido à interação entre as ondas emitidas pelas bordas internas e externas, que geram grandes lóbulos laterais e um baixo foco axial [Hutchins 90].

A implementação da técnica de apodização em transdutores para gerar campos uniformes tem sido estudado por vários autores. Weight [Weight 84b], por exemplo utiliza uma técnica de polarização não linear (altas tensões elétricas), que emprega potencial variável e eletrodos anulares no processo de polarização. Já. Hayward et al. [Hayward 91] utilizam um eletrodo central envolvido por um anel condutor. Quando se aplica uma tensão nesse eletrodo, devido ao aumento de resistência do anel com o raio tem-se uma função logarítmica de tensão elétrica que decresce do centro para as extremidades.

\subsection{Piezoeletricidade}

\subsubsection{Teoria Piezoelétrica}

Piezoeletricidade é uma propriedade linear que certos materiais apresentam, que provoca uma polarização elétrica do material (geração de cargas de polaridade opostas) quando o mesmo é sujeito à uma tensão mecânica, e a deformação do material quando o mesmo é 
sujeito a um campo elétrico. O primeiro caso é denominado efeito piezoelétrico direto, e o segundo efeito piezoclétrico inverso.

O efeito piezoclétrico surgc devido à interação entre as forças de Coulomb e as forças restauradoras elásticas numa célula unitária do material sujeita a um campo elétrico ou a uma força mecânica. Dessa forma a piezoeletricidade está intimamente relacionada com as propriedades cristalográficas dos materiais (item 3.3.3), existindo somente em materiais que não possuem simetria central. Para entender melhor essa afirmação, bem como as equações constitutivas que descrevem o meio piezoelétrico relacionando tensão mecânica $(T)$, deformação $(S)$, campo elétrico $(E)$ e o deslocamento elétrico $(D)$, considere o seguinte exemplo didático que analisa o comportamento da estrutura interna do material.

Seja o dipolo elétrico da fig. 3.14. Sabe-se que o campo elétrico devido ao dipolo num ponto situado à uma distância $r \gg l$ sobre o cixo do dipolo vale $E=p / 2 \pi \varepsilon_{0} r^{3}$, onde $p$ é o momento de dipolo elétrico $(p=q l)$. 9 Considere agora a célula unitária de um sólido hipotético, onde as moléculas (representadas pelas cargas) estão presas por forças elásticas (representadas pelas molas). Pode-se considerar essa célula como sendo formada pelos três dipolos $A B, H C$ e $G M$ (fig. 3.14). No equilíbrio o campo elétrico da célula num ponto $W$ situado a uma distância $r \gg l$, é dado por:

$$
E=E_{A B}-E_{H C}+E_{G M}=\frac{(q l-2 q l+q l)}{2 \pi \varepsilon_{0} r^{3}}=0
$$

Portanto o campo elétrico resultante é nulo. Se uma, força $F_{D}$ é simetricamente aplicada no sólido, o mesmo se deforma como mostrado na fig. 3.14. Por simplicidade suponha que os deslocamentos dos pontos $B, C, M$ sejam iguais, ou seja $\delta l_{1}=\delta l_{2}=\delta l$. O campo elétrico resultiante no ponto $W$ da célula unitária deformada será agora:

$$
E=\frac{2 q\left(2 \delta l_{1}-\delta l_{2}\right)}{2 \pi \varepsilon_{0} r^{3}}=\frac{2 q \delta l}{2 \pi \varepsilon_{0} r^{3}}
$$

onde o momento do dipolo pode ser escrito como $p=2 q \delta l=2 q l S$, e $S=\delta l / l$ é a deformação longitudinal. Se o sólido contém $N$ moléculas por volume, tem-se que a polarização elétrica $P$, ou seja, o momento dipolar por volume, vale:

$$
P=N p=2 q l N S=e S
$$

onde $e$ é por definição a constante de tensão piezoelétrica $e=2 q l N$. Para $N \cong 5,1027 \mathrm{~m}^{-3}$, $q \cong 1,6.10^{-19} \mathrm{C}$ e $l=5,10^{-10} \mathrm{~m}$, tem-se $e=0,8 \mathrm{C} / \mathrm{m}^{2}$, que é próxima por exemplo da constante piezoelétrica do $\mathrm{ZnO}\left(0,5 \mathrm{C} / \mathrm{m}^{2}\right)$ [Ristic 83].

A presença da polarização elétrica $P$, altera a relação $D=\varepsilon E$, onde $D$ é a densidade de cargas e está relacionada com o fluxo de corrente no material piezoelétrico $(I=\partial D / \partial t)$. A nova relação fica:

$$
D=\varepsilon E+e S
$$

Devido à aplicação da força $F$, os centros das cargas positivas e negativas que coincidem no ponto $O$, se deslocam para os pontos $O+$ e $O$ - respectivamente, produzindo uma 
(a)

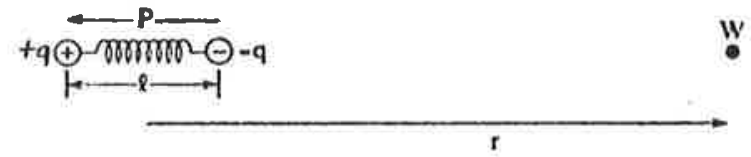

(b)
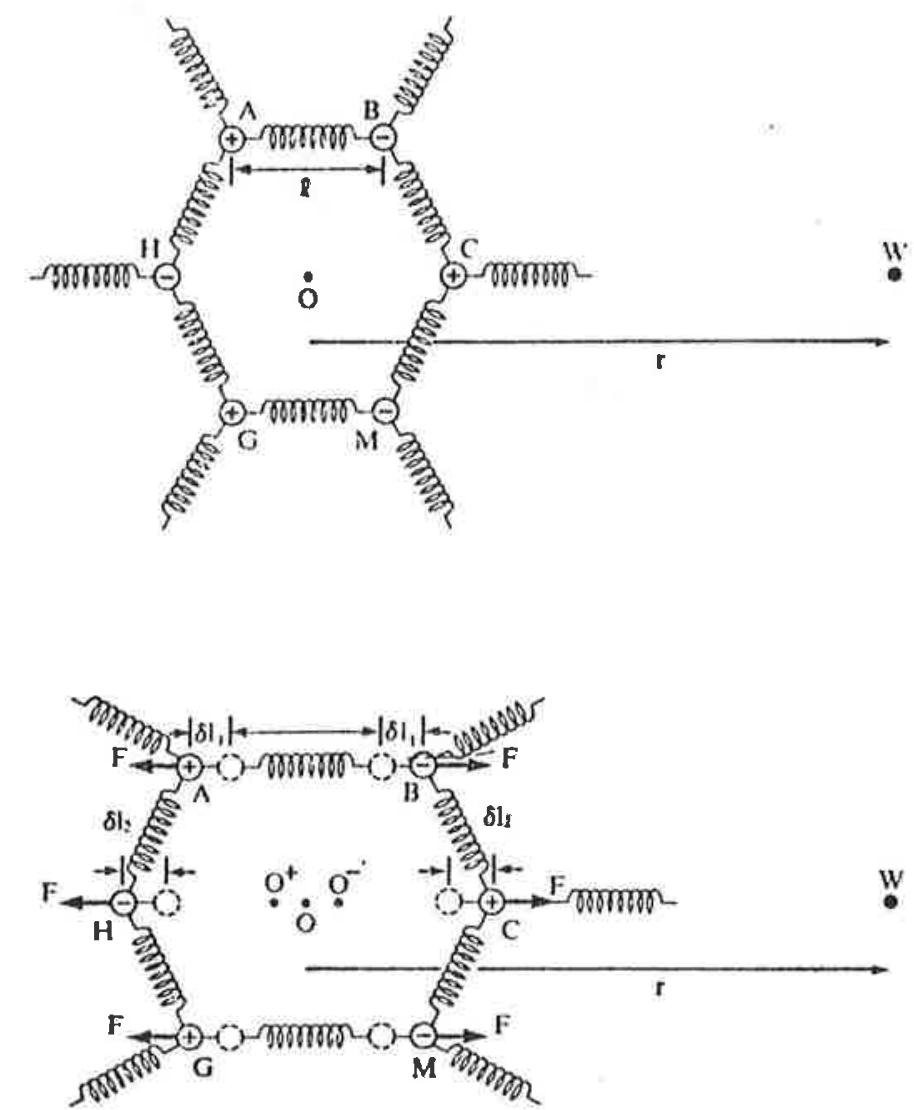

Figura 3.14: (a) - dipolo elétrico, (b) - célula unitária, (c) - célula unitária deformada [Ristic 83]. 
polarização, modificando $D$. Assim o deslocamento elétrico $(D)$ num material depende da deformação e do campo elétrico aplicado no material. Para o caso em que um campo elétrico externo $E$ é aplicado, mostra-se que a tensão mecânica total aplicada no meio é a soma da tensão externa aplicada $T$ e da tensão interna $T_{e}$ devido ao campo elétrico, que vale $e E$. Assim, aplicando a Lei de Hooke:

$$
T+T_{e}=c S \Rightarrow T=c S-T_{e} \Rightarrow T=c S-e E
$$

Se as cargas positivas e negativas forem diferentes em valor, o sólido apresentará polarização, mesmo sem forças aplicadas. As equações (3.10) e (3.11) são denominadas relações constitutivas da piezoeletricidade ou equações do meio piezoclétrico.

\subsubsection{Equaões do Meio Piezoelétrico}

Essas equações relacionam variáveis elétricas $(E, D)$ e mecânicas $(S, T)$, sendo deduzidas a partir da função de Gibbs (potenciais termodinâmicos) [Berlincourt 64]. No exemplo anterior essas equações foram apresentadas na forma unidimensional, entretanto na sua forma genérica, as constantes piezoelétricas relacionam tensores simétricos de $2^{a}$ ordem (tensão mecânica e deformação) e vetores (densidade de carga e campo elétrico), sendo portanto tensores de $3^{a}$ ordem. As constantes elásticas relacionam dois tensores simétricos de $2^{a}$ ordem, sendo portanto tensores de $4^{a}$ ordem e as constantes dielétricas relacionam dois vetores, e portanto constituem tensores de $3^{a}$ ordem. Entretanto, graças às propriedades de simétria dos materiais piezoelétricos, muitas das constantes se anulam, ou se igualam, permitindo que essas equações possam ser representadas na forma matricial.

Considerando ainda o modelo unidimensional, tomando-se $S$ e $E$ das equações piezoelétricas como variáveis independentes, tem-se: $\mathrm{T}=\mathrm{T}(\mathrm{S}, \mathrm{E})$ e $\mathrm{D}=\mathrm{D}(\mathrm{S}, \mathrm{E})$, e utilizando a expansão de Taylor:

$$
\begin{aligned}
& T=\left(\frac{\partial T}{\partial S}\right)_{E} S+\left(\frac{\partial T}{\partial E}\right)_{S} E \\
& D=\left(\frac{\partial D}{\partial S}\right)_{E} S+\left(\frac{\partial D}{\partial E}\right)_{S} E
\end{aligned}
$$

onde os efeitos magnéticos e térmicos, e os termos não lineares foram desprezados [Berlincourt 64,Ristic 83]. Dessa forma tem-se as constantes:

$$
\begin{array}{rlrl}
c^{E} & =\left(\frac{\partial T}{\partial S}\right)_{E} ; & e^{E}=\left(\frac{\partial D}{\partial S}\right)_{E} \\
e^{S}=\left(\frac{\partial T}{\partial E}\right)_{S} ; & \varepsilon^{S}=\left(\frac{\partial D}{\partial E}\right)_{S}
\end{array}
$$

onde os subscritos indicam que $c^{E}$ e $e^{E}$ devem ser obtidos sob um campo elétrico constante (p.ex.: nulo) e $e^{S}$ e $\varepsilon^{S}$ sob deformação nula.

A medição das constantes de rigidez e dielétrica definidas acima, depende das condições de contorno como indicado. Considere o caso quando um campo elétrico é aplicado no meio piezoelétrico. Realizando uma medição da constante $\varepsilon^{S}$, sem o material estar confinado mecanicamente, obtém-se um valor errado de $\varepsilon^{S}$, pelo fato de uma deformação surgir 
em resposta da tensão, contribuindo na equação (3.12) para alterar a relação entre $D$ e $E$. O mesmo vale para as outras constantes. Assim a medição das propriedades elétricas do meio piezoelétrico é dependente das restrições mecânicas, e a medição das propriedades mecânicas é dependente das restrições elétricas, devido ao acoplamento piezoelétrico. Entretanto seguindo considerações termodinâmicas, mostra-se que o efeito piezoelétrico inverso $\left(e^{S}\right)$ é uma conseqüência do efeito piezoelétrico direto $\left(e^{E}\right)$ [Berlincourt 64], assim:

$$
-e^{S}=e^{E}=e
$$

e pode-se escrever as equações (3.12) como:

$$
\left\{\begin{array}{l}
T=c^{E} S-e E \\
D=e S+\varepsilon^{S} E
\end{array}\right.
$$

Alternando-se em pares as variáveis independentes escolhidas, obtém-se outras expressões das equações piezoelétricas [Berlincourt 64]:

$$
\begin{aligned}
& S=s^{E} T+d E \\
& D=d T+\varepsilon^{T} E \\
& S=s^{D} T+g D \\
& E=-g T+\beta^{T} D \\
& T=c^{D} S-h D \\
& E=-h S+\beta^{S} D
\end{aligned}
$$

A utilização de uma ou outra relação vai depender das características necessárias no projeto do transdutor. Assim no projeto de um detector de ondas acústicas em líquidos (hidrofone) se está interessado no valor da constante $g$, e portanto na equação (3.17), e no caso de um acelerômetro [Ristic 83], no valor de $d$, e portanto na equação (3.16).

\subsubsection{Materiais Piezoelétricos}

Os cristais são sólidos em que os átomos ocorrem de forma repetitiva numa matriz tridimensional, e as propriedades de tais sólidos são denominadas propriedades cristalográficas. Cada átomo é representado por um ponto na matriz tridimensional. Uma célula unitária é feita da combinação de pontos da matriz, sendo escolhida para representar parte dessa matriz. Dessa forma a matriz tridimensional pode ser dividida em células unitárias idênticas. O tipo mais geral de célula unitária é o paralelepípedo com os eixos $a, b$, e $c$ obedecendo a regra da mão direita e completamente especificado pelas arestas $a, b, c$ e ângulos $\alpha, \beta$ e $\gamma$ (fig. 3.15) [Van Vlack 85]. No estudo de cristais, os elementos de simetria do cristal necessários para descrever sua forma externa são denominados elementos de simetria macroscópicos, e são suficientes para descrever o fenômeno da piezoeletricidade. Um conjunto desses elementos de simetria dá origem a chamada classe cristalográfica [Ristic 83]. 


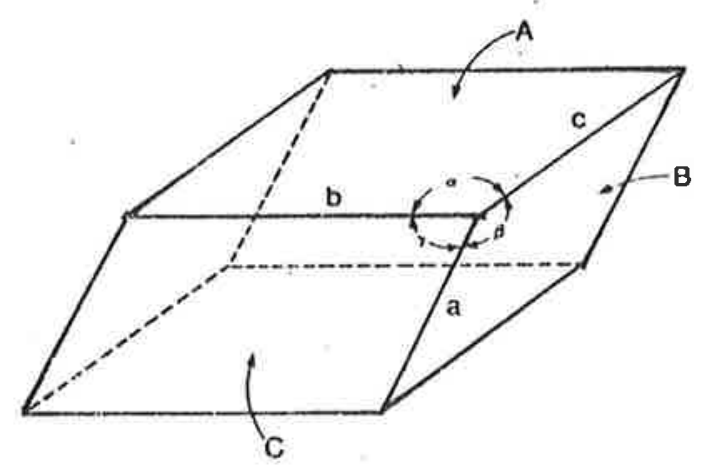

Figura 3.15: Célula unitária genérica, [Ristic 83].

\section{Sistemas e Classes Cristalográficas}

Uma classe cristalográfica é uma coleção de todos os elementos de simetria num ponto da matriz. O conjunto completo de elementos de simetria que podem existir numa matriz, consiste de 10 elementos, que são seis eixos de rotação (simples, duplo, triplo, quádruplo, quíntuplo e sêxtuplo), um centro de simetria, eixos de inversão de rotação, e plano de espelho, descritos nas referências [Ristic 83, Van Vlack 85]. Dependendo do grau de simetria, os cristais são classificados em sete sistemas, com cada sistema dividido em classes: triclínico (2 classes), monoclínico (3 classes), ortorrômbico (3 classes), romboédrico (ou trigonal) ( 5 classes), tetragonal ( 7 classes), hexagonal ( 7 classes) e cúbico $(5$ classes). Cada sistema possui um tipo de célula unitária descrita pelas dimensões $a, b, c$ e $\alpha$, $\beta$ e $\gamma$, mostradas na fig. 3.15. Maiores detalhes sobre cada uma das classes são encontrados nas referências [Ristic 83,Standard 78,Van Vlack 85]. Assim, por exemplo, a cerâmica PZT (Titananto Zirconato de Chumbo) pertence à classe hexagonal e o $\mathrm{BaTiO}_{3}$ à classe tetragonal. Cada classe no sistema é representada através da notação completa de Hermann-Mauguin [Ristic 83,Standard 78], que consiste numa combinação de símbolos numéricos associado com a operação de simetria. Para identificar uma direção específica ou plano no cristal, o sistema Miller de índices é usado [Van Vlack 85]. 9 O tratamento teórico de elasticidade e eletricidade é desenvolvido em termos de um sistema de coordenadas retangular denominado cristalográfico, designado pelas letras $X, Y$ e $Z$. Assim por exemplo, no caso das cerâmicas ferrelétricas, o eixo de polarização é tomado como eixo $Z$, e os outros dois de maneira a se ter uma base positiva. Para se utilizar as constantes apropriadas a relação entre os eixos naturais $a, b, c$ e os eixos cristalográficos $X, Y \mathrm{e}$ $Z$ deve ser conhecida. Várias constantes piezoelétricas, elásticas e outras do cristal são avaliadas em termos dos eixos $X, Y$ e $Z$. Esses eixos podem ou não coincidir com os eixos de coordenados $x, y, z$, que se escolhe num particular problema. Dessa forma a relação entre $(x, y, z)$ e $(X, Y, Z)$ deve ser conhecida para se utilizar as constantes apropriadas. $\mathrm{Na}$ referência [Standard 78] estas relações são discutidas para o caso do quartzo, onde os eixos $X, Y$ e $Z$ são representados através de ângulos que esses eixos formam com os planos de uma placa retangular (largura, espessura e comprimento), que representam os eixos coordenados $x, y, z$. São os chamados cortes. 

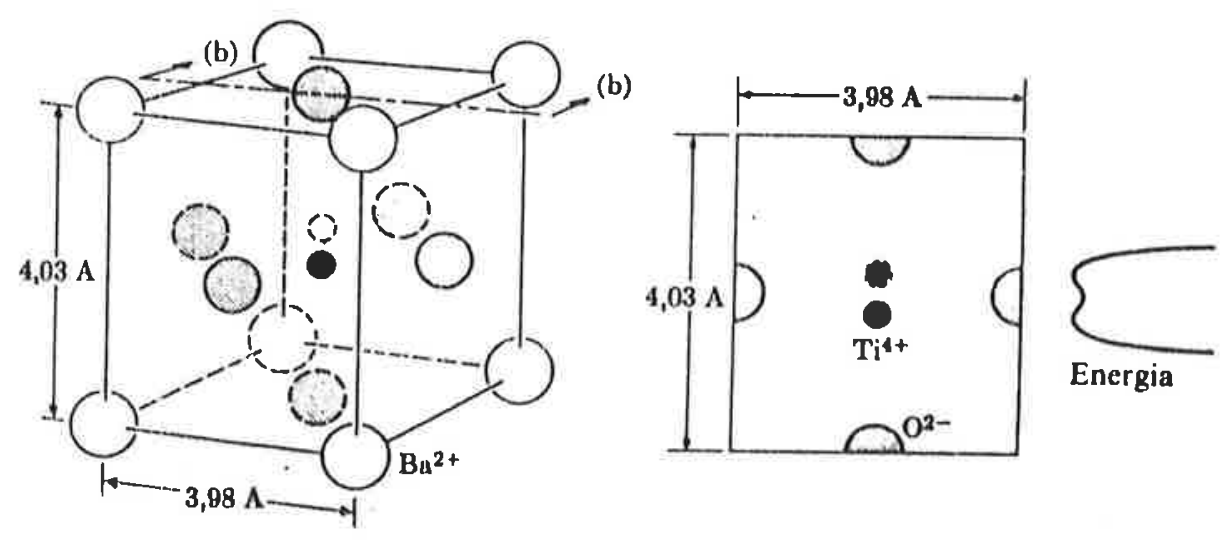

Figura 3.16: Célula unitária do $\mathrm{BaTiO}_{3}$ [Van Vlack 85].

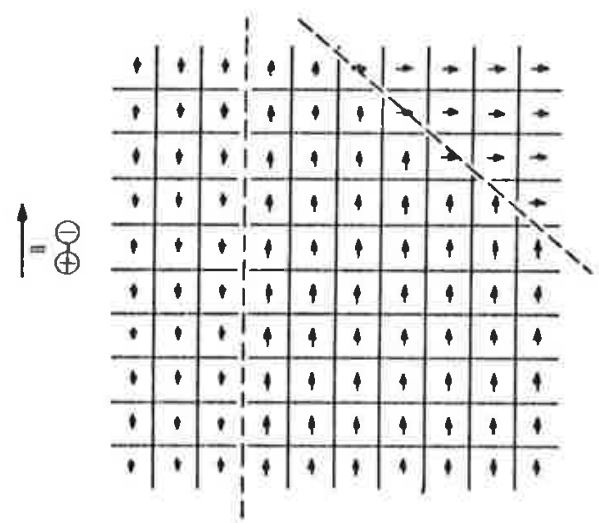

Figura 3.17: Dominio [Van Vlack 85].

Como já comentado no item 3.1, entre os materiais piezoelétricos mais utilizados tem-se as cerâmicas e o quartzo. Materiais cerâmicos ferrelétricos como o Titanato de Bario ( $\mathrm{BaTiO}_{3}$ ), o Niobato de Lítio, e o Titanato Zircanato de Chumbo (cerâmicas PZT), que são materiais piezoelétricos importantes, apresentam momento dipolar. No caso do $\mathrm{BaTiO}_{3}$, a célula unitária na temperatura ambiente apresenta uma estrutura tetragonal (fig. 3.16), na qual o $\mathrm{Ti}^{++}$pode escolher entre duas posições. Como nenhuma das posições está no centro da célula unitária, o centro das cargas positivas não coincide com o das cargas negativas, ou seja, tem-se um dipolo elétrico. Um grupo de células unitárias cujas polaridades elétricas são paralelas é denominado domínio (fig. 3.17). Essa propriedade de alinhamento orientado dos dipolos elétricos recebe o nome de ferreletricidade. $\mathrm{O}$ alinhamento dos dipolos num certo domínio é aleatório com relação aos dipolos de outro domínio [Ristic 83, Van Vlack 85,Kino 87].

Ao se aplicar um campo elétrico externo intenso, os dipolos são alinhados, segundo a direção do campo aplicado, polarizando c material [Kino 87, Van Vlack 85]. 
Após a polarização o material passa a apresentar propriedades piezoelétricas, alterandose o comprimento dos dipolos com a aplicação de uma tensão elétrica, e vice-versa. Assim um material ferrelétrico é um cristal que possui um momento de dipolo interno que tende a se alinhar com a direção próxima a do campo elétrico aplicado, e portanto todo material ferrelétrico é piezoelétrico [Ristic 83]. Já o quartzo pode ser piezoelétrico sem ser ferrelétrico. É o que acontece com os cristais que possuem um eixo de simetria triplo, como no exemplo didático dado no começo do item 3.3.1. Inicialmente o centro das cargas positivas e negativas concidem na célula unitária (não há dipolo). Ao se aplicar uma tensão (força) os centros das cargas se deslocam de posição gerando um dipolo. O mesmo raciocínio vale quando um campo elétrico externo é aplicado, afastando o centro das cargas, provocando a deformação. Entretanto este tipo de material piezoelétrico apresenta constantes piezoelétricas de valores bem menores do que a dos materiajs ferrelétricos, que por natureza já apresentam um dipolo na sua célula unitária.

Existem outros efeitos, como por exemplo a eletroestriç̧ão, em que a aplicação de um campo elétrico também gera tensão mecânica [Ristic 83]. Entretanto trata-se de um efeito não-linear, não sendo tratado neste texto.

\subsubsection{Equeões do Meio Piezoelétrico na Forma Tensorial}

Neste item serão apresentadas as equações que descrevem o meio piezoelétrico na sua forma tensorial e matricial [Ristic 83,Standard 78,Kino 87]. É assumido que os eixos $x$ e $y, z$ coincidem com os eixos cristalográficos $X, Y$ e $Z$ do material.

Na notação tensorial as equações piezoelétricas são representadas da seguinte maneira:

$$
\left\{\begin{array}{l}
T_{j k}=c_{j k l m}^{E} S_{l m}-e_{j k i} E_{i} \\
D_{i}=e_{i j k} S_{j k}+\varepsilon_{i j}^{S} E_{j}
\end{array}\right.
$$

onde os tensores de $2^{a}$ ordem $\varepsilon_{i j}^{S}, T_{j k}, S_{j k}$ são respectivamente os tensores dielétrico, de tensão e de deformação, sendo o primeiro um tensor simétrico $\left(\varepsilon_{j k}^{S}=\varepsilon_{k j}^{S}\right)$.

$$
\begin{aligned}
& {\left[\varepsilon_{i j}^{S}\right]=\left[\begin{array}{lll}
\varepsilon_{x x}^{S} & \varepsilon_{x y}^{S} & \varepsilon_{x z}^{S} \\
\varepsilon_{x y}^{S} & \varepsilon_{y y}^{S} & \varepsilon_{y z}^{S} \\
\varepsilon_{x z}^{S} & \varepsilon_{y z}^{S} & \varepsilon_{z z}^{S}
\end{array}\right] ; \quad\left[T_{j k}\right]=\left[\begin{array}{lll}
T_{x x} & T_{x y} & T_{x z} \\
T_{y x} & T_{y y} & T_{y z} \\
T_{z x} & T_{z y} & T_{z z}
\end{array}\right]} \\
& {\left[S_{j k}\right]=\left[\begin{array}{lll}
S_{x x} & S_{z: y} & S_{x z} \\
S_{y x} & S_{y / y}^{S} & S_{y z} \\
S_{z x} & S_{z \hat{y}} & S_{z z}
\end{array}\right] \text { onde: } S_{j k}=\frac{1}{2}\left(\frac{\partial u_{j}}{\partial x_{k}}+\frac{\partial u_{k}}{\partial x_{j}}\right)}
\end{aligned}
$$

$D_{i}, E_{i}$ são vetores de densidade de carga e campo elétrico dados por:

$$
\left[D_{i}\right]=\left\{\begin{array}{c}
D_{x} \\
D_{y} \\
D_{z}
\end{array}\right\} ; \quad\left[E_{i}\right]=\left\{\begin{array}{c}
E_{x} \\
E_{y} \\
E_{z}
\end{array}\right\}
$$

$e_{i j k}$ é um tensor de $3^{a}$ ordem das constantes piezoelétricas com 27 componentes 


\begin{tabular}{|c|c|}
\hline $\mathrm{jk}$ & $\mathrm{I}$ ou J \\
\hline \hline $\mathrm{xx}$ & 1 \\
$\mathrm{yy}$ & 2 \\
$\mathrm{zz}$ & 3 \\
$\mathrm{yz}=\mathrm{zy}$ & 4 \\
$\mathrm{xz}=\mathrm{zx}$ & 5 \\
$\mathrm{xy}=\mathrm{yx}$ & 6 \\
\hline
\end{tabular}

Tabela 3.1: Coeficientes.

independentes, dadas por:

$$
e_{i j k}=\left(\frac{\partial D_{i}}{\partial S_{j k}}\right)_{E}=-\left(\frac{\partial T_{j k}}{\partial E_{i}}\right)_{S}
$$

mas devido à simetria das propriedades piezoelétricas o número de constantes é reduzido para 18:

$$
e_{i j k}=e_{i k j}
$$

$c_{j k l m}$ é um tensor de $4^{a}$ ordem das constantes de rigidez com 81 componentes, dadas por:

$$
c_{j k l m}=\left(\frac{\partial T_{j k}}{\partial S_{l m}}\right)_{S_{l m}}
$$

mas devido à simetria das propriedades de rigidez, o tensor é simétrico, sendo o número de constantes reduzido de 81 para 21:

$$
\begin{aligned}
& c_{j k l m}=c_{k j l m}=c_{j k m l}=c_{k j m l} \\
& c_{j k l m}=c_{l m j k}
\end{aligned}
$$

Sendo os tensores tensão e deformação simétricos $\left(T_{j k}=T_{k j}, S_{j k}=S_{k j}\right)$, existem somente 6 componentes. Dessa forma, ao invés de se utilizar a notação tensorial $T_{j k}$ e $S_{j k}$ é mais conveniente utilizar a notação de engenharia $T_{J}$ e $S_{I}$, onde os subscritos $J$ e $I$ são derivados da tabela (3.1), e escrever os tensores na notação matricial [Ristic 83]. Assim para o tensor tensão tem-se:

$$
\left[T_{j k}\right]=\left[\begin{array}{ccc}
T_{1} & T_{6} & T_{5} \\
T_{6} & T_{2} & T_{4} \\
T_{5} & T_{4} & T_{3}
\end{array}\right] \Rightarrow\left[T_{J}\right]=\left\{\begin{array}{c}
T_{1} \\
T_{2} \\
T_{3} \\
T_{4} \\
T_{5} \\
T_{6}
\end{array}\right\}
$$

e para o tensor deformação:

$$
S_{I}=\left\{\begin{array}{lll}
S_{j k} & \text { se } & j=k \\
2 S_{j k} & \text { se } & j \neq k
\end{array}\right.
$$




$$
\left[S_{j k}\right]=\left[\begin{array}{ccc}
S_{1} & \frac{S_{6}}{2} & \frac{S_{5}}{2} \\
\frac{S_{6}}{2} & S_{2} & \frac{S_{4}}{2} \\
\frac{S_{5}}{2} & \frac{S_{4}}{2} & S_{3}
\end{array}\right] \Rightarrow\left[S_{J}\right]=\left\{\begin{array}{c}
S_{1} \\
S_{2} \\
S_{3} \\
S_{4} \\
S_{5} \\
S_{6}
\end{array}\right\}=\left\{\begin{array}{c}
S_{x x} \\
S_{y y} \\
S_{z z} \\
2 S_{x y} \\
2 S_{x z} \\
2 S_{y z}
\end{array}\right\}=\left[\begin{array}{ccc}
\frac{\partial}{\partial x} & 0 & 0 \\
0 & \frac{\partial}{\partial y} & 0 \\
0 & 0 & \frac{\partial}{\partial z} \\
0 & \frac{\partial}{\partial z} & \frac{\partial}{\partial y} \\
\frac{\partial}{\partial z} & 0 & \frac{\partial}{\partial x} \\
\frac{\partial}{\partial y} & \frac{\partial}{\partial x} & 0
\end{array}\right]\left\{\begin{array}{l}
u_{x} \\
u_{y} \\
u_{z}
\end{array}\right\}=B u
$$

onde: $u=\left\{\begin{array}{l}u_{x} \\ u_{y} \\ u_{z}\end{array}\right\}$ forma:

Da mesma forma $e_{i J}=e_{i j k}$, e a matriz piezoelétrica passa a ser escrita da seguinte

$$
\left[e_{i, J}\right]=\left[\begin{array}{cccccc}
e_{x 1} & e_{x 2} & e_{x 3} & e_{x 4} & e_{x 5} & e_{x 6} \\
e_{y 1} & e_{y 2} & e_{y 3} & e_{y 4} & e_{y 5} & e_{y 6} \\
e_{z 1} & e_{z 2} & e_{z 3} & e_{z 4} & e_{z 5} & e_{z 6}
\end{array}\right]
$$

que é chamada de matriz de tensão piezoelétrica, e $[d]=[e]^{-1}$ é a matriz de deformação piezoelétrica.

O tensor de elasticidade, também sendo simétrico fica:

$$
\left[c_{I J}\right]=\left[\begin{array}{llllll}
c_{11} & c_{12} & c_{13} & c_{14} & c_{15} & c_{16} \\
c_{21} & c_{22} & c_{23} & c_{24} & c_{25} & c_{26} \\
c_{31} & c_{32} & c_{33} & c_{34} & c_{35} & c_{36} \\
c_{41} & c_{42} & c_{43} & c_{44} & c_{45} & c_{46} \\
c_{51} & c_{52} & c_{53} & c_{54} & c_{55} & c_{56} \\
c_{61} & c_{62} & c_{63} & c_{64} & c_{65} & c_{66}
\end{array}\right]=\left[c^{E}\right]
$$

e da mesma forma o tensor de compliância: $\left[s^{E}\right]=\left[c^{E}\right]^{-1}$

Assim na forma matricial, tem-se:

$$
\left\{\begin{array}{l}
T=\left[c^{E}\right] S-[e]^{t} E \\
D=[e] S+\left[\varepsilon^{S}\right] E
\end{array}\right.
$$

De forma análoga tem-se:

$$
\left\{\begin{array}{l}
S=\left[S^{E}\right] T+[d]^{t} E \\
D=[d] T+\left[\varepsilon^{T}\right] E
\end{array}\right.
$$

onde o índice $t$ indica transposta da matriz.

Em geral a notação tensorial é utilizada em problemas envolvendo transformação de coordenadas, enquanto que a notação matricial é utilizada em problemas envolvendo 
computação numérica. As equações podem ser escritas ainda, definindo-se uma matriz $9 \times 9$ elasto-piezo-dielétrica, como mostrado a seguir:

$$
\left\{\begin{array}{l}
T_{1} \\
T_{2} \\
T_{3} \\
T_{4} \\
T_{5} \\
T_{6} \\
D_{x} \\
D_{y} \\
D_{z}
\end{array}\right\}=\left[\begin{array}{lllllllll}
c_{11}^{E} & c_{12}^{E} & c_{13}^{E} & c_{14}^{E} & c_{15}^{E} & c_{16}^{E} & e_{x 1} & e_{y 1} & e_{z 1} \\
c_{21}^{E} & c_{22}^{E} & c_{23}^{E} & c_{24}^{E} & c_{25}^{E} & c_{26}^{E} & e_{x 2} & e_{y 2} & e_{z 2} \\
c_{31}^{E} & c_{32}^{E} & c_{33}^{E} & c_{34}^{E} & c_{35}^{E} & c_{36}^{E} & e_{x 3} & e_{y 3} & e_{z 3} \\
c_{41}^{E} & c_{42}^{E} & c_{43}^{E} & c_{44}^{E} & c_{45}^{E} & c_{46}^{E} & e_{x 4} & e_{y 4} & e_{z 4} \\
c_{51}^{E} & c_{52}^{E} & c_{53}^{E} & c_{54}^{E} & c_{15}^{E} & c_{56}^{E} & e_{x 5} & e_{y 5} & e_{z 5} \\
c_{61}^{E} & c_{62}^{E} & c_{63}^{E} & c_{64}^{E} & c_{65}^{E} & c_{66}^{E} & e_{x 6} & e_{y 6} & e_{z 6} \\
e_{x 1} & e_{x 2} & e_{x 3} & e_{x 4} & e_{x 5} & e_{x 6} & \varepsilon_{x x}^{S} & \varepsilon_{x y}^{S} & \varepsilon_{x z}^{S} \\
e_{y 1} & e_{y 2} & e_{y 3} & e_{y 4} & e_{y 5} & e_{y 6} & \varepsilon_{x y}^{S} & \varepsilon_{y y}^{S} & \varepsilon_{y z}^{S} \\
e_{z 1} & e_{z 2} & e_{z 3} & e_{z 4} & e_{z 5} & e_{z 6} & \varepsilon_{x z}^{S} & \varepsilon_{y z}^{S} & \varepsilon_{z z}^{S}
\end{array}\right]\left\{\begin{array}{c}
S_{1} \\
S_{2} \\
S_{3} \\
S_{4} \\
S_{5} \\
S_{6} \\
E_{x} \\
E_{y} \\
E_{z}
\end{array}\right\}
$$

Através desssa matriz $9 \times 9$ é possível exprimir as características de todas as classes cristalográficas. Essas tabelas encontram-se tabuladas para diferentes classes cristalográficas nas referências [Ristic 83,Kino 87]. Na apresentação é utilizada uma notação que indica os elementos nulos, iguais ou de sinais opostos da matriz, para cada classe.

\section{Equaão do Movimento}

Se somente tensôes internas estão atuando no material piezoelétrico, pela aplicação da Segunda Lei de Newton a um elemento de volume infinitesimal (dV), obtém-se a seguinte equação de movimento:

$$
\rho_{m} \frac{\partial^{2} u}{\partial t^{2}}=\nabla . T
$$

onde $\rho_{m}$ é a densidade do material e $u$ o vetor definido em (3.25), e sendo o tensor de tensões $T$ simétrico, pode-se escrever:

$$
\nabla . T=\left[\begin{array}{cccccc}
\frac{\partial}{\partial x} & 0 & 0 & 0 & \frac{\partial}{\partial z} & \frac{\partial}{\partial y} \\
0 & \frac{\partial}{\partial y} & 0 & \frac{\partial}{\partial z} & 0 & \frac{\partial}{\partial x} \\
0 & 0 & \frac{\partial}{\partial z} & \frac{\partial}{\partial y} & \frac{\partial}{\partial x} & 0
\end{array}\right]
$$

\section{Equaões Elétricas}

O comportamento elétrico do material piezoelétrico é descrito pela equação de Maxwell considerando o meio piezoelétrico isolante (pois não há cargas livres), ou seja, não há fluxo de cargas elétricas. Assim pelo Teorema de Gauss:

$$
\nabla \cdot D=0
$$

onde $D$ é o vetor deslocamento elétrico ou vetor densidade de fluxo. O campo elétrico é relacionado com o potencial elétrico $(\phi)$ pela expressão:

$$
E=-\nabla \phi
$$




\subsubsection{Propagaão de Onda em Materiais Piezoelétricos}

Combinando-se as equações do meio piezoelétrico com as equações do movimento anteriormente apresentadas, obtém-se as equações que descrevem a propagação tridimensional de ondas no interior do material piezoelétrico. Ristic [Ristic 83] obteve essas equações para um material anisotrópico (piezoelétrico ou não piezoelétrico) pertencente à classe triclínica. Para essa classe geral obtém-se equações complexas envolvendo muitos termos e constantes. No entanto os materiais piezoelétricos utilizados na prática apresentam os tensores de rigidez e constantes piezoelétricas com muitos termos nulos, o que causa uma considerável simplificação nessas equações.

Ristic [Ristic 83] resolveu essas equações considerando casos unidimensionais com propagação de ondas planas ao longo dos eixos cristalográficos $X, Y$ e $Z$ para materiais que possuam os tensores de materiais simplificados. Obteve-se como solução equações que descrevem a propagação de ondas mecânicas de cisalhamento, mecânicas longitudinais, piezoelétricas longitudinais (ondas longitudinais acopladas com o potencial elétrico $\phi)$, piezoelétricas acopladas (longitudinal e cisalhamento), etc..., bem como as respectivas velocidades de propagação no meio. Através dessas equações, supondo-se a solução de onda plana, ou seja, $u_{j}=U_{j} e^{j(\omega t-k y)}$ e $\phi=\Phi e^{j(\omega t-k y)}$, procurou-se encontrar uma relação entre freqüências e comprimento de onda, chegando-se no sistema de autovalores e autovetores:

$$
K^{2}[\Gamma][U]=\rho_{m} \omega^{2}[U] \quad \text { e } \quad K=\frac{2 \pi}{\lambda}
$$

onde $\omega$ é a freqüência angular, $[U]$ os deslocamentos dos modos de vibrar do meio e $[\Gamma]$ leva em conta os coeficientes piezoelétricos, sendo denominada Matriz de Christoffel quando esses coeficientes são nulos, e Matriz Rígida de Christoffel quando os coeficientes piezoelétricos são diferentes de zero [Ristic 83].

Para o caso unidimensional (por exemplo, propagação de ondas no interior da espessura de uma chapa infinita), a obtenção das equações de propagação de onda e da matriz acima é simples, podendo ser resolvida analiticamente. A medida que surgem condições de contorno no problema, a obtenção das equações e a sua resolução analítica se torna complexa, tendo-se que recorrer aos métodos numéricos. Assim a solução das equações descritas anteriormente fornece, a princípio, as freqüências e modos de vibrar do elemento piezoelétrico, que estão intimamente ligados com a propagação de ondas no interior do material. Na literatura encontram-se soluções para casos particulares de geometria simples onde por exemplo, a espessura é desprezada em relação às demais dimensões [Berlincourt 64,Ristic 83].

O modelo unidimensional é aplicado com grande sucesso em transdutores finos, ou seja, transdutores em que a relação diâmetro/espessura é alta, aproximando-se de uma placa de dimensões infinitas. Diminuindo-se a relação $D / H$, a forma do transdutor se afasta do modelo unidimensional e os resultados obtidos não correspondem à realidade. Kunkel et al. [Kunkel 90] analisam as freqüências de ressonância do modo de espessura para um transdutor circular variando-se a relação $D / H$. São comparados os valores obtidos através do método dos elementos finitos (que fornece resultados próximos da realidade) 
com o modelo unidimensional. Observa-se que para relações $D / H<10$ os valores obtidos são bem diferentes (discrepantes). Isso acontece porque o modo de espessura, que é resultante da propagação na direção $Z$ (polarização) de uma onda longitudinal intensamente acoplada com o campo elétrico de excitação, é extremamente perturbado pela presença de modos radiais resultantes da propagação de ondas que surgem devido às condições de contorno (dimensões reduzidas do transdutor - que o torna distante de uma placa infinita). $O$ mesmo acontece com os demais modos, que ao se diminuir a relação $D / H$ se acoplam com outros modos, também se afastando do modelo unidimensional. Dessa forma Kunkel et al. mostraram que discos piezoelétricos podem ser modelados como estruturas que introduzem acoplamento entre vários modos ideais desacoplados, e que em certos limites assintóticos $(D / H \rightarrow \infty \Rightarrow$ Placa infinita $\Rightarrow$ modelo unidimensional $)$, os modos são quase desacoplados, exibindo o comportamento de simples sistemas vibracionais, quando então podem ser modelados com precisão. 


\section{Capítulo 4}

\section{MEF aplicado à Piezoeletricidade}

\subsection{Introdução}

O método de elementos finitos (MEF) permite obter uma solução numérica de um conjunto de equações algébricas que descrevem a resposta de um sistema contínuo. Através do MEF é possível estabelecer e resolver as equações representativas de estruturas e meios contínuos genéricos de uma maneira eficaz. Graças a essa generalidade, a relativa facilidade de estabelecer as equações representativas, e pelas boas propriedades numéricas do sistema de matrizes resultante, o MEF tem encontrado grande aplicação [Bathe 82]. O MEF foi inicialmente desenvolvido para análise de problemas em mecânica estrutural, sendo atualmente reconhecido que pode ser igualmente bem aplicado para solução de muitas outras classes de problemas como por exemplo, escoamento de fluidos, transferência de calor, etc....

O uso do MEF na análise estrutural é relativamente recente (1950), e depende basicamente da divisão da estrutura em elementos discretos chamados de elementos finitos, e do princípio variacional, que estabelece em cada instante o equilíbrio das energias cinética e potencial em todos os pontos do volume considerado [Naillon 83]. . Consiste num método de transformação de um problema apresentado na forma integral, em um problema aproximado de algebra linear, onde os coeficientes são integrais avaliadas sobre os elementos finitos da estrututra ou do meio. Entretanto, geralmente os problemas são expressos na forma diferencial (derivadas parciais). Assim a obtenção da forma integral é conseguida através da formulação variacional ou de métodos de resíduos ponderados [Bathe 82,Zienkiewicz 83].

A matriz de coeficientes associada com o problema de álgebra linear é geralmente uma matriz de banda ou uma matriz triangular de grandes dimensões, o que permite que se use métodos de resolução iterativos como o método de Gauss, Gauss-Seidel, Newton-Raphson e Cholesky [Bathe 82]. A fig. 4.1 mostra de uma forma esquemática a aproximação feita na aplicação do MEF'. 


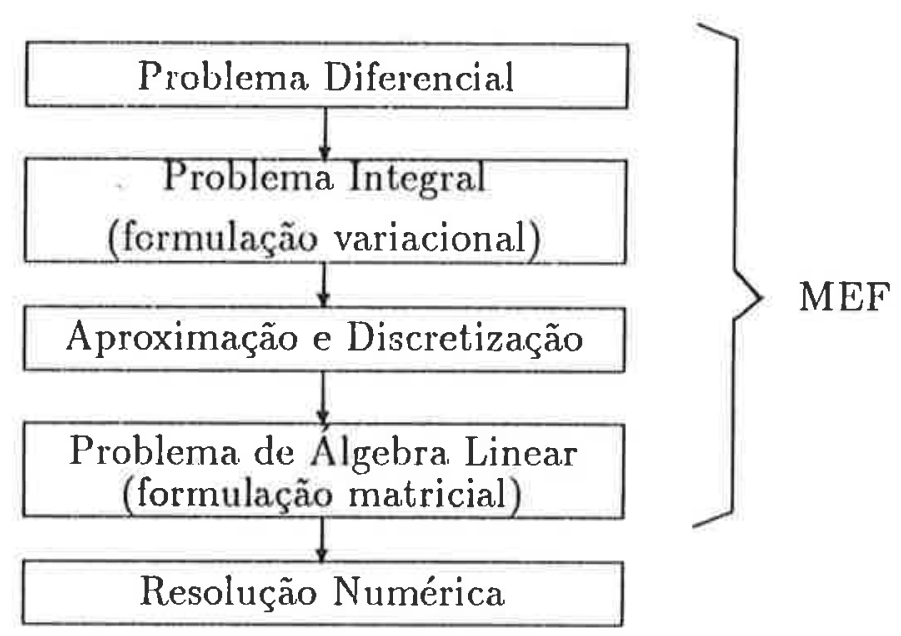

Figura 4.1: Aplicação do MEF.

O MEF se aplica na acústica ultrassônica através da análise vibracional de estruturas piezoelétricas e na obtenção de campos acústicos de transdutores, bem como no estudo de propagação de ondas ultrassônicas em fluidos e sólidos.

\subsection{Teoria de Elementos Finitos Piezoelétricos}

As equações na forma tensorial que são utilizadas na formulação do problema de elementos finitos, já, foram apresentadas no item 3.3.4, consistindo basicamente nas equações (3.28), (3.31), (3.25), (3.33), (3.34), onde as equações (3.28), relacionando quantidades elétricas e mecânicas do meio piezoelétrico, são a base para a derivação do modelo de elementos finitos piezoelétrico. Essas equações constituem o conjunto completo de equações diferenciais do modelo que descreve uma estrutura piezoelétrica.

Assim, o problema é apresentado na forma diferencial, sendo sua solução pelo MEF obtida aplicando-se o princípio variacional de Hamilton (formulação variacional) ou o método de Galerkin [Bathe 82]. A aplicação do método variacional encontra-se na referência [Lerch 90], e a do procedimento de Galerkin obtendo o chamado problema fraco, na referência [Naillon 83]. Aqui apresenta-se o resultado final, que consiste na formulação matricial do modelo piezoelétrico descrita abaixo, não considerando o amortecimento estrutural e elétrico.

$$
\left[\begin{array}{cc}
M_{U U} & 0 \\
0 & 0
\end{array}\right]\left(\begin{array}{l}
\ddot{U} \\
\ddot{\Phi}
\end{array}\right)+\left[\begin{array}{ll}
K_{U U} & K_{U \Phi} \\
K_{U \Phi}^{t} & -K_{\Phi \Phi}
\end{array}\right]\left(\begin{array}{c}
U \\
\Phi
\end{array}\right)=\left(\begin{array}{c}
F \\
Q
\end{array}\right)
$$

onde $M_{U U}, K_{U U}, K_{U \Phi}$ e $K_{\Phi \Phi}$, são respectivamente as matrizes de massa, rigidez mecânica, 


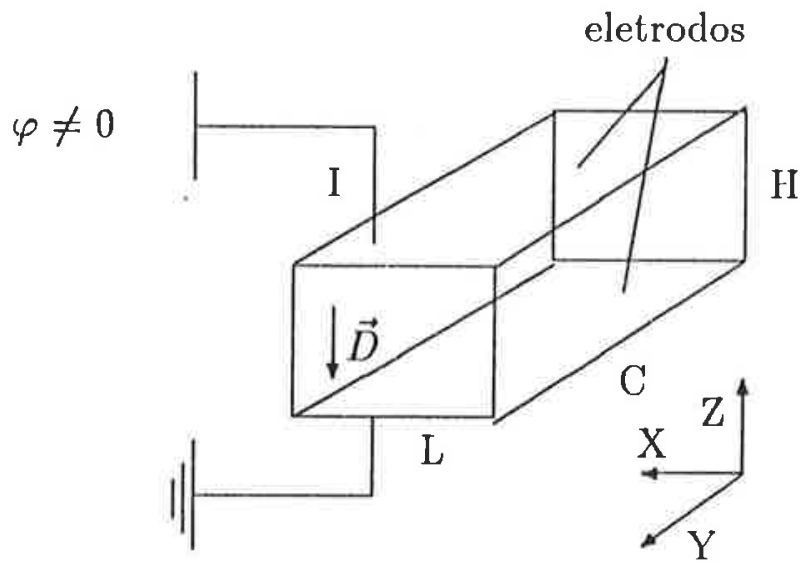

Fjgura 4.2: Barra paralelepipidica de cerâmica piezoelétrica [Naillon 83].

de acoplamento piezoelétrico e rigidez dielétrica, e sendo:

$$
\begin{aligned}
& u=\left[N_{U}\right] U \text { e } \quad \phi=\left[N_{\Phi}\right] \Phi \\
& S=B u=B\left[N_{U}\right] U=B_{U} U \\
& E=-\nabla \phi=-\nabla\left(\left[N_{\Phi}\right] \Phi\right)=-B_{\Phi} \Phi
\end{aligned}
$$

tem-se:

$$
\begin{aligned}
& M_{U U}=\iiint_{V} \rho\left[N_{U}\right]^{t}\left[N_{U}\right] d V \\
& K_{U U}=\iiint_{V}\left[B_{U}\right]^{t}\left[c^{E}\right]\left[B_{U}\right] d V \\
& K_{U \Phi}=\iiint_{V}\left[B_{U}\right]^{t}[e]^{t}\left[B_{\Phi}\right] d V \\
& K_{\Phi \Phi}=\iiint_{V}\left[B_{\Phi}\right]^{t}\left[\varepsilon^{S}\right]\left[B_{\Phi}\right] d V
\end{aligned}
$$

onde $\left[N_{U}\right]$ e $\left[N_{\Phi}\right]$ são as funções de interpolação de deslocamento e potencial elétrico respectivamente. $U, \Phi, F$ e $Q$ são respectivamente os vetores deslocamento, potencial elétrico, forças mecânicas (distribuídas no volume ou na superfície do corpo, e forças pontuais) e cargas elétricas (distribuídas na superfície, e cargas pontuais).

O sistema de equações (4.1) pode ser condensado introduzindo-se informações sobre a geometria do problema. Assim, por exemplo, considere uma barra polarizada no eixo $Z$, munida de dois eletrodos paralelos, perpendiculares a esse eixo fig. 4.2 , sendo que um deles está aterrado. Tem-se que o vetor coluna dos potenciais elétricos nodais $(\Phi)$ pode ser separado num vetor correspondente aos potenciais elétricos dos nós internos da barra $\left(\Phi_{i}\right)$, e outro correspondente aos potenciais elétricos dos nós do eletrodo superior $\left(\Phi_{P}:\right.$ potencial não-zero). Pelo fato do eletrodo inferior, estar aterrado, seu potencial é considerado zero, e seu vetor coluna pode ser eliminado do vetor $\Phi$. Assim o sistema (4.1) pode ser escrito da seguinte forma:

$$
\left[\begin{array}{ccc}
M_{U U} & 0 & 0 \\
0 & 0 & 0 \\
0 & 0 & 0
\end{array}\right]\left(\begin{array}{c}
\ddot{U} \\
\ddot{\Phi_{i}} \\
\ddot{\Phi}_{P}
\end{array}\right)+\left[\begin{array}{lll}
K_{U U} & K_{U \Phi_{i}} & K_{U \Phi_{P}} \\
K_{U \Phi_{i}}^{t} & -K_{\Phi_{\Phi_{i} \Phi_{i}}} & -K_{\Phi_{i} \Phi_{P}} \\
K_{U \Phi_{P}}^{t} & -K_{\Phi_{i} \Phi_{P}} & -K_{\Phi_{P} \Phi_{P}}
\end{array}\right]\left(\begin{array}{c}
U \\
\Phi_{i} \\
\Phi_{P}
\end{array}\right)=\left(\begin{array}{c}
F \\
0 \\
Q
\end{array}\right)
$$


Sendo nulas as cargas elétricas livres dos nós interiores da barra (meio isolante $\Rightarrow Q_{i}=$ 0 ), permanece somente o vetor coluna $Q_{P}$ cle cargas dos nós do eletrodo no potencial não zero. Da segunda expressão do sistemas de equação (4.1), pode-se obter $\Phi_{i}$ em função do vetor deslocamento $U$ e potenciais elétricos do eletrodo superior $\Phi_{P}$, obtendo-se a expressão [Naillon 83]:

$$
\Phi_{i}=K_{\Phi_{i} \Phi_{i}}^{-1}\left[K_{U \Phi_{i}}^{t} U-K_{\Phi_{i} \Phi_{P}} \Phi_{P}\right]
$$

Substituindo nas demais equações e rearranjando na forma matricial, tem-se:

$$
\left[\begin{array}{ll}
H_{U U} & H_{U \Phi_{P}} \\
H_{U \Phi_{P}}^{t} & -H_{\Phi_{P} \Phi_{P}}
\end{array}\right]\left(\begin{array}{c}
U \\
\Phi_{P}
\end{array}\right)+\left[\begin{array}{cc}
M_{U U} & 0 \\
0 & 0
\end{array}\right]\left(\begin{array}{c}
\ddot{U} \\
\ddot{\Phi}_{P}
\end{array}\right)=\left(\begin{array}{c}
F \\
Q_{P}
\end{array}\right)
$$

onde:

$$
\begin{aligned}
& H_{U U}=K_{U U}+K_{U \Phi_{1}} K_{\Phi_{i} \Phi_{i}}^{-1} K_{U \Phi_{i}}^{t}=K_{U U}+\Delta K \\
& H_{U \Phi_{P}}=K_{U \Phi_{P}}-K_{U \Phi_{i}} K_{\Phi_{i} \Phi_{i}}^{-1} K_{\Phi_{i} \Phi_{P}} \\
& H_{\Phi_{P} \Phi_{P}}=K_{\Phi_{P} \Phi_{P}}-K_{\Phi_{i} \Phi_{P}}^{t} K_{\Phi_{i} \Phi_{i}}^{-1} K_{\Phi_{i} \Phi_{P}}
\end{aligned}
$$

Como o eletrodo no potencial $\varphi_{P}$ não-zero é uma eqüipotencial, tem-se:

$$
\Phi_{P}=\varphi_{P}(I) \quad \text { e } \quad I=\left(\begin{array}{c}
1 \\
\vdots \\
1
\end{array}\right)
$$

Levando-se em conta a relação (4.8), multiplicando-se a equação (4.7) por $I^{t}$, e supondo:

$$
\begin{aligned}
& H_{U \Phi_{P}} I=H_{U \varphi} \\
& I^{t} H_{\Phi_{P} \Phi_{P}} I=H_{\varphi \varphi} \\
& \varphi_{P}=\varphi \\
& I^{l} Q_{P}=q
\end{aligned}
$$

chega-se no seguinte sistema linear sem amortecimento estrutural e elétrico [Najllon 83]:

$$
\left[\begin{array}{ll}
H_{U U} & H_{U \varphi} \\
H_{U \varphi}^{t} & -H_{\varphi \varphi}
\end{array}\right]\left(\begin{array}{c}
U \\
\varphi
\end{array}\right)+\left[\begin{array}{cc}
M_{U U} & 0 \\
0 & 0
\end{array}\right]\left(\begin{array}{c}
\ddot{U} \\
\ddot{\varphi}
\end{array}\right)=\left(\begin{array}{c}
F \\
q
\end{array}\right)
$$

O sistema de equação (4.1) é conhecido como formulação do tipo $K$, e o sistema (4.10) formulação do tipo $H$.

Nota-se que a primeira equação do sisterna corresponde num balanço de forças $H_{U U} U+$ $H_{U \varphi} \varphi+M_{U U} U=F$, onde os termos são respectivamente a força elástica, a força eletromecânica, força inercial e força externa aplicada. A segunda equação corresponde a um balanço de cargas $H_{U \varphi}^{t} U-H_{\varphi \varphi} \varphi=q$ onde os termos são respectivamente a carga de polarização devido à piezoeletricidade, cargas de condensação dielétrica e cargas livres.

A corrente que entra no eletrodo superior é dada pela expressão $I=-\frac{d}{d t} \int \vec{D} \cdot \vec{n} d S$, e sendo $q$ a carga no cletrodo superior pode-se escrever: $I=-\dot{q}$.

A solução do sistema (4.10) irá fornecer o deslocamento $U$ e o potencial elétrico $\varphi$, de acordo com as condições de contorno impostas. As duas equações estão acopladas 
pela matriz $K_{U \Phi}$, separando-se em duas equações matriciais com a diminuição do efeito piezoelétrico ([e] $\left.\rightarrow 0 \Rightarrow K_{U \Phi} \rightarrow 0\right)$. Essas duas equações isoladas descrevem respectivamente o modelo de elementos finitos puramente mecânico, já conhecido das estruturas mecânicas, e o modelo de problemas de campo eletrostático [Lerch 90].

\subsubsection{Amortecimento}

O amortecimento de uma estrutura é dado pela matriz de amortecimento $C_{U U}$, que pode ser obtida através de técnicas de elementos finitos. No caso geral, essa matriz pode ser montada através das propriedades de amortecimento da estrutura, que geralmente são dependentes da freqüência. Isso resultaria numa matriz cheia, e conseqüentemente numa significante quantidade de esforço computacional. Na prática é conveniente aproximar o amortecimento pela expressão de Rayleigh, que relaciona a matriz $C_{U U}$ com as matrizes $K_{U U}$ e $M_{U U}$ através das constantes $\alpha$ e $\beta$ [Bathe 82]:

$$
C_{U U}=\alpha M_{U U}+\beta K_{U U}
$$

Assim quatro tipos diferentes de amortecimento físico podem ser modelados de acordo com os valores de $\alpha$ e $\beta$ : o caso não amortecido $(\alpha=0$ e $\beta=0)$, o amortecimento viscoso que é proporcional a matriz rigidez $(\alpha=0$ e $\beta>0)$, o amortecimento proporcional à massa $(\alpha>0$ e $\beta=0)$ e o amortecimento de Rayleigh $(\alpha>0$ e $\beta>0)$. Os valores dos coeficientes $\alpha$ e $\beta$ dependem das características de dissipação de energia da estrutura. Para manipular estruturas com amortecimento não uniforme, os valores de $\alpha$ e $\beta$ podem diferir de elemento para elemento. Valores típicos dos coeficientes de Rayleigh para materiais piezocerâmicos operando na freqüência de $1 \mathrm{MHz}$ são $\alpha=7,5$ e $\beta=2 \cdot 10^{-5}$ [Lerch 90]. Quando a estrutura que apresenta amortecimento está sujeita a uma excitação cíclica (harmônica) surge o fenômeno de histerese, e nesse caso mostra-se [Meirovitch 86] que esse tipo de sistema pode ser tratado como estando sujeito à um amortecimento viscoso com coeficiente $\beta$ igual a $\beta=g / \omega$ e portanto:

$$
C_{U U}=\frac{g}{\omega} K_{U U}
$$

onde $g$ é uma constante sem dimensão e igual ao inverso do fator de qualidade mecânico $Q_{m}$ do material piezoelétrico considerado [Gindre 88]. Entretanto essa analogia entre o amortecimento estrutural e o viscoso só é válida para a excitação harmônica [Meirovitch 86].

Além do amortecimento estrutural mecânico, pode-se considerar também a matriz de amortecimento dielétrica, que caracteriza as perdas dielétricas, sendo dada pela expressão [Kohnke 89]:

$$
C_{\Phi \Phi}^{d}=\frac{1}{\omega} \iiint_{V}\left[N_{\Phi}\right]^{t}\left[\varepsilon^{d}\right]\left[N_{\Phi}\right] d V
$$

onde:

$$
\left[\varepsilon^{d}\right]=\left[\begin{array}{ccc}
\varepsilon_{11} & 0 & 0 \\
0 & \varepsilon_{22} & 0 \\
0 & 0 & \varepsilon_{33}
\end{array}\right]
$$


que está relacionada com a matriz dielétrica $\left[\varepsilon^{S}\right]$ pela expressão $\left[\varepsilon^{d}\right]=-\tan \delta_{E}\left[\varepsilon^{S}\right]$ [Kohnke 89], onde $h=-\tan \delta_{E}$ é denominado fator de perda dielétrica. Da expresssão (4.13) tem-se:

$$
C_{\Phi \Phi}^{d}=-\frac{h}{\omega} K_{\Phi \Phi}
$$

Essas perdas dielétricas provocam uma alteração de fase entre tensão e corrente. Assim, considerando o amortecimento, o sistema (4.1) fica:

$$
\left[\begin{array}{cc}
M_{U U} & 0 \\
0 & 0
\end{array}\right]\left(\begin{array}{c}
\ddot{U} \\
\ddot{\Phi}
\end{array}\right)+\left[\begin{array}{cc}
C_{U U} & 0 \\
0 & C_{\Phi \Phi}^{d}
\end{array}\right]\left(\begin{array}{c}
\dot{U} \\
\dot{\Phi}
\end{array}\right)+\left[\begin{array}{cc}
K_{U U} & K_{U \Phi} \\
K_{U \Phi}^{t} & -K_{\Phi \Phi}
\end{array}\right]\left(\begin{array}{c}
U \\
\Phi
\end{array}\right)=\left(\begin{array}{c}
F \\
Q
\end{array}\right)
$$

onde $C_{U U}=\alpha M_{U U}+\beta K_{U U} \operatorname{com} \beta=g / \omega$ e $\alpha=0$ no caso de excitação harmônica, com $C_{\Phi \Phi}^{d}$ dado por $(4.15)$.

\subsubsection{Freqüências de Ressonância e Anti-ressonância}

A ressonância de uma estrutura está relacionada com a rigidez do material, representada pelas componentes do tensor rigidez [c]. Рага o material piezoelétrico este tensor depende das condições de contorno elétricas, apresentando dois tipos: $\left[c^{E}\right]$ para um campo elétrico constante e $\left[c^{D}\right]$ para um deslocamento elétrico constante. Como visto no item 3.3 .5 o efeito piezoelétrico altera a velocidade de propagação das ondas no interior do material piezoelétrico (obtida a partir do tensor de rigidez de Christoffel) em comparação com a velocidade em malieriais puramente elásticos, e conseqüentemente a freqüência de ressonância da estrutura piezoelétrica [Naillon 83]. Por outro lado, o estado de ressonância da estrutura depende ainda das características intrínsecas do material e das condições de contorno elétricas e mecânicas, representadas respectivamente pela força e deslocamento, potencial elétrico e carga (fig. 4.3).

No estudo da vibração de estruturas piezoelétricas deve-se levar em conta que estas estruturas atuam nos dois sentidos, mecânico e elétrico. Quando a excitação é mecânica o transdutor opera em recepção, e quando é elétrica opera em emissão. Nesse estudo o transdutor será considerado inicialmente em emissão no ar, e sem amortecimento $\left(C_{U U}=0\right.$ - sistema conservativo). Com relação às condições de contorno mecânicas é considerado que as forças reativas agentes no transdutor são nulas, ou seja, a estrutura se encontra livre no espaço. Isso é perfeitamente válido, pois pelo fato das deformações envolvidas serem da ordem de $10^{-9} \mathrm{~m}$ no transdutor, seria necessário um material de elevada rigidez mecânica para provocar a vinculação da estrutura piezoelétrica [Lanceleur 92].

Conforme as condições de contorno elétricas numa estrutura piezoelétrica vibrando, tem-se duas famílias de ressonância mecânicas. Assim considere o sistema de equações (4.6) para o caso em que a excitação elétrica é o potencial. Aplicando as condições de contorno mecânica $(F=0)$, tem-se:

$$
M_{U U} \ddot{U}+H_{U U} U=-H_{U \varphi} \varphi
$$


forças elétricas forças elétricas

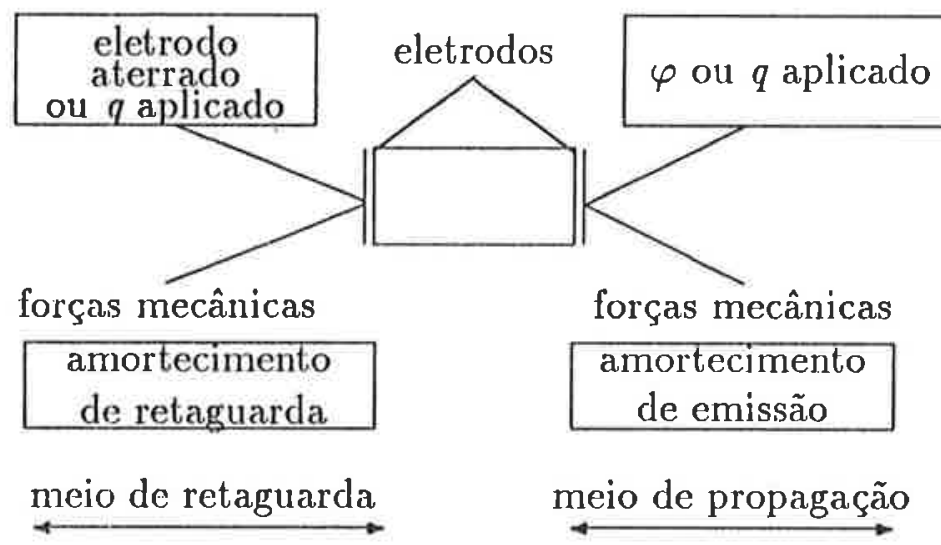

Figura 4.3: Condições de contorno, mecânica e elétrica [Naillon 83].

Para determinar as freqüências de ressonância nessa excitação, deve-se resolver a equação (4.17) para o caso em que não há excitação externa agindo, ou seja, os eletrodos estão curto-circuitados $(\varphi=0)$, resultando na equação de vibração livre do transdutor:

$$
\left\{H_{U U}-\omega_{r}^{2} M_{U U}\right\} U_{r}=0
$$

onde $\omega_{r}$ e $U_{r}$ representam as freqüências naturais e os modos de vibrar puros da estrutura.

As freqüências naturais de uma estrutura sem perdas são suas freqüências de ressonância (vibrações livres não amortecidas). Entretanto na realidade as estruturas apresentam amortecimento, mas para um transdutor piezoelétrico que não está acoplado a um meio de propagação, o único amortecimento é o estrutural, que nas cerâmicas piezoelétricas (material utilizado neste trabalho) é suficientemente pequeno de forma que se possa ignorar a diferença entre a freqüência natural e a de ressonância ' [Naillon 83]. Quando o transdutor estiver acoplado a um meio fluido a sua freqüência de ressonância será alterada. Assim $\omega_{r}$ e $U_{r}$ podem ser considerados freqüencias e modos de ressonância para condição de curto-circuito.

No caso da excitação consistir numa carga elétrica $q$ aplicada, eliminando-se o potencial elétrico e aplicando as condições de contorno $(F=0)$, o sistema (4.6) fica:

$$
M_{U U} \ddot{U}+\left(H_{U U}+\Delta H\right) U=H_{U \varphi} H_{\varphi \varphi}^{-1} q
$$

onde: $\Delta H=H_{U \varphi} H_{\varphi \varphi}^{-1} H_{U \varphi}^{t}$

Da mesma forma que no caso anterior, para determinação da frequiência de ressonância nessa excitação deve-se fazer $q=0$, o que corresponde aos eletrodos em circuito aberto, resultando a equação:

$$
\left\{H_{U U}+\Delta H-\omega_{a}^{2} M_{U U}\right\} U_{a}=0
$$




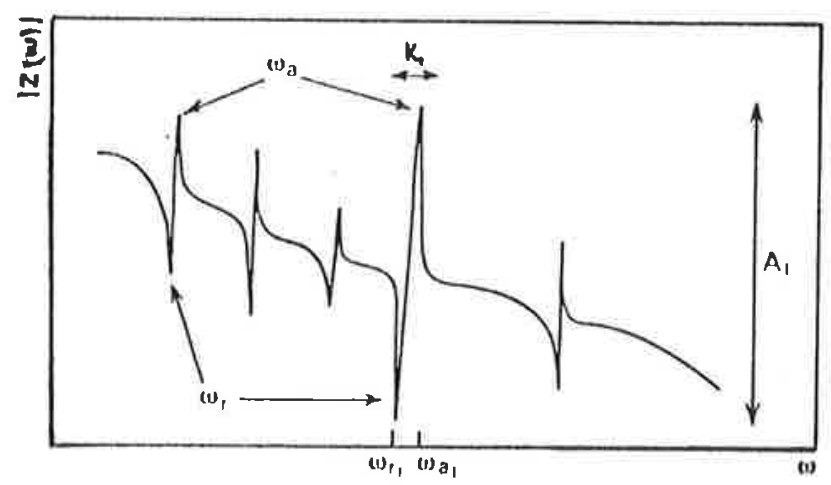

Figura 4.4: Curva do módulo de impedância [Naillon 83].

onde $\omega_{a}$ e $U_{a}$ correspondem aos chamados freqüências e modos de ressonância para condição de circuito aberto e $\Delta H$ representa a diferença entre as matrizes de rigidez dos dois estados de ressonância, podendo ser considerado uma perturbação da matriz rigidez $H_{U U}$. Dessa forma pode-se também calcular $\omega_{a}$, calculando a nova freqüência $\omega$, devido a uma perturbação $\Delta H$ em $H_{U U}$ (método das perturbações )[Boucher 81].

As freqüências definidas anteriormente, dependem de condições de contorno elétricas e estão associadas com o conceito de admitância, podendo ser obtidas determinando-se a curva de admitância (ou de impedância) do transdutor. Essas freqüências correspondem aos extremos da curva de admitância. Assim o máximo do módulo da admitância corresponde à freqüência de circuito fechado, e o mínimo à freqüência de circuito aberto, e viceversa na impedância. Portanto essas freqüências correspondem na verdade às freqüências de ressonância e anti-ressonância da impedância elétrica (fig. 4.4), ou seja, resumindo:

$$
\begin{aligned}
& \omega_{r} \stackrel{\text { def }}{=} \omega_{r, \text { elétrica }}=\omega_{r, \text { acústica }}^{\varphi} \\
& \omega_{a} \stackrel{\text { def }}{=} \omega_{a, \text { elétrica }}=\omega_{r, a c u ́ s t i c a}^{q}
\end{aligned}
$$

Isso é demonstrado analisando-se as expressões de impedância deduzidas por Naillon et al. [Naillon 83], através do MEF.

\subsubsection{Admitância}

A admitância $(Y)$ é obtida pelo MEF a partir da sua definição, que é $Y=I / \varphi$. No caso de excitação harmônica de potencial elétrico, tem-se, $\varphi(t)=\Phi e^{j \omega t}$, e supondo-se que não haja perdas, a carga elétrica estará em fase com o potencial elétrico, e portanto sendo $I=-\dot{q}$, tem-se:

$$
q(t)=Q e^{j\left(\omega t-\frac{\pi}{2}\right)} \Rightarrow \dot{q}(t)=j \omega Q e^{j\left(\omega t-\frac{\pi}{2}\right)} \Rightarrow I=-j \omega q(t)
$$


e portanto $Y=-j \omega q(t) / \varphi(t)$. Sendo $\varphi(t)=\Phi e^{j \omega t}$ tem-se: $Y=-\omega Q / \Phi$, e adotando $\Phi=1 V \Rightarrow Y=-\omega Q \Rightarrow|Y|=\omega Q$, onde $Q$ é obtido do sistema (4.6).

Caso haja perdas (amortecimento), haverá uma defasagem entre a carga elétrica e o potencial elétrico, e portanto:

$$
q(t)=Q e^{j\left(\omega t-\frac{\pi}{2}\right)} \text { e } Q=Q_{1}+j Q_{2} \Rightarrow Y=-\omega \frac{\left(Q_{1}+j Q_{2}\right)}{\Phi}
$$

e adotando $\Phi=1: Y=-\omega Q_{1}-j \omega Q_{2}$. Sendo $\omega Q_{1}=S$ (susceptância) e $\omega Q_{2}=C$ (condutância) tem-se:

$$
Y=-(S+j C) \Rightarrow|Y|=\sqrt{\left(S^{2}+C^{2}\right)}=\omega \sqrt{\left(Q_{1}^{2}+Q_{2}^{2}\right)}
$$

Obtém-se assim a curva do módulo da admitância. As curvas de impedância (ou admitância) elétrica podem ser obtidas experimentalmente utilizando-se um impedômetro fasorial, que permite determinar as frequiências de ressonância e anti-ressonância.

\subsubsection{Coeficiente de Acoplamento Eletromecânico (K)}

A obtenção dos coeficientes de acoplamento eletromecânico $(K)$ para cada modo de vibrar, permite avaliar a importância rclativa de um modo sobre os demais na resposta do transdutor (itern 3.1.1). Esse coeficiente é dado por [Berlincourt 64]:

$$
K^{2}=\frac{E_{m}^{2}(U, \varphi)}{E_{e}(U) E_{d}(\varphi)}
$$

onde $E_{e}(U), E_{m}(U, \varphi)$ e $E_{d}(\varphi)$ são respectivamente as energias elástica, dielétrica e eletromecânica, dadas por [Naillon 83]:

$$
\begin{aligned}
& E_{e}(U)=\frac{1}{2} U^{t} H_{U U} U \\
& E_{d}(\varphi)=\frac{1}{2} \varphi H_{\varphi \varphi} \varphi \\
& E_{m}(U, \varphi)=U^{t} H_{U \varphi} \varphi
\end{aligned}
$$

e portanto:

$$
K^{2}=\frac{\left(U^{t} H_{U \varphi} \varphi\right)^{2}}{\left(U^{t} H_{U U} U \varphi H_{\varphi \varphi} \varphi\right)}
$$

Esse coeficiente pode ser expresso em função das frequiências de ressonância e antiressonância. Simplificando a expressão de $K$ por $\varphi$ [Naillon 83], tem-se:

$$
K^{2}=\frac{U^{t} \Delta H U}{U^{t} H_{U U} U}
$$

e $\Delta H$ definido em (4.19). A equação (4.27) mostra que $K$ é a diferença relativa entre as energias elásticas correspondentes aos estados de ressonância para uma excitação por 
carga e por campo elétrico. Como comentado anteriormente, $\Delta H$ pode ser considerado uma perturbação em $H_{U U}$ que introduz uma variação em $1^{a}$ ordem $\omega_{\Delta}^{2}$ em $\omega_{r}^{2}$ dada por:

$$
\omega_{\Delta}^{2}=\omega^{2}+\frac{U \Delta H U}{U M_{U U} U}
$$

No caso $\omega_{\Delta}=\omega_{a}$ (freqüência de anti-ressonância) e $U=U_{r}$ (modo na ressonância $\mathrm{r}$ ), assim a diferença entre a freqüência de ressonância e a de anti-ressonância é dada por:

$$
\omega_{a}^{2}=\omega_{r}^{2}+\frac{U_{\tau} \Delta H U_{r}}{U_{r} M_{U U} U_{r}}
$$

Portanto o método das perturbações sugere um caminho mais curto na obtenção da freqüência de anti-ressonância. [Boucher 81]. Sendo $\omega_{r}^{2}=\left(U_{r}^{t} H_{U U} U_{r}\right) /\left(U_{r}^{t} M_{U U} U_{r}\right)$, tem-se [Boucher 81, Naillon 83]:

$$
\omega_{a}^{2}=\omega_{r}^{2}\left(1+K^{2}\left(U_{r}\right)\right) \Rightarrow K^{2}\left(U_{r}\right)=\frac{\left(\omega_{a}^{2}-\omega_{r}^{2}\right)}{\omega_{r}^{2}}
$$

Os coeficientes $K$ são obtidos experimentalmente, medindo-se as freqüências de ressonância e anti-ressonância (curva de impedância), e substituindo na expressão:

$$
K_{e x p}^{2}=\frac{\pi}{2} \frac{\omega_{r}}{\omega_{a}} \operatorname{cotg} \frac{\pi}{2}\left(\frac{\omega_{r}}{\omega_{a}}\right)
$$

A equação (4.31) é válida somente para modos vibracionais unidimensionais como o modo da espessura, por exemplo, fornecendo bons resultados para estados vibracionais quasi-unimodais, ou seja, onde ocorre a prepoderância energética de um modo sobre os demais. Caso não ocorra a quasi-unimodalidade a seguinte fórmula é utilizada:

$$
K_{e x p}^{2} \cong \frac{\left(\omega_{a}^{2}-\omega_{r}^{2}\right)}{\omega_{a}^{2}}
$$

A diferença entre o $K_{\text {exp }}$ obtido pelo modelo unidimensional e o obtido por análise estrutural surge pelo fato que o primeiro opera segundo uma formulação homogênea das equações piezoelétricas, supondo que o modo está desacoplado dos demais, enquanto que a análise estrutural leva em conta esse acoplamento, operando segundo uma formulação mista, o que faz com que a expressão da energia eletromecânica seja diferente nos dois casos [Boucher 81,Naillon 83]. A relação entre os dois cocficientes é dada por:

$$
K_{e x p}^{2}=\frac{K^{2}\left(U_{r}\right)}{\left(K^{2}\left(U_{r}\right)+1\right)}
$$

Através do MEF pode-se calcular o valor de $K$ para vários modos e diferentes configurações geométricas do transdutor, obtendo-se seu espectro de freqüências, que permite determinar para qual configuração geométrica um dado modo fornecerá uma alta amplitude de resposta (alt,o $K$ ), ou para qual configuração geométrica obter-se-á o maior valor de $K$ possivel para o transdutor, permitindo assim otimizar o material piezoelétrico com relação às suas qualidades de conversão eletromecânica de energia [Lerch 90, Naillon 83]. 


\subsection{Método de Elementos Finitos aplicado à Pro- pagação de Ondas Acústicas (Acoplamento Fluido Estrutura)}

Em geral os transdutores piezoelétricos estão acoplados a um meio fluido, por onde se propagam as ondas acústicas. Esse meio fluido tem o efeito de aumentar a inércia do transdutor, bem como introduzir um amortecimento, alterando as características vibracionais da cerâmica piezoelétrica. O mesmo acontece quando outras estruturas como as camadas de casamento e retaguarda são acopladas ao transdutor.

Dividindo-se o transdutor nas suas várias estruturas (camadas de retaguarda e casamento, material piezoelétrico e meio fluido) pode-se, através do MEF, modelar o sistema. Consiste em se determinar as matrizes de massa e rigidez para cada parte separadamente, e depois montar o conjunto [Kagawa 79, Lanceleur 92].

Os transdutores podem operar como emissores e receptores. Quando operam como emissores, o acoplamento fluido-estrutura transforma a vibração da estrutura piezoelétrica em ondas acústicas que se propagam pelo fluido. Quando o transdutor opera como receptor, o fluido torna-se um excitador mecânico para a estrutura, e a onda incidente gera uma vibração na estrutura, a qual é amortecida pelo próprio fluido. Assim para se obter resultados mais precisos sobre o transdutor, deve-se considerar o meio fluido. O problema do acoplamento fluido-estrutura pode ser modelado através do MEF, permitindo obter o campo acústico gerado pelo transdutor [Kagawa 79,Schillings 91, Lanceleur 92]. A seguir é apresentada a teoria de elementos finitos aplicada à acústica, utilizada em problemas onde há acoplamento fluido-estrutura.

Nesse tipo de problema as equaçóes dinâmicas estruturais são resolvidas juntamente com as seguintes equações:

- Equação da onda, que descreve a propagação de ondas num meio fluido, utilizando como variável a variação de pressão causada pela onda em relação a pressão de equilíbrio do fluido, limitando-se a pequenas variações de pressão acústica. O fluido é considerado isotrópico, homogêneo e compressivel, invíscido (não há efeito dissipativo), e não há fluxo médio de fluido.

$$
\nabla^{2} p-\frac{1}{c_{s}^{2}} \frac{\partial^{2} p}{\partial t^{2}}=0
$$

onde $c_{s}$ é a velocidade de fase para ondas acústicas em fluidos, conhecida como velocidade do som. Essa velocidade é uma propriedade característica do fluido, dependendo das variáveis termodinâmicas temperatura, pressão e densidade, sendo em geral independente da freqüência.

- Equação de condição de contorno na interface fluido-estrutura, que relaciona o gradiente de pressão normal do fluido e a aceleração normal da estrutura na interface 
fluido-estrutura.

$$
\vec{n} . \nabla p+\rho_{0} \vec{n} \cdot \frac{\partial^{2} \vec{U}}{\partial t^{2}}=0
$$

onde $\vec{n}$ é o versor normal à superfície fluido-estrutura.

- Equação da condição de contorno de absorção sonora:

$$
\vec{n} . \nabla p+\beta\left(\frac{1}{c_{s}}\right) \frac{\partial p}{\partial t}=0
$$

onde:

$$
\beta=\rho_{0} \frac{c_{s}}{Z_{n}}
$$

e $Z_{n}$ é a impedância acústica do material de amortecimento na interface.

Assim a primeira equação governa a propagação de onda no fluido, enquanto as demais, a interação fluido-estrutura e a absorção de som na interface, bem como a absorção de som no contorno do fluido.

Aplicando o procedimento de Galerkin, e manipulando as equações acima chega-se nas equações matriciais que descrevem o meio acústico [Kagawa 79,Kohnke 89,Lanceleur 92]:

$$
M^{P} \ddot{P}+C^{P} \dot{P}+K^{P} P+\rho_{0} R^{t} \ddot{U}=0
$$

onde $P$ é o vetor de pressão no nós e $M^{P}, K^{P}, R$ e $C^{P}$ são respectivamente as matrizes de massa do fluido, rigidez do fluido, acoplamento e amortecimento fluido, dadas por:

$$
\begin{aligned}
& p=\left[N_{P}\right] P \text { e } \quad \nabla p=\nabla\left(\left[N_{P}\right] P\right)=B_{P} P \\
& M^{P}=\frac{1}{c_{s}^{2}} \iiint_{V}\left[N_{P}\right]\left[N_{P}\right]^{t} d V \\
& K^{P}=\iiint_{V}\left[B_{P}\right]^{t}\left[B_{P}\right] d V \\
& R^{t}=\iint_{S_{2}}\left[N_{P}\right]\{n\}^{t}\left[\begin{array}{ccc}
{\left[N_{U}\right]^{t}} & 0 & 0 \\
0 & {\left[N_{U}\right]^{t}} & 0 \\
0 & 0 & {\left[N_{U}\right]^{t}}
\end{array}\right] d S_{2} \\
& \text { e }\{n\}=\left\{\begin{array}{c}
n_{x} \\
n_{y} \\
n z
\end{array}\right\}
\end{aligned}
$$

onde:

- $S_{2}$ é toda a superfície subtraída da superfície onde a pressão é aplicada pela estrutura.

- $C^{P}=\frac{\beta}{c_{s}} \iint_{S_{2}}\left[N_{P}\right]\left[N_{P}\right]^{t} d S_{2}$, levando em conta somente a perda de energia na interface. 
- $\left[N_{P}\right]$ é a função interpolação de pressão.

$\mathrm{Na}$ equação que descreve o comportamento dinâmico da estrutura, deve-se adicionar o termo da força devido a pressão do fluido agindo na interface. Assim:

$$
M_{U U} \ddot{U}+C_{U U} \dot{U}+K_{U U} U=F+F_{p r}
$$

e $F_{p r}=R P$.

Portanto acoplando as equações (4.38) e (4.40) tem-se o sistema de equações que descreve completamente a interação fluido-estrutura:

$$
\left[\begin{array}{cc}
M_{U U} & 0 \\
\rho_{0} R^{t} & M^{P}
\end{array}\right]\left(\begin{array}{c}
\ddot{U} \\
\ddot{P}
\end{array}\right)+\left[\begin{array}{cc}
C_{U U} & 0 \\
0 & C^{P}
\end{array}\right]\left(\begin{array}{c}
\dot{U} \\
\dot{P}
\end{array}\right)+\left[\begin{array}{ll}
K_{U U} & -R \\
0 & -K^{P}
\end{array}\right]\left(\begin{array}{c}
U \\
P
\end{array}\right)=\left(\begin{array}{c}
F \\
0
\end{array}\right)
$$

Essas equações são a base do MEF aplicado à acústica, permitindo resolver os problemas que envolvem acoplamento fluido-estrutura. As perdas no fluido, representadas na equação pela matriz $C^{P}$, levam em conta somente a dissipação de energia nas interfaces que apresentam admitância acústica $\beta$. 


\section{Capítulo 5}

\section{Aplicação do Método de Elementos Finitos}

No estudo da análise piezoelétrica por elementos finitos foi utilizado o software ANSYS. Uma breve descrição desse software encontra-se no apêndice $\mathrm{A}$.

\subsection{O Elemento Piezoelétrico}

Para modelar estruturas piezoelétricas o ANSYS dispõe de dois elementos tridimensionais designados pelos códigos STIF5 e STIF98 [ANSYS]. O primeiro consiste num elemento cúbico com 8 nós, com 6 graus de liberdade em cada nó (UX, UY, UZ, TEMP, VOLT, MAG), mas no modo piezoelétrico são utilizados somente 4 (UX, UY, UZ, VOLT) (fig. 5.1). O segundo consiste num elemento tetraédrico com 10 nós, com 6 graus de liberdade em cada nó, somente se utilizando 4, como no caso anterior (fig. 5.2).

Entre os resultados fornecidos por esses elementos tem-se as tensões mecânicas (SX, SY, SZ, SXY, SXZ, SYZ, Von Mises, etc...), as componentes do vetor campo elétrico (EX, $\mathrm{EY}, \mathrm{EZ})$, as componentes do vetor densidade de fluxo (DX, DY, DZ) e as energias elástica,
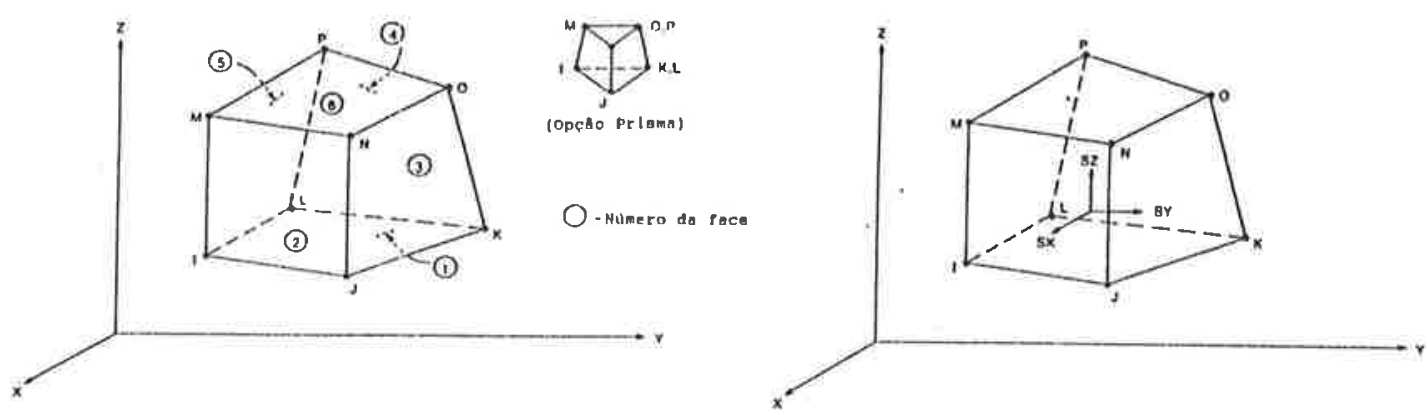

Figura. 5.1: Elemento STIF5 [ANSYS]. 

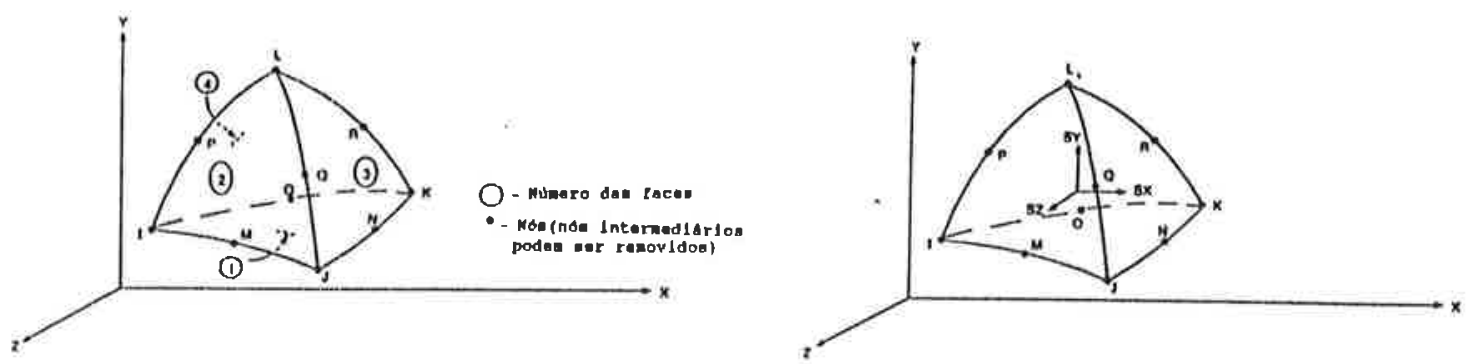

Figura 5.2: Elemento STIF98 [ANSYS].

dielétrica e eletromecînica para o elemento (UE, UD, UM), bem como os deslocamentos e potenciais elétricos nos nós [ANSYS].

\section{Tabela de Materiais}

Com relação às propriedades do material piezoelétrico, os elementos STIF5 e STIF98 são anisotrópicos permitindo diferentes propriedades nas 3 direções $x, y$ e $z$ do elemento. As propriedades do material piezoclétrico são representadas pelas matrizes rigidez, piezoelétrica e dielétrica, sendo fornecidas ao software através de tabelas, onde cada posição corresponde a um par linha e coluna das matrizes anteriores, que são simétricas. Para isso utiliza-se o comando NL no módulo de materiais. No lugar da matriz de rigidez pode-se definir a matriz de compliância $[d]=[c]^{-1}$, bastando para isso setar o comando KEYOPT(2) do elemento piezoelétrico. Deve-se tomar cuidado na ordem das linhas e colunas das matrizes que serão definidas. A ordem das componentes dos vetores no ANSYS é $\{x, y, z, x y, y z, x z\}$, enquanto que na maior parte das publicações sobre materiais piezoelétricos é $\{x, y, z, y z, x z, x y\}$, exigindo portanto que as matrizes rigidez e piezoelétrica. sejam corrigidas. A tabela de materiais deve ser indicada por um número $\geq 3$. Outras propriedades, como a densidade do meio, são definidas isoladamente através do comando MP [ANSYS].

As tabelas de materiais são extensas e trabalhosas de se construir. Dessa forma, uma vez montada a tabela para um certo material, a mesma é gravada num arquivo ("file29.dat") que pode ser lido posteriormente na montagem dos novos modelos, reduzindo assim o tempo de pré-processamento. Esse arquivo é obtido através dos comandos MPFILE, MPREAD e MPWRITE [ANSYS].

\subsection{Análise Piezoelétrica}

Entre as análises possíveis de se realizar com o elemento piezoelétrico no ANSYS tem-se as análises estálica, modal, harmônica (reduzida e completa), e transiente. Um estudo dos 
modelos utilizados em cada uma dessas análises, comentando as hipóteses consideradas, é apresentado a seguir, discutindo-se separadamente o caso da modelagem do elemento piezoelétrico isolado e o caso do acoplamento fluido-estrutura piezoelétrica.

\section{A) Estrutura Piezoelétrica Isolada}

No caso da modelagem do elemento piezoelétrico isolado foram realizadas as seguintes análises: modạl, harmônica e transiente, discutidas a seguir.

\section{A.1 Análise Modal}

Consiste basicamente em se resolver o problema de autovalores e autovetores:

$$
\left\{K-\omega_{i}^{2} M\right\} U_{i}=0
$$

No caso piezoelétrico, tem-se dois problemas a resolver, o de ressonância e anti-ressonância. A obtenção de um ou outro problema vai depender das condições de contorno elétricas. Assim para se obter as freqüencias de ressonância, como visto, deve-se curto-circuitar os eletrodos. Isso pode ser conseguido aterrando-se os potenciais dos nós dos eletrodos $(\varphi=0)$, através do comando NT, ou simplesmente acoplando os nós do eletrodo superior e inferior através do comando CP. Apesar de fisicamente as situações serem um pouco diferentes, teoricamente fornecem o mesmo resultado.

Para solução do problema de autovetores e autovalores o ANSYS dispõe de três procedimentos diferentes na extração dos modos: Householder, Subespaço Reduzido e Subespaço Completo [ANSYS]. O primeiro realiza a extração completa dos modos das matrizes reduzidas. $\mathrm{O}$ número de modos obtidos é igual ao número de graus mestres escolhidos. Para os métodos de Subespaço [Bathe 82], somente os primeiros p modos de um conjunto disponível de $\mathrm{N}$ GLs são calculados, onde $\mathrm{p}$ é geralmente muito menor do que N. No caso do Subespaço Reduzido, $\mathrm{N}$ é o número de graus mestres, e no Subespaço Completo é o número total de GLs. Nesse último não é feito nenhuma redução dé matrizes, não necessitando assim de graus mestres. Por essa razão o Subespaço Completo consome um maior tempo de processamento e major espaço em memória.

O método a ser utilizado depende da natureza do problema. Assim num problema em que o corpo se encontra livre no espaço (não há vinculações) é sempre possível obter os modos com o método de Householder, e possível com o Subespaço Reduzido desde que seja aplicada um deslocamento nas freqüências através do comando EXTMOD, FREQB [ANSYS]. Pelo fato de não utilizar graus mestres, o método de Subespaço Completo pode ser usado em análises acústicas, onde as matrizes não são simétricas, necessitando utilizar todos os GLs. A seleção do método desejado é feita através dos comandos KAY,1 e KAY,7.

$\mathrm{Na}$ análise piezoelétrica deve-se fazer com que o programa realize a condensação das 
matrizes, eliminando-se os GLs elétricos. Isso é conseguido selecionando-se os GLs de deslocamento (UX, UY, UZ) como graus mestres (pode-se selecionar alguns ou todos os GLs de deslocamentos como graus mestres). Assim, como será feita na realidade uma análise reduzida, recomenda-se o método de Householder [ANSYS]. O número de modos calculados é igual ao número de graus mestres. Pode-se especificar a faixa de freqüências em que se deseja obter os modos através do comando EXTMOD. Pelo fato de se utilizar graus mestres os vetores modais obtidos serão reduzidos, ou seja, referentes somente aos graus mestres. Deve-se portanto expandir esses modos, o que é feito especificando-se o número de modos que se deseja expandir através do comando $K A Y, 2$, ou a faixa de freqüência através do comando EXMOD. Somente os modos expandidos serão visualizados.

Como já apresentado, os dois elementos utilizados na modelagem piezoelétrica (STIF5 e STIF98) são elementos de múltipla aplicação apresentando 6 GLs por nó (UX, UY, UZ, TEMP, MAG, VOLT), e utilizando somente 4 (UX, UY, UZ, VOLT) na opção piezoelétrica. Entretanto os demais graus apesar de não serem utilizados e não interferirem nos resultados, são considerados no cálculo da dimensão das matrizes e da frente de onda (apêndice A), reduzindo o número de GLs úteis no modelo. Dessa forma é necessário realizar um acoplamento (comando CP) dos GLs TEMP e MAG em todas as análises envolvendo esses elementos na sua forma piezoelétrica [Schillings 91].

Construído o modelo deve-se procurar otimizar sua frente de onda, através do comando WSORT. Esse procedimento não altera a numeração dos elementos, mas sim atribui um outro número a cada um deles, de maneira que se tenha uma numeração que otimize a frente de onda. Esse procedimento deve ser feito em todas as análises, pois ajuda a reduzir o tempo de processamento, bem como aumentar o número de GLs do modelo. Muitas vezes a limitação na discretização do modelo é determinada pela frente de onda, o que obriga a se tomar outras medidas além dessas, no sentido de reduzir ao máximo os GLs, ficando somente com os necessários para a análise.

Terminado o pré-processamento é gerado o "file27.dat" através do comando AFWRITE. Antes de se iniciar a solução de qualquer análise recomenda-se verificar se a frente de onda do modelo não supera o valor máximo permitido que é $250 \mathrm{GLs}$ nas análises modal e harmônica completa, e 500 GLs nas análises harmônica reduzida, transiente e estática, no software utilizado. A verificação é feita através do comando /CHECK.

A resolução do problema de autovalores e autovetores fornece um grande número de freqüências e modos. Entretanto alguns desses modos são puramente mecânicos. Para identificá-los deve-se comparar as freqüências de ressonância e anti-ressonância. Se forem iguais, significa, quı o modo não é afetado pelas condições de contorno elétricas, o que caracteriza como sendo um modo mecânico. Essas frequiências e modos devem ser desconsiderados, pois estão desacoplados da excitação elétrica. Outro problema é associar corretamente as freqüências de ressonância $\left(\omega_{r}\right)$ e as de anti-ressonância $\left(\omega_{a}\right)$. Em geral $\omega_{a}>\omega_{r}$ e os modos correspondentes a cada uma são semelhantes. Entretanto existem situações em que, caso o modo seja fortemente acoplado, a diferença entre $\omega_{a}$ e $\omega_{r}$ é muito grande de maneira que $\omega_{a}$ passa a ser maior que $\omega_{r}$ e $\omega_{a}$ do modo posterior, caso o mesmo seja fracamente acoplado. Assim, as freqüências de ressonância e anti-ressonância 
do modo fortemente acoplado englobam as do modo fracamente acoplado. Quando isto acontece as freqüências de ressonância e anti-ressonância do modo fracamente acoplado encontram-se invertidas $\left(\omega_{a}<\omega_{r}\right)$, devendo-se tomar o cuidado de não se associar a $\omega_{r}$ do modo fortemente acoplado com a $\omega_{a}$ do modo fracamente acoplado, e vice-versa. Para evitar essa confusão, deve-se comparar a forma dos modos de ressonância e anti-ressonância, que devem ser semelhantes [Kunkel 90].

\section{A.2 Análise Harmônica Reduzida}

Consiste em se determinar o comportamento da estrutura sujeita a uma excitação harmônica, resolvendo-se um problema do tipo:

$$
M \ddot{U}+C \dot{U}+K U=F(t) ; \quad F(t)=F_{0} e^{j \omega t} \text { e } U=U_{0} e^{j(\omega t+\phi)}
$$

Chama-se reduzida porque são utilizados graus mestres, o que implica a redução das matrizes de rigidez, massa e amortecimento a esses graus. Dessa forma os vetores obtidos são reduzidos, exigindo que se faça uma expansão da solução parà os demais GLs. Assim a solução consiste em duas etapas, a primeira chamada "DISPLACEMENT PASS" onde é resolvida a equação (5.2) obtendo-se os vetores (deslocamentos, forças nodais, etc ...) referentes aos graus mestres, e a segunda chamada "STRESS PASS" onde os resultados são expandidos para os demais GLs para poderem ser pós-processados. O único vetor reduzido que pode ser pós-processado é o de deslocamentos, através do pós-processador POST26. As forças, se existirem, devem ser aplicadas nos graus mestres.

A equação (5.2) pode ser resolvida de duas formas no ANSYS: direta ou por superposição modal. Na análise direta, como a excitação é harmônica o problema torna-se estático resolvendo-se a equação:

$$
\left\{-\omega^{2} M+j \omega C+K\right\} U=F
$$

A análise de superposição modal utiliza a teoria de superposição modal. Consiste em se considerar os modos de vibrar como uma base ortonormal (somente se não houver perdas), em função da qual o vetor deslocamento é escrito, obtendo as chamadas coordenadas generalizadas. Assim tem-se:

$$
u=[L]^{t} q
$$

onde $[L]$ a matriz em que as colunas são os vetores modais e $q$ o vetor das coordenadas generalizadas [Meirovitch 86]. Através da superposição modal, numa análise transiente, por exemplo, pode-se analisar separadamente a contribuição de cada modo, estudando sua influência na resposta. Assim obtendo-se o espectro de freqüência da função de excitação, determina-se os modos que serão excitados com maior e menor intensidade, permitindo descobrir os modos que contribuirão significativamente na resposta, e que portanto devem ser levados em conta [Bathe 82].

Para se realizar esse tipo de análise no ANSYS deve-se inicialmente executar uma análise modal. Então utilizando o mesmo modelo, sem mudar as condições de contorno, 
uma vez que as matrizes de massa e rigidez já foram calculadas com as condições de contorno da análise modal, realiza-se a análise harmônica reduzida por superposição modal (ver [ANSYS]). Na análise modal do problema piezoelétrico os eletrodos são curtocircuitados ou abertos (conforme se deseja determinar as freqüências de ressonância ou anti-ressonância). Ao se realizàr a análise harmônica é aplicada uma tensão elétrica num dos eletrodos, o que implica que se modifique a condição de contorno da análise modal, alterando o cálculo das matrizes. Dessa forma não é possível executar a análise por superposição modal no caso piezoelétrico no ANSYS.

\section{A.3 Análise Harmônica Completa}

Consiste em se resolver o mesmo problema da análise reduzida (equação (5.2)), só que não utiliza graus mestres, sendo por isso denominada completa. Apresenta a vantagem de utilizar as matrizes na sua forma completa, não exigindo que as matrizes envolvidas sejam simétricas, como ocorre nos problemas de acoplamento fluido-estrutura. Outra vantagem é que não necessita expandir os resultados, o que facilita a análise, principalmente quando é necessário calcular a resposta da estrutura para várias freqüências. Entretanto o tempo de processamento e o espaço utilizado em disco são maiores do que na análise reduzida.

\section{A.4 Amortecimento}

$\mathrm{Na}$ análise piezoelétrica o amortecimento pode ser definido de duas maneiras. Na primeira definem-se os coeficientes $\alpha$ e $\beta$ do modelo de Rayleigh (item 3.5.2) através dos comandos ALPHAD e BETAD. Na segunda defire-se o amortecimento como uma propriedade do material, o que permite definir um valor diferente para cada elemento, ou para uma certa região, ao invés de considerá-lo uniforme para toda a estrutura como no caso anterior. Isso é feito através da propriedade DAMP do comando MP.

\section{A.5 Curva de Admitância}

Através da análise harmônica pode-se obter a curva de resposta em freqüência do transdutor para uma dada variável, como por exemplo, a admitância, bastando para isso realizar uma varredura na faixa de freqüências desejada. Se essa varredura for feita com incrementos constantes de freqüência seria necessário um grande número de pontos para representar a curva de resposta com precisão, o que exige grande tempo de processamento e espaço em disco. Dessa forma para a obtenção da curva de admitância, a varredura é feita nas regiões próximas das freqüências de ressonância obtidas na análise modal, numa faixa de \pm 10 $\mathrm{kHz}$ em torno da freqüiência, definindo-se seis freqüências espaçadas exponencialmente em ambos os lados de cada freqüência de ressonância [Schillings 91].

Para o cálculo da admitância utiliza-se a equação (4.21), onde a carga $Q$ do eletrodo é obtida somando-se as cargas de cada um dos seus nós. Estando os nós acoplados (comando 
CP) essa soma encontra-se armazenada na carga elétrica do nó de menor número do conjunto acoplado [ANSYS]. As cargas elétricas são armazenadas no vetor de reações. O levantamento da curva de admitância é feita através do POST26, lendo-se o vetor de reações com o comando RFORCE e realizando-se as operações da equação (4.21).

\section{A.6 Coeficiente de Acoplamento Piezoelétrico}

O coeficiente de acoplamento piezoelétrico para os diferentes modos, é dado pelas expressões $(4.27)$ e (4.30). O cálculo das energias elástica $\left(E_{e}\right)$, dielétrica $\left(E_{d}\right)$ e eletromecânica $\left(E_{e m}\right)$ é feito na análise harmônica, excitando-se a estrutura com um potencial elétrico na freqüência desejada. Essas informaçôes sobre energia não são fornecidas na análise modal, uma vez que esse tipo de análise envolve a solução de autovalores com excitação externa nula. O valor dessas energias para cada elemento é armazenado num módulo dos dados de pós-processamento denominado STRESS e devem ser somados no POST1 para se obter a energia total da estrutura. Para a obtenção do $K$, a estrutura sujeita à excitação harmônica deve ser vinculada de maneira que o movimento resultante $U$ da excitação seja igual ao modo de interesse, pois caso contrário como a excitação de potencial é simétrica em relação ao plano mediano da espessura, será excitado um modo simétrico de freqüência igual a do modo desejado, e não o mesmo, e o coeficiente piezoelétrico calculado não terá sentido físico. Assim, é mais fácil calcular o coeficiente $K$ através da expressão (4.27) em que são utilizados os vetores de deslocamento e potencial relativos nodais obtidos na análise modal. O ANSYS não permite realizar esse cálculo, o que faz com que os $K \mathrm{~s}$ para cada modo sejam calculados obtendo-se as freqüencias de ressonância e anti-ressonância, e utilizando-se a equação (4.30) [Hossak 91].

\section{A.7 Análise Transiente}

Consiste em se resolver a equação (5.2), em que $F(t)$ é uma função qualquer no tempo. Na análise transiente deve-se definir a função de excitação, especificando-se o valor da função para diferentes incrementos de tempo, através do pré-processador PREP6. A função é dividida nos chamados passos de carga, cada um contendo um ou mais incrementos de tempo [ANSYS], como mostra a fig. 5.3. Caso a definição da função de excitação exija poucos pontos, a mesma pode ser definida no PREP7, especificando-se os passos de carga num certo tempo através do comando 'TIME, e os incrementos de tempo através do comando ITER. Se a função for definida no PREP6 é gerado o "file23.dat", devendo-se na solução entrar com o comando /INPUT,23 após o comando /INPUT,27. A escolha dos incrementos de tempo envolve vários critérios descrito em [Bathe 82,ANSYS]. No caso de uma estrutura, recomenda-se que o incremento seja $1 / 10$ do período da maior freqüência que se deseja levar em conta.

Para a solução do problema transiente o ANSYS utiliza o método numérico de Newmark descrito em [Bathe 82]. Trata-se de um método de integração direta implícito, em que a equação (5.2) é resolvida entre um instante de tempo e o próximo. O que se faz é 


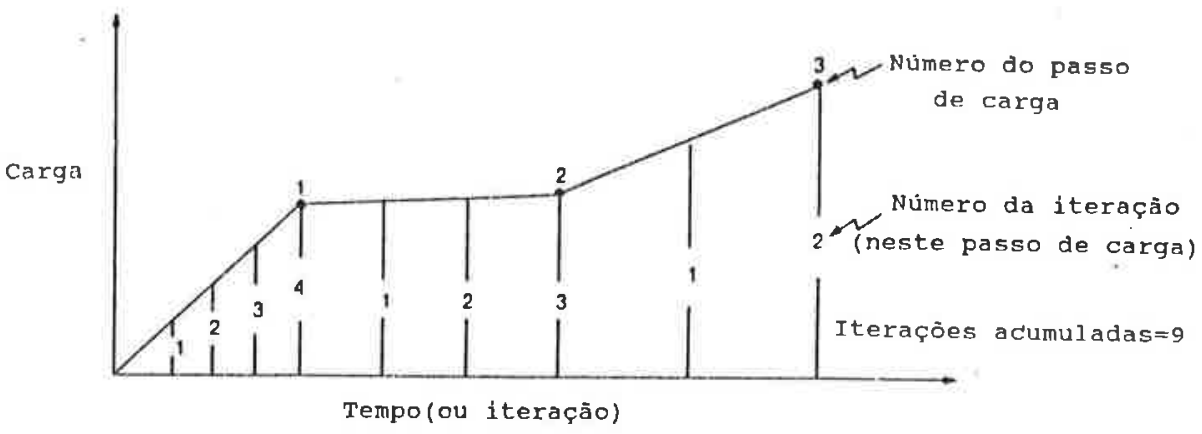

Figura 5.3: Passos de carga e incrementos de tempo [ANSYS].

interpretar os termos $M \ddot{U}$ e $C \dot{U}$, como forças de inércia e viscosa respectivamente, e impor o equilíbrio estático em cada instante de tempo seguinte. Nesse método são definidas algumas constantes que influenciam as características do resultado. $O$ principal é o fator $\gamma$ definido através do comando GAMMA, que age como um amortecedor numérico provocando um decréscimo, bem como uma assimetria, da amplitude de um pulso emitido, por exemplo. Outro parâmetro importante é o incremento de tempo. Uma baixa discretização no tempo da função de excitação leva a um aumento do período com o tempo de um pulso emitido [Bathe 82].

O ANSYS possui dois tipos de módulos para análise transiente, o linear (KAN,5) e o não-linear $(\mathrm{K} A N, 4)$. Para o problema piezoelétrico somente a análise não-linear é permitida, uma vez que a análise linear $(K \Lambda N, 5)$ não permite utilizar o elemento piezoelétrico. Apesar do problema piezoelétrico ser linear nas condições estudadas obteve-se bons resultados recalculando as matrizes de rigidez e de massa a cada incremento de tempo, o que é conseguido através do comando KUSE,0. O ANSYS dispõe de outros comandos que permitem por exemplo, definir o número máximo de iterações por incremento de tempo, o tempo máximo para convergência em cada iteração, etc..., entretanto pelo fato do problema ser linear a maior parte desses comandos não são necessários.

Nessa análise ainda não é incluído o meio externo (fluido). No entanto conhecendose os perfis de velocidade em cada instante, pode-se através de um programa analítico (que exige menor capacidade computacional) calcular o campo acústico transiente do transdutor, porém nesse caso o acoplamento fluido-estrutura não será considerado.

\section{B) Acoplamento Fluido-Estrutura}

Nessa análise é levado em conta a presença do fluido, e o objetivo agora é determinar o campo acústico gerado, ou seja a distribuição de pressões acústicas. Trata-se de um problema mais complicado de se resolver pelo MEF do que o anterior. A principal diferença do ponto de vista do $\mathrm{MEF}$, é que as matrizes de massa e rigidez da equação (5.2) são 


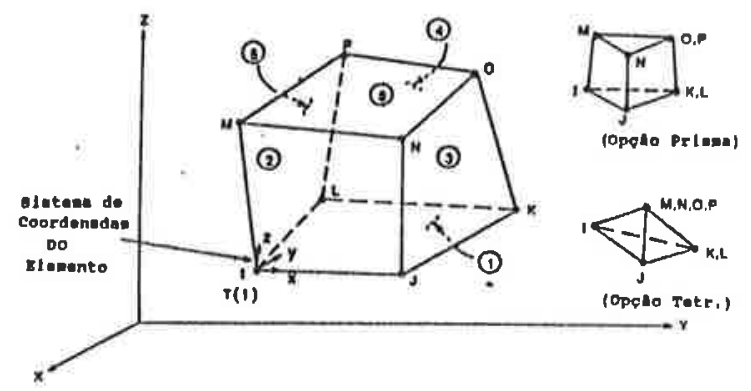

Figura 5.4: Elemento STIF30 [ANSYS].

ambas assimétricas, o que significa que não é mais possível utilizar os graus mestres (uma vez que todos os GLs devem ser utilizados), dificultando a realização da análise modal.

Na modelagem do meio acústico é utilizado o elemento STIF30. Na formulação desse elemento foram utilizados todas as hipóteses apresentadas no item 4.3 para equação de onda. Trata-se de um elemento tridimensional do tipo cúbico que apresenta 4 GLs por nó (UX, UY, UZ, PRES) como mostrado na fig. 5.4. Possui duas versões, uma na qual são utilizados todos os GIss por nó, e outra na qual somente o GL PRES (pressão) é utilizado. Entretanto apesar dos demais GLs (UX, UY, UZ) não influenciarem os resultados, estes contribuem para aumentar o tamanho das matrizes. Para reduzir o tamanho, deve-se acoplar os demais GLs [Schillings 91]. A primeira opção é recomendada para representar a interface fluido-estrutura, pois pelo fato do elemento fluido e o elemento estrutural piezoelétrico possuírem GLs em comum (UX, UY, UZ) garante o acoplamento entre eles. A segunda é recomendada para se descrever o meio fluido, onde somente o grau PRES é necessário [ANSYS]. As propriedades do meio fluido como velocidade do som e densidade, e absorção (nas interfaces) são definidas através dos comandos MP,VISC, MP,DENS e MP,MU respectivamente.

$\mathrm{Na}$ interface fluido-estrutura o elemento acústico encontra-se aderido ao elemento piezoelétrico, o que faz com que as deformações tangenciais à face do transdutor sejam transmitidas para o fluido. No caso de fluidos com alta viscosidade, essa hipótese é válida, já em fluidos de baixa viscosidade, como por exemplo a água, essa hipótese deixa de valer, ou seja, as deformações tangenciais quase não são transmitidas ao fluido. Assim num modelo mais completo, o efeito da viscosidade deve ser levado em conta, no entanto a modelagem da viscosidade na interface fluido-estrutura por elementos finitos é complexa, podendo ser analisada num estudo futuro.

Nos problemas de acoplamento fluido-estrutura somente três tipos de análise são possiveis: análise modal, harmônica completa e transiente. 


\section{B.1 Análise Modal}

Analogamente à análise modal da estrutura piezoelétrica isolada, na análise modal do acoplamento fluido-estrutura dever-se-ia realizar uma condensação do sistema eliminando os GLs elétricos (VOLT), permanecendo somente os GLs de pressão e deslocamento. Entretanto como as matrizes são assimétricas não é possível realizar a condensação, e os GLs de potencial elétrico não podem ser eliminados. Para resolver esse problema segundo [Schillings 91] é necessário utilizar a técnica de substruturas [ANSYS]. Esta técnica consiste basicamente ern substruturar a estrutura piezoelétrica, ou seja, eliminar todos os GLs elétricos, e substituir toda estrutura piezoelétrica por um super-elemento eqüivalente, com GLs estruturais (UX, UY, UZ). A análise modal pode ser feita agora com todos os GLs estruturais e de pressão, utilizando-se na resolução do problema de autovalores e autovetores o método de Subespaço Completo, indicado para matrizes assimétricas.

No problema acoplado o amortecimento fluido é muito maior do que no problema desacoplado (estrutura piezoelétrica isolada), devido à presença do fluido (inércia virtual). No caso do problema desacoplado, pelo fato de na realidade o amortecimento estrutural ser baixo, a utilização de um método de solução do problema de autovalores e autovetores, que não leve em conta o amortecimento não causa muita diferença nos resultados (freqüências de ressonância e natural), evitando um grande esforço computacional. Já no problema acoplado, isso faz diferença, e como a implementação do método de Subespaço Completo no ANSYS não leva em conta o amortecimento, as freqüências obtidas são somente uma aproximação daquelas que causam a ressonância, como pode ser determinado na análise harmônica em que o amortecimento é considerado [Varadan 90,Schillings 91]. Outra questão, é que a análise modal do problema acoplado fornece um número muito maior de freqüencias (autovalores) do que no caso do problema não acoplado, uma vez que além dos modos piezoelétricos e mecânicos (comentados anteriormente) surgem os modos acústicos, que representam ondas estacionárias no meio fluido, e os modos acústicos de corpo rígido que aparecem pelo fato de que nenhum GL de pressão foi especificado (dado um valor) no fluido. Para se identificar essas freqüências, verificando-se por exemplo, quais alteram a curva de admitância, deve-se realizar uma análise harmônica do problema acoplado, utilizando-se freqüências próximas às calculadas [Schillings 91]. Além disso o tempo de processamento e o espaço de memória requeridos na análise modal são maiores do que na análise harmônica.

Dessa forma devido a essas desvantagens decidiu-se por não realizar uma análise modal do problema acoplado. A determinação das frequiências de ressonância e antiressonância é feita levantando-se a curva de admitância através da análise harmônica, utilizando-se freqüências nas regiões em torno das freqüências obtidas na análise modal da estrutura piezoelétrica isolada (problema desacoplado). Segundo [Schillings 91] essas freqüências constituem em geral uma primeira aproximação para as freqüências do problema acoplado. Para a visualização dos modos de vibrar, basta excitar o transdutor nas freqüências de ressonância. 


\section{B.2 Análise Harmônica Completa}

$\mathrm{Na}$ análise harmônica completa, utilizam-se todos os GLs, simplificando a análise em relação a anterior. Com o intuito de se estudar a modelagem do problema fluido-estrutura, modelou-se inicialmente o campo acústico de um pistão plano.

Um fator que influencia consideravelmente nos resultados é a discretização da malha do fluido. É recomendado que a dimensão básica do elemento cúbico (lado) seja igual a pelo menos $1 / 10$ do comprimento de onda de operação. Uma discretização menor implica. que os resultados obtidos serão imprecisos [Rajakumar 89]. Dessa forma na obtenção da curva de admitância deve-se discretizar o meio fluido em função da maior freqüência de operação. É importante ressaltar que a faixa de freqüências de operação dos transdutores modelados nas análises envolvendo acoplamento fluido-estrutura depende da relações $D / H$ e $a / \lambda$ do transdutor circular. Assim em geral, $D / H=4-10$ e uma relação $a / \lambda$ até 4 , permitem realizar uma análise rápida, uma vez que relações $a / \lambda>4$ e modos altos necessitariam de uma discretização muito maior e portanto maior quantidade de dados, gerando arquivos da ordem de dezenas de Mbytes, além de um enorme tempo de processamento, o que torna a análise inviável com o equipamento disponível atualmente.

O problema não-a.coplado fornece informações importantes sobre o transdutor e exige um esforço computacional menor que o problema acoplado. Este por sua vez nos dá uma noção mais precisa do funcionamento do transdutor, entretanto exige uma maior capacidade computacional, bem como um tempo dispendido pelo analista maior no estudo do modelo. Assim, o tempo total para se projetar um transdutor, realizando-se a análise de acoplamento fluido-estrutura, muitas vezes pode ser maior do que um ciclo de experiências do tipo tentativa e erro. Esse tempo irá depender da experiência do analista bem como, da capacidade computacional disponível em relação à freqüência de operação que se deseja estudar o transdutor. A maior limitação computacional num problema que envolve acoplamento fluido-estrutura é a disponibilidade de memória. A configuração computacional recomendada para uma análise precisa e rápida acusto-piezoelétrica acoplada de um transdutor com relação $D / H=4$ e $D=25 \mathrm{~mm}$ operando até $50 \mathrm{kHz}$, é uma máquina de 20 Mflops, com 32 Mbyte de RAM, um disco rígido de 1 Gbyte e acesso rápido para leitura e escrita em disco (desempenho IO) [Schillings 91]. Portanto um computador exigido nesse tipo de análise pode estar além do que se está acostumado nas demais áreas de aplicação de elementos finitos, especialmente em altas freqüências de operação.

\section{B.3 Análise Transiente}

Não se pretende ainda realizar a análise transiente do problema do acoplamento fluidoestrutura. Inicialmente, tem-se por objetivo estudar a modelagem da propagação da onda emitida por um pistão plano num meio fluido, sujeito a uma excitação pulsada, com o intuito de visualizar a propagação das chamadas ondas planas e de borda. Até agora essa simulação foi conseguida por [Weight 84a], utilizando o método de diferenças finitas. A descrição e as clificuldades da análise transiente já foram apresentadas anteriormente. 
Cabe aqui um comentário, que no estudo da propagação de ondas por um meio fluido, deve-se procurar discretizar o espaço fluido segundo o incremento $\Delta e$ dado por [Bathe 82]: $\Delta e=c_{s} \Delta t$, onde $\Delta e$ é o tamanho do elemento. Essa discretização resulta num modelo com um grande número de elementos e portanto um alto tempo de processamento e grande quantidade de dados a ser processado, gerando um arquivo de pós-processamento da ordem de dezenas de Mbytes, podendo ocasionar problemas de memória. Para evitar esse problerna deve-se utilizar os comandos do ANSYS que controlam os dados armazenados no arquivo de pós-processamento (deslocamentos, forças e reações nodais entre outros), o que reduz consideravelmente o arquivo de pós-processamento. Entre os comandos tem-se PODISP, KRF, PORF e PONF. Esse procedimento é recomendado também na obtenção da curva de admitância, onde se está interessado somente no vetor de reações nodais (cargas elétricas), bem como na análise transiente da estrutura piezoelétrica isolada.

\subsection{Descrição dos Modelos Empregados}

O software ANSYS utilizado no trabalho, encontra-se instalado numa estação gráfica "SYLICON GRAPHICS" com 16 Mbytes de memória RAM e 300 Mbytes de disco rígido, operando de forma independente. A impressão dos gráficos e imagens coloridas são feitas utilizando-se as impressoras "HP PAINT JET" e "HP LASER JET III".

$\mathrm{Na}$ obtenção dos modelos foram programadas rotinas denominadas de MACROS no ANSYS, que se encontram parametrizadas para o caso de transdutores circulares. Assim especificando-se o raio, espessura, número de elementos no raio e na espessura, e demais dados do transdutor, o modelo é montado pela rotina. Isso facilita e agiliza consideravelmente o trabalho, permitindo analisar transdutores de diferentes diâmetros e espessuras, bem como ter repetibilidade nas análises. A seguir são descritas as hipóteses adotadas na construção de cada modelo, as rotinas programadas e os passos que devem ser seguidos para efetuar a análise.

\section{A) Disco Piezoelétrico}

A.1 ANÁLISE MODAL: Para a obtenção das freqüências de ressonância e anti-ressonância foram programadas as rotinas TCR e TCA respectivamente. Foram consideradas as seguintes hipóteses:

- Como não é possível restringir o disco piezoelétrico (item 4.2.2), o mesmo é modelado oscilando livre no espaço.

- Sendo a geometria do disco e a sua excitação axissimétricos é necessário considerar apenas um setor cilíndrico (fatia) do mesmo, definindo-se planos de simetria na sua lateral (restringe-se os deslocamentos perpendiculares aos planos). Isso é válido pois não há variáveis com o ângulo azimutal do disco. Com relação ao ângulo de abertura 
da fatia deve-se escolher um valor que seja pequeno o suficiente para discretizar bem o disco, mas que não afaste demais os elementos centrais de sua forma cúbica. $O$ mesmo modelo é utilizado nas demais análises. Na construção do modelo é utilizado o módulo de geração automático do ANSYS. Assim define-se inicialmente o plano lateral e posteriormente a sua área, e através do comando AGEN cria-se o outro plano lateral. Define-se o volume (comando V) e especificando-se o número de elementos em cada lado gera-se a malha com o comando VMESH. Como o elemento utilizado possui 8 nós, para que o elemento situado no centro do disco não seja um prisma triangular, deslocou-se os nós do centro do disco de um raio em torno de $0,01 \mathrm{~mm}$, obtendo-se assim os quatro nós da face do elemento [ANSYS].

- Os eletrodos foram simulados acoplando-se os GLs de potencial elétrico das faces do disco (cada face é um conjunto).

- Como a excitação é simétrica em relação à espessura, os modos simétricos na espessura, são os mais fortemente acoplados com o campo excitante. Assim restringiu-se os nós do plano mediano da espessura na direção perpendicular à face do disco (Z). Poder-se-ia representar somente a metade do disco com relação à espessura, o que reduziria o número de elementos, entretanto para se ter uma melhor visualização dos modos optou-se por representá-lo por inteiro. Foram impostas as condições de contorno necessárias nos eletrodos conforme o tipo de freqüência que se deseja obter (ressonância ou anti-ressonância). Caso seja representado somente a metade do disco na espessura, deve-se aterrar os GLs elétricos dos nós do plano mediano.

- Nos modelos em todas as análises, acoplou-se os GLs MAG e 'TEMP, e os elementos foram reordenados através do comando WSORT,Z.

- Ainda no intuito de reduzir o tamanho das matrizes, como não há variação dos deslocamentos com o ângulo azimutal, os GLS UX e UZ dos nós do plano lateral esquerdo do fatia foram acoplados $11 \mathrm{~m}$ a um com os dos nós do plano lateral direito. Essa otimização diminui a frente de onda do modelo permitindo obter modelos maiores, bem como eliminar modos indesejados. Esse acoplamento é realizado nos modelos de todas as análises.

- O material piezoelétrico utilizado fci a cerâmica PZT5A cujas matrizes de constantes de rigidez, piezoelétricas e dielétricas estão descritas no apêndice $\mathrm{C}$.

Um exemplo de modelo gerado com as rotinas TCR ou TCA, bem como as condições de contorno mecânicas e elétricas são mostradas na fig. 5.5. As variáveis de entrada da rotina TCR e TCA são: $\mathrm{R}$ (raio do disco), H (espessura do disco), RDIV (número de elementos no raio), HDIV (número de elementos na espessura), A (metade do ângulo de abertura) e NMOD (número de modos desejados). A seqüência a ser seguida na análise encontra-se no apêndice $B$.

A.2 ANÁLISE HARMÔNICA: Foram programadas duas rotinas, a TCHE6 e a TCHE3. A TCHE6 realiza uma análise harmônica reduzida com graus mestres e a TCHE3 realiza uma análise harmônica completa. Foram consideradas as seguintes hipóteses: 

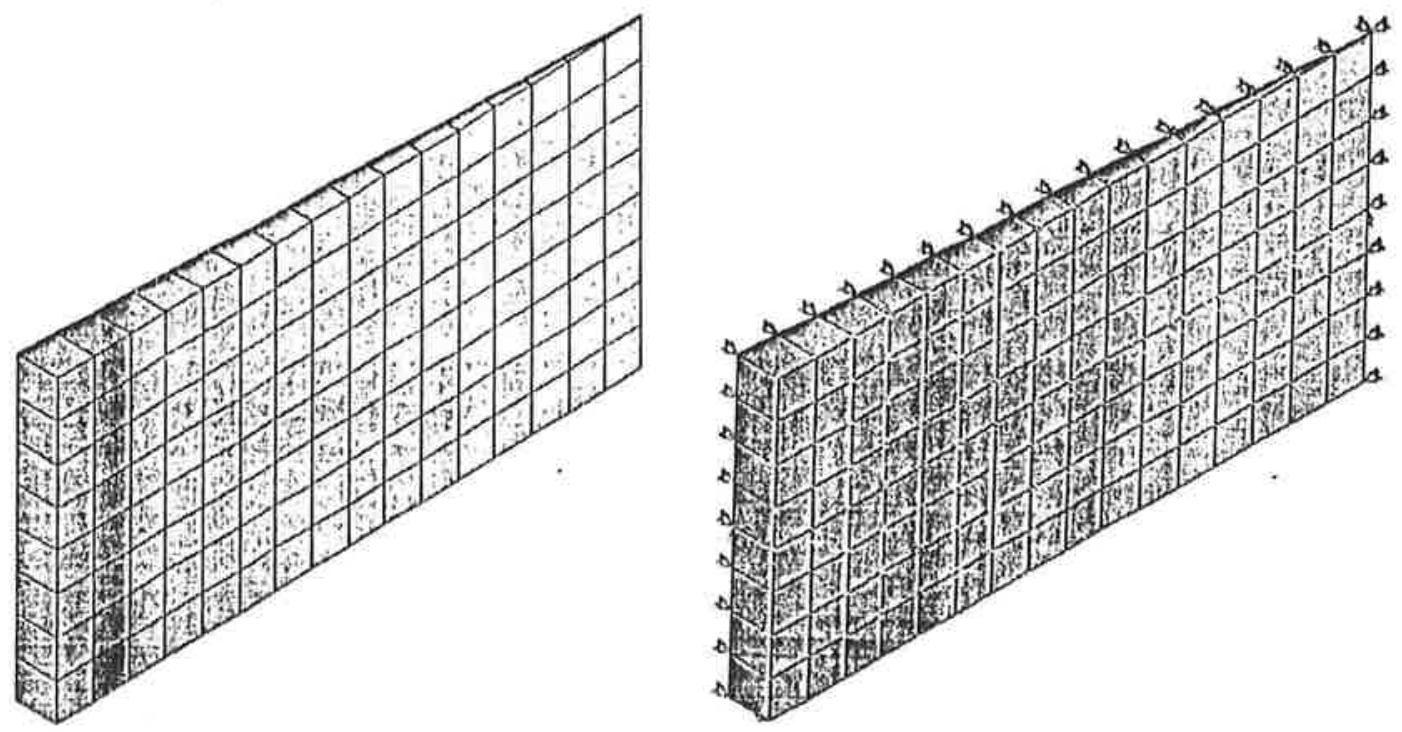

Figura 5.5: Modelo gerado e condições de contorno.

- A geometria e condições de contorno mecânicas são as mesmas da análise modal, sendo que como a excitação é simétrica na espessura, somente a metade superior da espessura da fatia foi considerada.

- Com relação à condição de contorno elétrica, os GLs elétricos do eletrodo são acoplados num único GL, correspondente ao nó de menor número, e nele é aplicado o potencial. No caso da TCHE3 é aplicado uma tensão de $1 \mathrm{~V}$ no eletrodo superior em relação ao inferior (aterrado). Entretanto como é representado somente a parte superior da fatia (setor cilíndrico), a base do modelo (plano mediano) é aterrada, e sendo a diferença de potencial simétrica em relação à espessura (ou seja, igual para as duas semi-metades definidas pelo plano mediano), é aplicada uma tensão de $0,5 \mathrm{~V}$ (comando NT) no eletrodo superior. No caso da TCHE6 esse grau é definido como mestre, sendo definido também uma tensão de $0,5 \mathrm{~V}$. Os demais graus mestres são estruturais (UX, UY, UZ), sendo definidos automaticamente, segundo um número especificado.

- O amortecimento é definido nas formas já apresentadas não sendo incluído nas rotinas. Nesse caso são fornecidos resultados reais e imaginários, devendo-se calcular as amplitudes e fases.

Um exemplo de modelo gerado é apresentado na fig. 5.5. As variáveis de entrada das rotinas TCHE3 e TCHE6 são:

- TCHE3: R, H, A , FA (primeira freqüência de excitação), FB (última freqüência de excitação), NF (número de freqüências entre FA e FB).

- TCHE6: R, H, A, FA, FB, NF, NM (número de graus mestres estruturais a serem definidos automaticamente). 


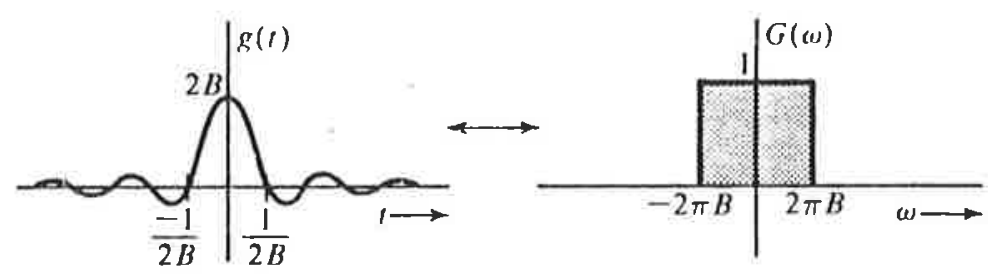

Figura 5.6: Pulso de banda limitada.

A seqüência a ser seguida na análise encontra-se descrita no apêndice B.

Na obtenção da curva de admitância, a tabela de freqüências para varredura é montada no PREP6 através da rotina RANGE, que tem como entrada um arquivo ASCII denominado "file40.dat", contendo as freqüências de ressonância escritas em coluna. Para se reduzir o arquivo de pós-processamento, gravando-se somente as reações nodais onde estão contidas as cargas elétricas, utilizam-se os comandos PODISP, POSTR e KRF. A primeira freqüência deve ser especificada no PREP7. O cálculo e a visualização da curva de admitância é realizado no POST26 pela rotina ADMIT, e ADMIT1 caso haja amortecimento. Essa curva pode ser representada na escala relativa (dB) através da expressão:

$$
Y(d B)=20 \log \frac{|Y|}{\left|Y_{m a ́ x}\right|}
$$

onde $\left|Y_{\text {máx }}\right|$ é o máximo valor de amplitude obtido.

As variáveis de entrada das rotinas ADMIT e ADMIT1 são: N1 (número de menor valor dos nós do eletrodo) e $\mathrm{F}$ (fator de multiplicação igual a 180/A). A única variável de entrada da rotina RANGE é o número de freqüências de ressonância $(\mathrm{N})$. A seqüência a ser seguida na obtenção da curva encontra-se no apêndice $B$.

A.3 ANÁLISE TRANSIENTE: Para obter a resposta do transdutor sujeito a uma excitação pulsada foi programada a rotina TRANS. As hipóteses adotadas e a construção do modelo são as mesmas da análise harmônica com a diferença que a excitação agora é um pulso. A intenção é obter a resposta impulsiva do transdutor, entretanto como na realidade não se consegue aplicar um "Dirac", a excitação consiste num pulso de banda limitada por uma certa faixa de freqüências $f_{0}$, como mostrado na fig. 5.6, que é obtido através da rotina DIRAC no preprocessador PREP6. O incremento de tempo recomendado é igual à $1 / 10$ da freqüência $f_{0}$ (maior freqüência considerada), como já comentado. Outras funções de excitação podem ser utilizadas, bastando-se para isso implementar outras rotinas no PREP6. No pós-processamento é possível animar a deformação do disco piezoelétrico no tempo. Para isso as imagens de deformação em cada instante devem ser 
geradas e armazenadas na memória através do comando /SEG,MULT. Posteriormente as imagens são mostradas na tela sucessivamente, através do comando ANIM. As variáveis de entrada das rotinas são:

- TRANS: R, H, A, RDIV, HDIV.

- DIRAC: NMAX (tempo máximo de análise), F (freqüência máxima da banda - $f_{0}$ ).

A seqüência a ser seguida na análise encontra-se no apêndice B.

A.4 APODIZAÇÃO: No estudo da apodização foram implementadas as rotinas ATCR, ATCA, ATCHE6 e ATCHE3, que permitem respectivamente, calcular as freqüências de ressonância e anti-ressonância, e a resposta à uma excitação harmônica reduzida e completa do disco apodizado. Para variar a propriedade piezoelétrica ao longo do raio foram montadas tabelas de materiais variaudo-se a constante piezoelétrica $e_{33}$ ao longo do raio segundo uma função matemática. Para isso implementou-se á rotina MONTAB. Posteriormente cada tabela é associada com o elemento respectivo ao longo do raio nas rotinas ATCA, ATCR e ATCHE3. As demais hipóteses e a construção do modelo são idênticas às anteriores. A seqüûncia a ser seguida na análise encontra-se no apêndice $B$.

\section{B) Acoplamento Fluido-Estrutura}

B.1 ANÁLISE HARMÔNICA COMPLETA: No intuito de estudar a modelagem do campo acústico gerado pelo $\mathrm{MEF}$, foi modelado inicialmente o problema do pistão plano, implementando-se a rotina. PP. Um exemplo de modelo construído pela rotina PP é mostrado na fig. 5.7. Foram consideradas as seguintes hipóteses para modelagem do meio acústico:

- Pelo fato do problema ser axissimétrico modelou-se apenas um setor cilíndrico (fatia), definindo-se planos de simetria nos planos laterais esquerdo e direito. A construção do modelo segue o mesmo procedimento descrito na construção do disco.

- Como condição de contorno do problema considerou-se um pistão plano emitindo em onda contínua (excitação harmônica), irradiando num meio fluido e circundado por $u$ refletor rígide peifeito.

- Foi utilizado o elemento acústico STIF30 na opção em que o mesmo apresenta somente os GLs de pressão para representar o meio fluido, e o mesmo elemento na opção completa (todos os GLs) para representar as interfaces estruturais.

- Para simular o refletor rígido perfeito que circunda o transdutor são restringidos os GLs nas três direções nessa região. O pistão plano é simulado restringindo-se os GLs nas direções do plano do pistão e impondo a amplitude de deslocamento na direção perpendicular ao mesmo plano. Além disso restringe-se também os deslocamentos UX dos nós pertencentes ao eixo axial do pistão. 


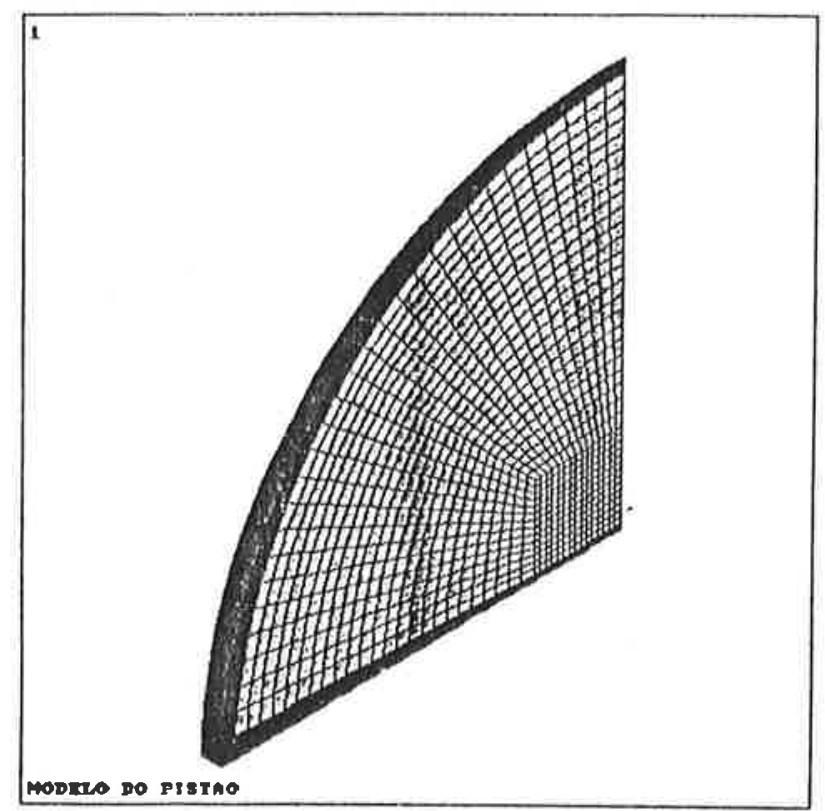

Figura 5.7: Modelo de um pistão plano.

- Para fazer com que o movimento do pistão plano, bem como a presença do refletor perfeito sejam transformados na forma de pressão para o fluido, deve-se utilizar o comando PSF.

- Na representação do meio acústico, a princípio seria necessário discretizar uma grande área em torno do pistão, exigindo um grande número de elementos. Para limitar esse número, o contorno externo do fluido foi modelado como uma interface fluido-estrutura (usando o elemento STIF30 com todos os graus e o comando PSF na interface da estrutura), definindo-se uma parede fictícia com coeficiente de absorção igual a 1 . Isto implica que a impedância acústica da parede é igual à impedância acuística do fluido, e tudo se passa como a parede fosse constituída de fluido, simulando o meio infinito [Schillings 91]. Esta solução no entanto, fornece resultados precisos, desde que a parede seja definida acima de uma certa distância do pistião, correspondente à região do campo distante, e apresente o formato circular. Tsso é explicado através da teoria de onda plana e de borda. Na região do campo próximo, a medida que se afasta do pistão, a frente de onda se aproxima de uma esfera. No caso limite em que o pistão passa a ser uma fonte pontual (grande distância do pistão), a frente de onda é uma esfera. Para que haja absorção total da onda, simulando assim o fluido, a frente de onda deve incidir paralelamente à superfície de absorção, pois a absorção só ocorre na direção normal à parede, caso contrário a onda será refletida pela parede interferindo com as demais que estão chegando, e gerando um campo acústico totalmente diferente da realidade. Dessa forma a parede de absorção situada na região do campo distante deve ser circular, pois a essa distância a frente de onda é aproximadamente esférica. Um pouco de reflexâo sempre ocorrerá, sendo menor quanto mais distante for definida a parede. Além disso deve-se lembrar que como se trabalha com a discretização do espaço, a parede não é exatamente um círculo, mas sim um polígono de $n$ lados, um efeito que também pode gerar reflexões. A parede é definida restringindo-se os GLs nas 

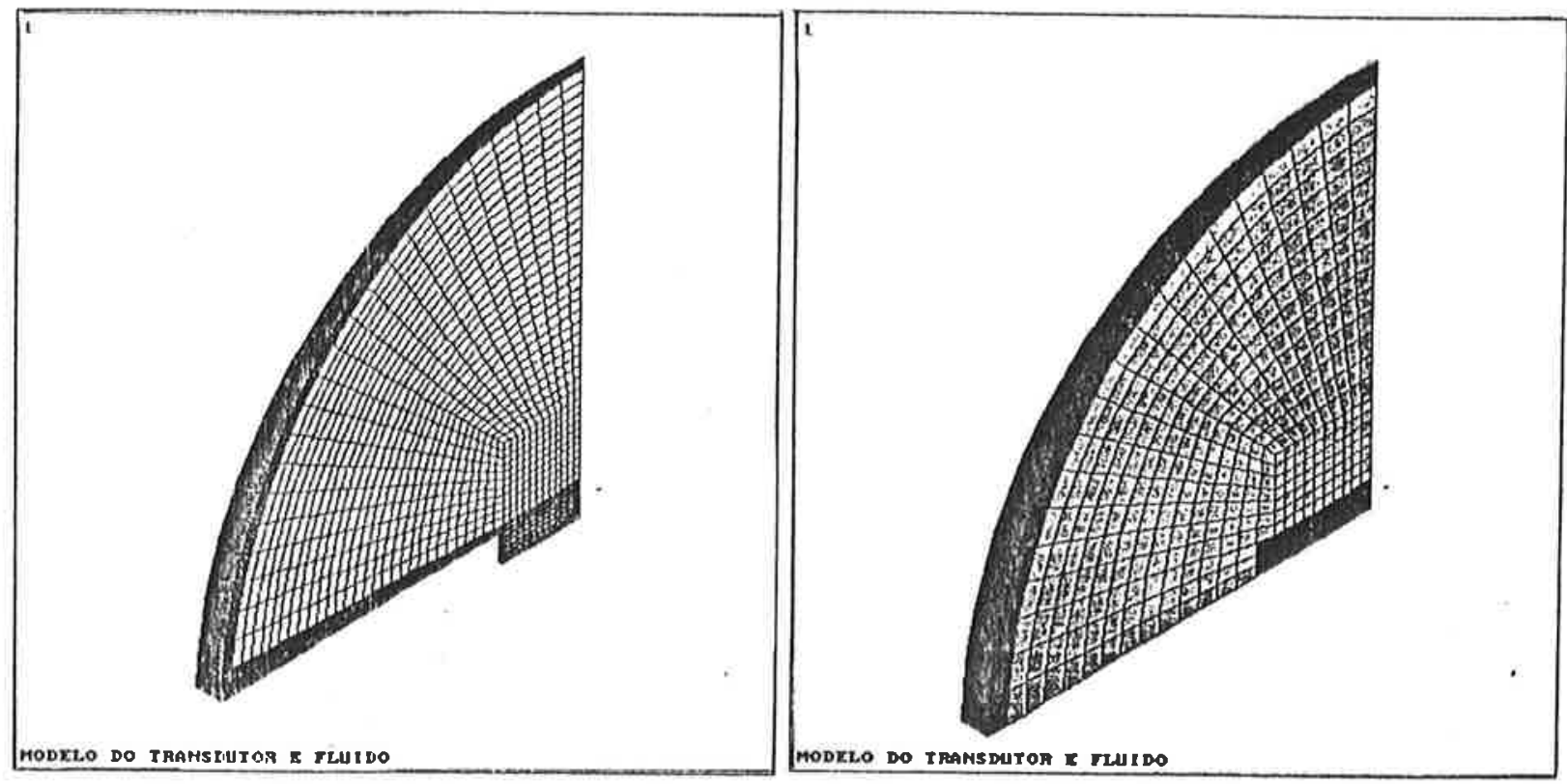

Figura 5.8: Modelos do transdutor acoplado com fluido - TCP1 e TCP2.

três direções.

Uma vez modelado o problema do pistão plano passou-se a considerar o disco piezoelétrico. Foram programadas duas rotinas denominadas TCP1 e TCP2, para duas condições de contorno diferentes. Na primeira o disco piezoelétrico é suposto circundado por um refletor rígido perfeito como no caso do pistão plano, apresentando o meio fluido na sua parte frontal e um vácuo na parte traseira. Na segunda o disco apresenta-se envolvido no fluido, podendo emitir ondas acústicas para todos os lados, não havendo refletor rígido. Essa hipótese é perfeitamente válida, pois apesar de na realidade o disco piezoelétrico estar encapsulado numa carcaça de metal ou polímero, não se pode supor que os deslocamentos radiais estejam restritos devido aos pequenos valores de deslocamento [Lanceleur 92], como já comentado no item 4.2.2. Outras condições de contorno podem ser consideradas.

A TCP1 é idêntica a rotina PP, a menos da presença do disco piezoelétrico. Como as condições de contorno do disco nesse caso não são simétricas, é necessário representá-lo por inteiro. Para excitação, o eletrodo $\mathrm{cm}$ contato com o fluido apresenta uma tensão de $1 \mathrm{~V}$ em relação ao eletrodo em contato com o vácuo (aterrado). Na TCP2, pelo fato das condiçôes de contorno do disco serem simétricas, somente a metade do mesmo é representado, reduzindo o tamanho do modelo em relação ao anterior. Na excitação o eletrodo superior apresenta uma tensão de $0,5 \mathrm{~V}$ em relação ao plano mediano (aterrado). Como não há mais refletor perfeito, restringiu-se os deslocamentos nessa região na direção perpendicular à face do transdutor, devido à simetria. As demais condições de contorno são idênticas. $O$ amortecimento interno do disco piezoelétrico deve ser representado na forma de propriedade do material piezoelétrico (comando MP,DAMP). Exemplos dos modelos obtidos com as rotinas TCP1 e TCP2 são apresentados na fig 5.8. As variáveis de entrada das rotinas são descritas abaixo: 


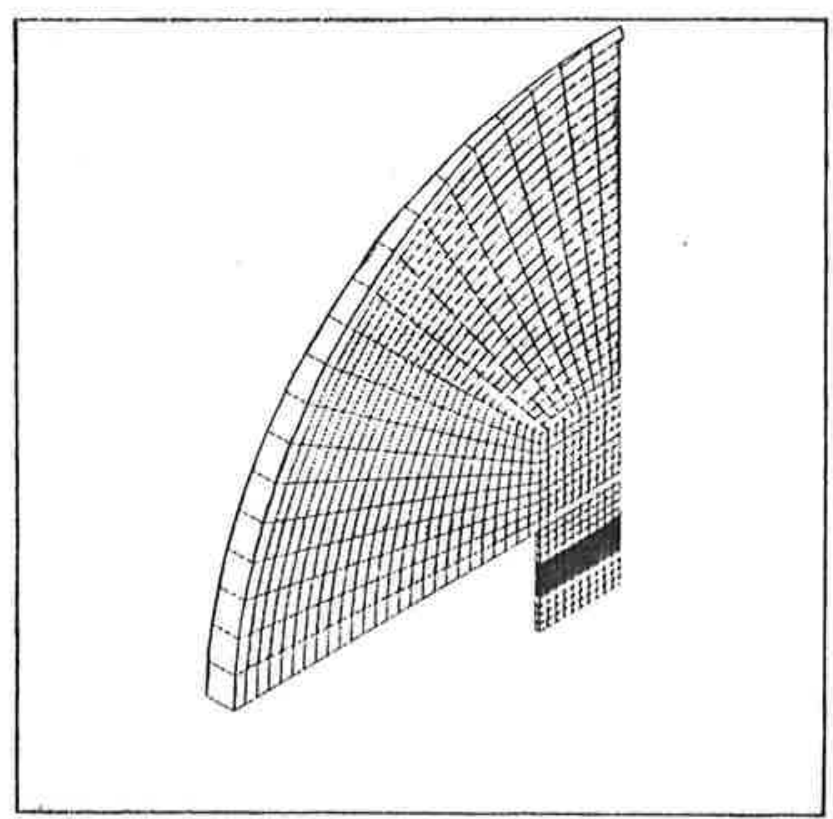

Figura 5.9: Modelo incluindo camadas de casamento e retaguarda - TCPMB.

- PP: R, A, R1 (raio da parede), RDIV (número de elementos no raio), LDIV (número de elementos entre R e R1), FA, FB, NF.

- TCP1: R, H, A, R1, RDIV, LDIV, HDIV, FA, FB, NF.

- TCP2: R, H, A, R1, RDIV, LDIV, HDIV, FA, FB, NF.

A seqüência a ser seguida na análise é descrita no apêndice B.

Os resultados obtidos são números complexos representados em componentes reais e imaginárias. Como se está interessado na amplitude de pressão e velocidade, foram implementadas as rotinas AMPL e VELOC para calcular as amplitudes de velocidade e pressão respectivamente, podendo ser visualizadas no POST1. As velocidades são representadas na forma de vetores cujas componentes são armazenadas no módulo STRESS do arquivo de pós-processamento.

Além das rotinas já descritas, implementou-se a rotina TCPMB que modela o campo acústico do disco piezoelétrico com as camadas de retaguarda e de casamento, sujeito a uma excitação harmónica, considerando como condições de contorno um refletor rígido perfeito. A construção do modelo segue o mesmo procedimento já descrito, devendo-se especificar a espessura e o material de cada camada. Um exemplo de modelo obtido com a rotina TCPMB é apresentado na fig.5.9. Entre as variáveis de entrada tem-se: HM (espessura da camadí de casamento), HB (espessura da camada de retaguarda), R, H, A, R1, RDIV, LDIV, HMDI (número de elementos na camada de casamento), HDIV, HBDI (número de elementos na camada de retaguarda), FA, FB, NF.

B.2 ANÁLISE TRANSIENTE ACÚSTICA: Para estudar a propagação da onda emitida por um pistão plano num meio fluido, sujeito a uma excitação pulsada foi programada 


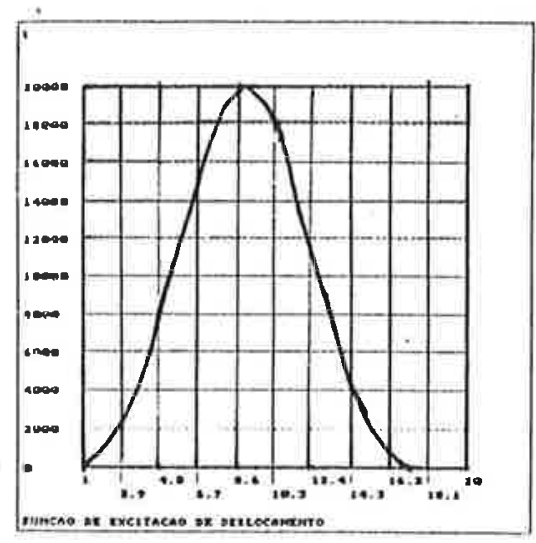

Figura 5.10: Pulso de excitação.

a rotina TRANPP. Como no caso da excitação harmônica, o pistão é considerado circundado por um refletor rígido perfeito. $\mathrm{Na}$ construção do modelo foram utilizados as mesmas hipóteses e procedimentos descritos na análise harmônica para o pistão plano. A diferença é que não é mais necessário definir uma parede fictícia circular com absorção igual a um, uma vez que tratando-se de um problema transiente a onda só será afetada pelas condições de contorno quando entrar em contato com as mesmas. Assim pode-se utilizar um volume cilindrico de fluido para representar o meio, o que simplifica consideravelmente a geração do modelo. Na excitação foi utilizado um pulso que apresenta baixas componentes de freqüência, pois caso contrário seria necessária uma alta discretização no tempo, e portanto no espaço, para representar a propagação do pulso, ocasionando um alto tempo de processamento e problemas de espaço em disco (dezenas de Mbytes). O pulso é dado pela seguinte expressão no tempo:

$$
f(t)= \begin{cases}\sin \omega t-\frac{1}{2} \sin 2 \omega t & \text { se } 0<t<\frac{2 \pi}{\omega} \\ 0 & \text { caso contrário }\end{cases}
$$

onde $\omega$ é a frequiência central do espectro do pulso.

A obtenção do pulso é feita no PREP6 através da rotina EXCIT, onde se encontra implementada a expressão acima. Um exemplo do pulso de excitação é apresentado na fig. 5.10. As variáveis de entrada das rotinas são:

- TRANPP: R (raio do pistão), H (altura do cilindro fluido), R1 (raio do cilindro fluido), A, KE (discretização do comprimento de onda no espaço), KT (discretização do pulso no tempo).

- EXCIT: KT, NMAX (número de períodos do pulso em que se deseja extender a análise).

A seqüência a ser seguida na análise é descrita no apêndice $B$. 


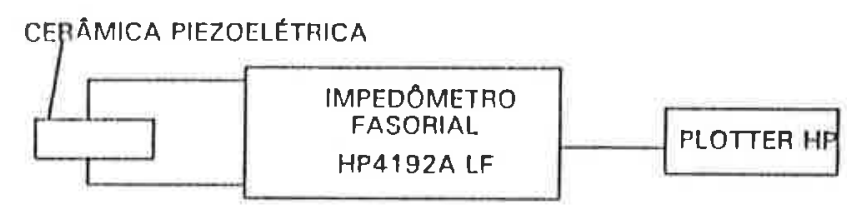

Figura 5.11: Montagem para a obtenção da curva de admitância.

\subsection{Parte Experimental}

Com o objetivo de comparar os resultados teóricos com os experimentais, foram realizados dois tipos de experimentos:

* Obtenção da curva de admitância do transdutor,

* Visualização dos modos de vibrar do disco cerâmico, utilizando-se um método de interferometria laser.

Para isso utilizou-se dois discos cerâmicos de material PZT5A, de dimensões descritas abaixo, doados pelo Instituto de Pesquisas Tecnológicas (IPT). Os resultados obtidos foram comparados com os resultados do $\mathrm{MEF}$, o que permitiu verificar a validade dos modelos realizados.

Dimensões das cerâmicas:

* $D=25,3 m m$ e $H=10,2 m m \Rightarrow D / H=2,5$

* $D=25,15 m m$ e $H=6,35 m m \Rightarrow D / H=4$

\subsubsection{Curva de Admitância}

Essa curva foi obtida utilizando-se um impedômetro fasorial HP4192A LF do Laboratório de Engenharia Biomédica (LEB) da Universidade de Campinas. Esse aparelho pode operar entre $5 \mathrm{~Hz}$ e $13 \mathrm{MHz}$, fornecendo como resultado o módulo e a fase da admitância (ou impedância), ou a sua parte real e imaginária, que podem ser plotados num ploter analógico HP. A montagem utilizada é descrita na fig.5.11.

Foram levantadas curvas numa faixa de freqüências entre 20 e $400 \mathrm{kHz}$. As curvas obtidas podem ser comparadas com as levantadas pelo MEF.

\subsubsection{Visualização dos Modos de Vibrar}

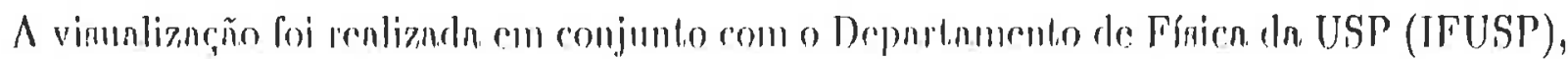
utilizando-se um método de interferometria laser denominado ESPI ("Electronic Speckle 


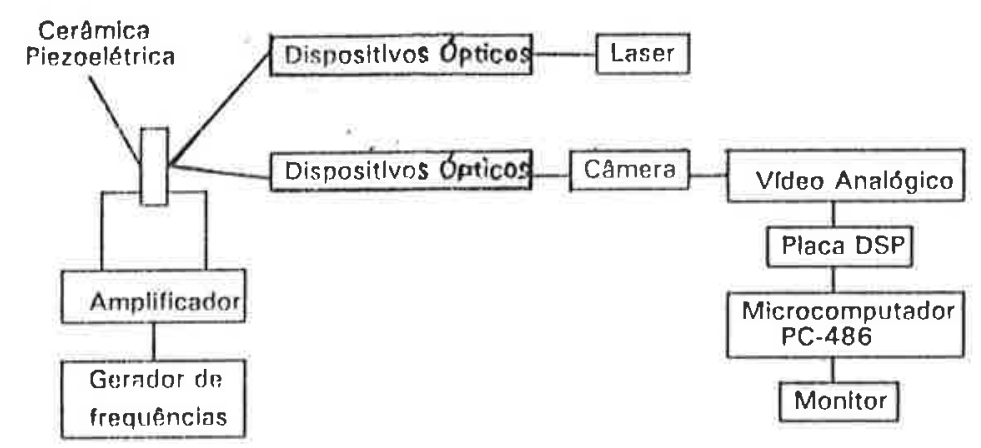

Figura 5.12: Montagem para visualização dos modos.

Pattern Interferometry") [Ferreira 92]. Basicamente consiste em através de um feixe de raio laser que é expandido, obter um padrão (granulado) da cerâmica deformada e não deformada. Subtraindo esses dois padrões (imagens) obtém-se o modo de vibrar da cerâmica. O equipamento utilizado, ou seja, laser, refletores, etc. . ., bem como a cerâmica a ser analisada, encontram-se montados sobre uma mesa pneumática, cuja função é amortecer as vibraçôes externas.

Na obtenção das imagens, a cerâmica foi excitada na freqüência de ressonância correspondente (OC) ao modo que se deseja visualizar. A determinação correta da freqüência de ressonância é conseguida variando-se a freqüência em torno de uma região esperada até que se visualize o modo. Para isso utilizou-se um gerador de freqüências e um amplificador que excita a cerâmica. A montagem realizada é mostrada na fig.5.12.

Devido à resolução do método de interferometria, para a visualização dos modos com maior nitidez, é necessário que as deformações na cerâmica (que normalmente são da ordem de décimos de mícrons) sejam consideráveis, o que é conseguido excitando-se a cerâmica com tensões elétricas entre 50 e $90 \mathrm{~V}$ (pico a pico). Isso no entanto ocasiona um certo aquecimento da cerâmica.

As visualizações obtidas foram comparadas com os resultados do MEF.

A verificação dos resultados do campo acústico pode ser feita obtendo-se experimentalmente o campo acústico OC do transdutor (no caso, a cerâmica). Essa obtenção pode ser conseguida utilizando-se o Sistema Automático de Mapeamento de Campo Acústico (SAMCA) que está sendo fabricado na oficina da EPUSP. Esse sistema é constituído por um manipulador cartesiano de 4 graus de liberdade, que utiliza fusos de esferas recirculantes acionados por motores de passo, e que será montado sobre um tanque de testes. $\mathrm{O}$ manipulador será controlado por um microcomputador IBM PC-486, que estará conectado a todo um aparato eletrônico (gerador de pulso, osciloscópio, amplificadores, etc...) destinado à: excitar o transdutor, captar o seu sinal, amplificá-lo, digitalizá-lo, e fornecer a sua intensidade associada com as respectivas coordenadas $\mathrm{X}, \mathrm{Y}$ e $\mathrm{Z}$ do ponto de captação, permitindo assim levantar o campo acústico do transdutor. 
Pelo fato de se estar operando em OC pode ocorrer a formação de ondas estacionárias no interior do tanque. Para evitar esse problema deve-se revestir a região interna do tanque com material absorvedor (p. ex.: espuma). 


\section{Capítulo 6}

\section{Resultados e Discussões}

\subsection{Características Vibracionais}

$\mathrm{Na}$ tabela (6.1) encontra-se a comparação entre as freqüências de ressonância obtidas na referência. [Guo 91] com as obtidas utilizando-se o ANSYS, para um disco circular de cerâmica PZT5A com relação $D / H=20$. A tabela (6.2) apresenta a mesma comparação com a referência [Lanceleur 92], para um disco circular de cerâmica P160, com relação $D / H=25$.

$\mathrm{Na}$ tabela (6.3) são apresentados as freqüências de ressonância e anti-ressonância e os coeficientes de acoplamento eletromecânico obtidos para a cerâmica PZT5A com relação $D / H=4$. Os casos em que ocorre repetição de frequiências constituem os modos não-piezoelétricos (mecânicos). Dessa forma para se obter as freqüências de operação do transdutor deve-se eliminar esses modos não-piezoelétricos. A distribuição de potencial elétrico no interior do disco (para algumas freqüências) são mostrados nas figs.6.12 e 6.13. Nota-se que as amplitudes de potencial elétrico no interior da cerâmica na ressonância podem ser muito maiores do que a tensão aplicada para excitá-la. Os valores do gráfico devem ser multiplicados por $10^{-4}$, pois os mesmos foram obtidos através da análise modal, sendo portanto valores relativos. Os valores absolutos de tensão elétrica são conseguidos através de uma análise harmônica, excitando-se o transdutor na freqüência de ressonância desejada. Já na anti-ressonância observa-se que as variações de potencial elétrico são baixas (os valores devem ser multiplicados por $10^{-9}$ ).

$\mathrm{Na}$ tabela (6.4) são comparadas as freqüências de ressonância obtidas experimentalmente com as obtidas pelo MEF (os modos não-piezoelétricos foram excluídos). Na tabela (6.5) são apresentadas as freqüências e o coeficiente de acoplamento $(K)$ obtidos pelo MEF, para a cerâmica PZT5A $(D / H=2,5)$, sendo que as freqüências de ressonância são comparadas com os valores experimentais. Os modos não-piezoelétricos foram eliminados. Nas figs. 6.3 à 6.11 são apresentados as configurações de alguns modos correspondentes às freqüências das tabelas (6.3) e (6.5). Os modos correspondentes às freqüências de antiressonância não foram apresentados, pois são semelhantes aos de ressonância. Os modos 


\begin{tabular}{|c|c|c|c|}
\hline modos & ANSYS & ref.[Guo 91] & desvio \% \\
\hline \hline 1 & 50 & 50 & 0 \\
2 & 129 & 128 & 0,8 \\
3 & 203 & 202 & 0,5 \\
4 & 274 & 272 & 0,7 \\
5 & 342 & 339 & 0,9 \\
6 & 406 & 400 & 1,5 \\
7 & 465 & 455 & 2,2 \\
8 & 518 & 504 & 2,8 \\
9 & 566 & 546 & 3,7 \\
10 & 609 & 582 & 4,6 \\
11 & 647 & 614 & 5,4 \\
\hline
\end{tabular}

Tabela 6.1: Comparação das freqüências de ressonância $(\mathrm{kHz})$ para a cerâmica PZT5A $(D / H=20)$ obtidas pelo ANSYS e pela referência [Guo 91] - RDIV=48; HDIV=2.

\begin{tabular}{|c|c|c|c|}
\hline modos & ANSYS & ref.[Lanceleur 92] & desvio \% \\
\hline \hline 1 & 193 & 193 & 0 \\
2 & 507 & 506 & 0,2 \\
3 & 802 & 800 & 0,3 \\
4 & 1090 & 1093 & 0,3 \\
5 & 1370 & 1390 & 1,4 \\
\hline
\end{tabular}

Tabela 6.2: Comparação das freqüências de ressonância $(\mathrm{kHz})$ para a cerâmica $\mathrm{P} 160$ $(D / H=25)$ obtidas pelo ANSYS e pela referência [Lanceleur 92] - RDIV=48; HDIV=2. 


\begin{tabular}{|c|c|c|c|}
\hline modos & $\omega_{r}$ & $\omega_{a}$ & $K$ \\
\hline \hline 1 & 76,8 & 85,5 & 0,44 \\
2 & $155,8^{*}$ & 155,8 & 0 \\
3 & 170,2 & 173,4 & 0,19 \\
4 & 200,6 & 203,1 & 0,16 \\
5 & 228,8 & 229,2 & 0,06 \\
6 & $230,4^{*}$ & 230,4 & 0 \\
7 & $256,1^{*}$ & 256,1 & 0 \\
8 & 271,2 & 275,2 & 0,17 \\
9 & $278,6^{*}$ & 278,6 & 0 \\
10 & 287,1 & 287,1 & 0,01 \\
11 & $309,1^{*}$ & 309,1 & 0 \\
12 & $310,2^{*}$ & 310,2 & 0 \\
13 & 313,5 & 319,7 & 0,2 \\
14 & $330,7^{*}$ & 330,7 & 0 \\
15 & 340,5 & 343,2 & 0,13 \\
16 & 370,2 & 370,3 & 0,02 \\
17 & $381,3^{*}$ & 381,3 & 0 \\
18 & 389,6 & 389,6 & 0,01 \\
19 & $393,3^{*}$ & 393,3 & 0 \\
20 & 416,4 & 416,6 & 0,03 \\
21 & $439,1^{*}$ & 439,1 & 0 \\
22 & 457 & 457,1 & 0,02 \\
\hline
\end{tabular}

Tabela 6.3: Freqüências de ressonância $\left(\omega_{r}\right)$ e anti-ressonância $\left(\omega_{a}\right)(\mathrm{kHz})$, e coeficiente piezoelétrico $(K)$ calculado através da expressão 4.32 - Cerâmica PZT5A $(D / H=4)$ $R D I V=16$ e $H D I V=8 ; \quad$ * modos não-piezoelétricos (mecânicos). 


\begin{tabular}{|c|c|c|}
\hline$\omega_{r}$ & $\omega_{r}^{\text {exp. }}$ & desvio(\%) \\
\hline \hline 76,8 & 75,4 & 1,9 \\
170,2 & 170,8 & 0,4 \\
200,6 & 201,0 & 0,5 \\
228,8 & 235,0 & 2,6 \\
271,2 & 270,8 & 0,1 \\
287,1 & 295,0 & 2,7 \\
313,5 & 325,0 & 3,5 \\
340,5 & 345,0 & 1,3 \\
\hline
\end{tabular}

Tabela 6.4: Comparação das freqüências de ressonância $\left(\omega_{r}\right)$ com os valores experimentais $\left(\omega_{r}^{e x p .}\right)$, para a cerâmica PZT5A $(D / H=4) R D I V=16$ e $H D I V=8$.

\begin{tabular}{|c|c|c|c|c|}
\hline$\omega_{r}$ & $\omega_{a}$ & $K$ & $\omega_{r}^{\text {exp. }}$ & desvio(\%) \\
\hline \hline 72,4 & 81,4 & 0,46 & 72,3 & 0,1 \\
123,7 & 127,2 & 0,23 & 125,0 & 1,0 \\
143,5 & 144 & 0,09 & 149,0 & 3,7 \\
179,4 & 183,4 & 0,21 & 185,0 & 3,0 \\
214,9 & 217,1 & 0,14 & 225,0 & 4,5 \\
229,4 & 229,7 & 0,05 & 231,0 & 0,7 \\
244,6 & 244,8 & 0,04 & - & - \\
295,3 & 295,4 & 0,02 & - & - \\
310,3 & 310,5 & 0,03 & 315,4 & 1,6 \\
314,8 & 314,9 & 0,02 & - & - \\
341,5 & 341,6 & 0,01 & - & - \\
\hline
\end{tabular}

Tabela 6.5: Freqüências de ressonância $\left(\omega_{r}\right)$ e anti-ressonância $\left(\omega_{a}\right)(\mathrm{kHz})$, e coeficiente piezoelétrico $(K)$ calculado através da expressão 4.32. As freqüências $\left(\omega_{r}\right)$ são comparadas com os valores experimentais - Cerâmica PZT5A $(D / H=2,5) R D I V=12 \mathrm{e}$ $H D I V=12$. 
calculados pelo $\mathrm{MEF}$ para as cerâmicas $D / H=2,5$ e $D / H=4$ podem ser comparados com as visualizações por interferometria laser mostradas nas fotos das figs. 6.3 à 6.11 . Nessas fotos a região escura indica ausência de deslocamento (nós) e as regiões claras as partes oscilantes. Observa-se uma boa concordância qualitativa dos resultados. Nota-se também pelas fotos que alguns modos apresentam uma pequena variação com o ângulo azimutal do disco.

Verifica-se pelas tabelas anteriores, como mostrado em [Kunkel 90], que os primeiros modos (denominados modos radiais) são fortemente acoplados, apresentando os mais altos coeficientes $K$ dentre as freqüências. Nota-se que no caso da cerâmica PZT5A $D / H=4$ os modos correspondentes às freqüências $313,5 \mathrm{kHz}$ (ressonância) e $319,7 \mathrm{kHz}$ (anti-ressonância - não apresentado, pois é semelhante ao anterior) apresentam um deslocamento médio positivo, um alto coeficiente de acoplamento, além de um perfil de deformações suave em relação aos demais modos, constituindo no modo da espessura. Essas freqüências e modos são portanto indicados para, por exemplo, emitirem ondas de compressão num fluido.

A curva de admitância para a cerâmica $D / H=4$ encontra-se no gráfico da fig. 6.14, onde se observa que os pontos de máxima $(|Y| \rightarrow \infty)$ correspondem às freqüências de ressonância e os pontos de mínima $(|Y|=0)$ às freqüências de anti-ressonância. $\mathrm{A}$ inclinação positiva da curva revela um caráter capacitivo da cerâmica. A mesma curva, incluindo agora o amortecimento mecânico na cerâmica PZT5A $\left(\alpha=0\right.$ e $\beta=10^{-8}$ comum na faixa de freqüências analisada) é mostrada na fig. 6.14 , e incluindo amortecimento dielétrico ( $\tan \delta=0,2$ - catálogo comercial) na fig. 6.15. Nota-se principalmente na curva com amortecimento mecânico, que o valor de admitância nas freqüências de ressonância, diminue com as freqüências maiores, sendo o quarto modo por exemplo, quase imperceptível no gráfico. A curva de admitância experimental para cerâmica $D / H=4$ é mostrada na fig. 6.15 podendo ser comparada com as teóricas. Nota-se que que as curvas que consideram o o amortecimento estão mais próximas da experimental. As curvas de admitância calculada e.experimental para a cerâmica $D / H=2,5$ encontram-se na fig. 6.16 .

\subsection{Apodização}

$\mathrm{Na}$ tabela (6.6) são apresentadas as freqüências de ressonância e anti-ressonância, e os coeficientes $K \mathrm{~s}$ para um transdutor com relação $D / H=4$ não-apodizado, apodizado segundo uma variação linear decrescente do coeficiente $e_{33}$ com o raio, e segundo uma função cossenoidal decrescente com o raio. Na tabela (6.7) são apresentados os resultados para a mesma cerâmica apodizada segundo uma função gaussiana decrescente com o raio e uma função cossenoidal crescente com o rajo. Os modos não-piezoelétricos foram eliminados. Nota-se que houve uma diminuição das freqüências em relação ao transdutor comum, além de provocar uma aproximação entre as freqüências de ressonância e antiressonância, diminuindo o coeficiente de acoplamento piezoelétrico dos modos, tornandoos mais fracamente acoplados. Essa diminuição era de certa forma esperada, uma vez que 


\begin{tabular}{|c|c|c|c|c|c|c|c|c|}
\hline \multicolumn{3}{|c|}{ Não-a.podizado } & \multicolumn{3}{|c|}{ Linear } & \multicolumn{3}{|c|}{ Cossenoidal } \\
\hline$\omega_{r}$ & $\omega_{a}$ & $K$ & $\omega_{r}$ & $\omega_{a}$ & $K$ & $\omega_{r}$ & $\omega_{a}$ & $K$ \\
\hline \hline 76,8 & 85,5 & 0,44 & 76,8 & 80,6 & 0,31 & 76,8 & 80,5 & 0,30 \\
170,2 & 173,4 & 0,19 & 168,9 & 169,0 & 0,04 & 168,9 & 168,9 & 0,01 \\
200,6 & 203,1 & 0,16 & 199,1 & 199,2 & 0,03 & 199,0 & 199,0 & 0,02 \\
228,8 & 229,2 & 0,06 & 222,9 & 223,0 & 0,02 & 222,8 & 222,9 & 0,01 \\
271,2 & 275,2 & 0,17 & 267,2 & 267,7 & 0,06 & 267,4 & 267,9 & 0,06 \\
287,1 & 287,1 & 0,01 & 281,5 & 281,6 & 0,03 & 281,8 & 281,9 & 0,03 \\
313,5 & 319,7 & 0,20 & 308,9 & 309,4 & 0,06 & 308,8 & 309,3 & 0,05 \\
340,5 & 343,2 & 0,13 & 338,3 & 339,0 & 0,07 & 338,3 & 339,1 & 0,07 \\
370,2 & 370,3 & 0,02 & 364,3 & 364,3 & 0,00 & 364,4 & 364,4 & 0,00 \\
389,6 & 389,6 & 0,01 & 385,6 & 385,8 & 0,03 & 385,7 & 386,0 & 0,03 \\
416,4 & 416,6 & 0,03 & 416,3 & 416,1 & 0,02 & 416,4 & 416,6 & 0,03 \\
\hline
\end{tabular}

Tabela 6.6: Freqüências de ressonância $\left(\omega_{r}\right)$ e anti-ressonância $\left(\omega_{a}\right)(\mathrm{kHz})$, e coeficiente piezoelétrico $(K)$ calculado através da expressão 4.32 - Cerâmica PZT5A $(D / H=4)$ $R D I V=16$ e $H D I V=8$; apodizada segundo uma função decrescente ao longo do raio.

houve uma redução em média do coeficiente $e_{33}$ ao longo do raio. Entretanto a função gaussiana foi a que apresentou a menor redução.

Observa-se que na apodização com as funções lineares e cossenoidal decrescente houve uma redução significativa no acoplamento $(K)$ da maior parte dos modos, sendo que alguns modos tiveram o acoplamento ligeiramente aumentado. Já com a função gaussiana a redução do acoplamento foi menor, sendo portanto uma boa escolha para a apodização. Para uma apodização utilizando uma função cossenoidal crescente nota-se que a variação dos $K$ s é pequena, e portanto numa apodização crescente, o desacoplamento dos modos é menor. Nas figs. 6.17 e 6.18 são apresentados alguns modos, bem como a curva de admitância para a cerâmica apodizada com uma função gaussiana, que pode ser comparada com a da cerâmica não-apodizada.

\subsection{Análise Transiente}

Nas figs. 6.19 e 6.20 são apresentadas os perfis de deformação do disco cerâmico de relação $D / H=10(\mathrm{D}=20 \mathrm{~mm}$ e $\mathrm{H}=2 \mathrm{~mm})$ nos tempos $0,1-0,4 \mu \mathrm{s}, 0,7-1,0 \mu \mathrm{s}, 1,1-1,4 \mu \mathrm{s}, 1,7$ $2,0 \mu s, 2,7-3,4 \mu s, 3,7-4,0 \mu s$ sujeito à excitação de um pulso com banda de freqüência limitada em $f_{0}=1,5 \mathrm{MHz}$ (fig 6.1). O incremento de tempo utilizado foi $0,1 \mu \mathrm{s}$ e o tempo máximo de análise foi de $15 \mu \mathrm{s}$. O deslocamento vertical $(U Z)$ em função do tempo para três nós ao longo do raio são mostrados nas figs. 6.21 e 6.22 . Através desses gráficos observa-se que o tempo em que ocorre a máxima amplitude é diferente para 


\begin{tabular}{|c|c|c|c|c|c|}
\hline \multicolumn{3}{|c|}{ Gaussiana } & \multicolumn{3}{|c|}{ Cossenoidal Cresc. } \\
\hline$\omega_{r}$ & $\omega_{a}$ & $K$ & $\omega_{r}$ & $\omega_{a}$ & $K$ \\
\hline \hline 76,8 & 83,1 & 0,38 & 76,8 & 81,8 & 0,36 \\
169,5 & 170,3 & 0,10 & 169,1 & 173,6 & 0,23 \\
199,6 & 200,1 & 0,07 & 199,3 & 203.1 & 0,19 \\
225,5 & 225,6 & 0,03 & 224,4 & 224,7 & 0,05 \\
269,4 & 271,1 & 0,11 & 267,4 & 269,9 & 0,14 \\
283,6 & 283,7 & 0,02 & 282,8 & 282,8 & 0,01 \\
311,1 & 313,2 & 0,12 & 309,6 & 312,7 & 0,14 \\
339,6 & 341,4 & 0,10 & 337,8 & 338,1 & 0,04 \\
366,4 & 366,4 & 0,01 & 366,2 & 366,4 & 0,03 \\
387,6 & 387,7 & 0,02 & 385,8 & 386,0 & 0,03 \\
416,5 & 416,5 & 0,00 & 415,2 & 415,6 & 0,04 \\
\hline
\end{tabular}

Tabela 6.7: Freqüências de ressonância $\left(\omega_{r}\right)$ e anti-ressonância $\left(\omega_{a}\right)(\mathrm{kHz})$, e coeficiente piezoelétrico $(K)$ calculado através da expressão 4.32 - Cerâmica PZT5A $(D / H=4)$ $R D I V=16$ e $H D I V=8$; apodizada segundo uma função ao longo do raio.

cada nó, indicando a propagação de uma onda ao longo do raio. Essa onda radial pode ser visualizada nos gráficos de deformações das figs. 6.19 e 6.20 , nos tempos indicados anteriormente. Essa onda é a responsável pela geração das "head waves" comentadas no item 3.2.3. As deformações, bem como o gráfico de deslocamento ( $U Z \times$ tempo) para o nó do centro da face podem ser comparados com os da referência [Guo 91]. Nessa referência - máximo deslocamento vertical do nó do centro ocorre no tempo $10 \mu s$, resultando numa velocidade de $1000 \mathrm{~m} / \mathrm{s}$, enquanto que no caso obteve-se $5 \mu \mathrm{s}$, resultando numa velocidade de $2000 \mathrm{~m} / \mathrm{s}$. A diferença é atribuída ao fato das constantes de rigidez utilizadas pela referência não serem bem conhecidas. Assim como essas constantes e a densidade do material, influem na velocidade de propagação da onda, utilizando-se constantes um pouco

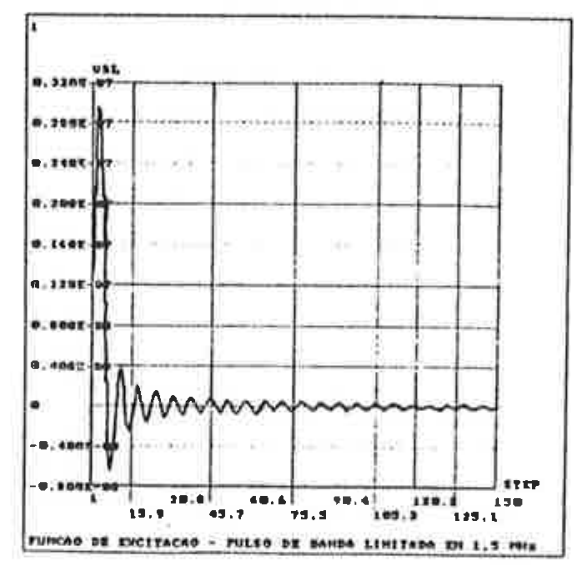

Figura 6.1: Pulso de excitação. 
diferentes (10\%) obtém-se resultados discrepantes. A influência das propriedades adotadas pode ser analisada observando-se a tabela (6.1), onde são comparadas as freqüências de ressonância para a cerâmica de PZT5A $(D / H=20)$ com a mesma referência. A diferença entre as freqüências é maior por exemplo, do que na comparação realizada na tabela (6.2), onde as propriedades utilizadas eram bem conhecidas.

\subsection{Acoplamento Fluido-Estrutura}

$\mathrm{Na}$ fig. 6.23 é mostrado a distribuição de amplitudes de pressão (campo acústico) resultante da excitação de um pistão plano em $\mathrm{OC}$ no meio fluido água $(c=1500 \mathrm{~m} / \mathrm{s}$ e $\left.\rho=1000 \mathrm{Kg} / \mathrm{m}^{3}\right)$, para uma relação raio/comprimento de onda $a / \lambda$ igual à 1 . Os gráficos de amplitude de pressão ao longo do eixo do pistão, ao longo do plano da face do pistão e ao longo de um raio em torno do pistão (R1) são apresentados nas figs. 6.26 à 6.29 , também para um pistão plano com relação $a / \lambda=2$, onde se pode observar a presença dos lóbulos laterais.

As distribuições de amplitudes das velocidacles na direção X e Z são apresentadas respectivamente nas figs. 6.24 e 6.25 para o pistão com relação $a / \lambda$ igual a 1 . Nota-se que a medida que se afasta do pistão, ocorre a predominância das velocidades na direção $\mathrm{Z}$ (e portanto das componentes radiais da velocidade), o que era de se esperar, uma vez que o pistão passa a ser visto como uma fonte pontual, e assim, quando as velocidades na direção $\mathrm{X}$ se anulam (e portanto as componentes tangenciais), as componentes radiais da velocidade passam a determinar a direção da frente de onda. Os gráficos de amplitudes de pressão ao longo do eixo do pistão obtidos pelo MEF nas figs. 6.26 à 6.29 , podem ser comparados com os obtidos pela expressão analítica do pistão plano [Kinsler 82], como mostrado na fig. 6.2 para as relações $a / \lambda$ iguais à 1 e 2 . Nota-se no gráfico obtido pelo MEF, a presença do ruído comentado no item 5.3. Observou-se que aumentando a discretização esse ruído diminui, como pode ser observado para relação $a / \lambda=1$ na fig. 6.26, em que foram consideradas duas discretizações diferentes. O mesmo ocorre, como esperado, quando a fronteira do modelo (parede fictícia) é afastada do pistão.

Nas figs. 6.30 e 6.36 encontram-se o campo acústico do problema transdutor mais fluido, com o transdutor possuindo uma relação $D / H=5,5(\mathrm{D}=55 \mathrm{~mm} \mathrm{e} \mathrm{H=10} \mathrm{mm})$ emitindo na água $\left(c=1500 \mathrm{~m} / \mathrm{s}\right.$ e $\left.\rho=1000 \mathrm{Kg} / \mathrm{m}^{3}\right)$. Nas figs. 6.30 à 6.34 são apresentados os resultados segundo o modelo da rotina $\mathrm{TCP} 1$, para uma relação $a / \lambda$ igual à 1 , e nas figs. 6.36 à 6.40 , segundo o modelo da rotina $\mathrm{TCP} 2$, para uma relação $a / \lambda$ igual à 1,5 . Os resultados da TCP1 podem ser comparados com os obtidos por [Kagawa 79]. Nas figs. 6.31 e 6.32 encontram-se os campos das velocidades VLZ e VLX respectivamente, para o modelo TCP1 em que $a / \lambda=1$, e nas figs. 6.37 e 6.38 para o modelo TCP2 em que $a / \lambda=1,5$. Os gráficos de amplitude de pressão ao longo do eixo do transdutor, ao longo do plano da face do transdutor, e ao longo de um raio (R1) em torno do transdutor encontram-se nas figs. $6.33,6.34,6.39$ e 6.40 .

- Os gráficos do modelo TCP1 para relação $a / \lambda=1$ podem ser comparados com o 

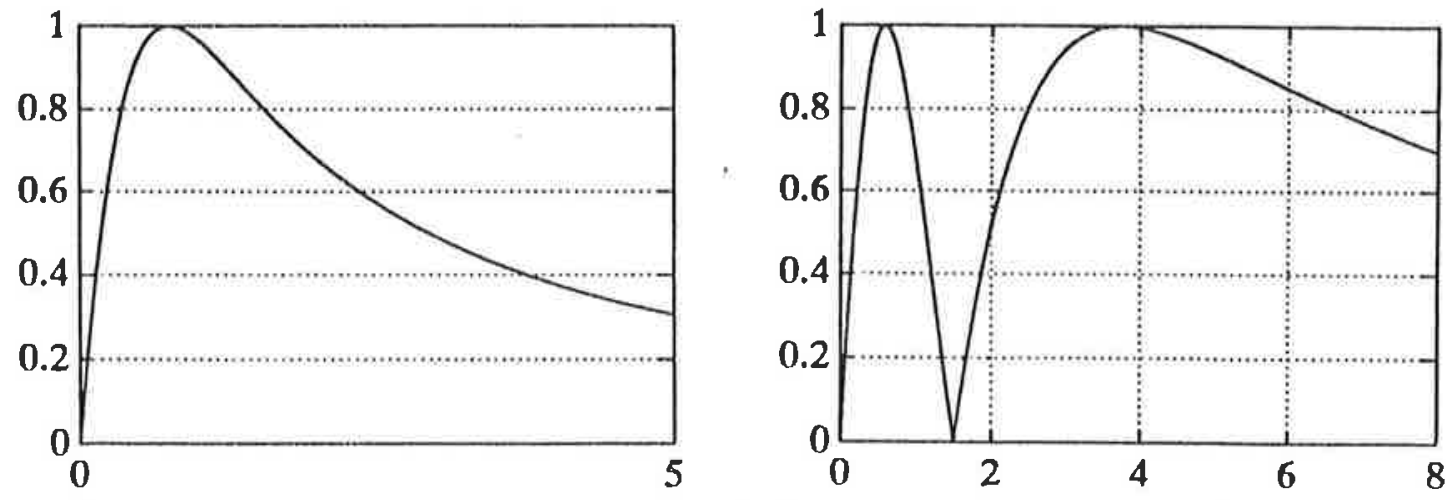

Figura 6.2: Amplitude de pressão ao longo do eixo do pistão para relações $a / \lambda=1$ (fig. da esquerda) e $a / \lambda=2$ (fig. da direita) - expressão analítica. Valores de pressão normalizados segundo a pressão máxima, e valores de distância dados em função do comprimento de onda $\lambda$.

modelo do pistão plano (mesma relação $a / \lambda$ ) observando-se as discrepâncias.

$\mathrm{Na}$ fig. 6.35 é apresentado o campo acústico do transdutor com relação $D / H=5,5$ considerando camadas de casamento e relaguarda de aço (transdutor tipo "Langevin"), obtido através da rotima TCPMB, para uma relação $a / \lambda=1,31$.

\subsection{Análise Transiente Acústica}

A distribuição de pressão resultante da propagação de ondas acústicas originárias do movimento pulsado de um pistão plano com relação $a / \lambda=3$ excitado com um pulso de freqüência central $1 \mathrm{MHz}$, é mostrado na fig. 6.41. O tempo total analisado foi de $6 \mu s$. Observam-se claramente as ondas planas e de borda. Nos gráficos das figs. 6.40 e 6.42 são mostradas a variação de pressão em função do tempo em pontos situados às distâncias de $1 \mathrm{~mm}, 2 \mathrm{~mm}$ e $4 \mathrm{~mm}$ da face do pistão. No ponto situado à distância $1 \mathrm{~mm}$ observam-se os pulsos correspondentes às ondas plana e de borda. Já nos pontos seguintes observa-se a interferência entre essas ondas (no último gráfico elas estão superpostas). As resoluções no tempo e no espaço utilizadas foram baixas $(K E=K T=6)$, apenas o suficiente para fornecer uma aproximação dos resultados, incentivando o estudo nesse tipo de análise. 

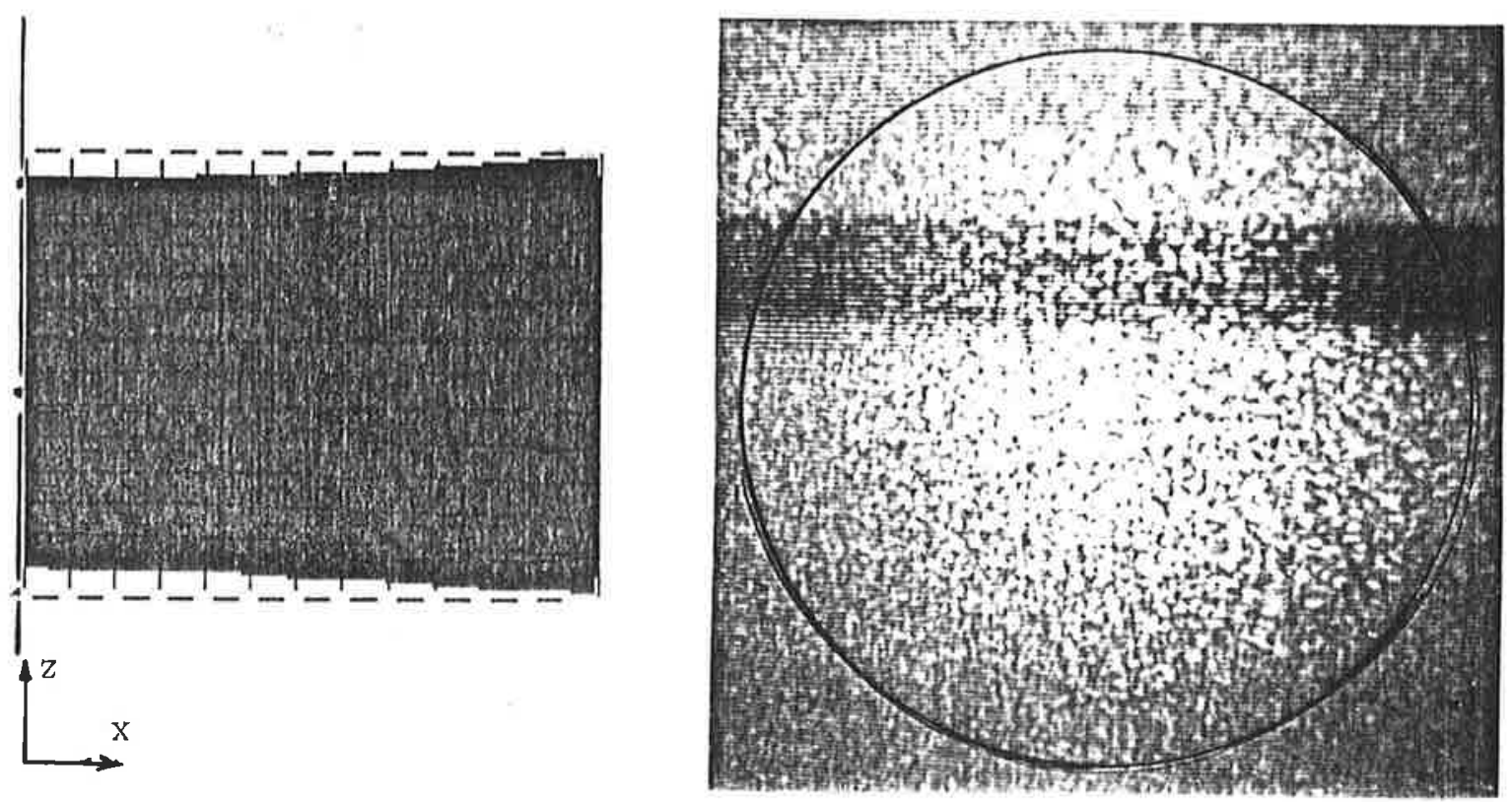

Figura 6.3: Esquerda - 1 으 modo de ressonância $(72,4 \mathrm{kHz}$ ) (cerâmica PZT5A D/H=2,5); Direita - visualização por interferometria laser.
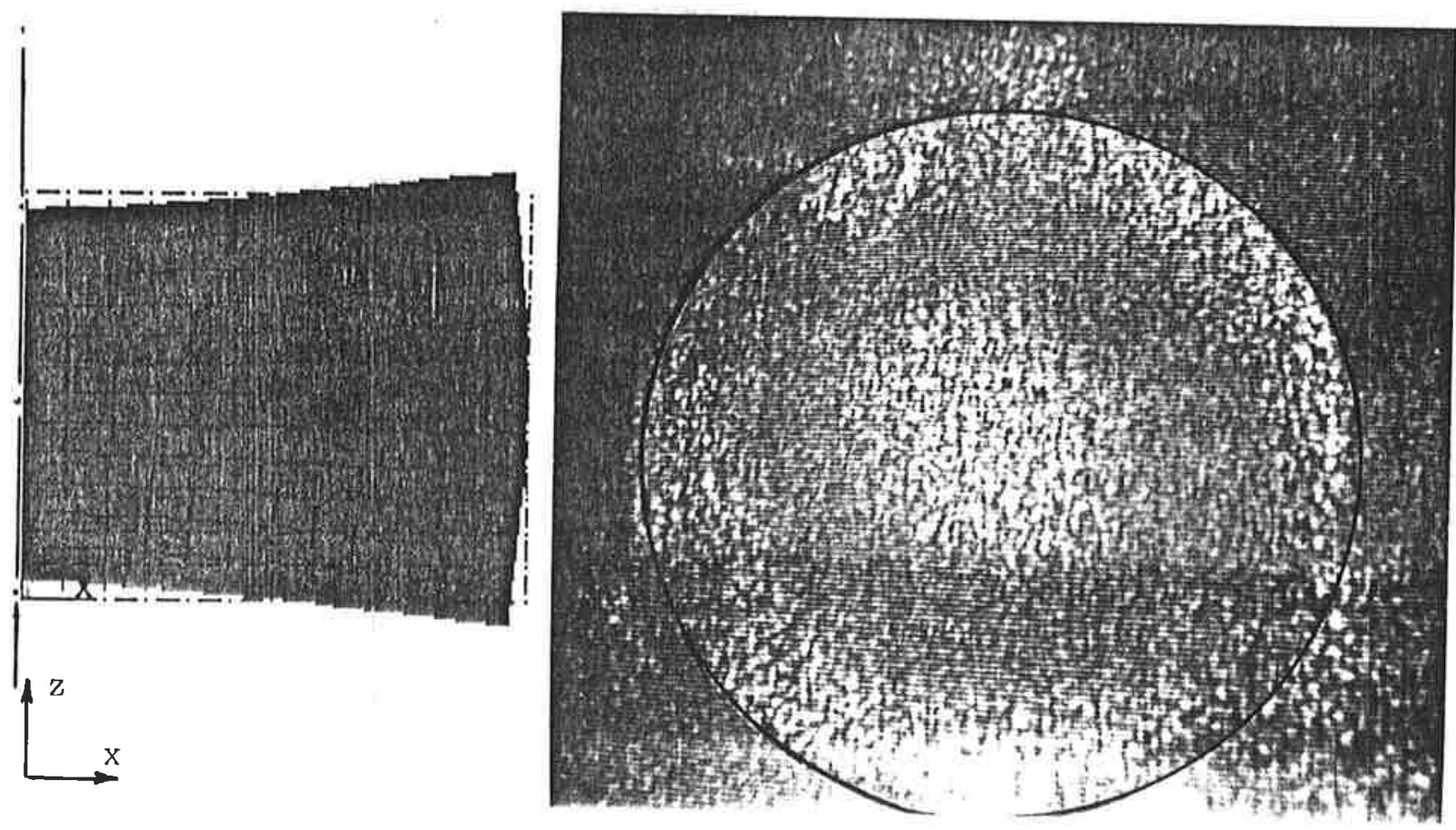

Figura 6.4: Esquerda - 20 modo de ressonância (124 kHz) (cerâmica PZT5A D/H=2,5); Direita - visualização por interferometria laser. 

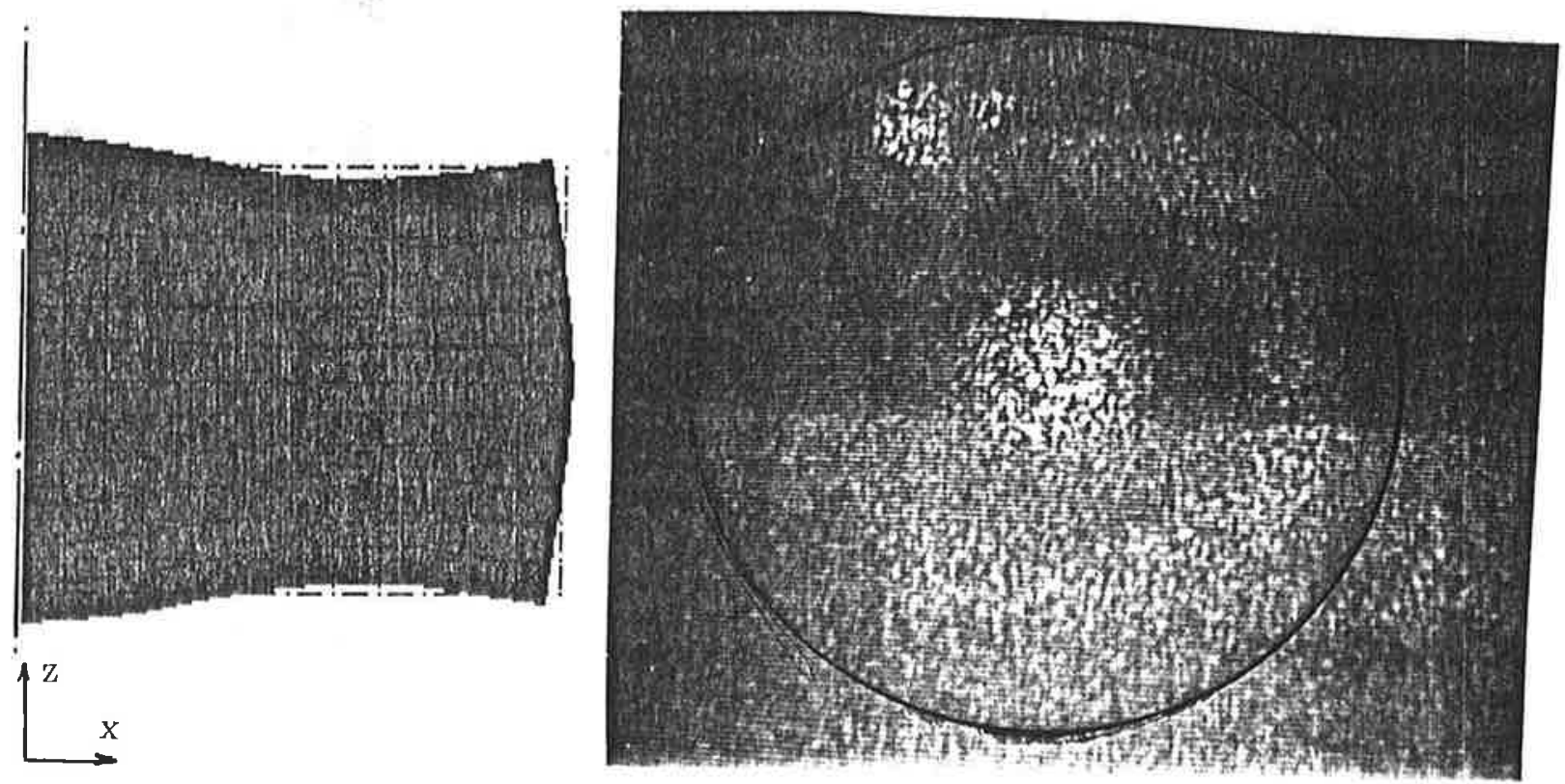

Figura 6.5: Esquerda - 3으 modo de ressonância (144 kHz) (cerâmica PZT5A D/H=2,5); Direita - visualização por interferometria laser.
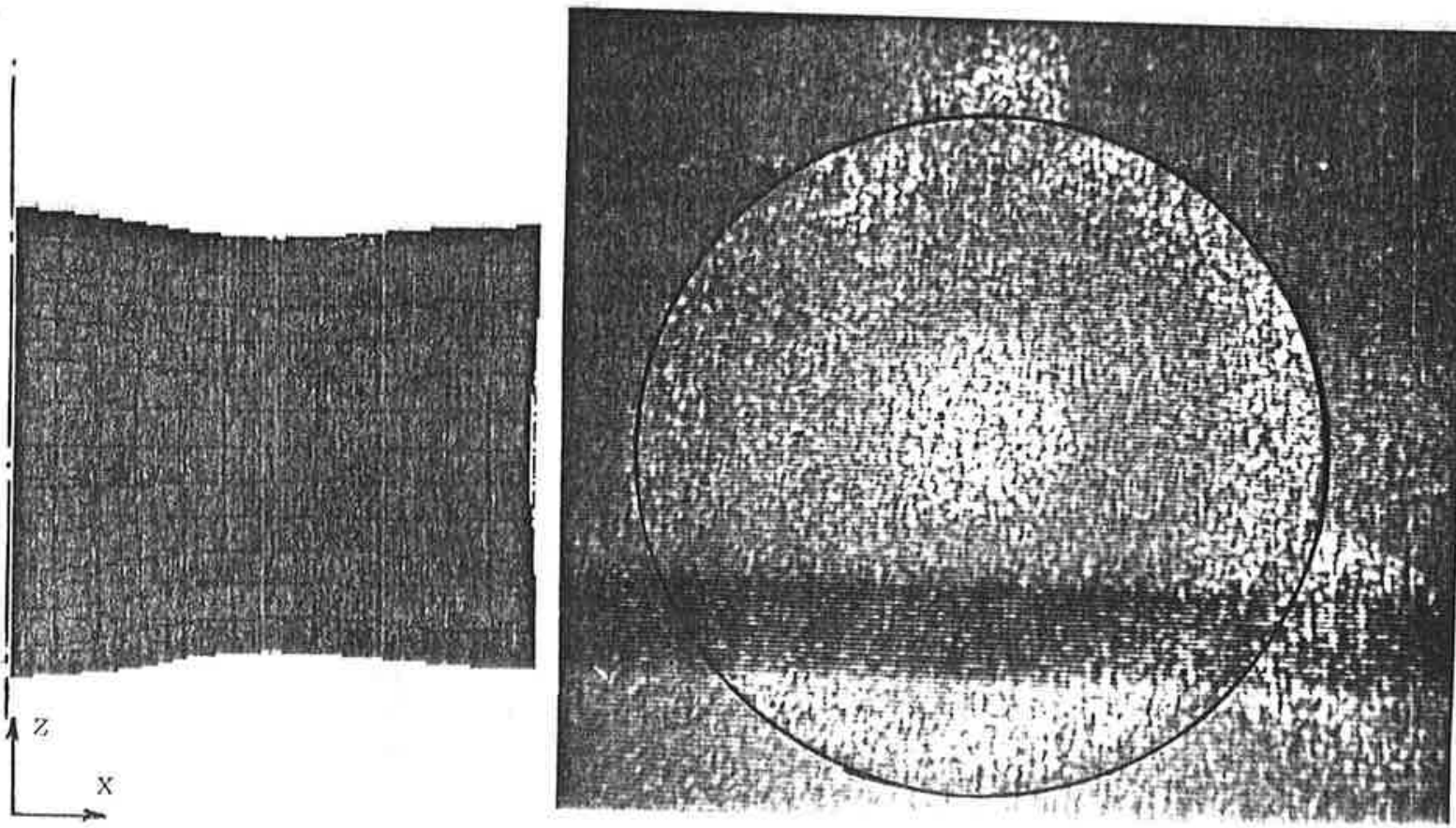

Figura 6.6: Esquerda - 40 modo de ressonância (180 kHz) (cerâmica PZT5A D/H=2,5); Direita - visualização por interferometria laser. 

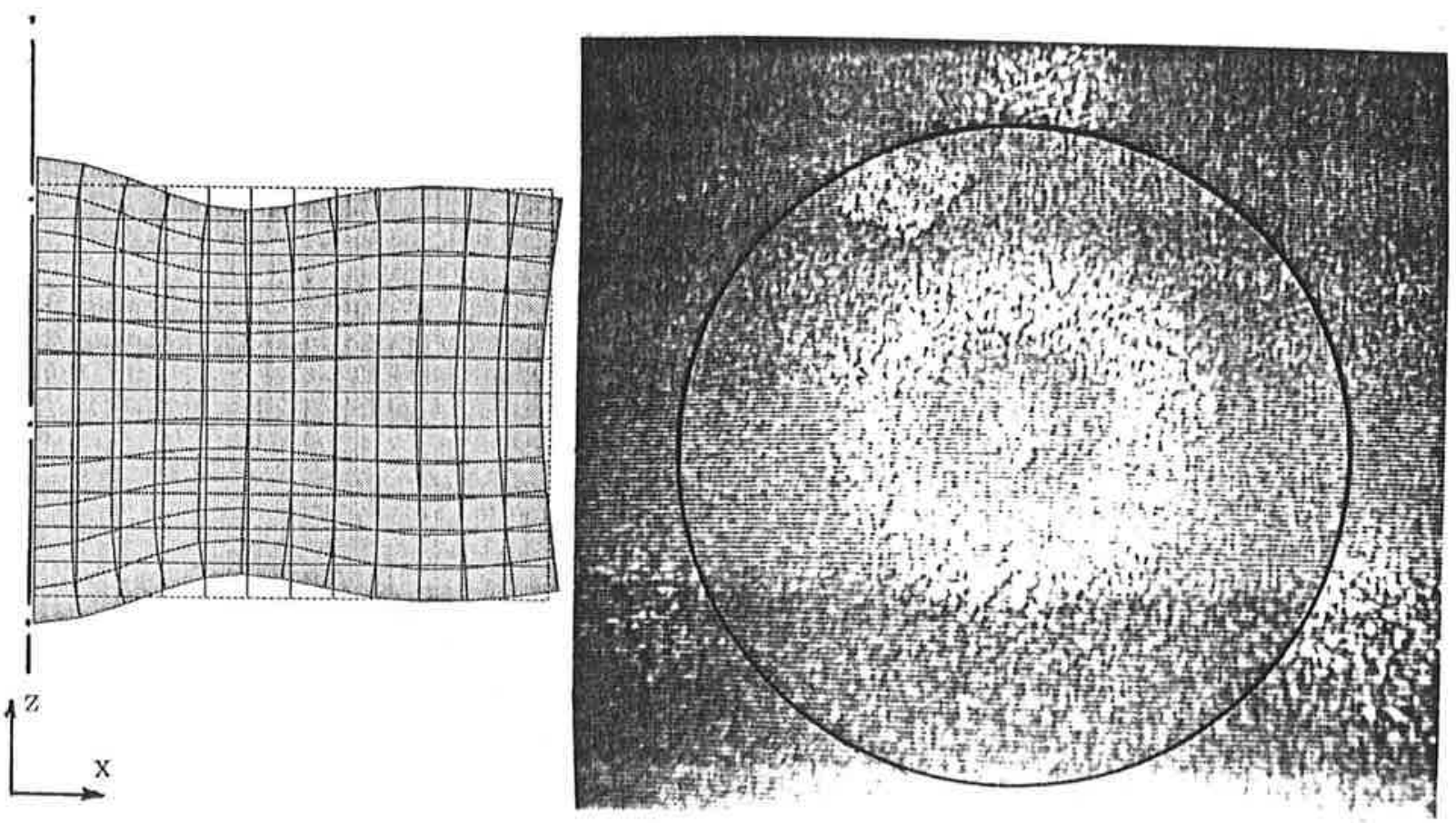

Figura 6.7: Esquerda - 50 modo de ressonância (216 kHz) (cerâmica PZT5A D/H=2,5); Direita - visualização por interferometria laser.
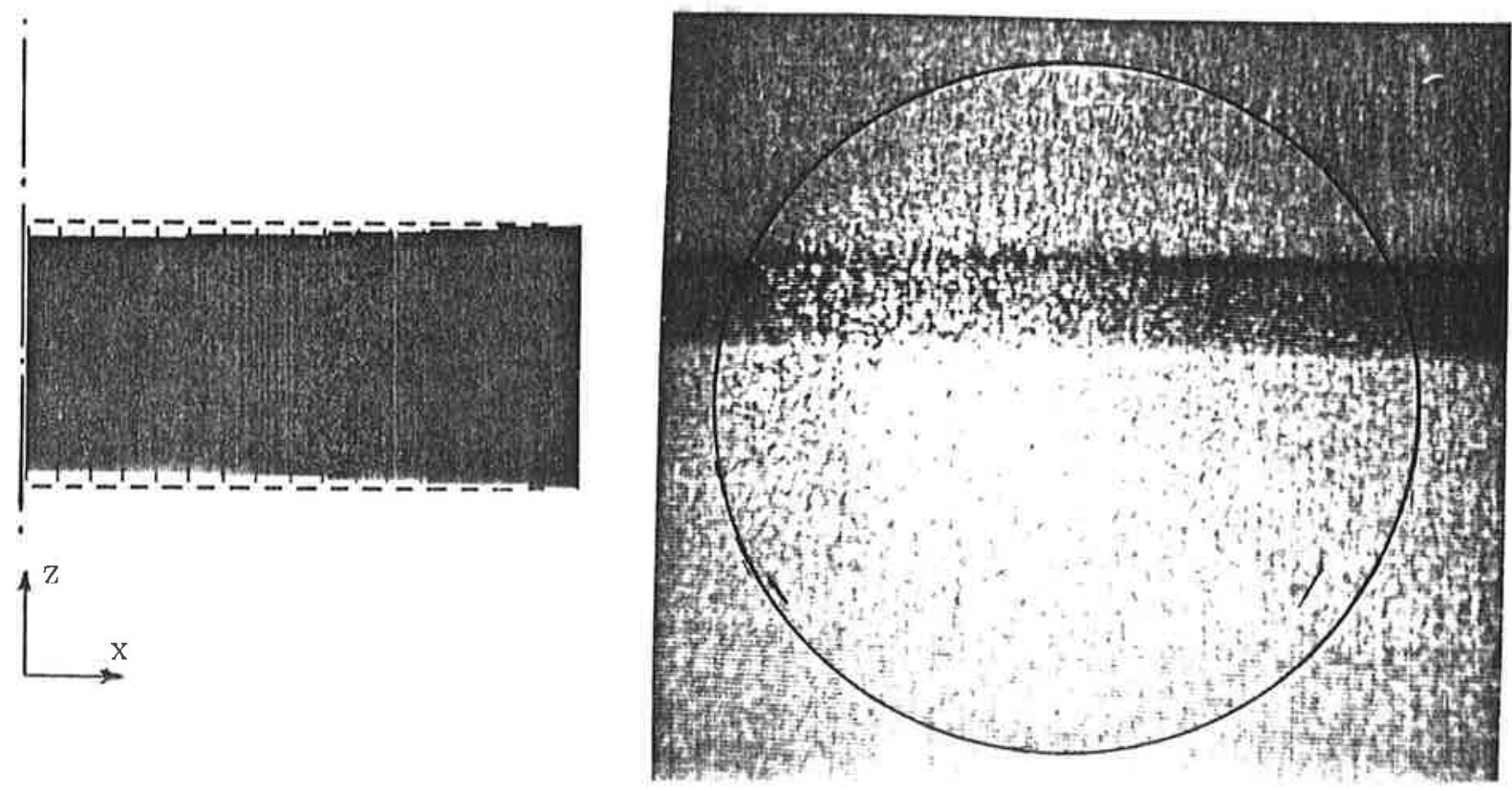

Figura 6.8: Esquerda - 1으 modo de ressonância $(76,8 \mathrm{kHz})$ (cerâmica PZT5A D/H=4); Direita - visualização por interferometria laser. 

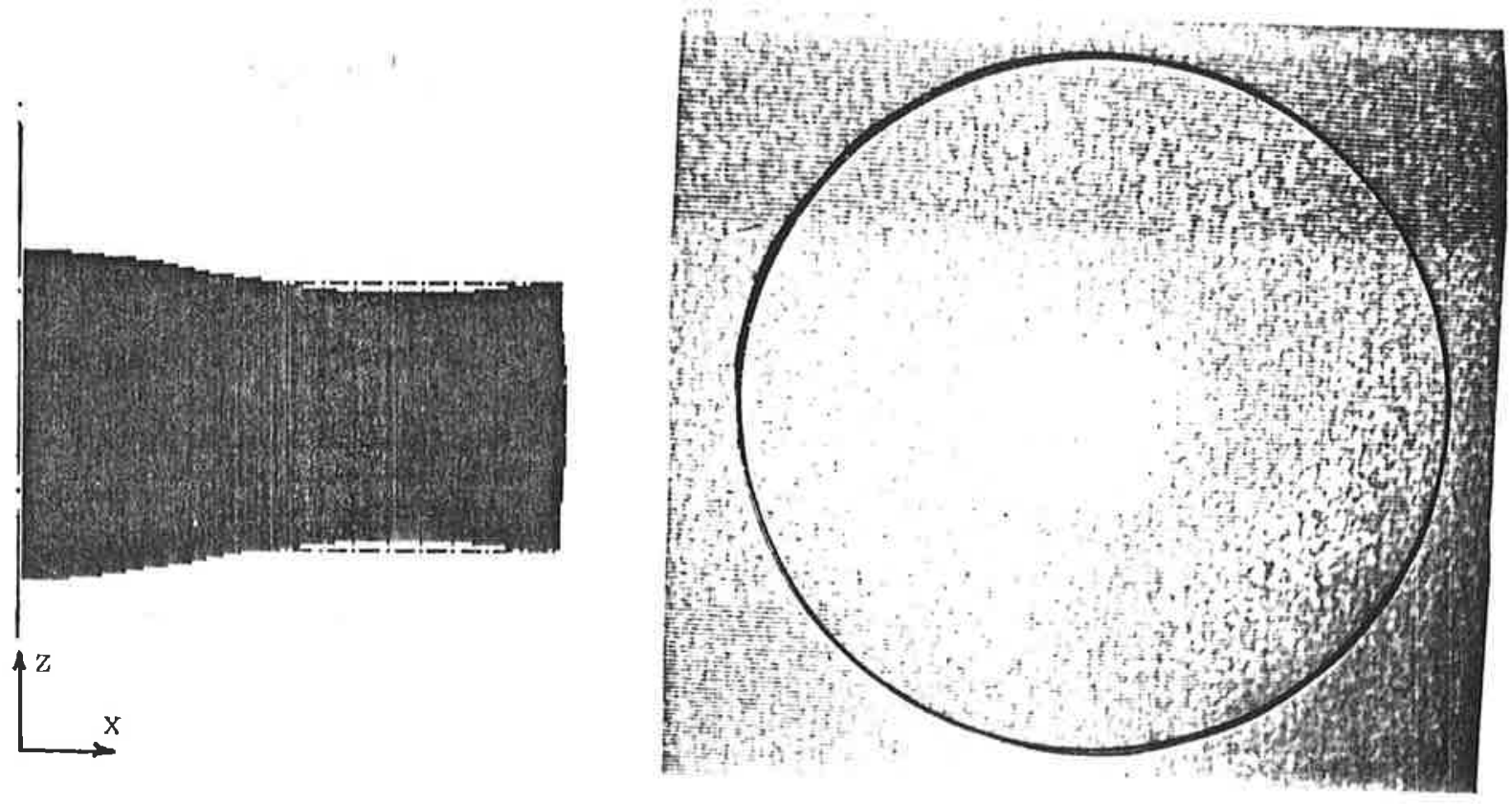

Figura 6.9: Esquerda - 20 modo de ressonância (170 kHz) (cerâmica PZT5A D/H=4); Direita - visualização por interferometria laser.
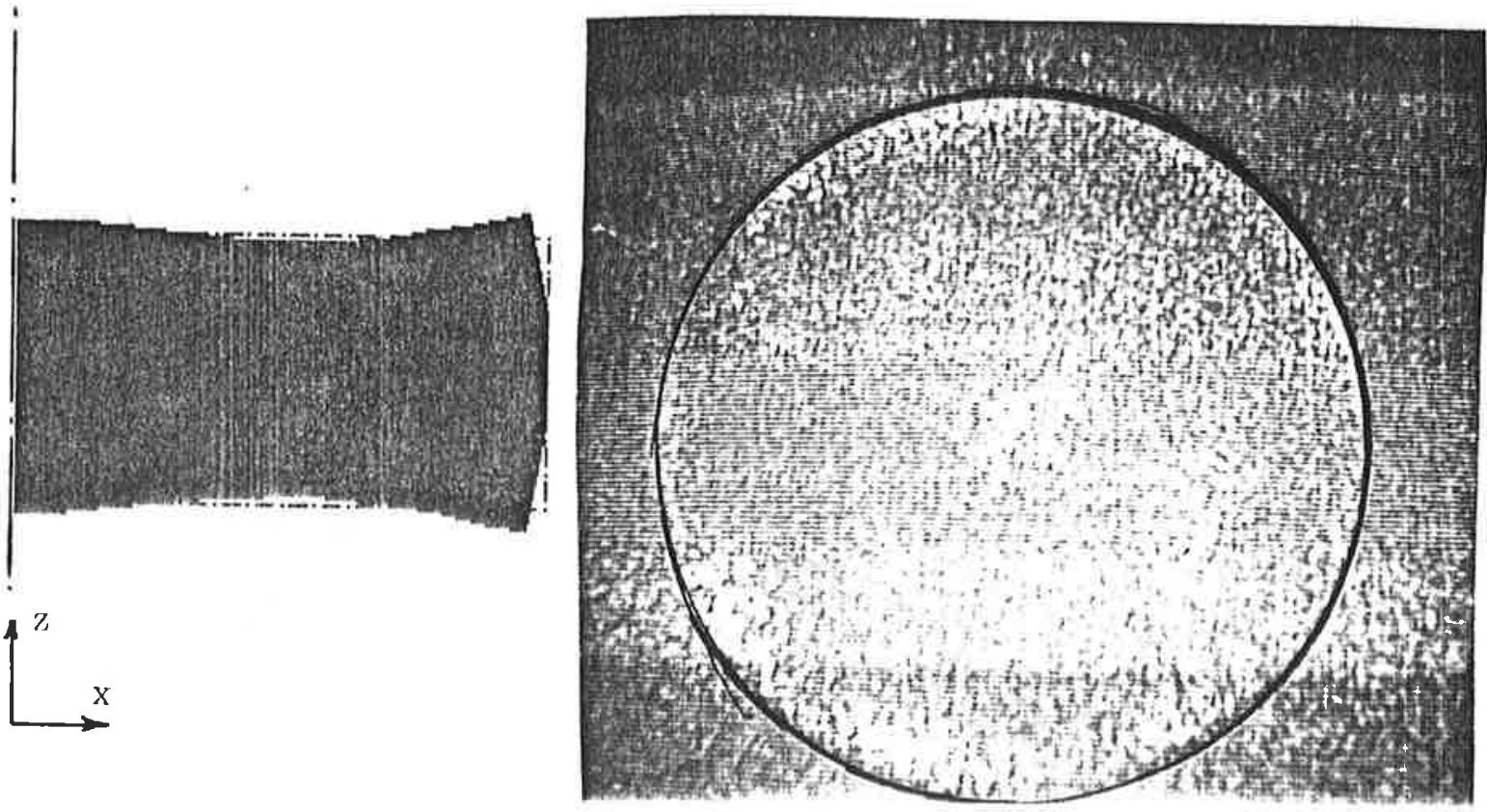

Figura 6.10: Esquerda - 3ㅇ modo de ressonância (200 kHz) (cerâmica PZT5A D/H=4); Direita - visualização por interferometria laser. 


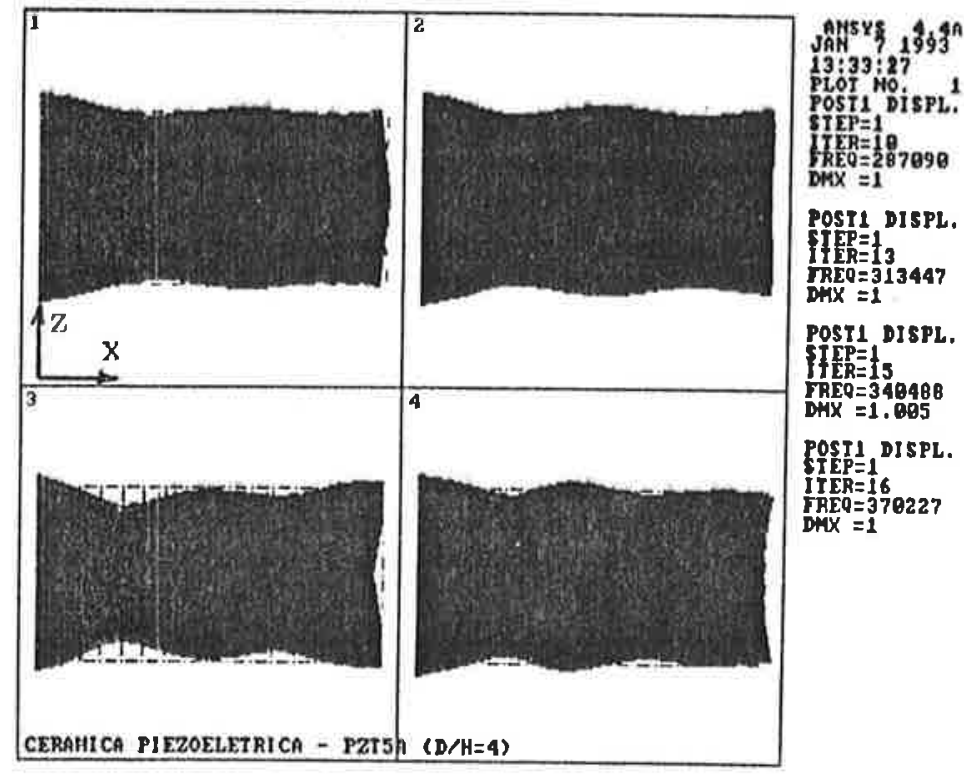

Figura 6.11: Modos de vibrar na ressonância (cerâmica PZT5A D/H=4). Freqüências indicadas em FREQ.
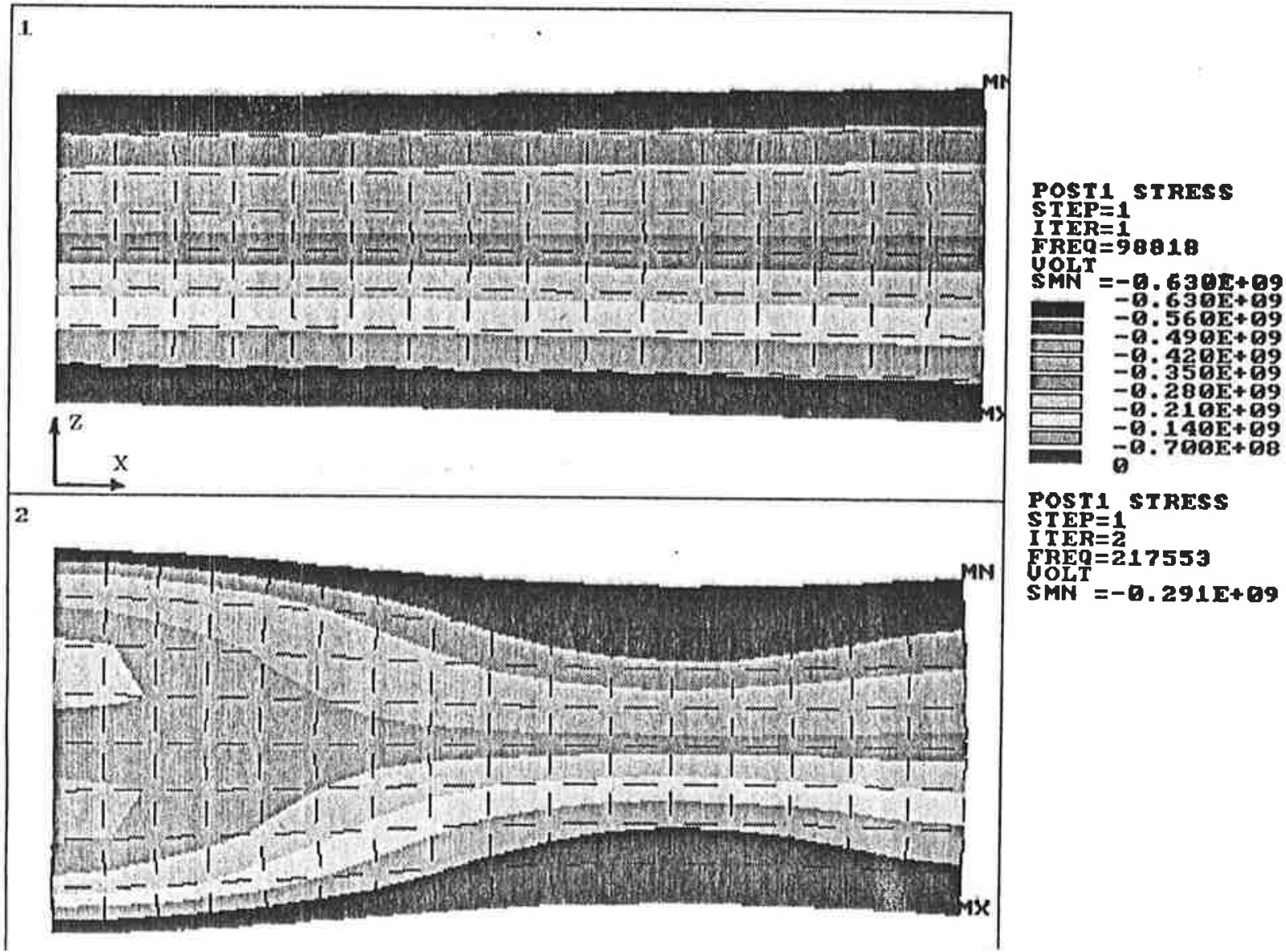

Figura 6.12: Campo de potencial elétrico (cerâmica PZT5A D/H=4). 


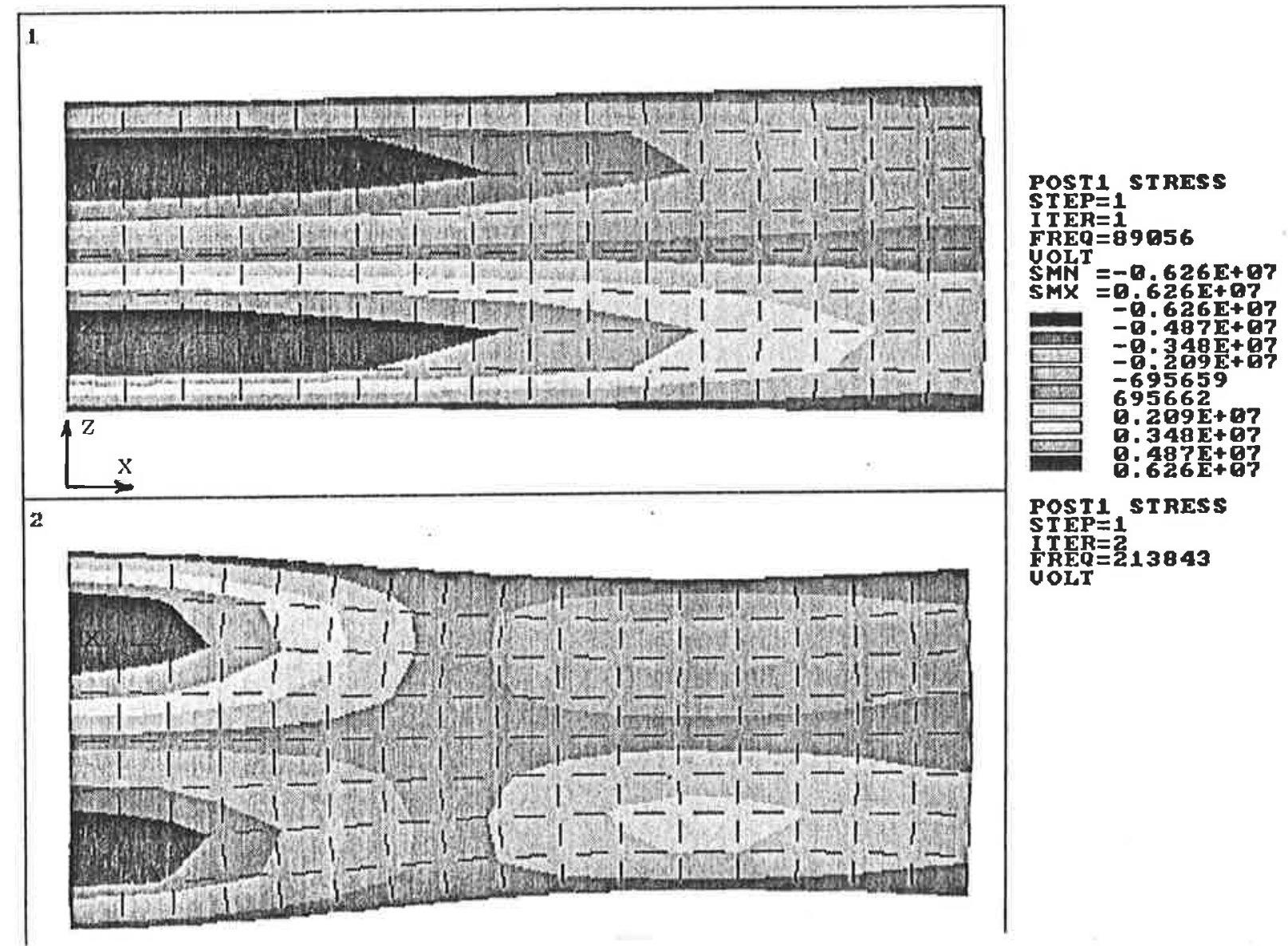

Figura 6.13: Campo de potencial elétrico (cerâmica PZT5A D/H=4).
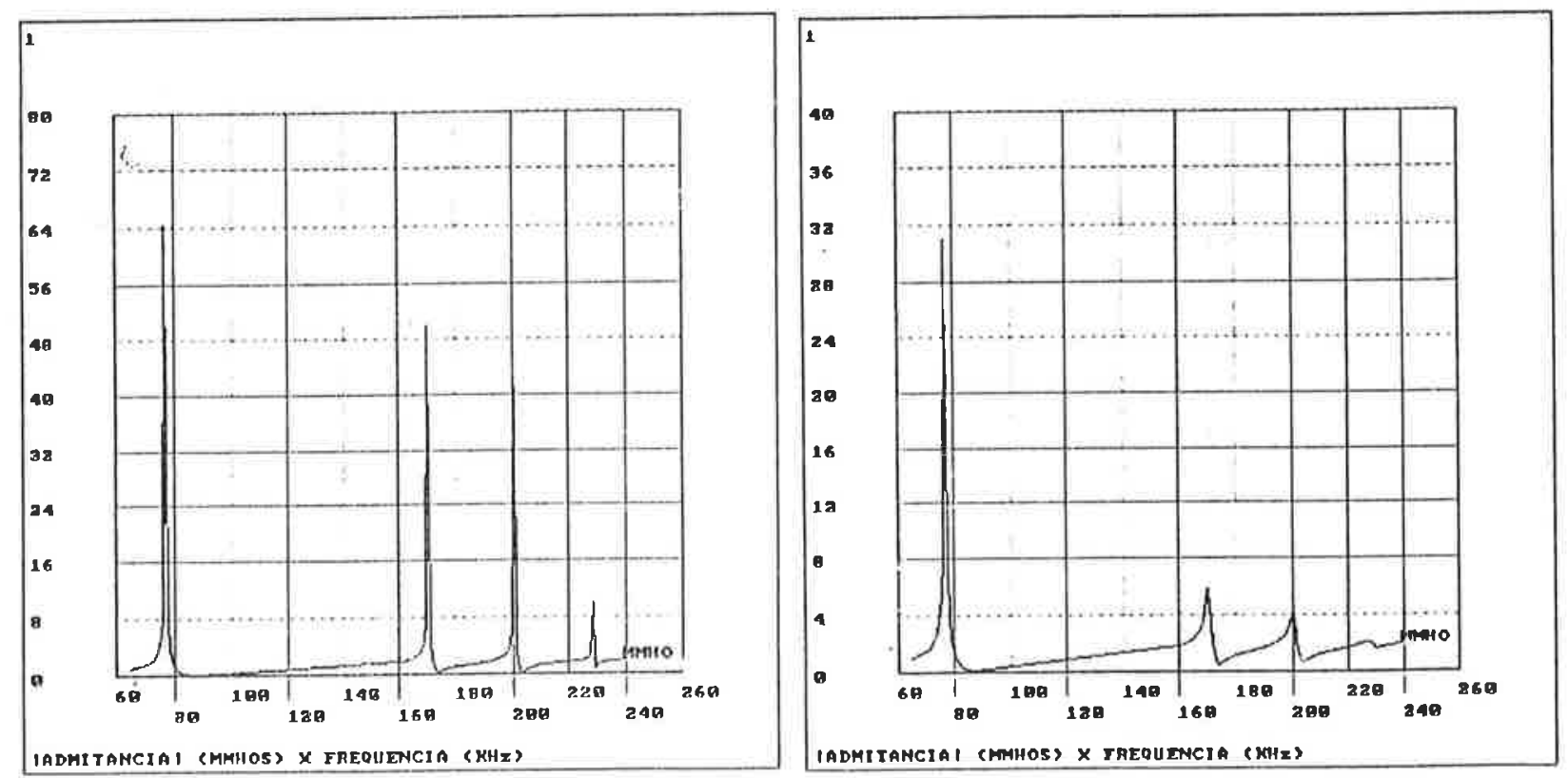

Figura 6.14: Curva de admitância para cerâmica PZT5A D/H=4. Esquerda - sem amortecimento; Direita - com amortecimento ( $\alpha=0$ e $\beta=10^{-8}$ )(amplitude). 

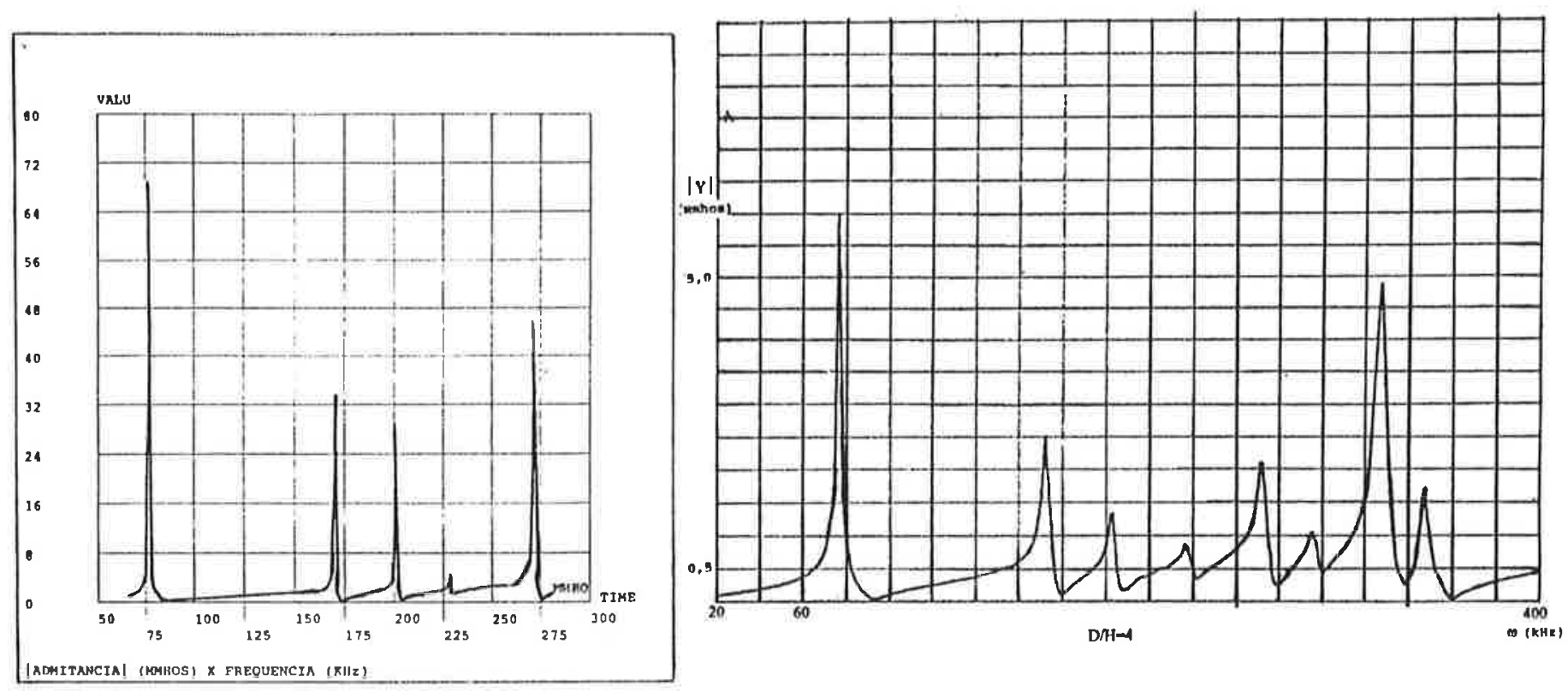

Figura 6.15: Curva de admitância para cerâmica PZT5A D/H=4. Esquerda - com amortecimento dielétrico $(\tan \delta=0,2)$; Direita - obtida experimentalmente.
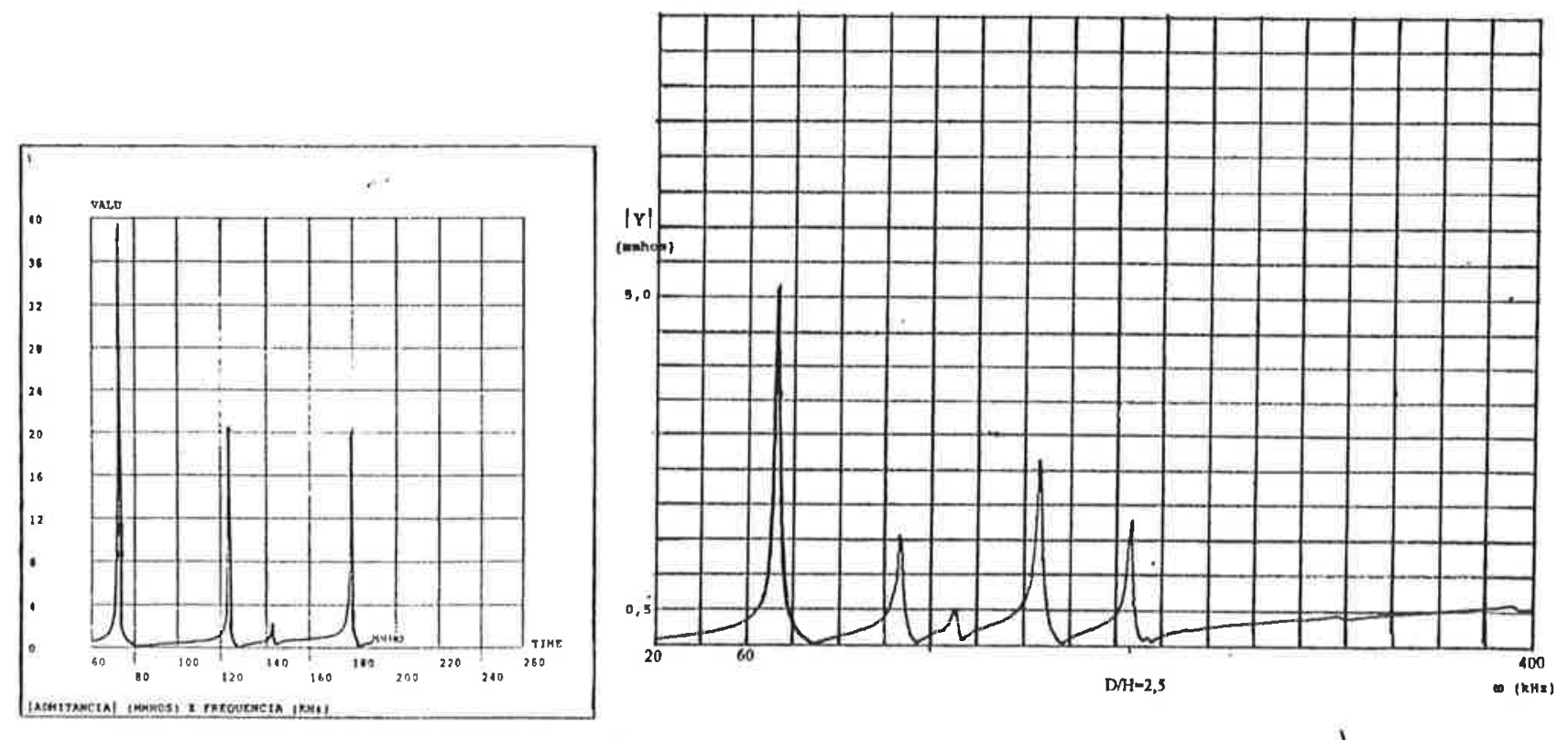

Figura 6.16: Curva de admitância para cerâmica PZT5A D/H=2,5. Esquerda - com amortecimento dielétrico $(\tan \delta=0,2)$; Direita - obtida experimentalmente. 


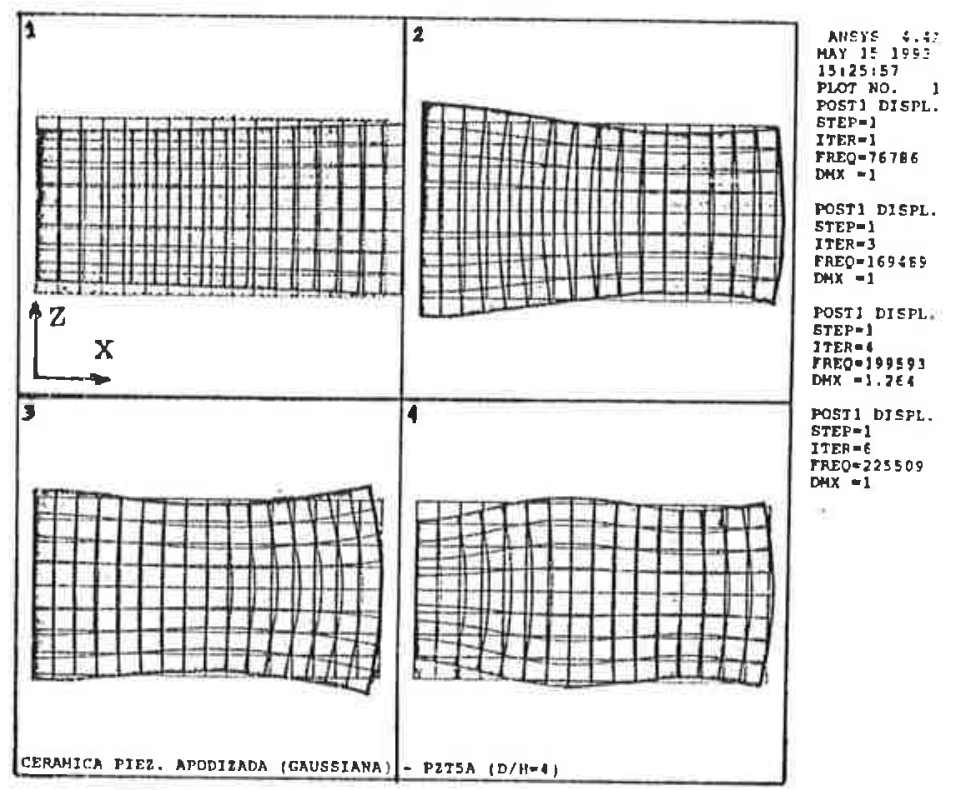

Figura 6.17: Modos de vibrar na ressonância (cerâmica PZT5A D/H=4 - apodizada segundo uma função gaussiana no raio).
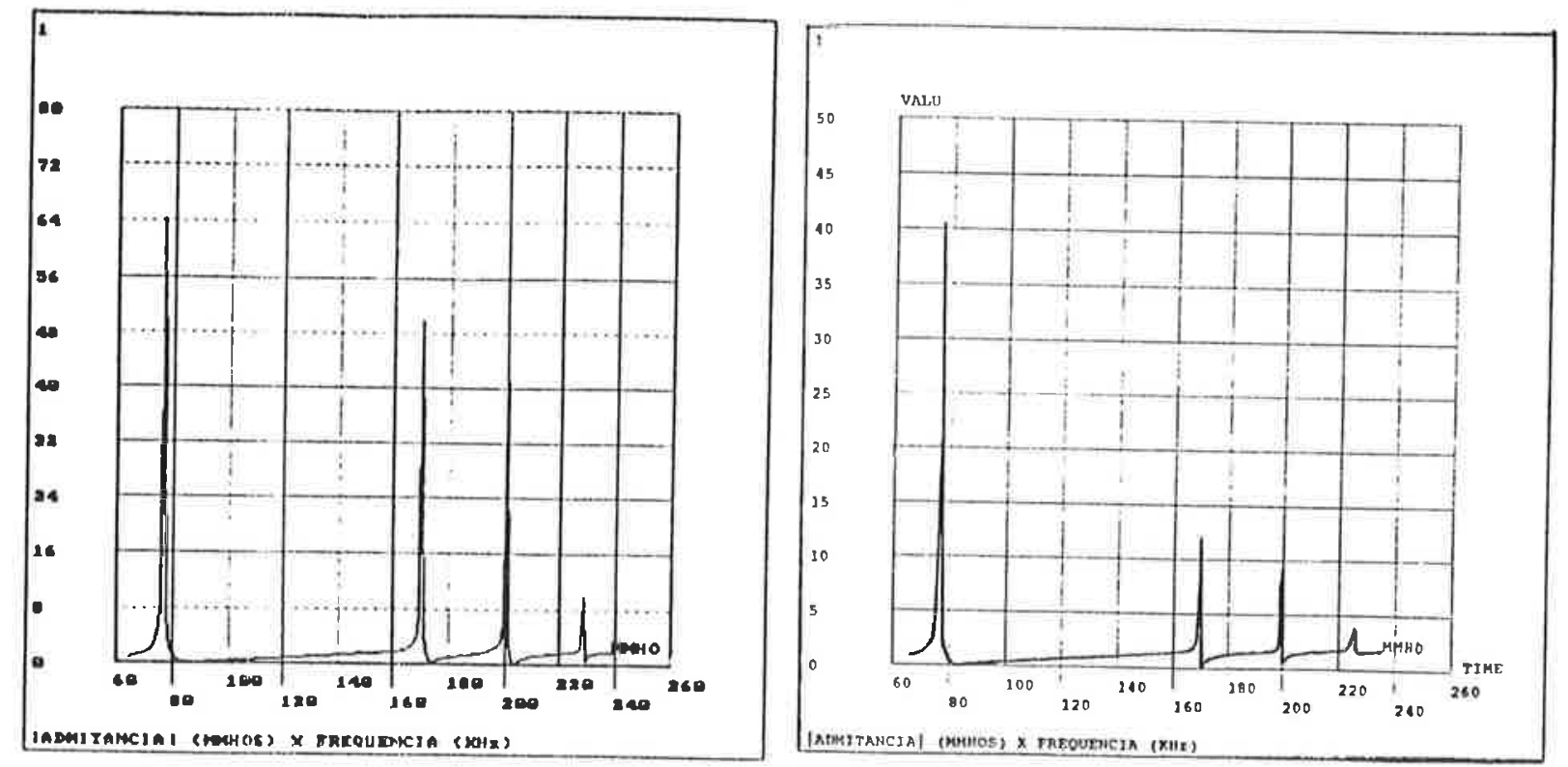
Figura 6.18: Curva de admitância para cerâmica PZT5A D/H=4. Esquerda - não
apodizada; Direita - apodizada. 

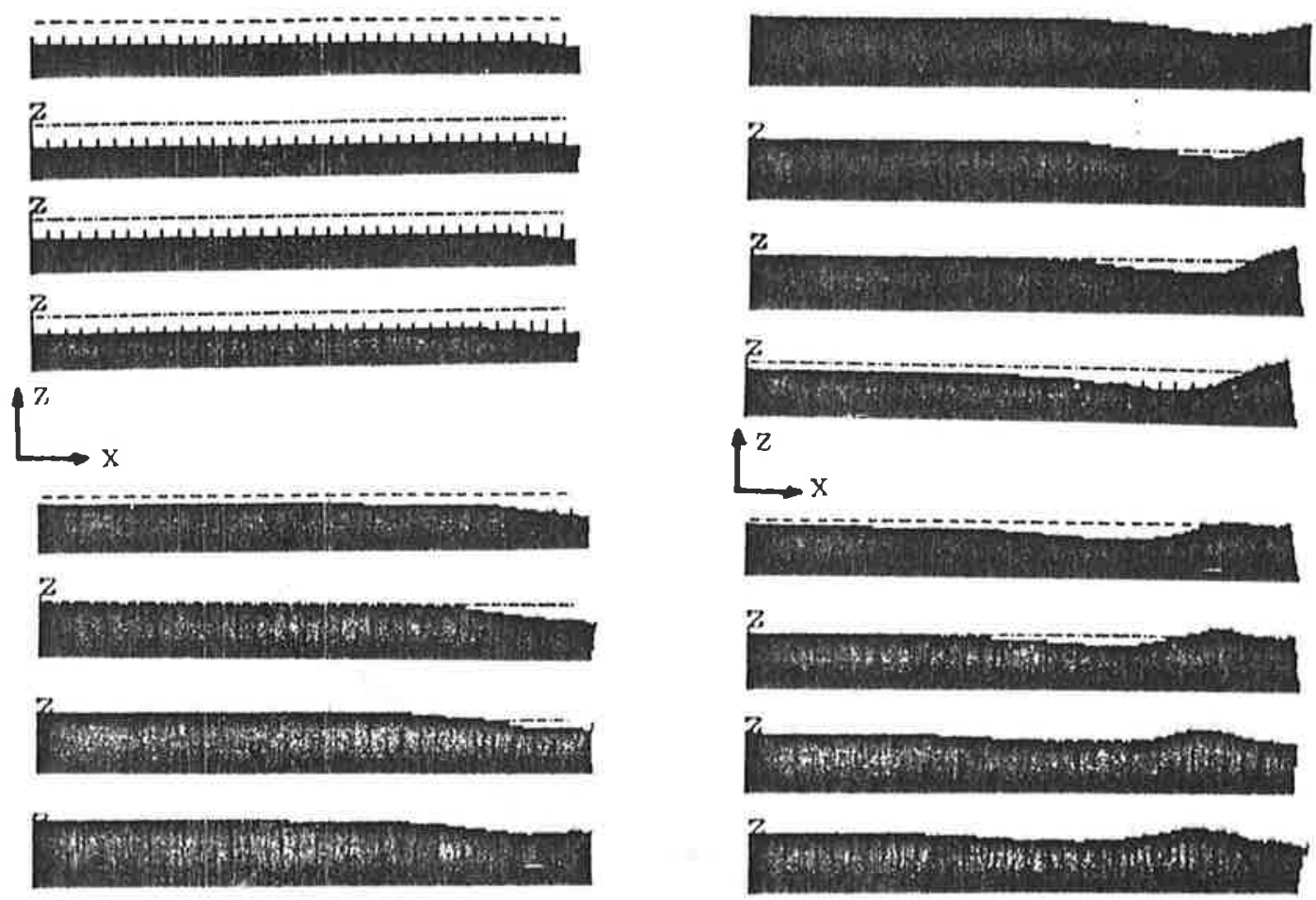

Figura 6.19: Deformação da cerâmica PZT5A $(\mathrm{D} / \mathrm{H}=10)$ nos tempos: Esquerda: 0,1 a 0,4 $\mu \mathrm{s}, 0,7$ a $1 \mu \mathrm{s}$; Direita: 1,1 a $1,4 \mu \mathrm{s}$ e 1,7 a $2 \mu$ s (incrementos de $0,1 \mu \mathrm{s}$ ).
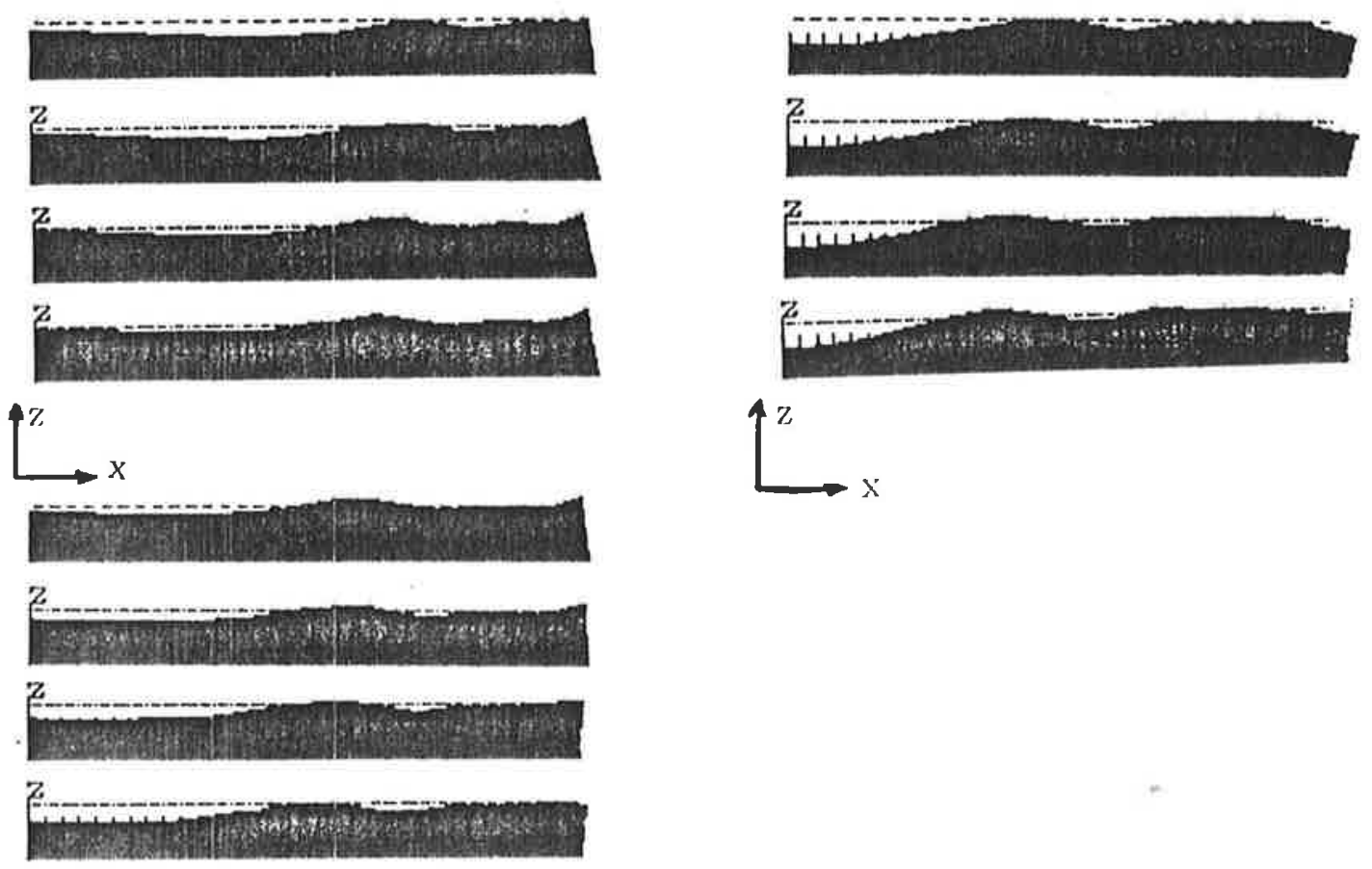

Figura 6.20: Deformação da cerâmica PZT5A (D/H=10) nos tempos: Esquerda: 2,7 a 3,4 $\mu \mathrm{s}$; Direita: 3,7 a $4 \mu$ (incrementos de $0,1 \mu \mathrm{s}$ ). 

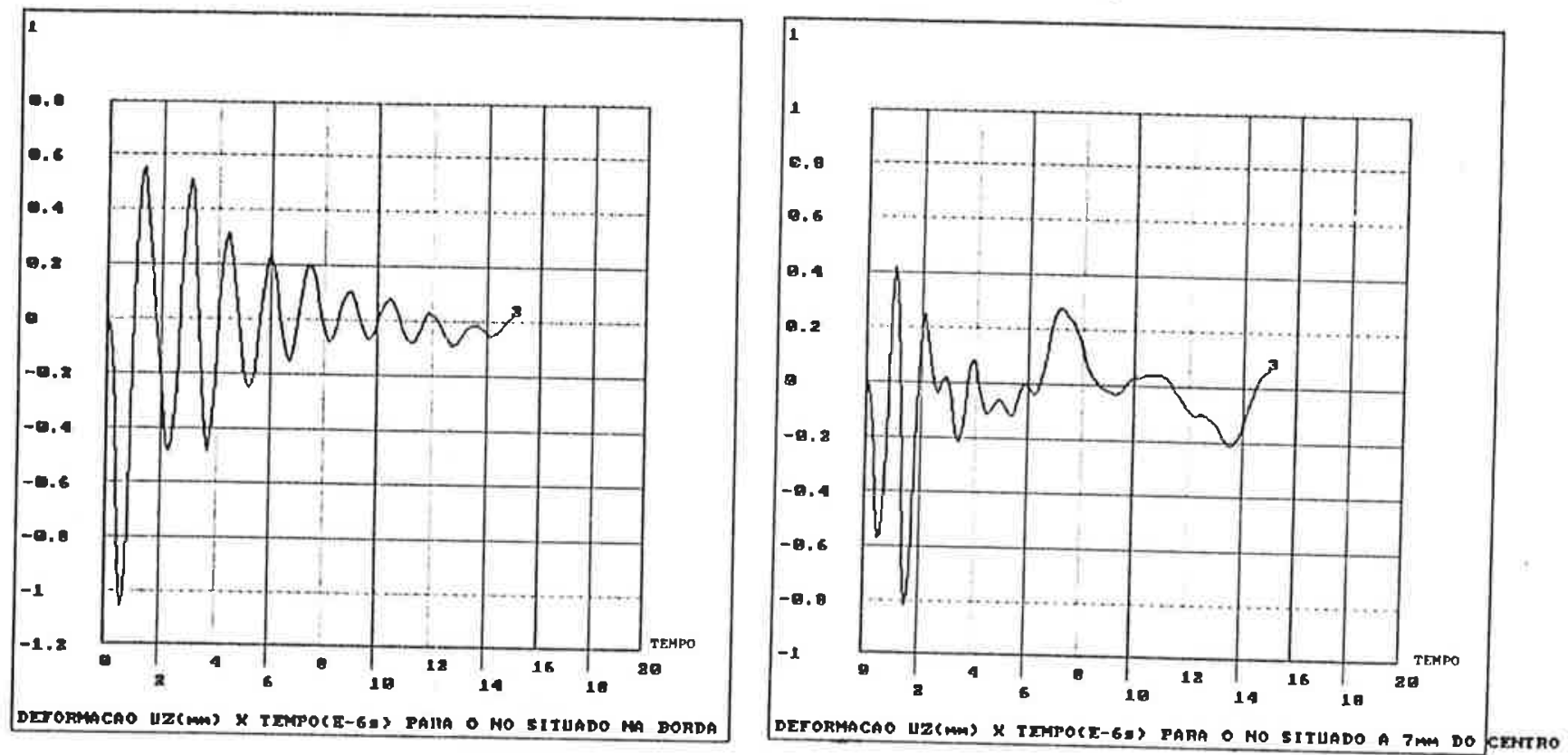

Figura 6.21: Deformação X tempo ( $\mu$ s) para o nó da borda (esquerda) e um nó situado a $7 \mathrm{~mm}$ do centro (direita).

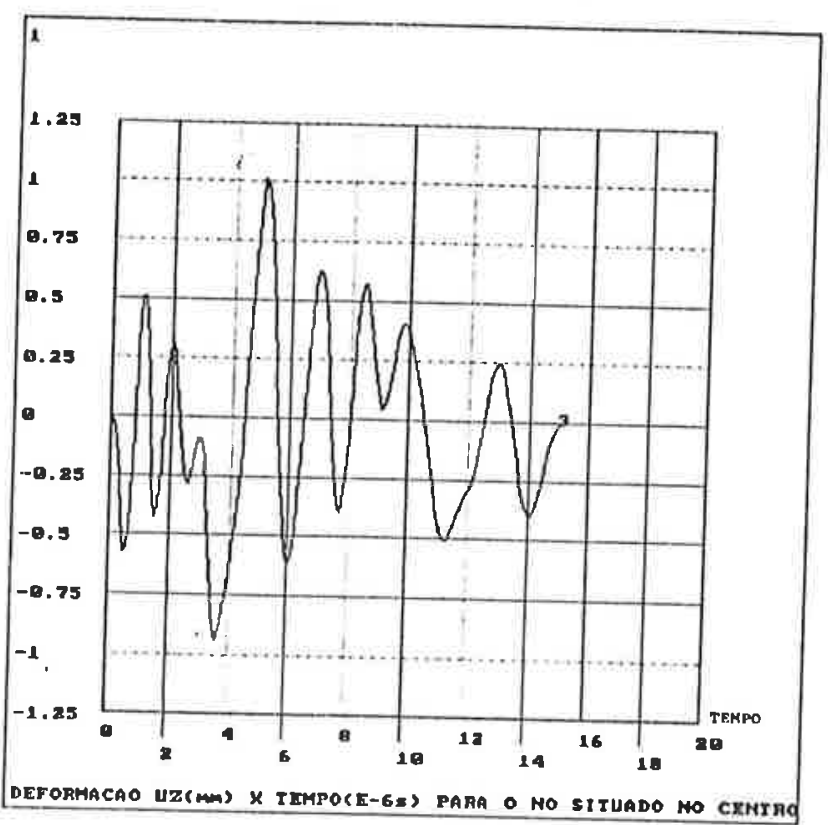

Figura 6.22: Deformação $\mathrm{X}$ tempo ( $\mu$ s) para o nó situado no centro. 


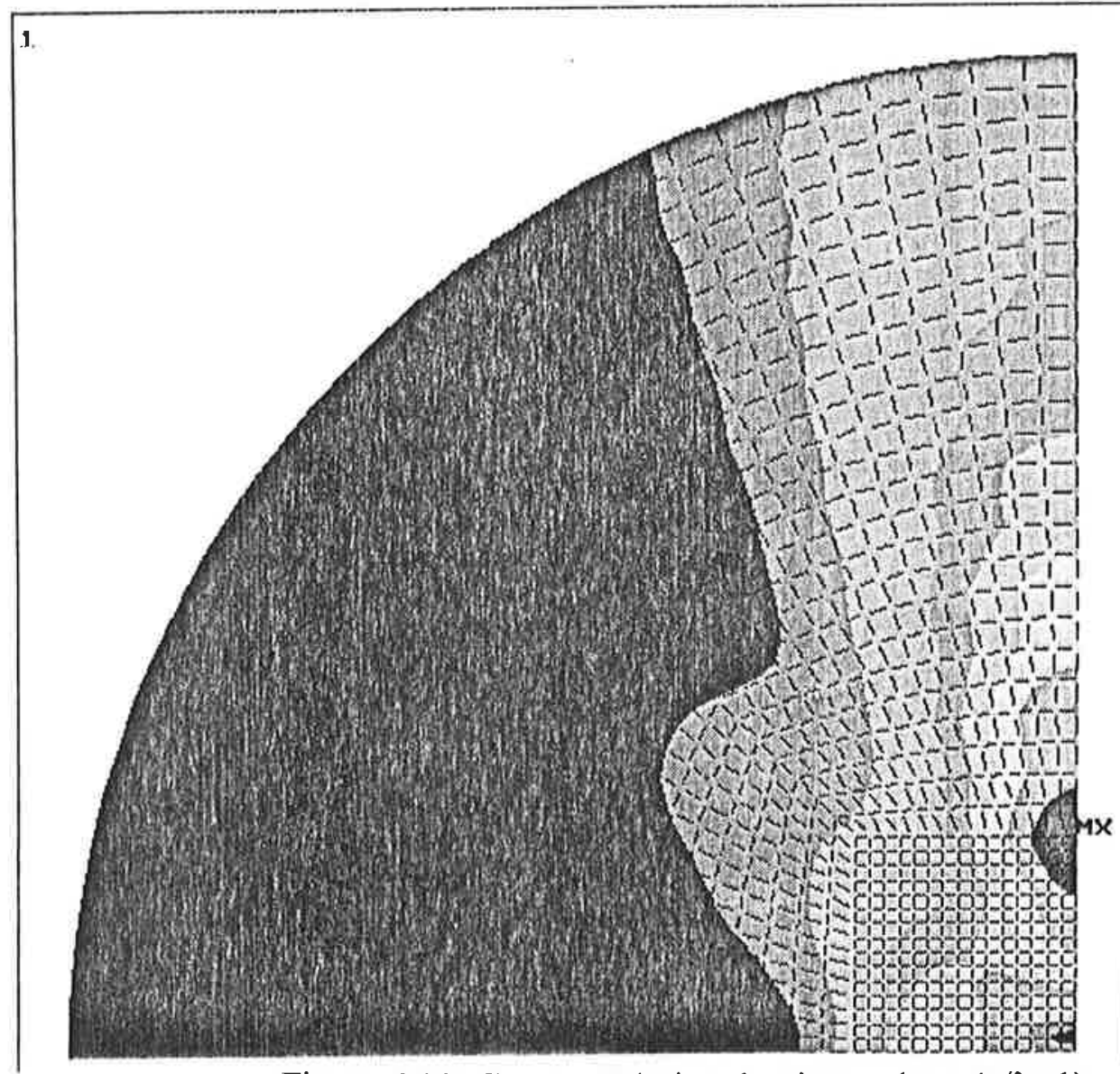

ANSYS $19 \dot{9}^{49}$

$17: 17: 43$

PLOT NO 1 TRES 3

I T ER=1

PRES

$\operatorname{Sin}=63095$

$\sin =0.851 \mathrm{E}+0$ ?

YU $=1.08$

$\times F=0.079978$

$\mathrm{ZF}=0.08$

PNGEI 1 BE H DDEN

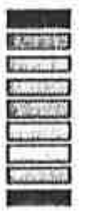
63095

Q.10日E+07

$0.194 \mathrm{E}+07$

Q. $288 \mathrm{E}+07$

Q.382E+ 97

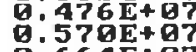

. $664 E+\theta^{7}$

Q.758E+9?

Figura 6.23: Campo acústico do pistão plano $(a / \lambda=1)$.

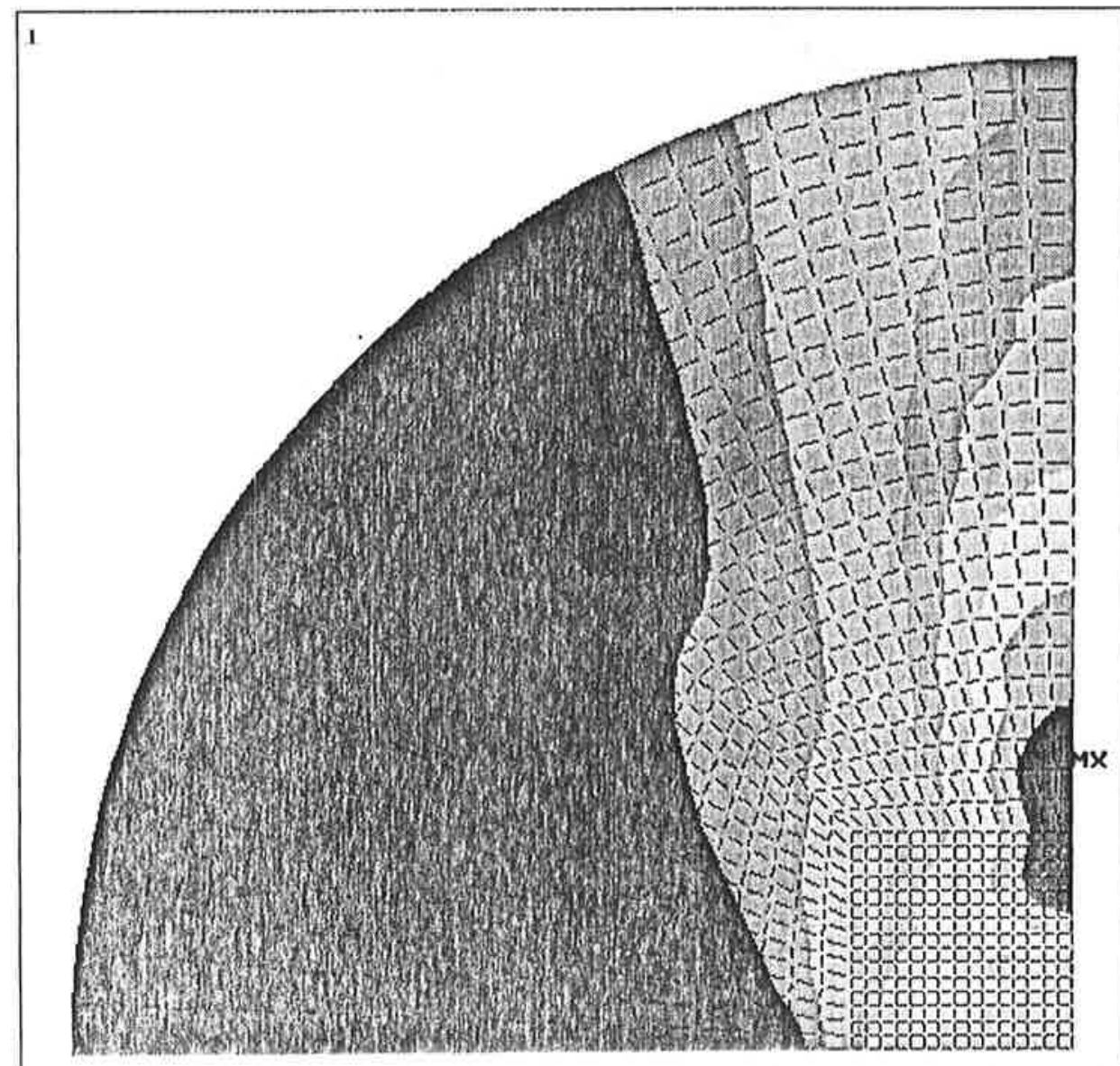

JANSYS $1993^{4 A}$

$16: 35: 41$

PLOT NOT
POST 1
STEP

ITER=1

ULZ (AUG)

SMN $=0.063243$
SiMX $=4.435$

Yu $=1$

DIST $=1,088$

$\times F=0.079978$

$\mathrm{ZF}=0.08$

ANGE= $18 B$ HIDDEN

0.003243

0.995631
0.988010

1.48

$\frac{1}{2}: 965$

2.958

$3: 492$

Figura 6.24: Distribuição das amplitudes de velocidade na direção Z (VLZ) para o pistão plano com $a / \lambda=1$. 


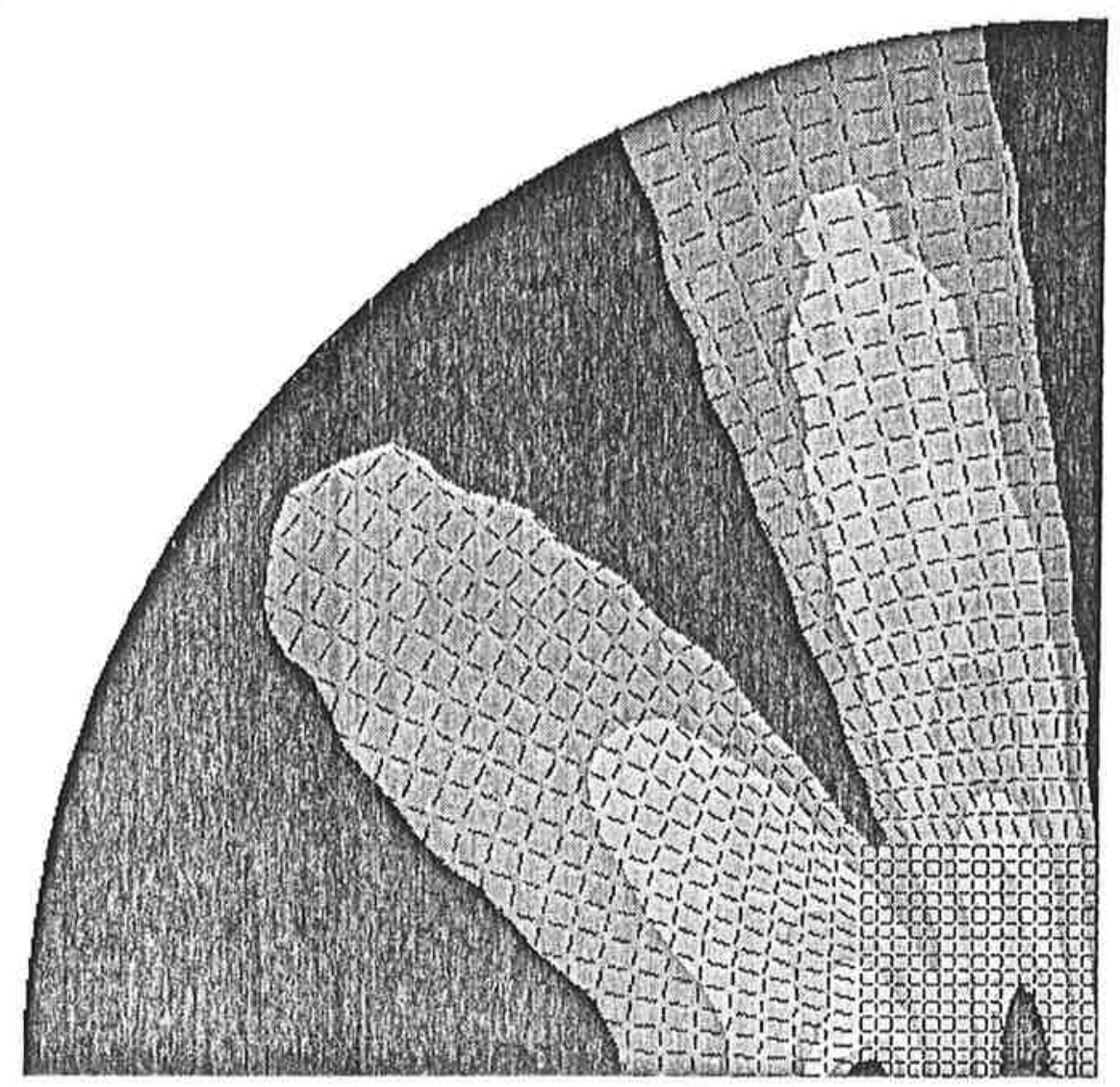

JANSYS $1999^{49}$

16:38:09

PLOT NOTHES
PTEP 19999 TTES
ITER=1

ULX (AUG)

SMN $=0.059581$

SMX $=1.509$

YU

$X F \quad=0.079978$

$2 F=0.68$

PRECI I

0.059581

0. 226646

Q. 38171

ด: 70384

0.8649

1.026

1.187

1:569

Figura 6.25: Distribuição das amplitudes de velocidade na direção X (VLX) para o pistão plano com $a / \lambda=1$.
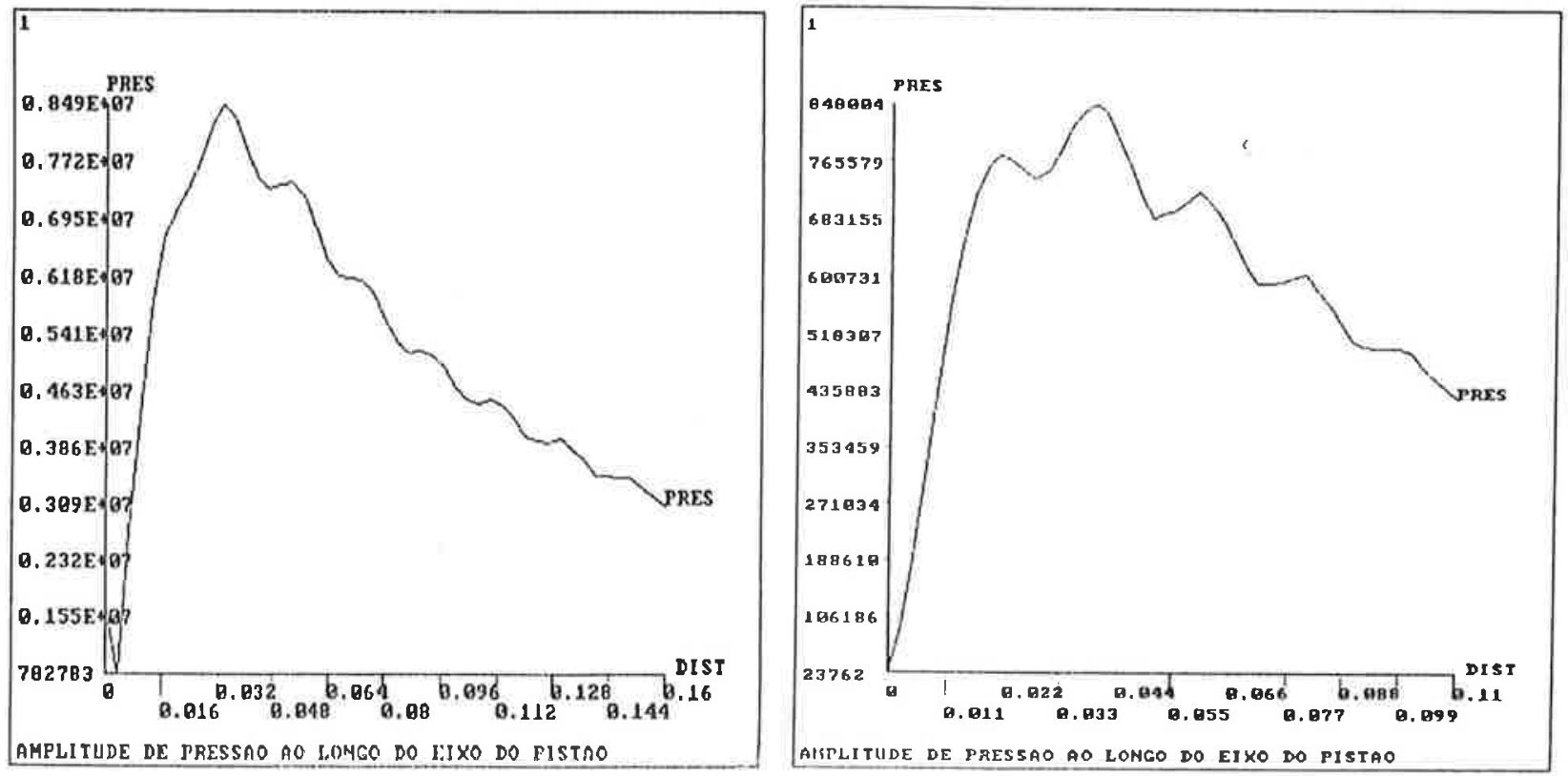

Figura 6.26: Gráfico da amplitude de pressão no longo do eixo do pistão. Esquerda discretizaç:ão fina; Direita - discretização grosseira. $(a / \lambda=1)$. 

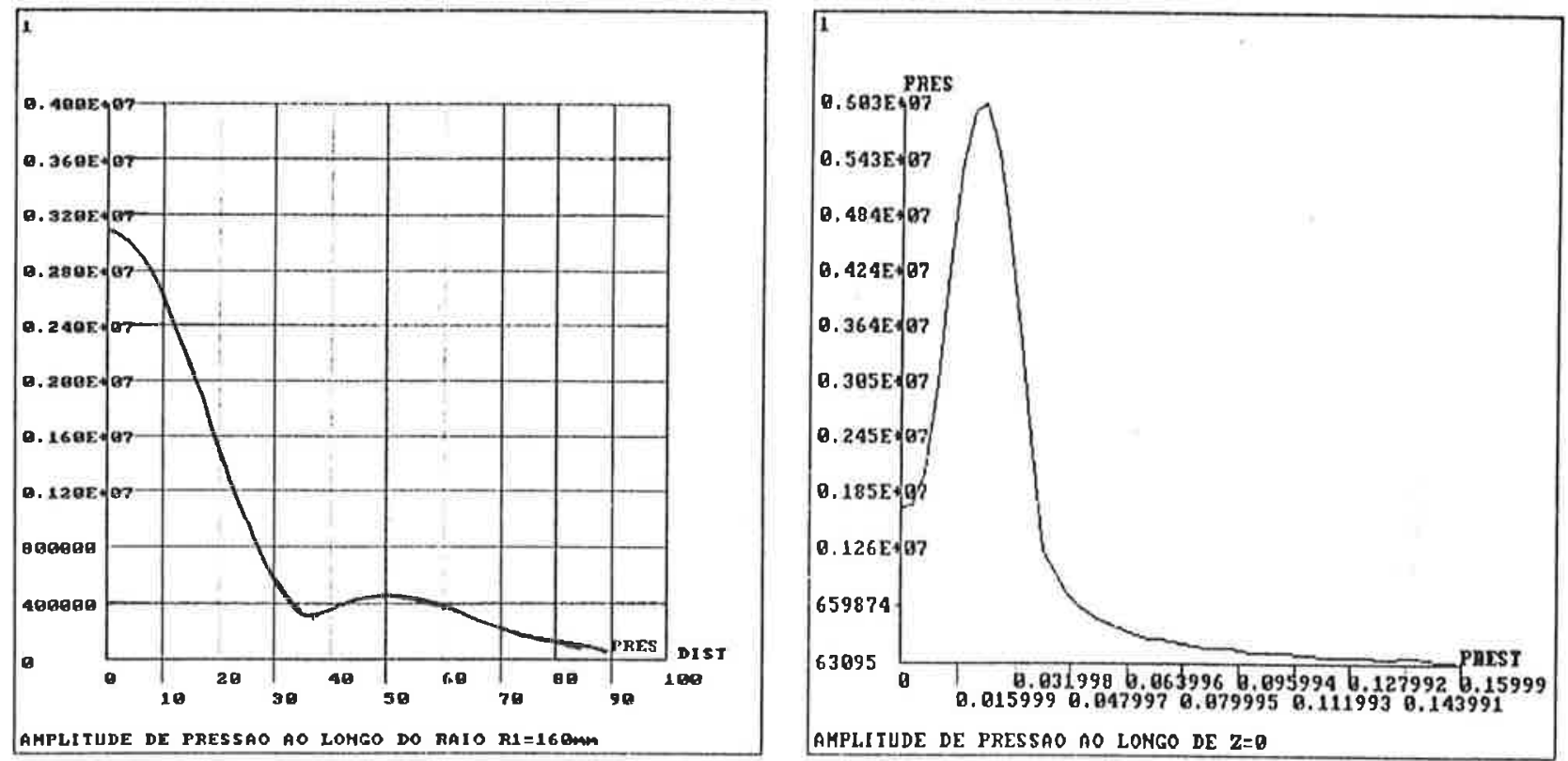

Figura 6.27: Esquerda - gráfico da amplitude de pressão ao longo do raio R 1 indicado $(a / \lambda=1)$; Direita - gráfico da amplitude de pressão ao longo do plano da face do pistão $(Z=0)(a / \lambda=1)$.
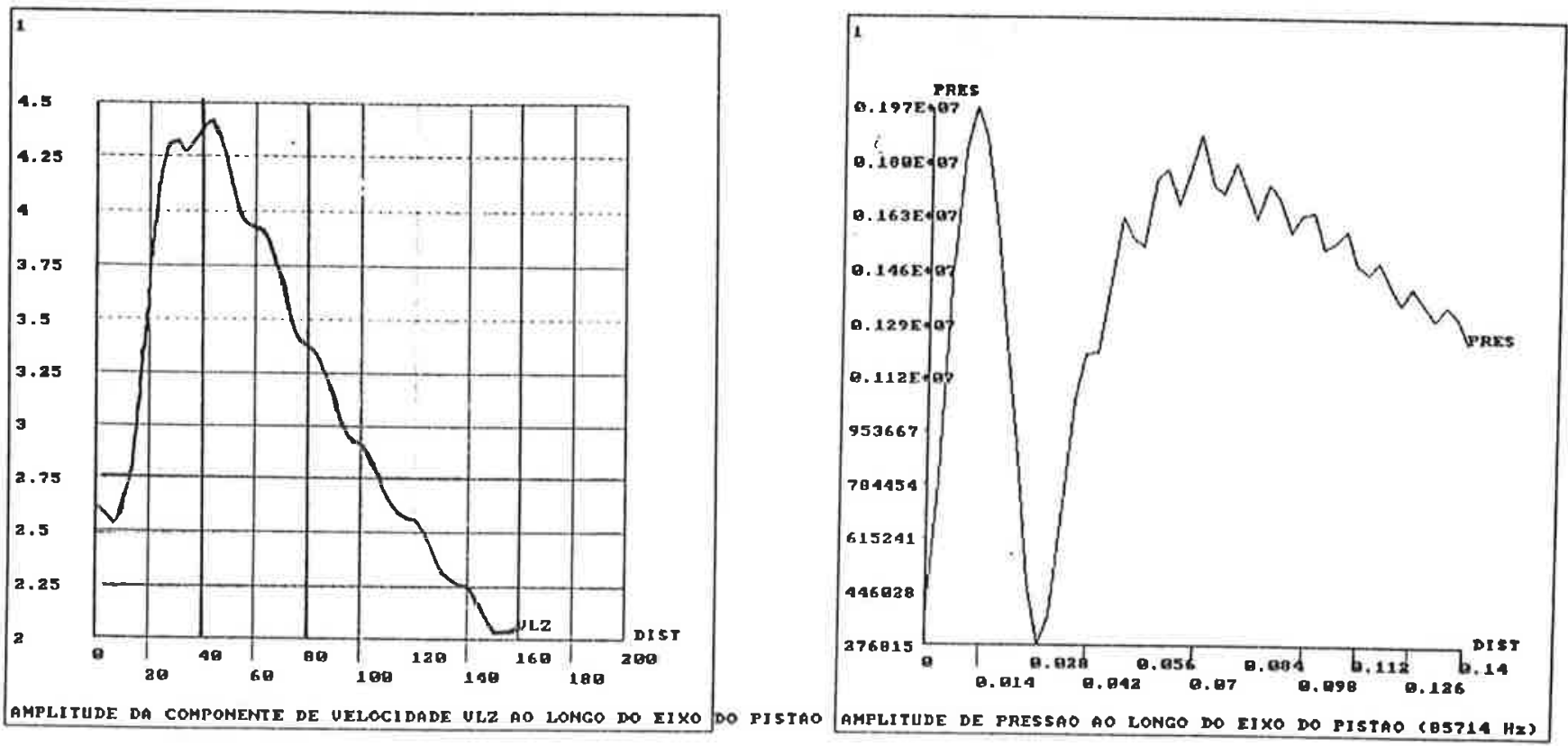

Figura 6.28: Esquerda - gráfico da amplitude velocidade VLZ ao longo do eixo do pistão $(\mathrm{a} / \lambda=1)$; Direita - gráfico da amplitude de pressão ao longo do eixo $(\mathrm{a} / \lambda=2)$. 

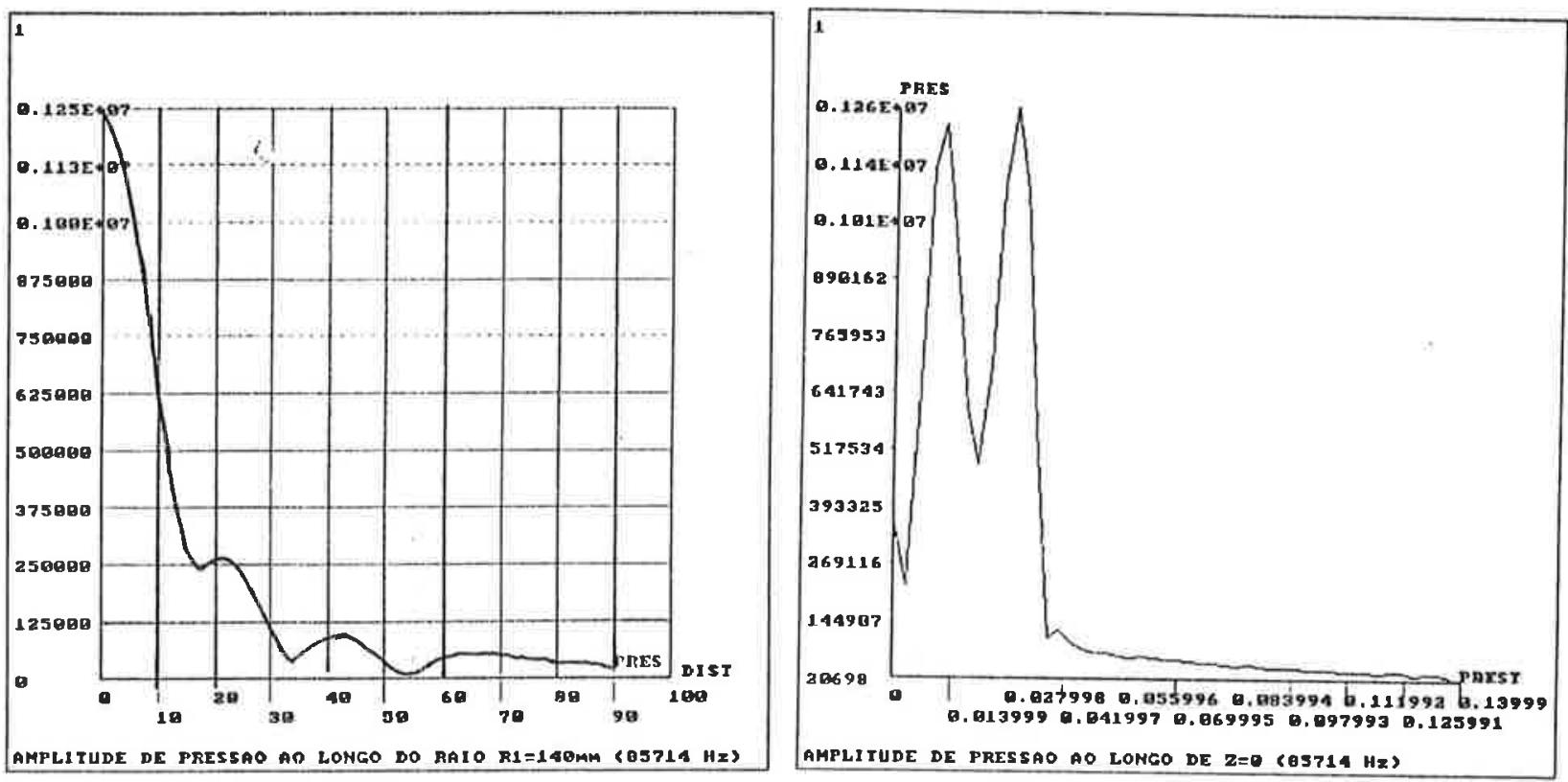

Figura 6.29: Esquerda - Amplitude de pressão ao longo do raio R1 indicado $(\mathrm{a} / \lambda=2)$; Direita - Amplitude de pressão ao longo do plano da face do pistão $(\mathrm{Z}=0)$ $(\mathrm{a} / \lambda=2)$.

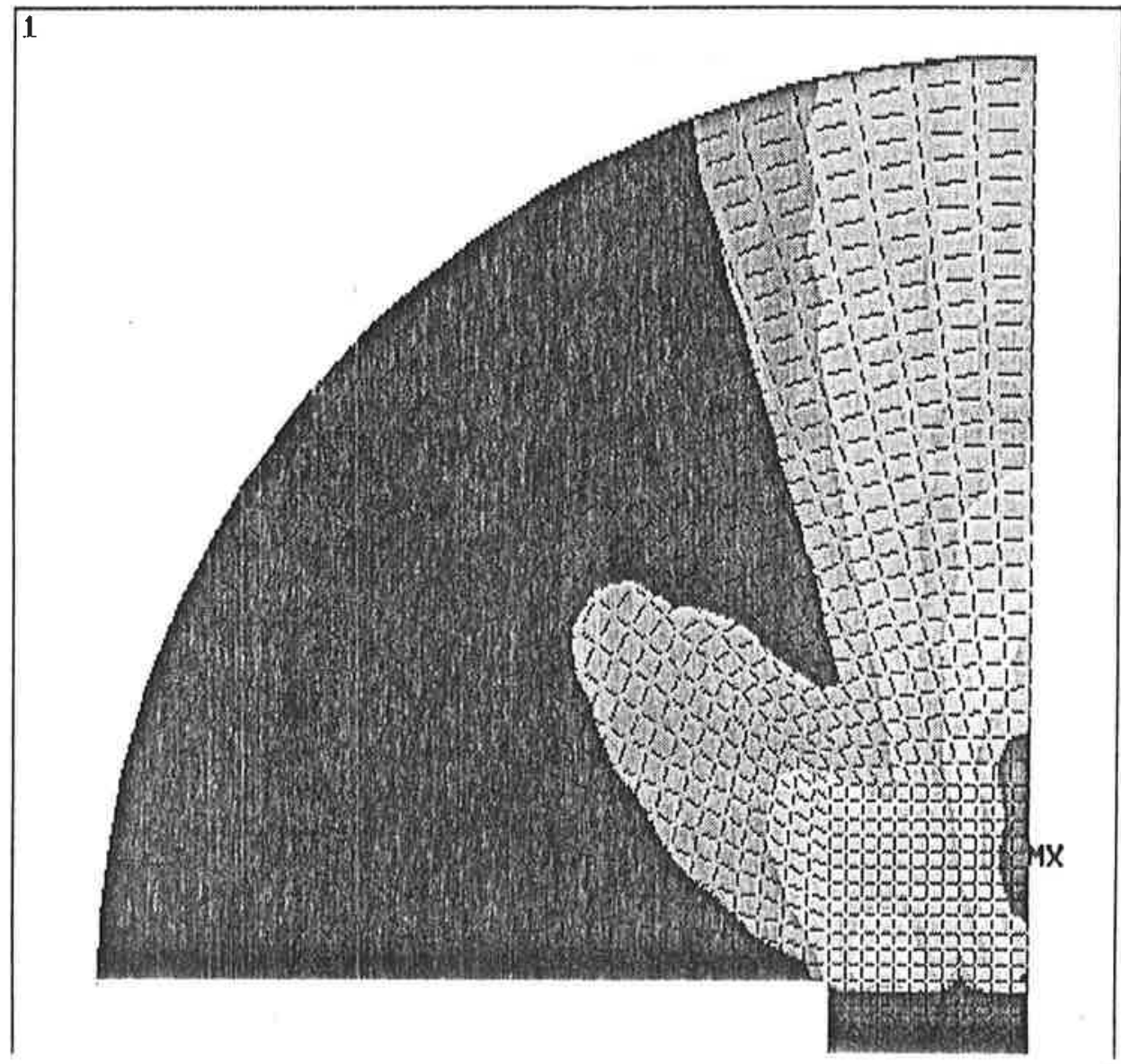

JANSYS $14.4 A$

10:09:30

PLOT NO.

POST1 STRESS

STEP $=9999$

ITER=1

SMX $=261.42$

YU $=1$

DIST $=0.0779$

$\mathrm{ZF}=0.06$

ANGZ $=180$

PRECISE HIDDEN

9
29.647
58.693
87.14
116.187
1.25
175.233
174.28
293.326
232.373
261.42

Figura 6.30: Campo acústico do transdutor $(\mathrm{a} / \lambda=1)$ - TCP1. 

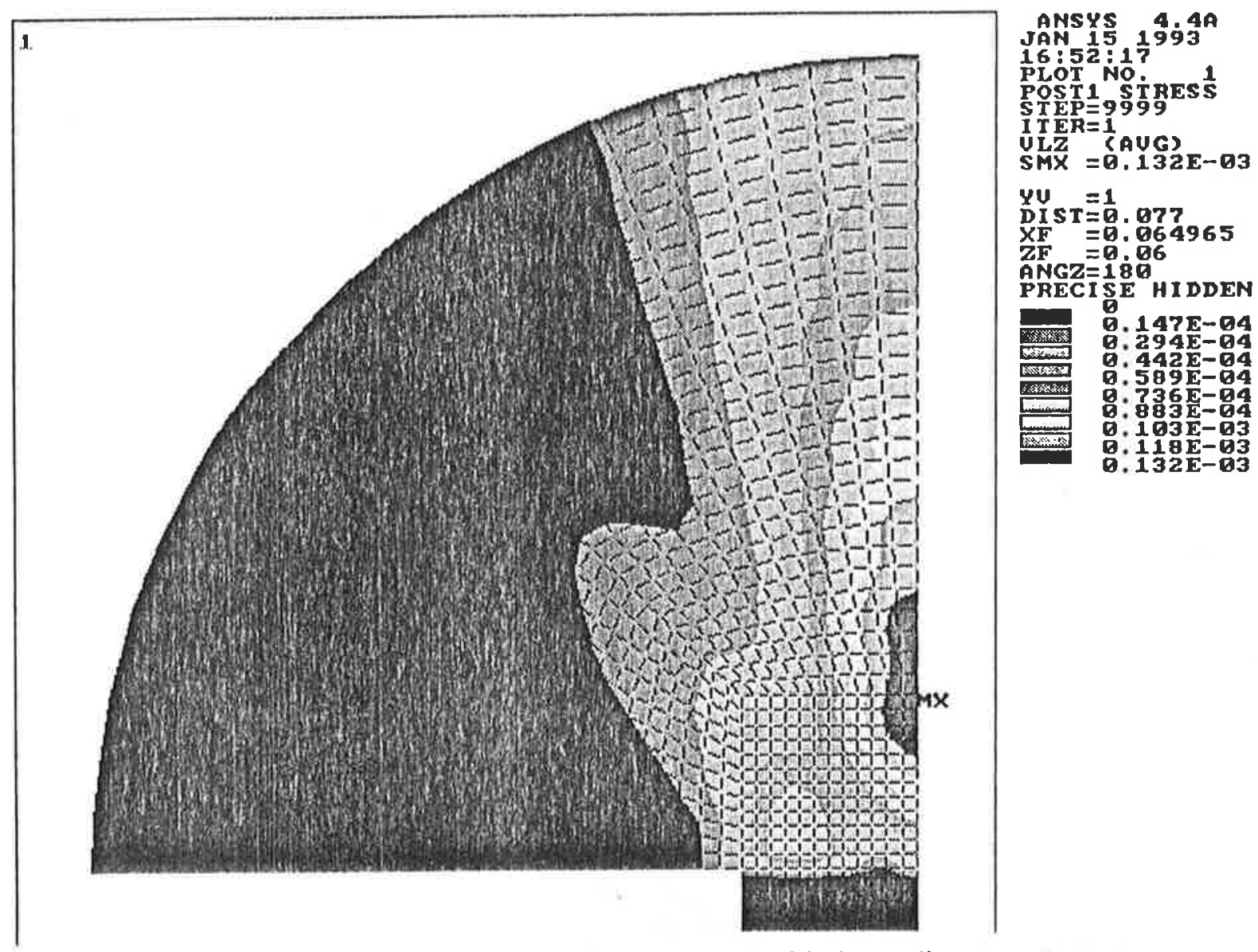

Figura 6.31: Distribuição das amplitudes de velocidade na direção $Z$ (VLZ) $(a / \lambda=1)$ TCP 1 .
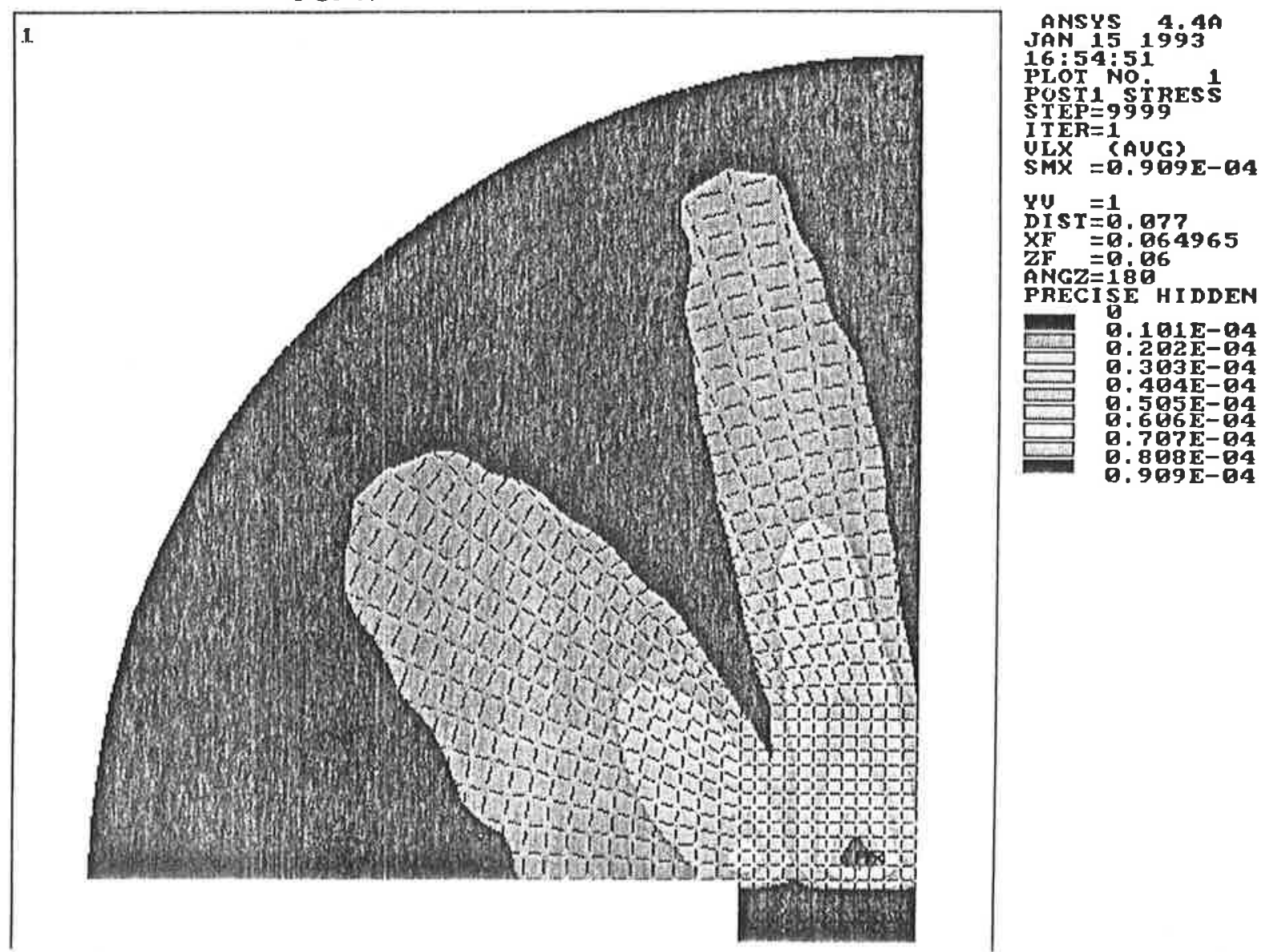

Figura 6.32: Distribuição das amplitudes de velocidade na direção X (VLX) $(a / \lambda=1)$ TCPI. 

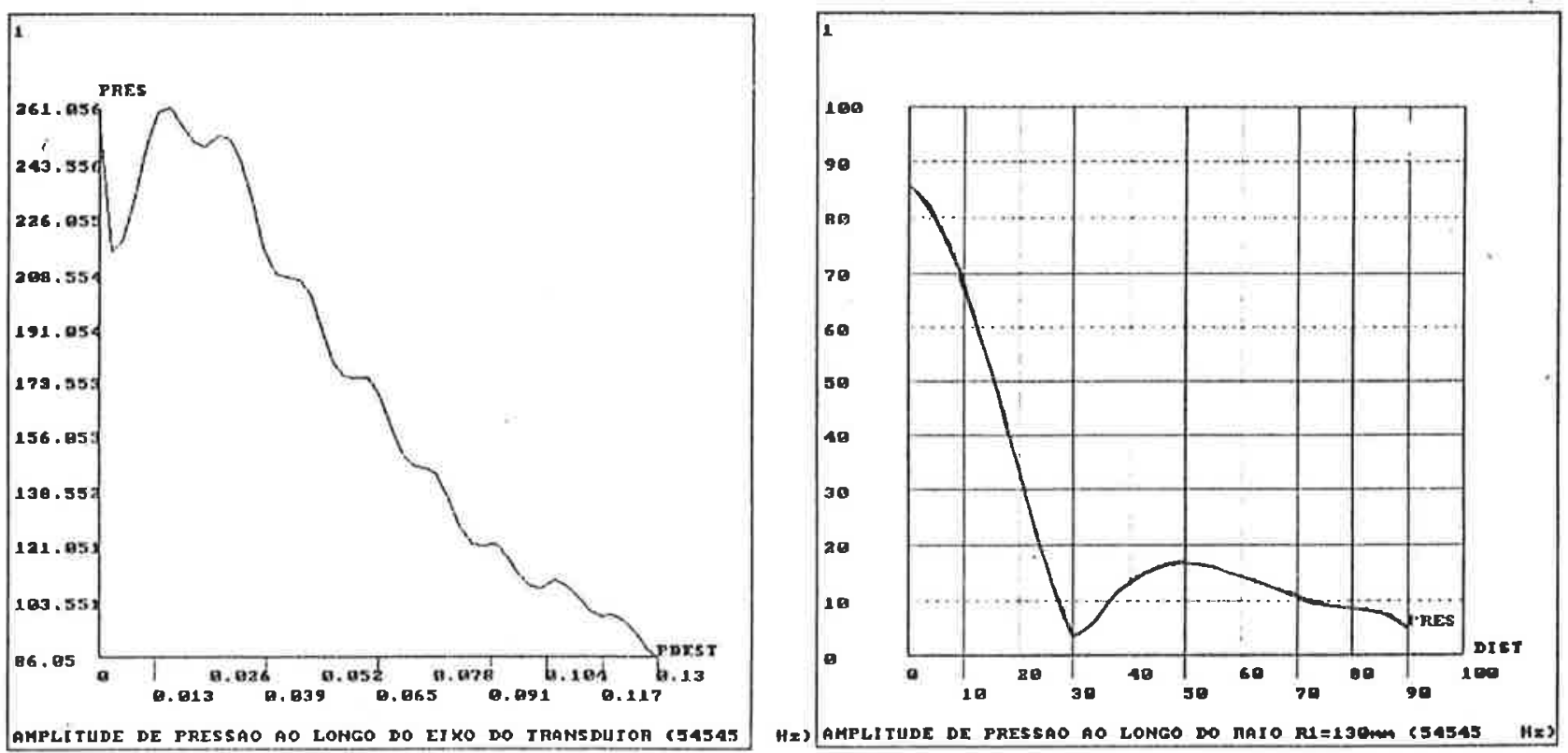

Figura 6.33: Esquerda - gráfico da amplitude de pressão ao longo do eixo do transdutor $(a / \lambda=1)$; Direita - gráfico da amplitude de pressão ao longo do raio R1 indicado $(a / \lambda=1)-$ TCP 1 .
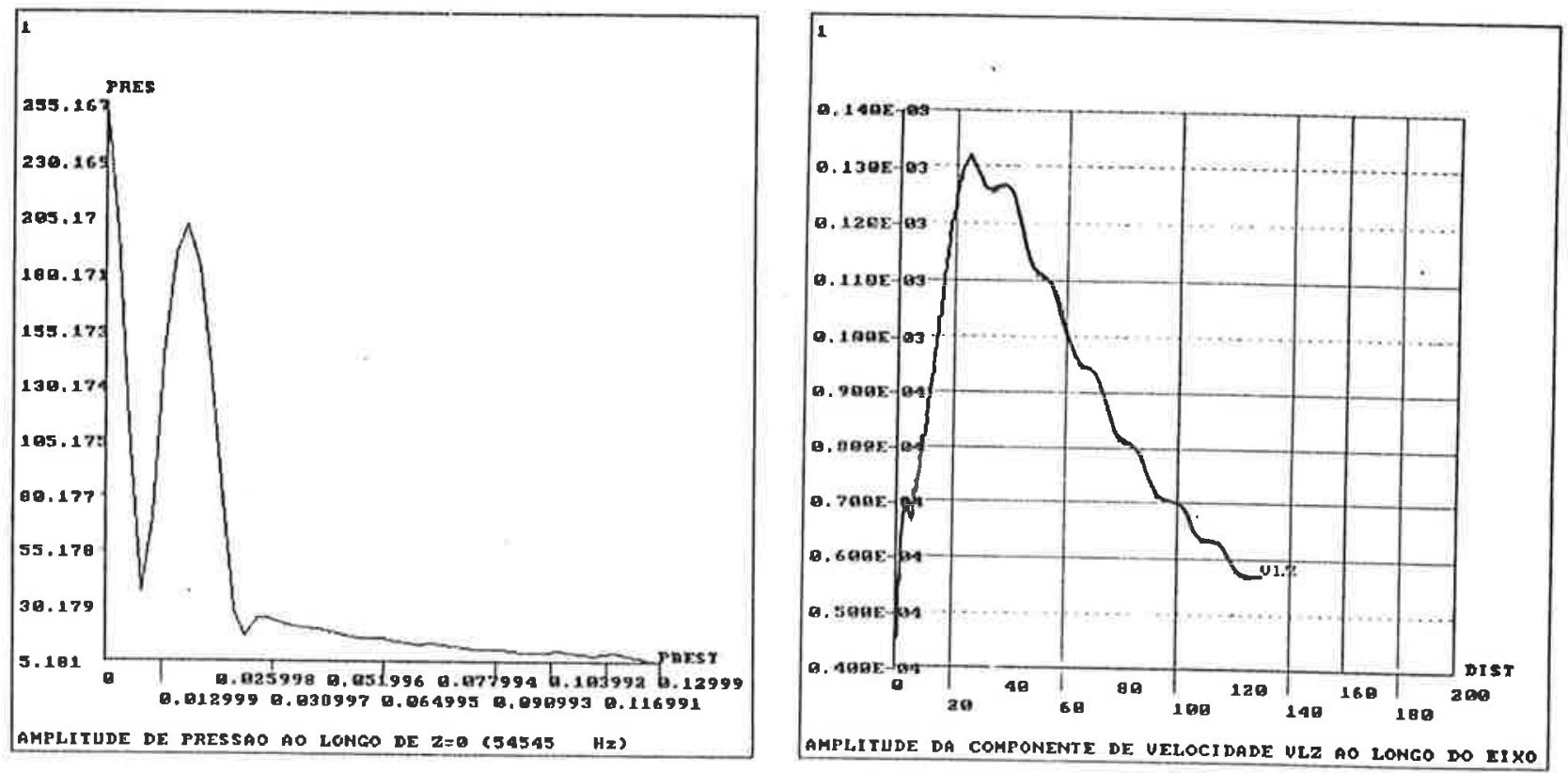

Figura 6.34: Esquerda - amplitude de pressão ao longo de $Z=0(a / \lambda=1)$; Direita amplitude da velocidade VLZ ao longo do eixo do transdutor $(a / \lambda=1)$ TCP1. 


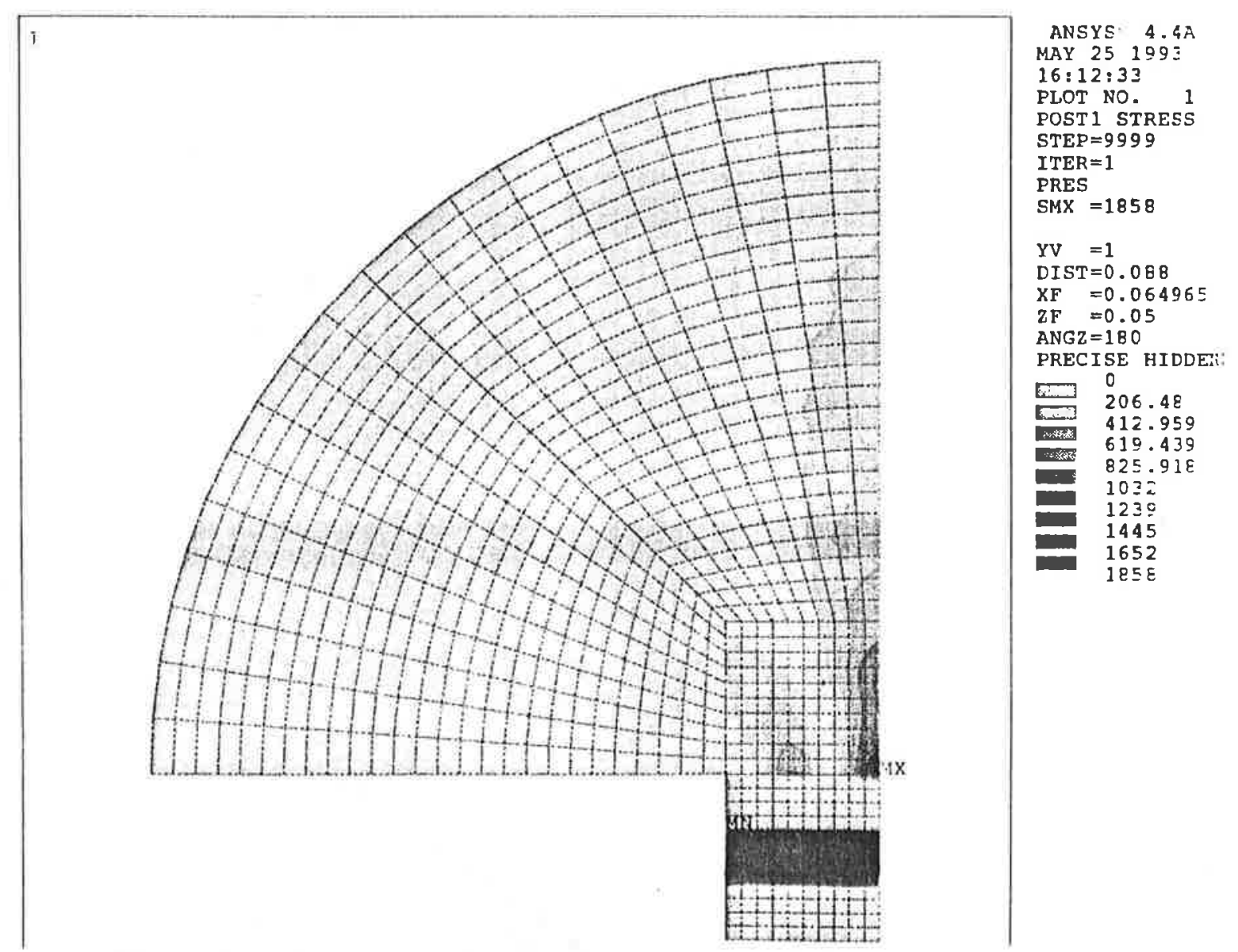

Figura 6.35: Campo acústico do transdutor $(\mathrm{a} / \lambda=1,31)$, considerando camadas de casamento e retaguarda - TCPMB.
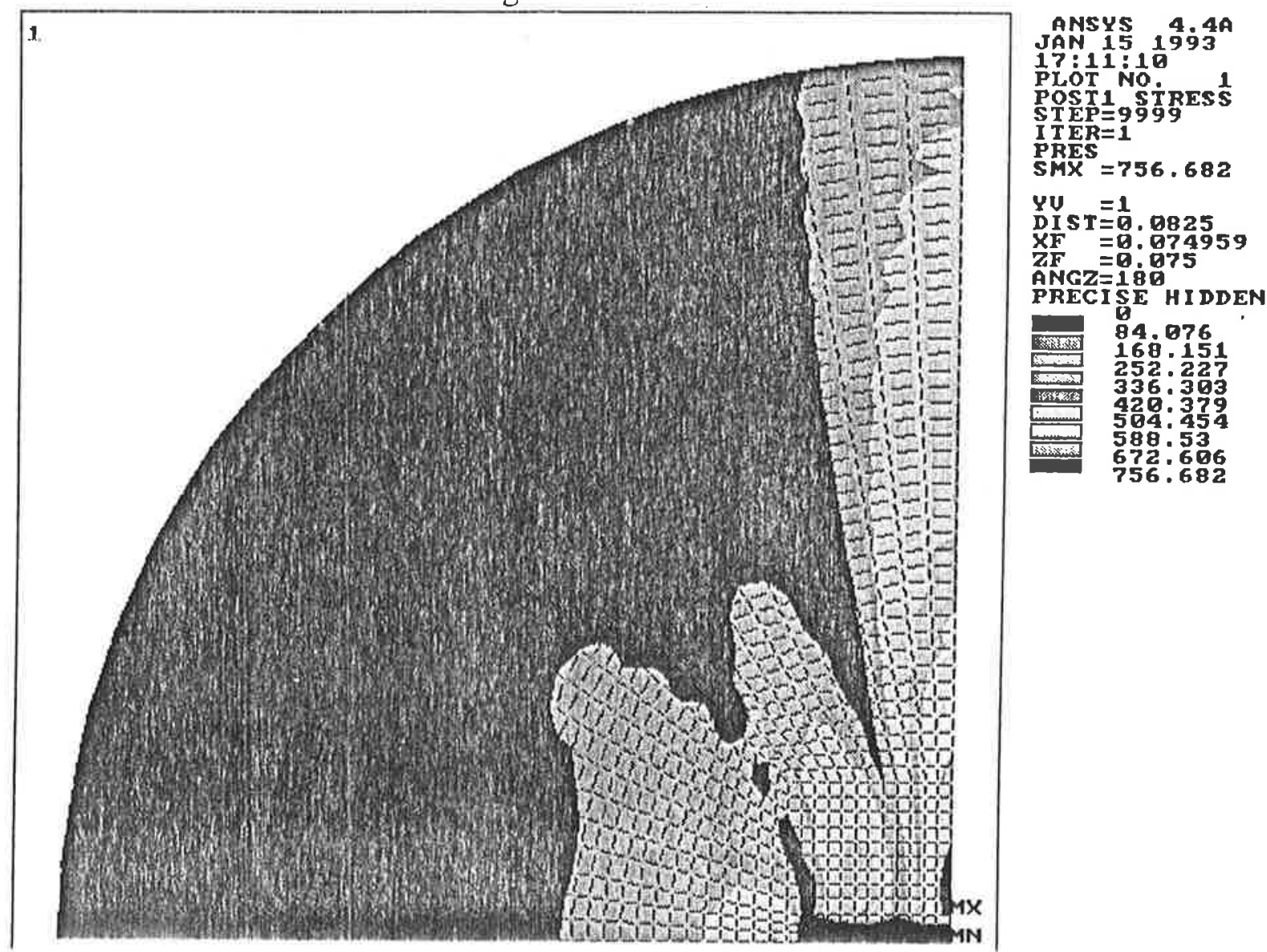

Figura 6.36: Campo acústico do transdutor $(\mathrm{a} / \lambda=1,5)$ - TCP2. 


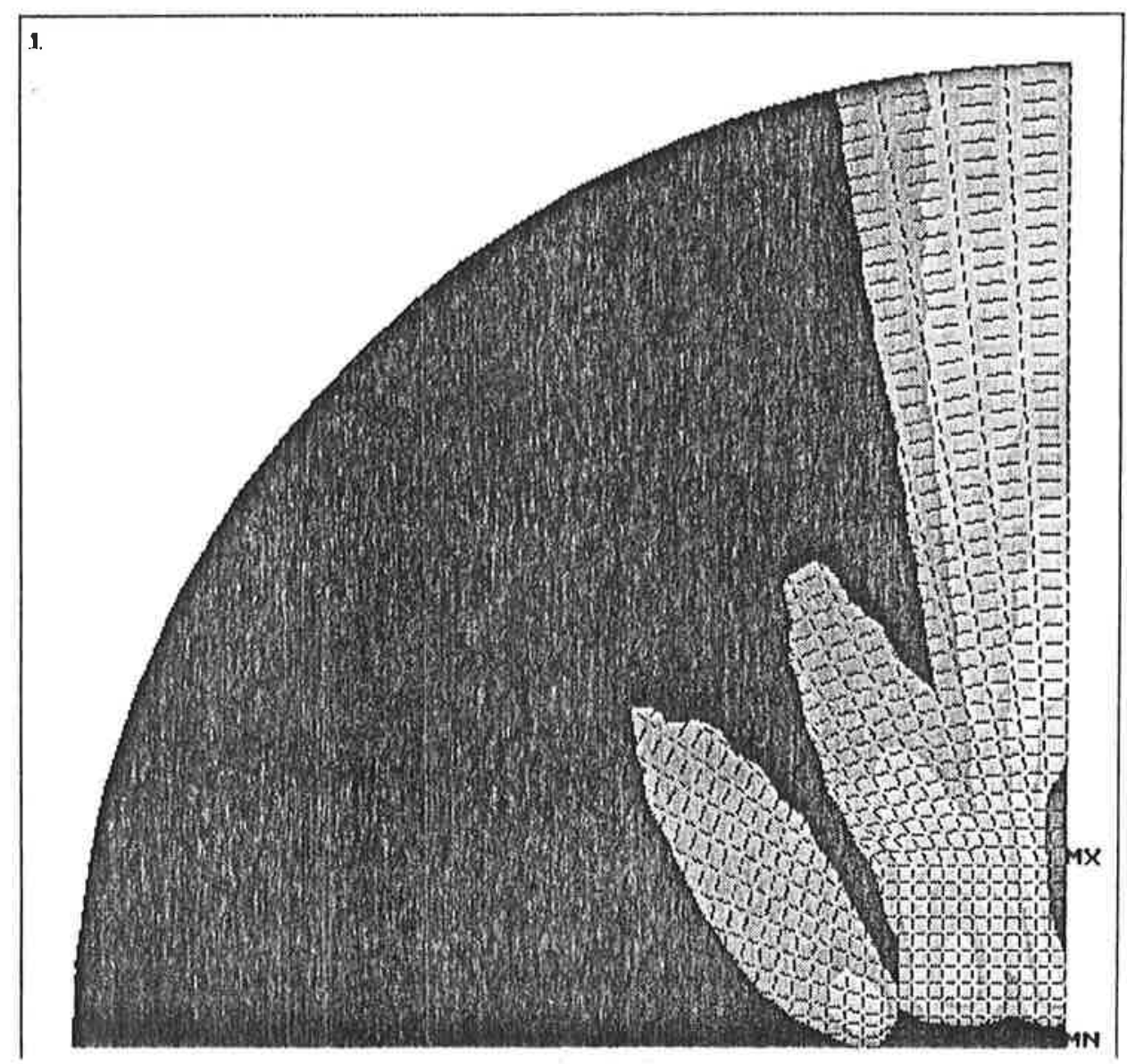

JANSYS $199^{4 A}$

17:24:51

PLOT NOT 1

ITER=1

SHX (AUG)

YU $=1$

DIST=0. 9825

$Z F=0.075$

ANGZ $=186$

PRECISE HIDDEN

$\longrightarrow$ D.

GE HI DDEN

F.323E- 04 . 647E-64

: $970 \mathrm{E}-04$

G: $162 \mathrm{E}-03$

0.226 E-03

$0.259 \mathrm{E}-03$

Figura 6.37: Distribuição da amplitude de velocidade na direção $Z$ (VLZ) $(a / \lambda=1,5)$ TCP2.

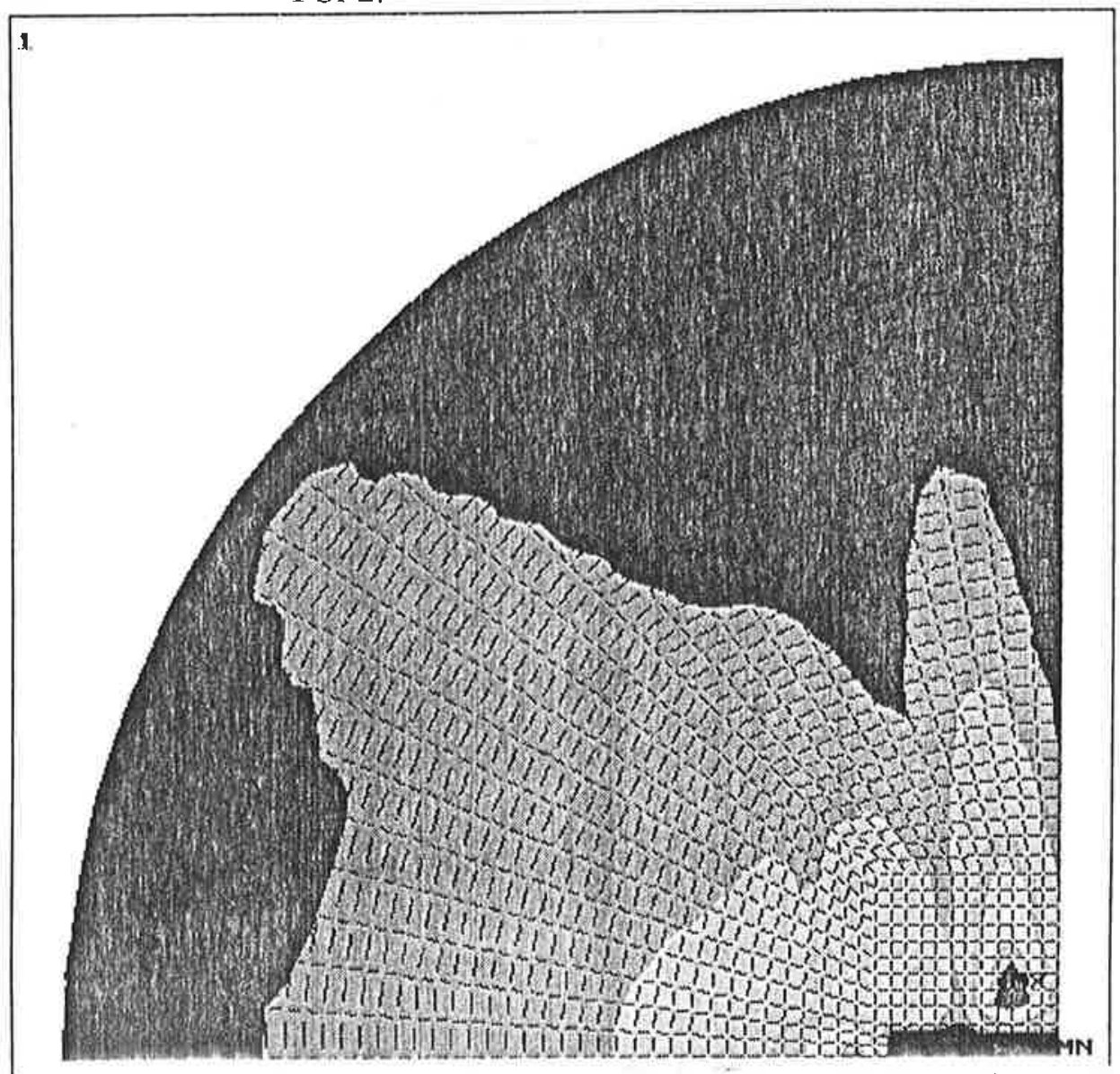

JANSYS $199^{4 A}$

PLOT Nó 1

I T ER $=1$

UTX (AUG)
SMX $=0.223 \mathrm{E}-63$

YU $=1.0825$

DIST $=0.6825$
$\times F \quad 0.97959$

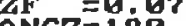

PRECISE

I SE HIDDEN

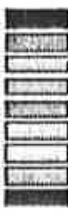

ด. $248 \mathrm{E}-04$

日. $248 \mathrm{E}-04$

G.745E-04

G. $993 \mathrm{E}-04$

פ.124 -03

: $149 \mathrm{E}-03$

0.174E-03

ด.199E-03

ด. 223E- -3

Figura 6.38: Distribuição da amplitude de velocidade na direção X (VLX) $(a / \lambda=1,5)$ TCP2. 

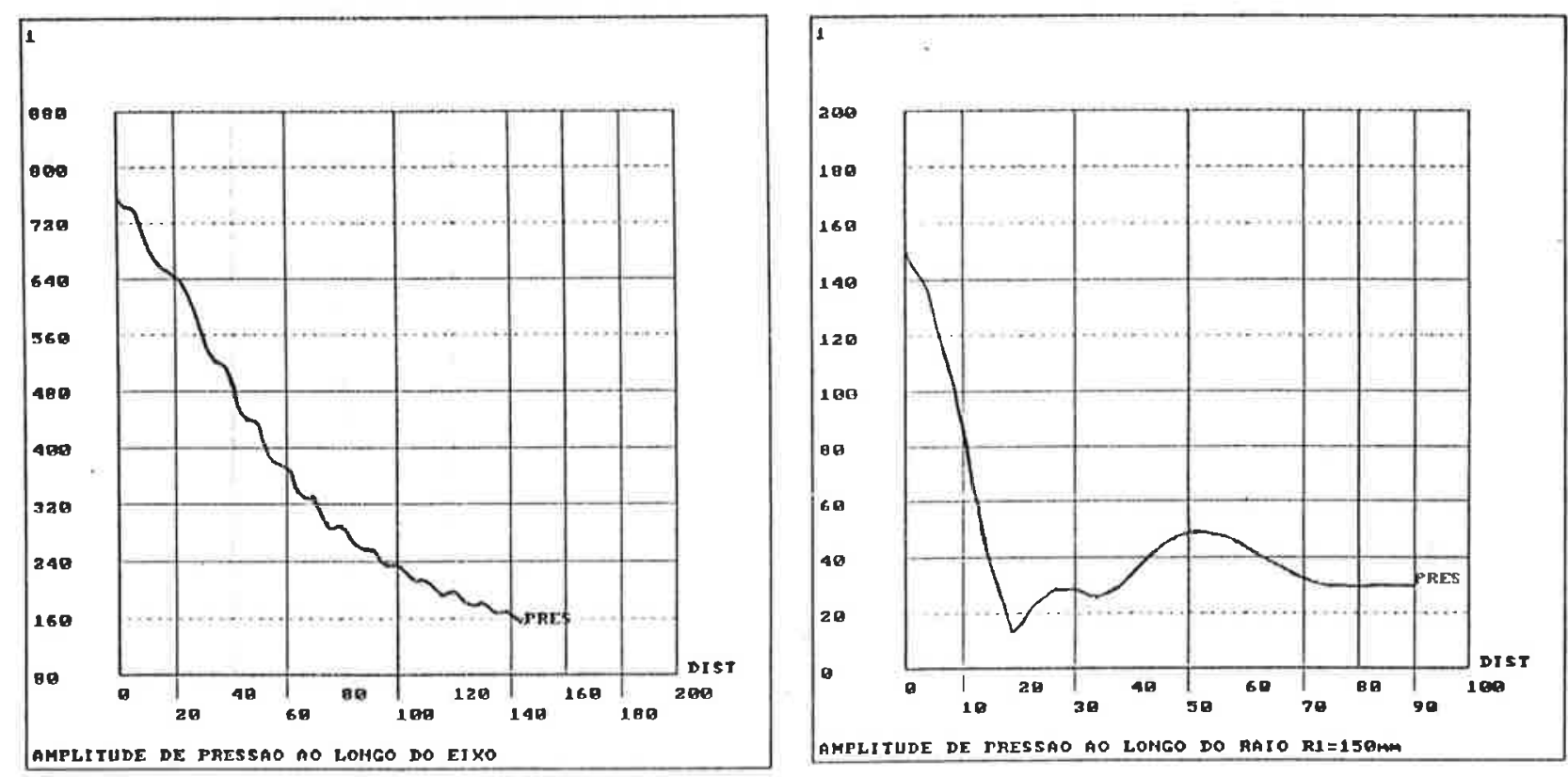

Figura 6.39: Esquerda - amplitude de pressão ao longo do eixo do transdutor $(a / \lambda=1,5)$; Direita - amplitude de pressão ao longo do raio $\mathrm{R} 1$ indicado $(\mathrm{a} / \lambda=1,5)$ TCP2.
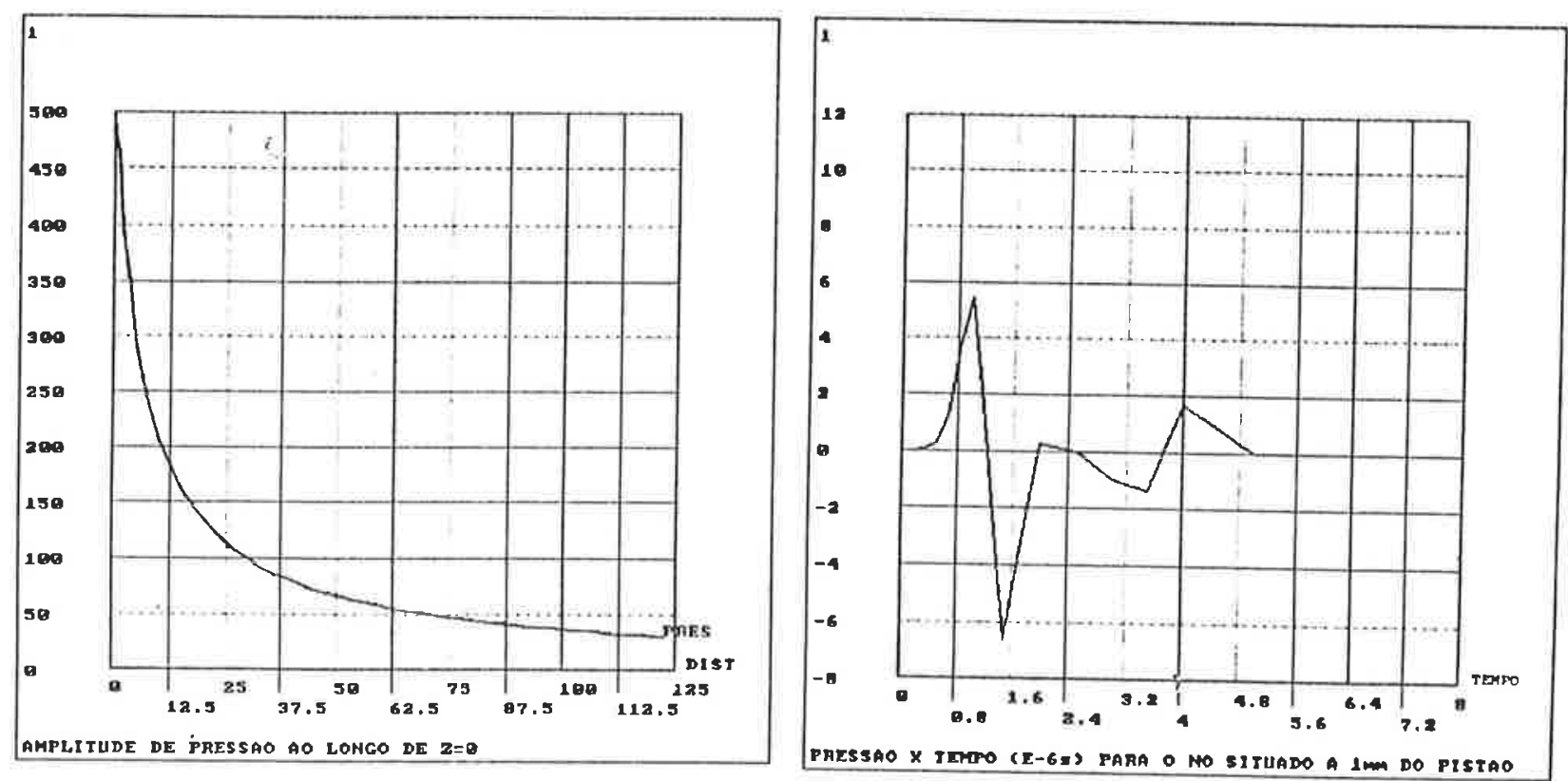

Figura 6.40: Esquerda - amplitude de pressão ao longo de $Z=0(a / \lambda=1,5)$; Direita amplitude de pressão $X$ tempo ( $\mu s)$ para um nó situado a $1 \mathrm{~mm}$ da face do pistão $(a / \lambda=3)$. 

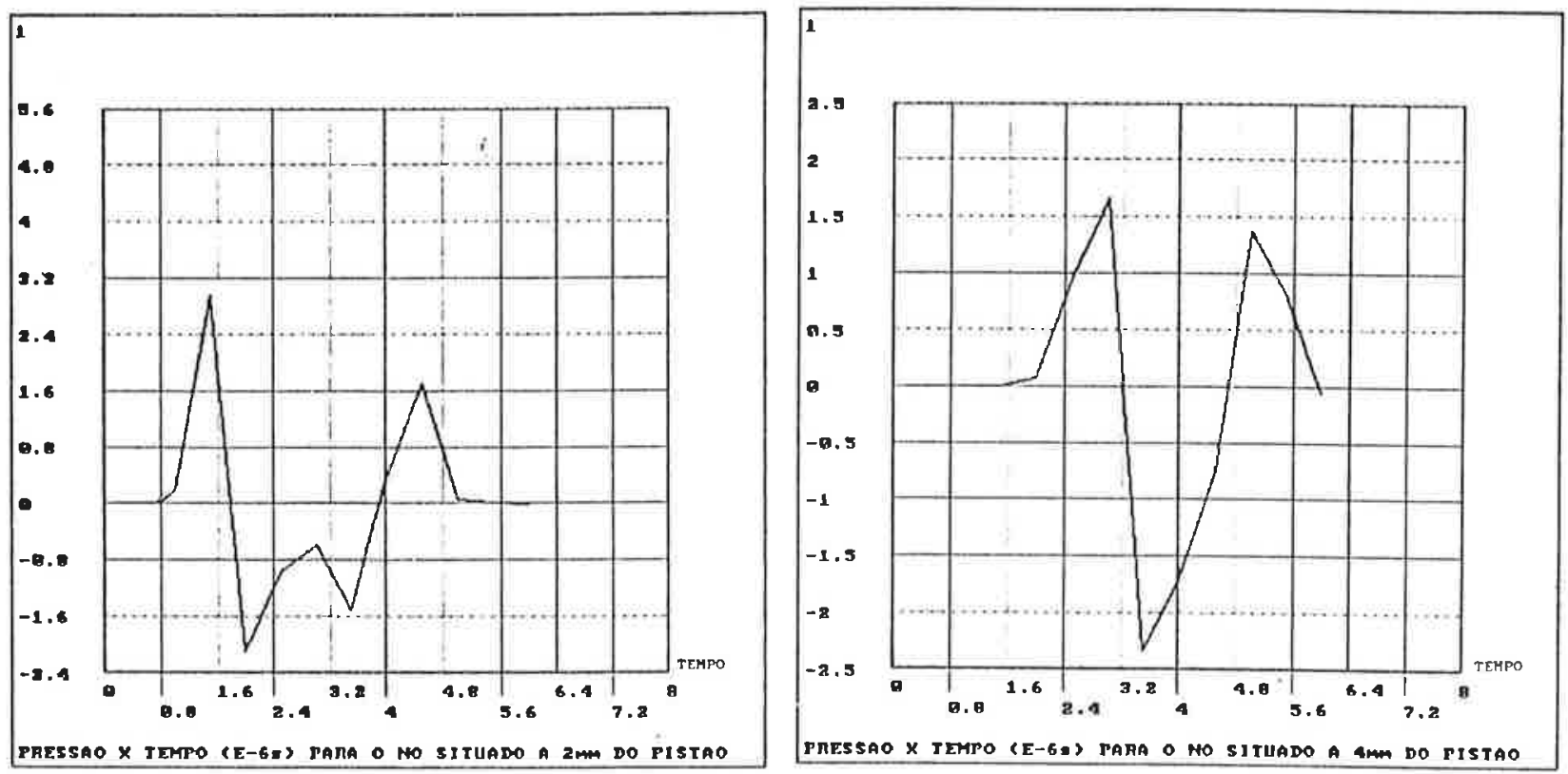

Figura 6.42: Esquerda - amplitude pressão $X$ tempo ( $\mu \mathrm{s})$ para um ponto situado a $2 \mathrm{~mm}$ da face do pistão $(a / \lambda=3)$; Direita - amplitude de pressão $X$ tempo $(\mu \mathrm{s})$ para um ponto situado a $4 \mathrm{~mm}$ da face do pistão $(\mathrm{a} / \lambda=3)$.

1
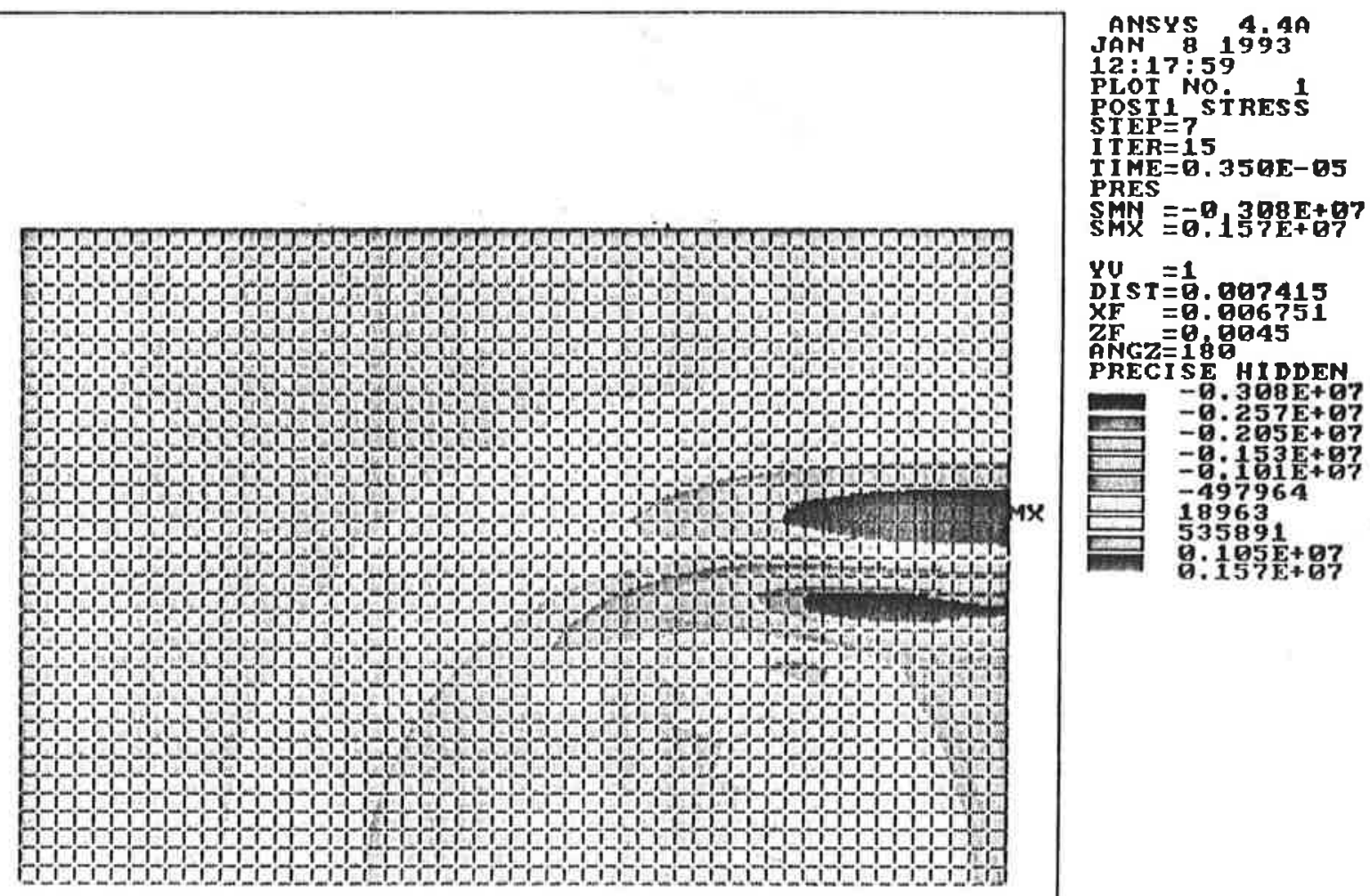

PROPAGACAO DA ONDA EMITIDA POR UM PISTAO PLANO

Figura 6.41: Campo acústico do pistão num dado instante $(a / \lambda=3)$. 


\section{Capítulo 7}

\section{Conclusões}

Foram apresentadas as bases teóricas do MEF piezoelétrico e do MEF aplicado à acústica, discutindo a obtenção das características vibracionais do transdutor e seu campo acústico. As hipóteses adotadas na construção dos modelos, bem como a utilização do software ANSYS na análise piezoelétrica foram comentadas.

Através da análise modal determinou-se as freqüências de ressonância, anti-ressonância, modos de vibrar e o coeficiente de acoplamento piezoelétrico $(K)$. A obtenção experimental das freqüências do transdutor através de um impedômetro fasorial e a visualização dos modos através de uma técnica de interferometria laser se mostraram importantes para a aferição dos modelos do MEF. A concordância dos resultados teóricos com os experimentais foi satisfatória.

Verificou-se, como esperado, que os primeiros modos (modos radiais) são fortemente acoplados, apresentando os mais altos $K \mathrm{~s}$. Além destes o modo, denominado modo da espessura, que se caracteriza por apresentar um deslocamento médio positivo e um perfil de deformações suaves em relação aos demais, também apresenta um al to $K$, sendo portanto indicado para emissão de ondas de compressão num fluido.

A curva de admitância obtida pelo MEF foi comparada com a experimental apresentando concordância satisfatória, principalmente a medida que o amortecimento (estrutural e dielétrico) é considerado.

$\mathrm{Na}$ análise da apodização discutiu-se três tipos diferentes de funções crescentes com o raio (linear, cossenoidal e gaussiana). Em todos os casos houve uma redução do acoplamento dos modios, entretanto a função gaussiana forneceu a menor redução. No caso da apodização com uma função cossenoidal decrescente, a variação dos $K$ s foi pequena, indicando que o desacoplamento dos modos é menor com esse tipo de função. Outras formas de apodização podem ser estudadas, como por excmplo variando-se a geometria do disco piezoelétrico ao longo do raio.

A análise transiente, realizada com o objetivo de analisar o comportamento do transdutor excitado por um pulso banda larga permitiu visualizar a propagação das ondas 
"head waves" ao longo do raio, além de mostrar o comportamento de pistão rígido da cerâmica nos primeiros $\mu \mathrm{s}$ do movimento.

Através do $\mathrm{MEF}$ aplicado à acústica obteve-se o campo acústico gerado pelo transdutor, levando-se em conta o acoplamento fluido-estrutura. A modelagem do fluido infinito foi conseguida através de uma parede fictícia com absorção igual a $1(\beta=1)$ situada na região do campo distante do transdutor. Dois tipos de condições de contorno foram consideradas: o transdutor circundado por um refletor rígido perfeito e o transdutor totalmente imerso no fluido. Em outro modelo levou-se em conta também as camadas de casamento e retaguarda. Os resultados obtidos permitem verificar o afastamento do campo acústico do transdutor em relação ao modelo do pistão plano (também modelado), bem como a influência da presença do fluido no modo de vibrar do transdutor (surgimento de uma parte complexa). Outras condições de contorno podem ser discutidas, bem como a influência da distância entre a parede fictícia e o transdutor nos resultados.

Utilizando-se os perfis de velocidade obtidos com o MEF (que levam em conta o acoplamento fluido-estrutura) pode-se, através de um programa analítico, calcular o campo acústico, o que exige uma capacidade computacional menor. Devido à capacidade computacional disponível atualmente, uma análise eficiente e rápida está limitada a uma relação $a / \lambda \leq 4$, pois caso contrário haverá um grande número de elementos ocasionando problemas de espaço em disco. Dessa forma atualmente o MEF seria recomendado principalmente para o projeto de hidrofones.

A realização de uma análise transiente acústica permitiu visualizar as ondas plana e de borda emitidas por um pistão plano, permitindo estudar a propagação de ondas em fluidos. Esta análise pode ser extendida para a propagação de ondas em sólidos, e futuramente para o estudo de ondas emitidas por um transdutor num sólido, de grande aplicação em END. 


\section{Bibliografia}

[Allik 70] ALLIK, H. and HUGHES, T. J. R., "Finite Element Method for Piezoelectric Vibration", International Journal for Numerical Methods in Engineering, vol. 2: pp.151-157, 1970.

[Allik 74] ALLIK, H. and WEBMAN, K. M., "Vibrational Response of Sonar Transducers Using Piezoelectric Finite Elements", J. Acoust. Soc. Am., vol. 56, no 6: pp.1782-1791, december, 1974.

[ANSYS] DESALVO, G. J. and GORMAN, R. W., ANSYS Engineering Analysis System User's Manual, Swason Analysis System, Inc., Houston, PA, 15342: Vol.I and II, may, 1989.

[Asher 83] ASHER, R. C., "Ultrasonic Sensors in the Chemical and Process Industries", Invited Review Article, J. Phys. B. Sci. Instrum, vol. 16, pp.959$963,1983$.

[Bathe 82] BATHE, K. J., Finite Element Procedures in Engineering Analysis, Prentice-Hall, Inc., Englewood Cliffs, New Jersey 07632, USA, 1982.

[Berlincourt 64] BERLINCOURT, D. A., CURRAN, D. R. and JAFFE, H., "Piezoelectric and Piezomagnetic Materials and Their Function in Transducers", Physical Acoustics, vol. I, Part A. New York: Academic Press,Inc.: pp.169-269, 1964.

[Boucher 81] BOUCHER, D., LAGIER, M. and MAERFELD, C., "Computation of the Vibrational Modes for Piezoelectric Array Transducers using a Mixed Finite Element-Perturbation Method", IEEE Trans. on Sonics and Ultrasonics, vol. SU-28, no 5: pp.318-330, september, 1981.

[Challande 90] CHALLANDE, P., "Optimizing Ultrasonic Transducers Based on Piezoelectric Composites Using a Finite-Element Method", IEEE Trans. on Ultrasonics, Ferroelectrics, and Frequency Control, vol. 17, no 2: pp.135140, may, 1990.

[Claus 83] CLAUS, R. O. and ZERWEKH, P. S., "Ultrasonic Transducer with a Two-Dimensioanal Gaussian Field Profile", IEEE Trans, on Sonics and Ultrasonics, vol. 30, no 1: pp.36-39, january, 1983. 
[Dubus 91] DUBUS, B., DEBUS, J. C., DECARPIGNY, J. N. and BOUCHER, D., "Analysis of Mechanical Limitations of High Power Piezoelectric Transducers using Finite Element Modelling", Ultrasonics, vol. 29, pp.201-207, may, 1991.

[EerNisse 67] EER NISSE, E. P., "Variational Method for Electroelastic Vibration Analysis", IEEE Trans. on Sonics and Ultrasonics, vol. SU-14, no 4: pp.153-160, october, 1967.

[Ferreira 92] FERREIRA, G.M., FORNERIS, R. e MURAMATSU, M. "Detecção de Linhas Nodais por "Electronic Speckle Pattern Interferometry" ", Simpósio do Instituto de Física da USP, São Paulo, 1992.

[Gazis 60] GAZIS, D. C. and MINDLIN, R. D., "Extensional Vibrations and Waves in a Circular Disk and a Semi-infinite Plate", J. App. Mech., vol.27: pp.541-547, september, 1960.

[Gindre 88] GINDRE, M., URBACH, W., COURSANT, R. H. and FINK, M., "Mechanical Displacement induced in a Piezoelectric Structure: Experimental Measurement by Laser Interferometry and Simulation by a Finite Element Method", J. Acoust. Soc. Am. 84 (1): pp.11-19, july, 1988.

[Guo 91] GUO, N. and CAWLEY, P., "Transient Response of Piezoelectric Discs to Applied Voltage Pulses", Ultrasonics, vol. 29: pp.208-217, may, 1991.

[Hayward 91] HAYWARD, G., HAMILTON R., KANANI, B. and REILLY, D. A., "A Thin Film Technique for Spatial Apodization of Disc-Shaped Piezoceramic Transducers", J. Acoust. Soc. Am. 89 (4), Pt. 1: pp.1808-1815, april, 1991.

[Hossak 91] HOSSAK, J. A. and HAYWARD, G., "Finite Element Analysis of 13 Composite Transducers", IEEE Trans. on Ultrasonics, Ferroelectrics, and Frequency Control, vol. 38, no 6: pp.618-629, november, 1991.

[Hutchins 90] HUTCHINS, D. A. and HAYWARD, G., "Ultrasonic Measurement Methods", Physical Acoustics, vol. XIX, New York: Academic Press, Inc.: pp.1-80, 1990.

[Ikegami 74] IKEGAMI, S., UEDA, I. and KOBAYASHI, S., "Frequency Spectra of Resonant Vibration in Disk Plates of $\mathrm{PbTiO}_{3}$ Piezoelectric Ceramics", J. Acoust. Soc. Am., vol. 55, no 2: pp.339-344, february, 1974.

[Kagawa 76] KAGAWA, Y. and YAMABUCHI, T., "Finite Element Approach for a Piezoelectric Circular Rod", IEEE Trans, on Sonics and Ultrasonics, vol. SU-23, no 6: pp.379-385, november, 1976.

[Kagawa 79] KAGAWA, Y. and YAMABUSHI, T., "Finite Element Simulation of a Composite Piezoelectric Ultrasonic Transducer", IEEE Trans. on Sonics and Ultrasonics, vol. SU-28, no 2: pp.81-88, march, 1979. 
[Kino 87] KINO, G. S., Acoustic waves: Devices, Imaging and Analog Signal Processing, Prentice Hall, Englewood Cliffs, New Jersey 07632, USA, 1987.

[Kinsler 82] KINSLER, L. E., COPPENS, A. B., FREY, A. R. and SANDERS, J. V., Fundamentals of Acoustics, Third edition, John Wiley \& Sons, New York, USA, 1982.

[Kohnke 89] KOHNKE, P. C., Theoretical Manual ANSYS Engineering Analysis System, Revision 4.4, Swanson Analysis Systems, Inc., Houston, Pennsylvania, USA : chaps. $1.2,1.13,2.30,1989$.

[Kunkel 90] KUNKEL, H. A., LOCKE, S. and PIKEROEN, B., "Finite Element Analysis of Vibrational Modes in Piezoelectric Ceramic Disks", IEEE Trans. on Ultrasonics, Ferroelectrics, and Frequency Control, vol. 37, no 4: pp.316-328, july, 1990.

[Lanceleur 92] LANCELEUR, P., BELLEVAL, J. F. and MERCIER, N., "Modelling of Transient Deformation of Piezoelectric Ceramics", IEEE Trans. on Ultrasonics, Ferroelectrics, and Frequency Control, vol. 39, no 2: pp.293301, march, 1992.

[Lerch 90] LERCH, R., "Simulation of Piezoelectric Devices by Two- and ThreeDimensional Finite Elements", IEEE Trans. on Ultrasonics, Ferroelectrics, and Frequency Control, vol.37, no 2: pp.233-247, may, 1990.

[Meirovitch 86] MEIROVITCH, L., Elements of Vibration Analysis, second edition, McGraw-Hill International editions - Mechanical Engineering Series, New York, USA, 1986.

[Naillon 83] NAILLON, M., COURSANT, R. H. and BESNIER, F., "Analysis of Piezoelectric Structures by a. Finite Element Method", Acta Electronica, 25, 4: pp.341-362, 1983.

[O'Donnell 81] O'DONNELL, M., BUSSE, L. J. and MILLER, J. G., "Piezoelectric 'Transducers", Methods of Experimental Physics, vol. 19, New York: Academic Press, Inc. pp.29-65, 1981.

[Ostergaard 86] OSTERGAARD, D. F. and PAWLAK, T. P., "Three-Dimensional Finite Elements for Analyzing Piezoelectric Structures", IEEE Proceedings Ultrasonics Symposium, vol. 2: pp. 639-644, november, 1986.

[Rajakumar 89] RAJAKUMAR, C. and JAMNIA, M-A., Acoustic Pressure Wave Propagation, ANSYS Revision 4.4A Tutorial, Swanson Analysis Systems, Inc., Houston, Pennsylvania, USA: pp.1.1-5.1, 1989.

[Ristic 83] RISTIC, V. M., Principles of Acoustic Devices, John Wiley \& Sons, New York, USA, 1983. 
[Sato 79] SA'TO, J., KAWABUCHI, M. and FUKUMOTO, A., "Dependence of the Electromechanical Coupling Coefficient on the Width-to-Thickness Ratio of Plank-Shaped Piezoelectric Transducers used for Electronically Scanned Ultrasound Diagnostic Systems", J. Acoust. Soc. Am. 66 (6): pp.1609-1611, december,1979.

[Schillings 91] SCHILLINGS, J., "A Coupled Piezoelectric-Acoustic FE Analysis of a Transducer Unit using ANSYS", ANSYS Conference Proceedings - Swanson Analysis Systems,Inc., vol. I, The Pittsburgh Hilton \& Towers, Pittsburgh, PA, USA: pp.2.89-2.115, 1992.

[Shaw 56] SHAW, E. A. G., "On the Resonant Vibrations of Thick Barium Titanate Disks", J. Acoust. Soc. Am., vol. 28, no 1: pp.38-50, january, 1956.

[Smith 73] SMITH, R. R., HUNT, J. T. and BARACH, D. "Finite Element Analysis of Acoustically Radiating Structures with Applications to Sonar Transducers", J. Acoust. Soc. Am., vol. 54, no 5: pp.1277-1288, 1973.

[Standard 78] "IEEE Standard on Piezoelectricity", ANSI/IEEE Std 176-1978, IEEE Trans. on Sonics and Ultrasonics, vol. SU-31, no 2, march, 1984.

[Stepanishen 71] STEPANISHEN, P. R., "Transient Radiation from Pistons in an Infinite Planar Baffe", J. Acoust. Soc. Am. vol.29, no 5 (Part 2): pp.1629-1638, 1971.

[Tiersten 67] TIERSTEN, H. F., "Hamilton's Principle for Linear Piezoelectric Media.", Proc. IEEE, pp.1523-1524, 1967.

[Van Vlack 85] VAN VLACK, L. H., Princípios de Ciência dos Materiais, Edgard Blücher Ltda., São Paulo, Brasil, 1985.

[Varadan 90] VARADAN, V. V., CHIN, L-C. and VARADAN, V. K., "Hybrid Finite Element Methods for the Numerical Simulation of the Sensor and Actuator Performance of Composite Transducers including the Effect of Fluid Loading", IEEE Proceedings Ultrasonics Symposium: pp.11771181, 1990.

[Zienkiewicz 83] ZIENKIEWICZ, O. C. and MORGAN, K., Finite Elements and Approximation, John Wiley \& Sons, New York, USA, 1983.

[Weight 84a] WEIGHT, J. P., "Ultrasonics Beam Structures in Fluid Media", J. Acoust. Soc. Am. 76 (4): pp.1184-1191, october, 1984.

[Weight 84b] WEIGHT, J. P., "New Transducers for High-resolution Ultrasonic Testing", NDT International, vol. 17, no 1: pp.3-8, february, 1984. 


\section{Apêndice A}

\section{O Software ANSYS}

O software ANSYS, desenvolvido pela "SWANSON ANALYSIS SYSTEMS INC.", tem grande capacidade e alta flexibilidade na análise por elementos finitos, sendo de grande aplicação em diversas áreas de engenharia.

Além dos diversos elementos destinados à análise estrutural mecânica, a qual constitui a base da aplicaçăo do MEF, o software possui outros elementos implementados que permitem modelar entre outros, problemas térmicos (transferência de calor), problemas envolvendo efeitos magnéticos, elétricos, termo-elétricos e termo-magnético-elétricos, escoamento laminar bidimensional de fluidos, propagação de ondas acústicas, e o elemento piezoelétrico destinado à modelagem de estruturas piezoelétricas [ANSYS]. Com relação a parte estrutural mecânica permite analisar materiais anisotrópicos, levando em conta efeitos térmicos (variação das propriedades com a temperatura), pré-tensionamento e perdas (amortecimento). O software possui também um módulo não-linear que permite modelar fenômenos como a plasticidade (materiais plásticos), fluência e capacidade de expansão, bem como calcular grandes deflexóes em estruturas, entre outros problemas [ANSYS].

Entre as análises executadas pelo ANSYS, tem-se:

- Análise Estática Linear e Não-linear

- Análise Modal

- Análise de Flambagem em estruturas

- Resposta Harmônica Completa

- Resposta Harmônica Reduzida

- Análise Dinâmica Transiente Linear

- Análise Transiente Não-linear

- Análise por Subestruturas 
- Transferência de Calor

Um problema de elementos finitos é geralmente resolvido em três fases:

1. Pré-processamento

2. Solução

3. Pós-processamento

Para cada uma dessas fases o ANSYS apresenta rotinas responsáveis por determinadas tarefas

\section{Pré-processamento}

No pré-processamento será gerada a malha, definido os vínculos e cargas aplicadas, tipo de elemento, material, etc... [ANSYS]. Essas tarefas são executadas por duas rotinas, a PREP7 e a PREP6. A primeira apresenta comandos destinados a gerar geometricamente a malha, definindo os tipos de elementos a serem utilizados, o tipo de análise desejada, material, restrição e acoplamento dos graus de liberdade (GL), definir as cargas, além de otimizar o modelo (renumera elementos e nós). A rotina PREP6 é utilizada quando se pretende aplicar muitas condições de carga. É o caso, por exemplo, da análise transiente, em que a carga aplicada varia com o tempo segundo uma função diferente de um seno ou cosseno, o que exigirá muitos pontos para definir a função. O mesmo acontece numa análise harmônica quando se deseja obter a resposta da estrutura para diversas frequêencias que variam segundo uma certa função. Assim as diversas condições de carga são armazenadas numa tabela que será lida pelo software durante a solução. Em geral define-se a primeira condição de carga através do PREP7 e as demais no PREP6 [ANSYS]. Os comandos de acionamento dessas rotinas são respectivamente, /PREP7 e /PREP6.

O ANSYS é um software versátil, trabalhando de forma modular, ou seja, os dados gerados e as matrizes montadas ao longo da análise, são gravados em arquivos diferentes designados pelo nome "fileN.dat", onde $\mathrm{N}$ é um número. Isso permite que se acompanhe passo-a-passo a análise, podendo se ter acesso a certas informações, como as matrizes de massa e rigidez da estrutura, além de poder reutilizar determinados arquivos em análises posteriores (como os arquivos de materiais, geometria e de carga). Isso facilita também a transferência de arquivos para outros softwares, pois se transfere somente o necessário. Os arquivos podem estar escritos sob a forma de texto (código ASCII), ou em código binário. No último caso, existem rotinas auxiliares "AUX" que convertem os arquivos para o código ASCII. No manual [ANSYS] encontram-se o formato de impressão dos arquivos convertidos.

Encerrada a fase de pré-processamento todos os dados referentes ao modelo (PREP7) e as condições de carga (PREP6) estarão armazenados em dois arquivos, "file27.dat" e "file23.dat" respectivamente. 


\subsection{Graus Mestres}

Com o objetivo de poder analisar estruturas com grande número de nós, o ANSYS utiliza uma técnica de condensação de matrizes conhecida como redução de Guyan. Sem essa técnica, a execução de uma análise dinâmica seria economicamente impraticável (muitos nós).

Consiste em se especificar determinados graus de liberdade (GL), denominados mestres, que correspon dem àqueles GLs que são suficientes para caracterizar o comportamento dinâmico da estrutura. Assim seriam os graus associados com os modos e freqüências mais baixas da estrutura, enquanto que os eliminados estariam associados com os altos modos e freqüências da estrutura. A análise passa a ser feita então, em cima desses GLs, o que reduz a sua complexidade. Isso permite que os GLs pouco importantes não sejam levados em conta, aumentando o espaço disponível na memória e reduzindo o tempo de processamento. Através do procedimento de Guyan, as matrizes são reduzidas a esses graus. A redução da matriz rigidez é exata, enquanto que as matrizes de massa e amortecimento reduzidas são aproximadas. No caso da matriz de massa o procedimento é semelhante à aglutinação de massa exceto que é gerada uma matriz cheia ao invés de uma matriz diagonal [Ostergaard 86,ANSYS]. Os graus mestres podem ser especificados diretamente pelo usuário, ou selecionado automaticamente pelo programa. Entre as principais sugestões para escolha dos graus mestres, tem-se:

- o número de graus mestres selecionados deve ser pelo menos duas vezes o número dos modos de interesse.

- Selecionar os graus mestres nas regiões que tenham grande quantidade de massa evitando as regiões que tenham massa insignificante.

Uma discussão sobre o número de graus mestres que devem ser utilizados na representação de uma estrutura piezoelétrica, o tempo de processamento e a precisão dos resultados obtidos em relação a análise completa (sem os graus mestres) encontra-se em [Ostergaard 86], recomendando-se que seja utilizado um número de graus mestres no mínimo igual à metade dos GLs existentes.

\section{Solução}

Nessa fase são formuladas as matrizes (massa, rigidez, etc...) dos elementos, e obtida a matriz completa que é triangularizada. Na resolução do problema estático $[K] U=F$, o ANSYS utiliza a técnica de frente de onda, que reduz a quantidade de dados que deve ser armazenada pelo programa [Kohnke 89]. Após a solução são calculadas as tensões mecânicas, reações e outras grandezas (térmicas, elétricas e magnéticas) conforme o tipo de problema. 
Para cada uma das análises apresentadas existe uma rotina. O tipo de análise desejada deve ser especificada no pré-processamento através do comando KAN seguido de um número correspondente ao tipo de análise [ANSYS]. Nessa fase é possível fazer uma verificação se não haverá problemas durante o processamento, bem como ter uma idéia do tempo de processamento, através do comando /CHECK.

Como já comentado as matrizes (rigidez, massa, etc...) dos elementos e a matriz completa triangularizada são escritas $\mathrm{cm}$ arquivos binários, que após convertidos para o código ASCII podem ser lidos. Os resultados gerados e que serão pós-processados são armazenados no "file12.dat". No caso de se utilizar graus mestres deve-se fazer uma expansão dos resultados para os demais graus através do comando /STRESS, quando então será gerado o "file12.dat". O comando para se iniciar a solução é /INPUT,27 e caso exista o "file23.dat", acrescenta-se o comando /INPUT,23.

\section{Pós-processamento}

Nessa fase os resultados contidos no "file12.dat" são pós-processados, ou seja, são apresentados na forma de gráficos e imagens em diferentes cores. Para isso o ANSYS apresenta várias rotinas de pós-processamento que são: POST1, POST26, POST27, POST29 e POST30. O POST29 e POST30 são utilizados com alguns tipos de elementos específicos. O POST1 permite a visualização dos resultados como a estrutura deformada, distribuição das tensões mecânicas (ou outras grandezas), etc.... Permite também realizar operações com os resultados, como por exemplo, somar, subtrair, multiplicar, derivar, integrar, entre outras, bem como imprimir e animar (no caso de uma análise dinâmica) os resultados. Pode ser utilizado também na obtenção de gráficos de uma certa variável (pressão deslocamento, etc...) ao longo de um certo caminho sobre a estrutura, através do comando LPATH [ANSYS]. O POST26 permite obter gráficos ou listagens de uma variável de um nó ou elemento emn função de outra variável de um nó ou elemento, ou em função do tempo em análises dinâmicas. Assim no caso de uma análise transiente poder-se-ia obter o deslocamento UZ de um nó em função do tempo (ou da freqüência, no caso de uma análise harmônica), ou em função do deslocamento UY de um outro nó por exemplo. Também realiza operaçôes com os resultados, como somar, multiplicar, derivar, integrar ,log, ln, entre outras, além de imprimir e mostrar os resultados obtidos [ANSYS]. O POST27 é semelhante co POST1, entretanto permite somente obter a impressão dos resultados. $\mathrm{O}$ comando para o acionamento dessas rotinas é /POSTN e $\mathrm{N}=\{1,26,27,29,30\}$.

Se desejado, o pós-processamento pode ser feito por outro software, devendo-se para isso converter o "file12.dat" para o código ASCII. Da mesma forma, a estrutura pode ser gerada num programa tipo CAD, e transferida para o ANSYS, uma vez que o mesmo apresenta interface com vários programas de CAD, e até mesmo com outros softwares de elementos finitos [ANSYS]. O ANSYS dispõe ainda de um módulo gráfico que permite visualizar o modelo e os resultados de diferentes vistas, ângulos e formas [ANSYS]. 


\section{Apêndice B}

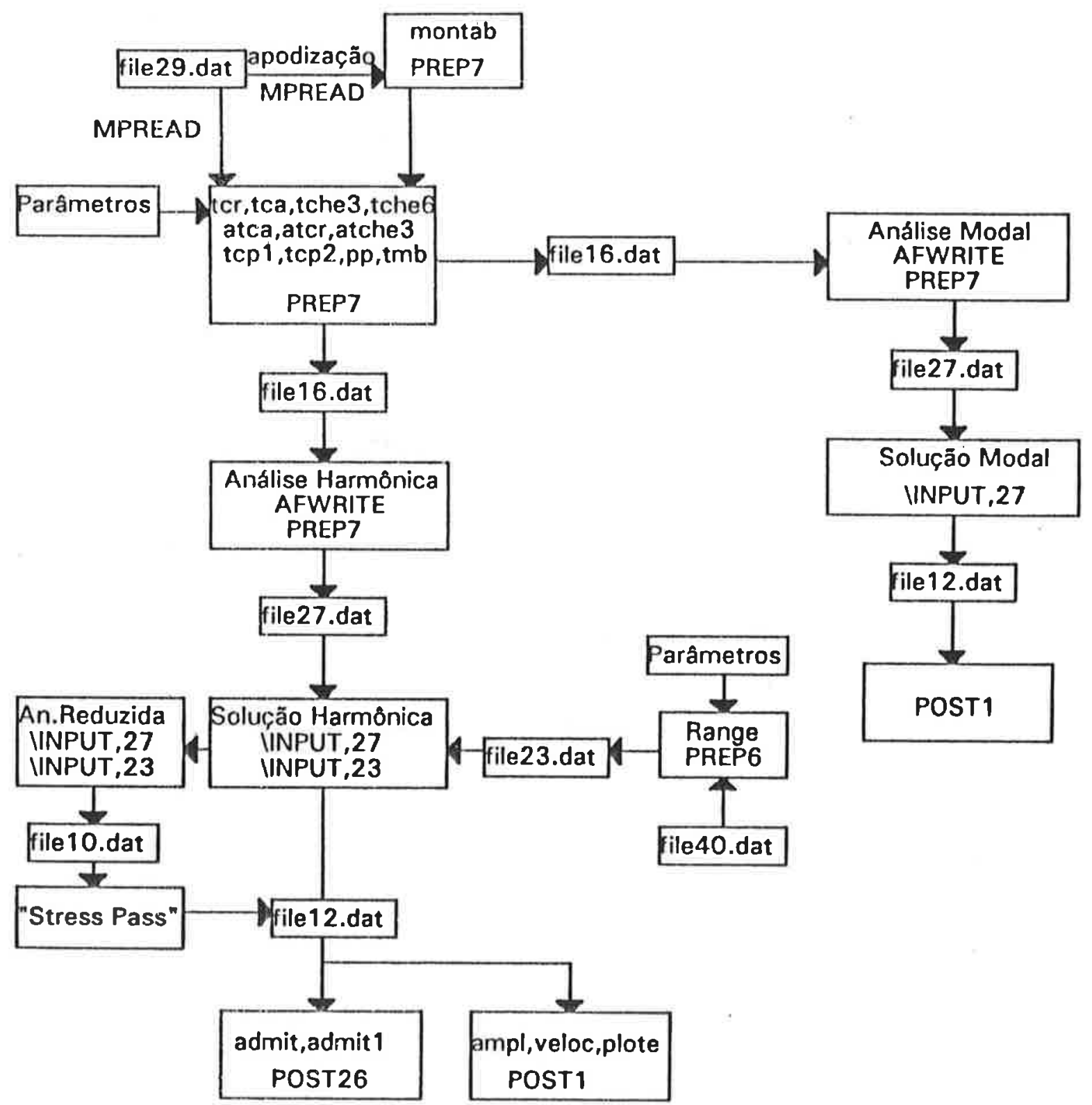

Figura B.1: Seqüência para a execução das análises harmônica e modal no ANSYS. 
APÊNDICE B.

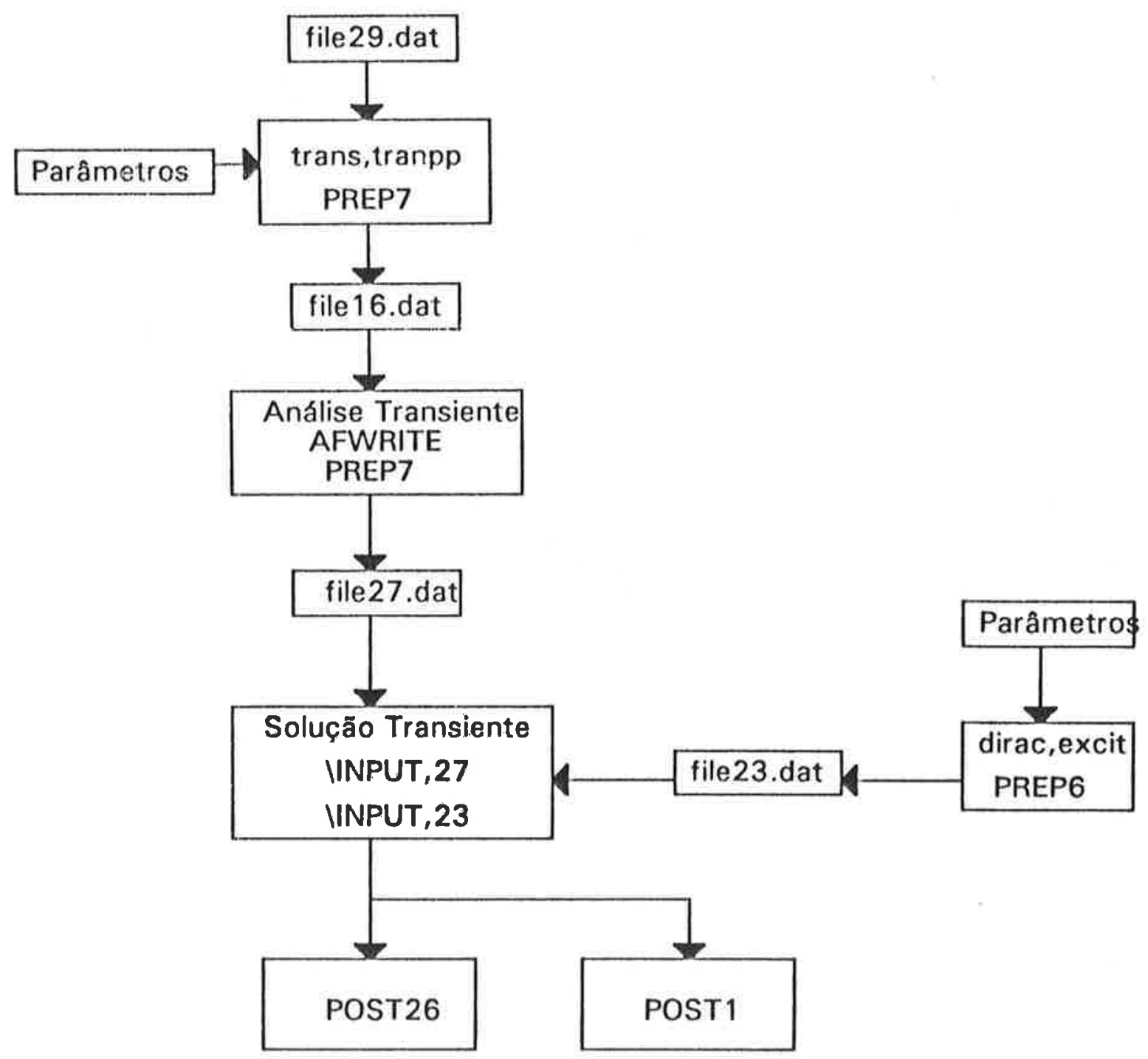

Figura B.2: Seqüência para a execução da análise transiente. 


\section{Apêndice $\mathbf{C}$}

\section{C.1 Constantes do Material PZT5A (formato ANSYS}

$$
\rho=7750 \mathrm{Kg} / \mathrm{m}^{3}
$$

$$
\begin{aligned}
& {[c]=\left[\begin{array}{cccccc}
12,1 & 7,54 & 7,52 & 0 & 0 & 0 \\
7,54 & 12,1 & 7,52 & 0 & 0 & 0 \\
7,52 & 7,52 & 11,1 & 0 & 0 & 0 \\
0 & 0 & 0 & 2,26 & 0 & 0 \\
0 & 0 & 0 & 0 & 2,11 & 0 \\
0 & 0 & 0 & 0 & 0 & 2,11
\end{array}\right] 10^{10} \mathrm{~N} / \mathrm{m}^{2}} \\
& {[e]=\left[\begin{array}{ccc}
0 & 0 & -5,4 \\
0 & 0 & -5,4 \\
0 & 0 & 15,1 \\
0 & 0 & 0 \\
0 & 12,3 & 0 \\
12,3 & 0 & 0
\end{array}\right] C / m^{2}} \\
& {[\varepsilon]=\left[\begin{array}{ccc}
1,531 & 0 & 0 \\
0 & 1,531 & 0 \\
0 & 0 & 1,505
\end{array}\right] 10^{-8} \mathrm{~F} / \mathrm{m}}
\end{aligned}
$$


APÊNDICE C.

C.2 Constantes do Material P160 (formato ANSYS)

$\rho=7500 \mathrm{Kg} / \mathrm{m}^{3}$

$[c]=\left[\begin{array}{cccccc}10,9 & 6,29 & 6,33 & 0 & 0 & 0 \\ 6,29 & 10,9 & 6,33 & 0 & 0 & 0 \\ 6,33 & 6,33 & 9,27 & 0 & 0 & 0 \\ 0 & 0 & 0 & 2,3 & 0 & 0 \\ 0 & 0 & 0 & 0 & 1,9 & 0 \\ 0 & 0 & 0 & 0 & 0 & 1,9\end{array}\right] 10^{10} \mathrm{~N} / \mathrm{m}^{2}$

$[e]=\left[\begin{array}{ccc}0 & 0 & -4,762 \\ 0 & 0 & -4,762 \\ 0 & 0 & 14,92 \\ 0 & 0 & 0 \\ 0 & 11,6 & 0 \\ 11,6 & 0 & 0\end{array}\right] C / m^{2}$

$[\varepsilon]=\left[\begin{array}{ccc}0,849 & 0 & 0 \\ 0 & 0,849 & 0 \\ 0 & 0 & 0,770\end{array}\right] 10^{-8} \mathrm{~F} / \mathrm{m}$ 


\section{Apêndice D}

\section{Listagem das rotinas MACRO implementadas no ANS}

\section{D.1 Análise Modal}

\section{Rotina TCR}

/COM Essa rotina realiza uma analise modal de um disco piezoeletrico /COM de raio $R$, espessura $H$, determinando os

/COM seus primeiros NMOD modos e frequencias de ressonancia. /COM Deve ser usada no PREP7.

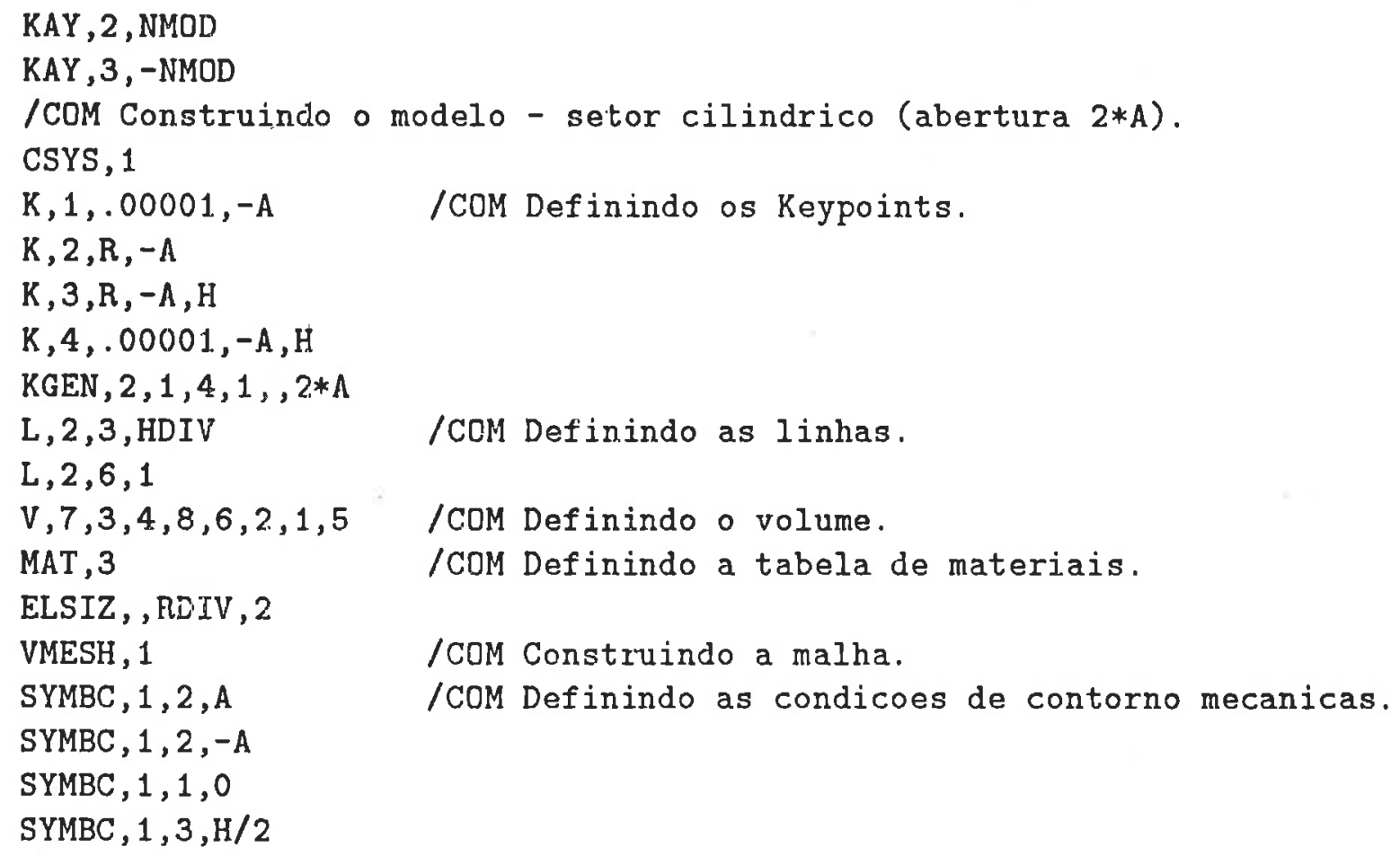


NSEL, $Z, O$ NT, ALL, VOLT , 0

NSEL , $Z, H$

NT , ALL , VOLT , $O$

NALL

CPSIZE , 380

CP , 1, TEMP , ALL

CP , 2, MAG, ALL

$\mathrm{B}=(\mathrm{R}-.00001) / \mathrm{RDIV}$

$\mathrm{H}=\mathrm{O}$

$\mathrm{N}=3$

$\mathrm{L}=\mathrm{B}+.00001$

$: A$

NSEL , $Z, W$

NRSEL , $X, L$

$C P, N, U X, A L L$

NALL

$L=L+B$

$\mathrm{N}=\mathrm{N}+1$

*IF , L , LE , R, : A

$\mathrm{W}=\mathrm{W}+\mathrm{H} / \mathrm{HDIV}$

$\mathrm{L}=\mathrm{B}+.00001$

*IF, W, LE, H, : A

$\mathrm{W}=0$

$\mathrm{L}=.00001$

: $\mathrm{E}$

NSEL $, Z, W$

NRSEL, $X, L$

$C P, N, U Z, A L L$

NALL

$\mathrm{N}=\mathrm{N}+1$

$\mathrm{L}=\mathrm{L}+\mathrm{B}$

$* I F, L, L E, R,: E$

$: F$

$\mathrm{W}=\mathrm{W}+\mathrm{H} / \mathrm{HDIV}$

$\mathrm{L}=.00001$

$* I F, W, E Q, H / 2,: F$

*IF, W, LE , H, : E

HSORT, $Z$

ITER, $1,0,1$

$M, A L L, U X$

$M, A L L, U Z$
/COM Definindo as condicoes de contorno eletricas.

/COM Acoplando os GLs nao utilizados.

/COM Acoplando os GLs dos planos laterais do /COM setor cilindrico. 
APÊNDICE D.

$\mathrm{N}=\mathrm{N}+1$

$* I F, L, L E, R,: A$

$W=W+H / H D I V$

$\mathrm{L}=\mathrm{B}+.00001$

$* I F, W, L E, H,: A$

$\mathrm{W}=0$

$\mathrm{L}=.00001$

:E

NSEL , $Z, W$

NRSEL , $X, L$

$\mathrm{CP}, \mathrm{N}, \mathrm{UZ}, \mathrm{ALL}$

NALL

$\mathrm{N}=\mathrm{N}+1$

$\mathrm{L}=\mathrm{L}+\mathrm{B}$

$* I F, L, L E, R,: E$

:F

$\mathrm{W}=\mathrm{W}+\mathrm{H} / \mathrm{HDIV}$

$\mathrm{L}=.00001$

$* I F, W, E Q, H / 2,: F$

$* I F, W, L E, H,: E$

WSORT, $Z$

ITER $, 1,0,1$

$M, A L L, U X$

$M, A L L, U Z$

\section{D.2 Análise Harmônica}

\section{Rotina TCHE3}

/COM Essa ratina realiza uma analise harmonica de um disco piezoeletrico /COM de raio $R$ e espessura $H$, excitado nas $N F$ frequencias do intervalo /COM de extremos FA e FB. Deve ser usada no PREP7.

CSYS, 1

/COM Construindo o modelo e a malha - setor cilindrico

$\mathrm{K}, 1, .00001,-\mathrm{A} \quad$ /COM Definindo os Keypoints.

$K, 2, R,-A$

$\mathrm{K}, 3, \mathrm{R},-\mathrm{A}, \mathrm{H} / 2$

$\mathrm{K}, 4, .00001,-\mathrm{A}, \mathrm{H} / 2$

KGEN, $2,1,4,1,2 * A$

$\mathrm{L}, 2,3, \mathrm{HDIV} / 2$

$\mathrm{L}, 2,6,1$

$\mathrm{V}, 7,3,4,8,6,2,1,5$ /COM Definindo o volume. 
APÊNDICE D.

\section{Rotina TCA}

/COM Essa rotina segue o mesmo procedimento da TCR, calculando /COM os NMOD primeiros modos e frequencias de anti-ressonancia /COM de un disco piezoeletrico de raio $R$ e espessura $H$. Sao /COM alteradas apenas as condicoes de contorno eletricas. /COM Deve ser usada no PREP7.

KAY , 2 , NMOD

KAY, 3, -NMOD

CSYS, 1

$\mathrm{K}, 1, .00001,-\mathrm{A}$

$\mathrm{K}, 2, \mathrm{R},-\mathrm{A}$

$\mathrm{K}, 3, \mathrm{R},-\mathrm{A}, \mathrm{H}$

$\mathrm{K}, 4, .00001,-\mathrm{A}, \mathrm{H}$

$\mathrm{KGEN}, 2,1,4,1,, 2 * \mathrm{~A}$

$\mathrm{L}, 2,3, \mathrm{HDIV}$

$\mathrm{L}, 2,6,1$

$\mathrm{V}, 7,3,4,8,6,2,1,5$

MAT , 3

ELSIZ , , RDJV , 2

VMESH , 1

SYMBC $, 1,2, A$

SYMBC $, 1,2,-A$

SYMBC $, 1,1,0$

SYMBC $, 1,3, \mathrm{H} / 2$

NSEL , $Z, 0$

/COM Definindo as condicoes de contorno eletricas.

NT, ALL ; VDL'T, 0

NALL

NSEL, $\mathrm{Z}, \mathrm{H}$

CPSIZE , 380

CP , 3, VOLT, ALL

NALL

CP, 1,TEMP,ALL /COM Acoplando os GLs nao utilizados.

CP, 2 , MAG , ALL

$\mathrm{B}=(\mathrm{R}-.00001) / \mathrm{RDIV}$

$\mathrm{W}=0$

$\mathrm{N}=4$

$\mathrm{L}=\mathrm{B}+.00001$

$: A$

NSEL , $\mathrm{Z}, \mathrm{W}$

NRSEL, $X, L$

$C P, N, U X, A L L$

NALL

$\mathrm{L}=\mathrm{L}+\mathrm{B}$ 
APÊNDICE D.

MAT , 3

ELSIZ, , RDIV , 2

VMESH , 1

/COM Construindo a malha.

SYMBC $, 1,2,-A$

/COM Definindo as condicoes de contorno mecanicas.

SYMBC , 1, 2, A

SYMBC , $1,1,0$

SYMBC , 1, 3, 0

CPSIZE, 300

/COM Acoplando os GLs nao utilizados.

CP , 1 , TEMP , ALL

tCP, 2, MAG , ALL

$\mathrm{B}=(\mathrm{R}-.00001) / \mathrm{RDIV} / \mathrm{COM}$ Acoplando os GLs dos planos laterais do

$\mathrm{W}=0$

$\mathrm{N}=4$

/COM setor cilindrico.

$9 \mathrm{~L}=\mathrm{B}+.00001$

$: A$

NSEL , $\mathrm{Z}, \mathrm{W}$

NRSEL, $X, L$

CP, N, UX, ALL

NALL

$\mathrm{N}=\mathrm{N}+1$

$\mathrm{L}=\mathrm{L}+\mathrm{B}$

$* I F, L, L E, R,: A$

$\mathrm{W}=\mathrm{W}+\mathrm{H} / \mathrm{HDIV}$

$\mathrm{L}=\mathrm{B}+.00001$

*IF, W, LE, H/2, : A

$\mathrm{W}=\mathrm{H} / \mathrm{HDIV}$

$\mathrm{L}=.00001$

:E

NSEL, Z, W

NRSEL, $X, L$

CP, $N, U Z$, ALL

NALL

$\mathrm{N}=\mathrm{N}+1$

$\mathrm{L}=\mathrm{L}+\mathrm{B}$

*IF , L , LE, R, : E

$\mathrm{W}=\mathrm{W}+\mathrm{H} / \mathrm{HDIV}$

$\mathrm{L}=.00001$

$* I F, W, L E, H / 2,: E$

NSEL, $Z, 0$

/COM Definindo as condicoes de contorno eletricas.

NT , ALL , VOLT , 0

/COM Aterrando um eletrodo.

NALL

NSEL, $\mathrm{Z}, \mathrm{H} / 2$

CP , 3, VOLT, ALL

/COM Escolha do no de menor numero para representar o grupo acoplado. *GET, N1 , NMIN 


\section{APÊNDICE D.}

NALL

NT,N1, VOLT, 0.5 /COM Aplicando a tensao eletrica.

/COM Definindo uma amplitude de excitacao constante ao longo

/COM do intervalo de frequencias.

$\mathrm{KBC}, 1$

WSORT , Z

/COM Reordenando os elementos.

/COM Definindo o intervalo de frequencias de excitacao.

HARFREQ, FA, FB

ITER, NF , 0,1

\section{Rotina TCHE6}

/COM Idem rotina TCHE3, entretanto utiliza graus mestres. Deve ser /COM usada no PREP7.

CSYS, 1

$\mathrm{K}, 1, .00001,-\mathrm{A}$

$\mathrm{K}, 2, \mathrm{R},-\mathrm{A}$

$\mathrm{K}, 3, \mathrm{R},-\mathrm{A}, \mathrm{H} / 2$

$\mathrm{K}, 4, .00001,-\mathrm{A}, \mathrm{H} / 2$

KGEN , 2, 1, 4, 1, , 2*A

$\mathrm{L}, 2,3, \mathrm{HDIV} / 2$

L, $2,6,1$

$\mathrm{V}, 7,3,4,8,6,2,1,5$

MAT, 3

ELSIZ, ,RDIV , 2

VMESH, 1

SYMBC , 1, 2,-A

SYMBC , 1, 2,A

SYMBC , 1, 1, 0

SYMBC , 1, 3, 0

NSEL, $\mathrm{Z}, \mathrm{H} / 2$

CPSIZE, 380

CP , 3, VOLT, ALL

*GET, N1, NMIN

NT, N1, VOLT, , 5

NALL

NSEL , Z , 0

NT, ALL, VOLT, 0

NALL

CP , 1, TEMP , ALL

CP , 2 , MAG , ALL

$\mathrm{B}=(\mathrm{R}-.00001) / \mathrm{RDIV}$

$\mathrm{W}=0$ 
APÊNDIC'E D.

$\mathrm{N}=4$

$\mathrm{L}=\mathrm{B}+.00001$

$: A$

NSEL , Z, W

NRSEL , X, L

$\mathrm{CP}, \mathrm{N}, \mathrm{UX}, \mathrm{ALL}$

NALL

$\mathrm{N}=\mathrm{N}+1$

$\mathrm{L}=\mathrm{L}+\mathrm{B}$

$* I F, L, L E, R,: A$

$\mathrm{W}=\mathrm{W}+\mathrm{H} / \mathrm{HDIV}$

$\mathrm{L}=\mathrm{B}+.00001$

$* I F, W, L E, H / 2,: A$

$\mathrm{W}=\mathrm{H} / \mathrm{HDIV}$

$\mathrm{L}=.00001$

:E

NSEL , $Z, W$

NRSEL , $X, L$

$C P, N, U Z, A L L$

NALL

$\mathrm{N}=\mathrm{N}+1$

$\mathrm{L}=\mathrm{L}+\mathrm{B}$

$* I F, L, L E, R,: E$

$W=W+H / H D I V$

$\mathrm{L}=.00001$

$* I F, W, L E, H / 2,: E$

$M, N 1$, VOLT /COM Escolhendo o no N1 como grau mestre.

TOTAL, NM,1 /COM Especificando a escolha pelo programa de mais NM graus mestres. KBC, 1

WSORT, Z

HARFREQ , FA, FB

ITER, NF , 0,1

\section{D.3 Apodização}

\section{Rotina ATCR}

/COM Essa rotina realiza analise modal de um disco piezoeletrico /COM apodizado, calculando os seus NMOD primeiros modos e frequencias /COM de ressonancia. A funcao de apodizacao e dada por uma das rotinas /COM MONTAB. Deve ser usada no PREP7.

KAY , 2, NMOD 
APENDICE D.

KAY, 3, -NMOD

CSYS, 1

/COM Construcao do modelo - setor cilindrico.

$\mathrm{B}=(\mathrm{R}-.00001) / \mathrm{RDIV}$

$\mathrm{L}=0.00001$

/COM Definicao dos Keypoints.

$M=1$

$: \mathrm{K}$

$\mathrm{K}, \mathrm{M}, \mathrm{L},-\mathrm{A}$

$M=M+1$

$\mathrm{L}=\mathrm{L}+\mathrm{B}$

$* I F, L, L E, R,: K$

$\mathrm{L}=\mathrm{R}$

$: \mathrm{J}$

$\mathrm{K}, \mathrm{M}, \mathrm{L},-\mathrm{A}, \mathrm{H}$

$M=M+1$

$\mathrm{L}=\mathrm{L}-\mathrm{B}$

$*$ IF , L , GE, $0.00001,: \mathrm{J}$

$M=M-1$

KGEN , 2, 1, M, 1, , 2*A , , M

/COM Definindo as linhas.

$I=1$

$J=M$

: LK

$\mathrm{L}, \mathrm{I}, \mathrm{J}, \mathrm{HDIV}$

$I=I+1$

$\mathrm{J}=\mathrm{J}-1$

*IF , I , LE , M/ 2, : LK

/COM Definindo os volumes.

$I=1$

$\mathrm{J}=\mathrm{M}$

$\mathrm{K}=2 * \mathrm{M}$

$\mathrm{L}=\mathrm{M}+1$

$: \mathrm{JP}$

$\mathrm{V}, \mathrm{K}-1, \mathrm{~J}-1, \mathrm{~J}, \mathrm{~K}, \mathrm{~L}+1, \mathrm{I}+1, \mathrm{I}, \mathrm{L}$

$I=I+1$

$\mathrm{L}=\mathrm{L}+1$

$\mathrm{J}=\mathrm{J}-1$

$\mathrm{K}=\mathrm{K}-1$

*IF , I, LE , (M/2) -1 , : JP

$I=1$

$\mathrm{N}=3$

: T

VLSEL, , I

/COM Associando uma tabela de materiais com cada conjunto de 
APENDICE D.

/COM elementos a uma distancia L do centro.

VATT, $N,, 1$

VLALL

$\mathrm{N}=\mathrm{N}+1$

$I=I+1$

$* I F, I, L E$, RDIV , :T

ELSIZ, , 1,2

VMESH, ALL /COM Construindo a malha.

/COM Definindo as condicoes de contorno mecanicas.

SYMBC $, 1,2, A$

SYMBC $, 1,2,-A$

SYMBC $, 1,1,0$

SYMBC , 1, 3, H/2

/COM Definindo as condicoes de contorno eletricas.

NSEL , $Z, 0$

NT, ALL , VOLT , 0

NSEL , Z, H

NT, ALL , VOLT , 0

NALL

CPSIZE, 380

/COM Acoplando GLs nao utilizados.

CP , 1, TEMP , ALL

CP , 2, MAG, ALL

/COM Acoplando os GLS dos planos laterais do setor cilindrico.

$\mathrm{B}=(\mathrm{R}-.00001) / \mathrm{RDIV}$

$\mathrm{W}=0$

$\mathrm{N}=3$

$\mathrm{L}=\mathrm{B}+.00001$

:A

NSEL, $\mathrm{Z}, \mathrm{W}$

NRSEL, $X, L$

CP, $N$, UX, ALL

NALL

$\mathrm{L}=\mathrm{L}+\mathrm{B}$

$\mathrm{N}=\mathrm{N}+1$

$*$ IF , L , LE , R, : A

$\mathrm{W}=\mathrm{W}+\mathrm{H} / \mathrm{HDIV}$

$\mathrm{L}=\mathrm{B}+.00001$

$*$ IF , W, LE , H, : A

$\mathrm{W}=0$

$\mathrm{L}=.00001$

:E

NSEL, $Z, W$

NRSEL , X, L

$\mathrm{CP}, \mathrm{N}, \mathrm{UZ}, \mathrm{ALL}$ 
APENDICE D.

NALL

$\mathrm{N}=\mathrm{N}+1$

$\mathrm{L}=\mathrm{L}+\mathrm{B}$

$*$ IF , L , LE , R, : E

$: \mathrm{F}$

$\mathrm{W}=\mathrm{W}+\mathrm{H} / \mathrm{HDJ} \mathrm{V}$

$\mathrm{L}=.00001$

*IF, W, EQ , H/2, :F

*IF, W, LE , H, : E

WSORT,Z /COM Reordenando os elementos.

ITER , 1, 0, 1

/COM Definindo os graus mestres.

$M, A L L, U X$

$M, A L L, U Z$

\section{Rotina ATCA}

/COM Idem a ATCR, calculando no entanto os NMOD primeiros modos e /COM frequencias. Somente as condicoes de contorno eletricas sao /COM alteradas. Deve ser usada no PREP7.

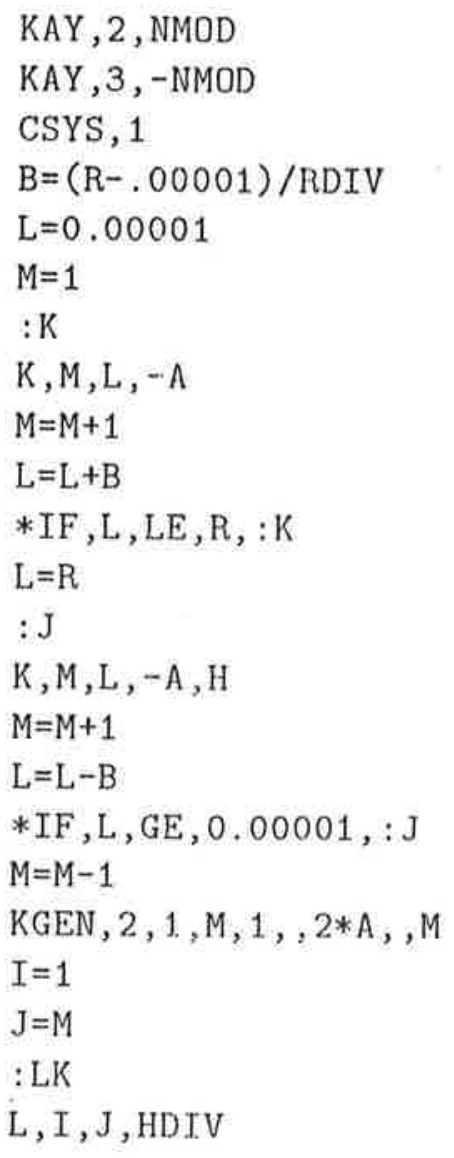


APÊNDICE D.

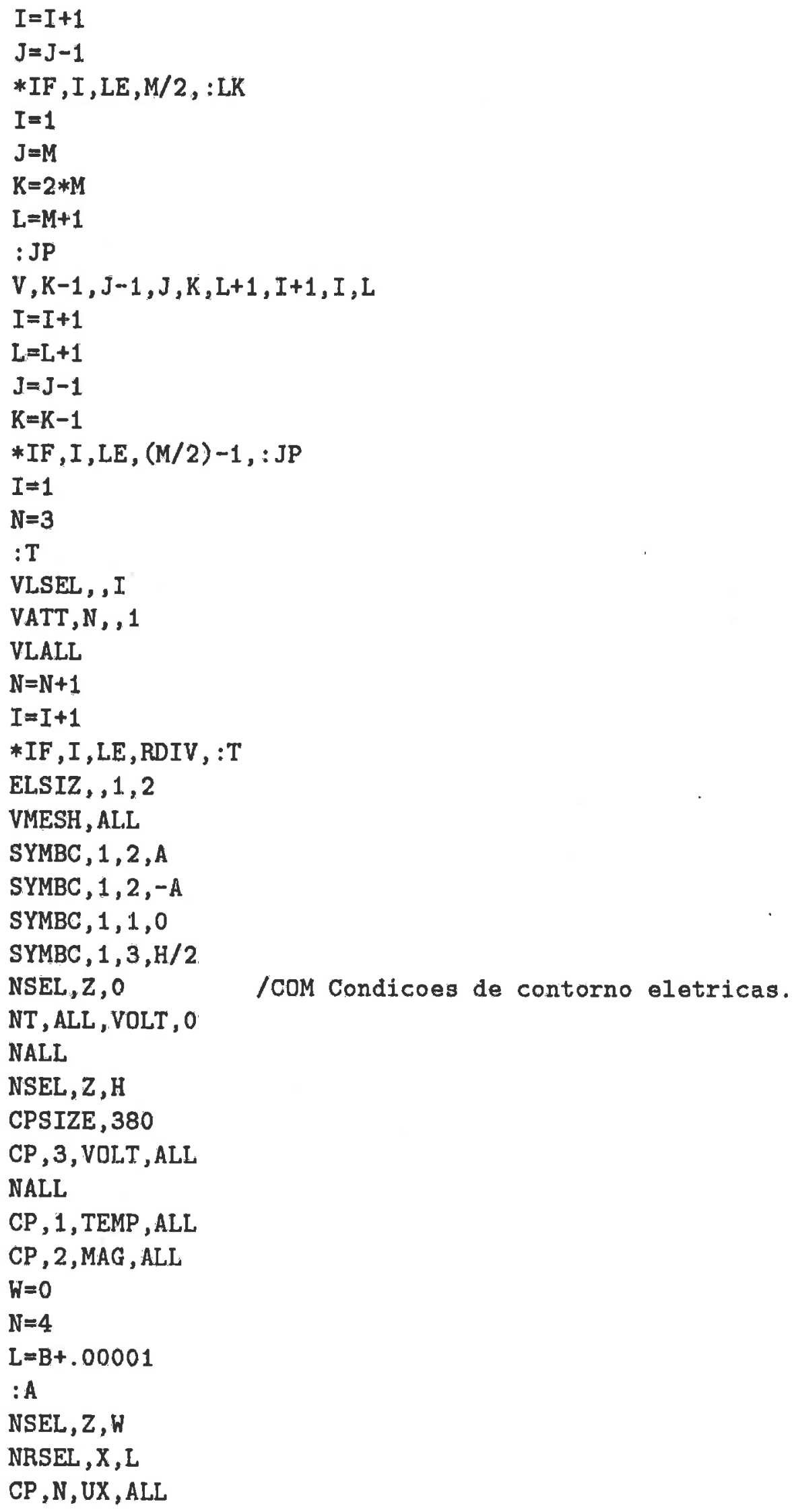


APÊNDICE D.

\author{
NALL \\ $\mathrm{L}=\mathrm{L}+\mathrm{B}$ \\ $\mathrm{N}=\mathrm{N}+1$ \\ *IF , L , LE, R, : A \\ $\mathrm{W}=\mathrm{W}+\mathrm{H} / \mathrm{HDIV}$ \\ $\mathrm{L}=\mathrm{B}+.00001$ \\ $* I F, W, L E, H,: A$ \\ $\mathrm{W}=0$ \\ $\mathrm{L}=.00001$ \\ :E \\ NSEL , $Z, W$ \\ NRSEL, $X, I$ \\ $\mathrm{CP}, \mathrm{N}, \mathrm{UZ}, \mathrm{ALL}$ \\ NALL \\ $\mathrm{N}=\mathrm{N}+1$ \\ $\mathrm{L}=\mathrm{L}+\mathrm{B}$ \\ *IF , L , LE , R, : E \\ $: F$ \\ $\mathrm{W}=\mathrm{W}+\mathrm{H} / \mathrm{HDIV}$ \\ $\mathrm{L}=.00001$ \\ *IF, $W, E Q, H / 2,: F$ \\ *IF, $W, L E, H,: E$ \\ WSORT, Z \\ ITER, $1,0,1$ \\ $M, A L L$, UX \\ $M, A L L$, UZ
}

\title{
Rotina ATCHE3
}

/COM Realiza a analise harmonica de um disco piezoeletrico /COM apodizado, excitado em NF frequencias no intervalo de /COM extremos FA e FB. Deve ser usada no PREP7.

CSYS, 1

/COM Construcao do modelo - setor cilindrico.

/COM Mesmo procedimento anterior.

$B=(R-.00001) / R D I V$

$\mathrm{L}=0.00001$

$M=1$

$: \mathrm{K}$

$\mathrm{K}, \mathrm{M}, \mathrm{L},-\mathrm{A}$

$M=M+1$

$\mathrm{L}=\mathrm{L}+\mathrm{B}$

$* I F, L, L E, R,: K$ 
APÊNDICE D.

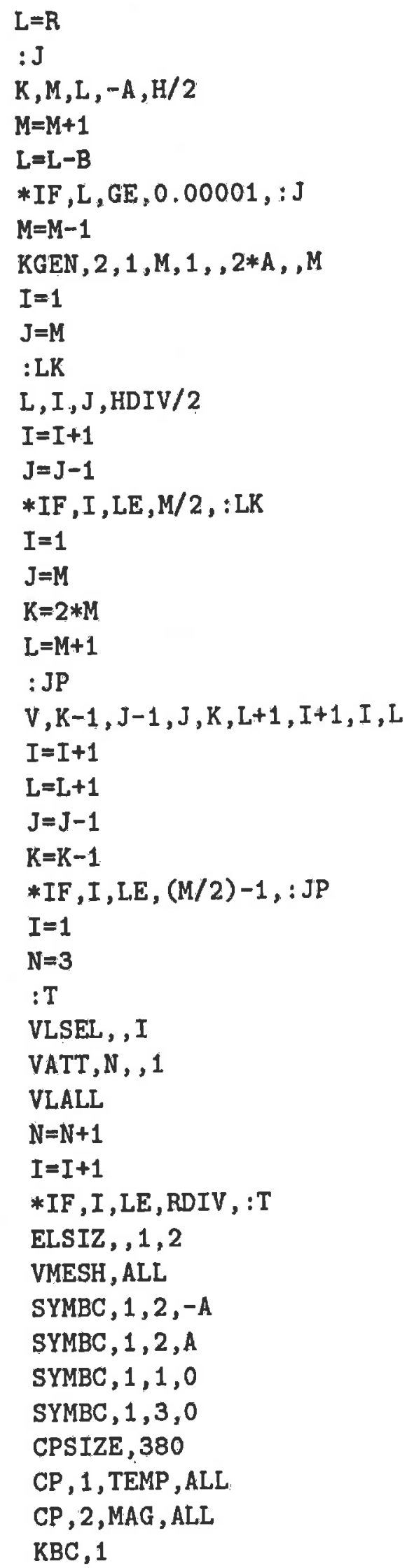


APÊNDICE D.

$W=0$

$\mathrm{N}=4$

$\mathrm{L}=\mathrm{B}+.00001$

$: A$

NSEL, $Z, W$

NRSEL, $X, L$

$C P, N, U X, A L L$

NALL

$\mathrm{N}=\mathrm{N}+1$

$\mathrm{L}=\mathrm{L}+\mathrm{B}$

$* I F, L, L E, R,: A$

$\mathrm{W}=\mathrm{H}+\mathrm{H} / \mathrm{HDIV}$

$\mathrm{L}=\mathrm{B}+.00001$

*IF , W, LE , H/2, :A

$\mathrm{W}=\mathrm{H} / \mathrm{HDIV}$

$\mathrm{L}=.00001$

:E

NSEL, $Z, W$

NRSEL, $X, L$

$\mathrm{CP}, \mathrm{N}, \mathrm{UZ}, \mathrm{ALL}$

NALL

$\mathrm{N}=\mathrm{N}+1$

$\mathrm{L}=\mathrm{L}+\mathrm{B}$

$* I F, L, L E, R,: E$

$\mathrm{W}=\mathrm{W}+\mathrm{H} / \mathrm{HDIV}$

$\mathrm{L}=.00001$

*IF, $\mathrm{W}, \mathrm{LE}, \mathrm{H} / 2,: \mathrm{E}$

NSEL , $Z, 0$

/COM Aterrando um eletrodo.

NT, ALL , VOLT , O

NALL

/COM Acoplando os GLs do eletrodo.

NSEL , $\mathrm{Z}, \mathrm{H} / 2$

CP, 3, VOLT, ALL

/COM Escolhendo o no de menor numero do grupo

/COM acoplado para representa-10.

*GET, N1, NMIN

NALL

NT,N1, VOLT, 0.5 /COM Aplicando a tensao eletrica.

WSORT,Z /COM Reordenando os elementos.

/COM Definindo o intervalo de frequencias.

HARFREQ, FA, FB

ITER, NF , 0,1 


\section{Rotinas MONTAB}

/COM Essas rotinas definem a funcao apodizacao, montando as /COM tabelas de materiais, atraves da variacao do coeficiente /COM piezoeletrico e33 ao longo do raio segundo uma dada funcao. /COM Devem ser usadas no PREPT.

/COM MONTABC - funcao co-senoidal crescente com o raio. $\mathrm{N}=3$

$\mathrm{I}=\mathrm{R} / \mathrm{RDIV}$

$\mathrm{L}=\mathrm{I}$

$: A$ $E=(1+\operatorname{COS}(3.1415 *(R+L) / R)) * E 1 / 2 \quad / C O M$ Variando e33=E. /COM Alterando na tabela de materiais.

NL , N , $147, \mathrm{E}$

MP, DENS , $N, 7750$

$* I F, N, E Q, R D I V+2,: B$

/COM Criando nova tabela.

NLCOPY , N , N+1

$\mathrm{N}=\mathrm{N}+1$

$\mathrm{L}=\mathrm{L}+\mathrm{I}$

/COM Total de RDIV tabelas.

$* I F, N, L E, R D I V+2,: A$

:B

/COM MONTABDC - funcao co-senoidal decrescente com o raio. $\mathrm{N}=3$

$\mathrm{I}=\mathrm{R} / \mathrm{RDIV}$

$\mathrm{L}=\mathrm{I}$

$: A$

$E=(1+\operatorname{COS}(3.1415 * \mathrm{~L} / \mathrm{R})) * \mathrm{E} 1 / 2$

NL , N , $147, E$

MP , DENS , N,7750

$* I F, N, E Q, R D I V+2,: B$

$\mathrm{NLCOPY}, \mathrm{N}, \mathrm{N}+1$

$\mathrm{N}=\mathrm{N}+1$

$\mathrm{L}=\mathrm{L}+\mathrm{I}$

$* I F, N, L E, R D I V+2,: A$

:B

/COM MONTABL - funcao linear decrescente com o raio. $\mathrm{N}=3$

$\mathrm{I}=\mathrm{R} / \mathrm{RDIV}$

$\mathrm{L}=\mathrm{I}$

$: A$ 
APENNDICE D.

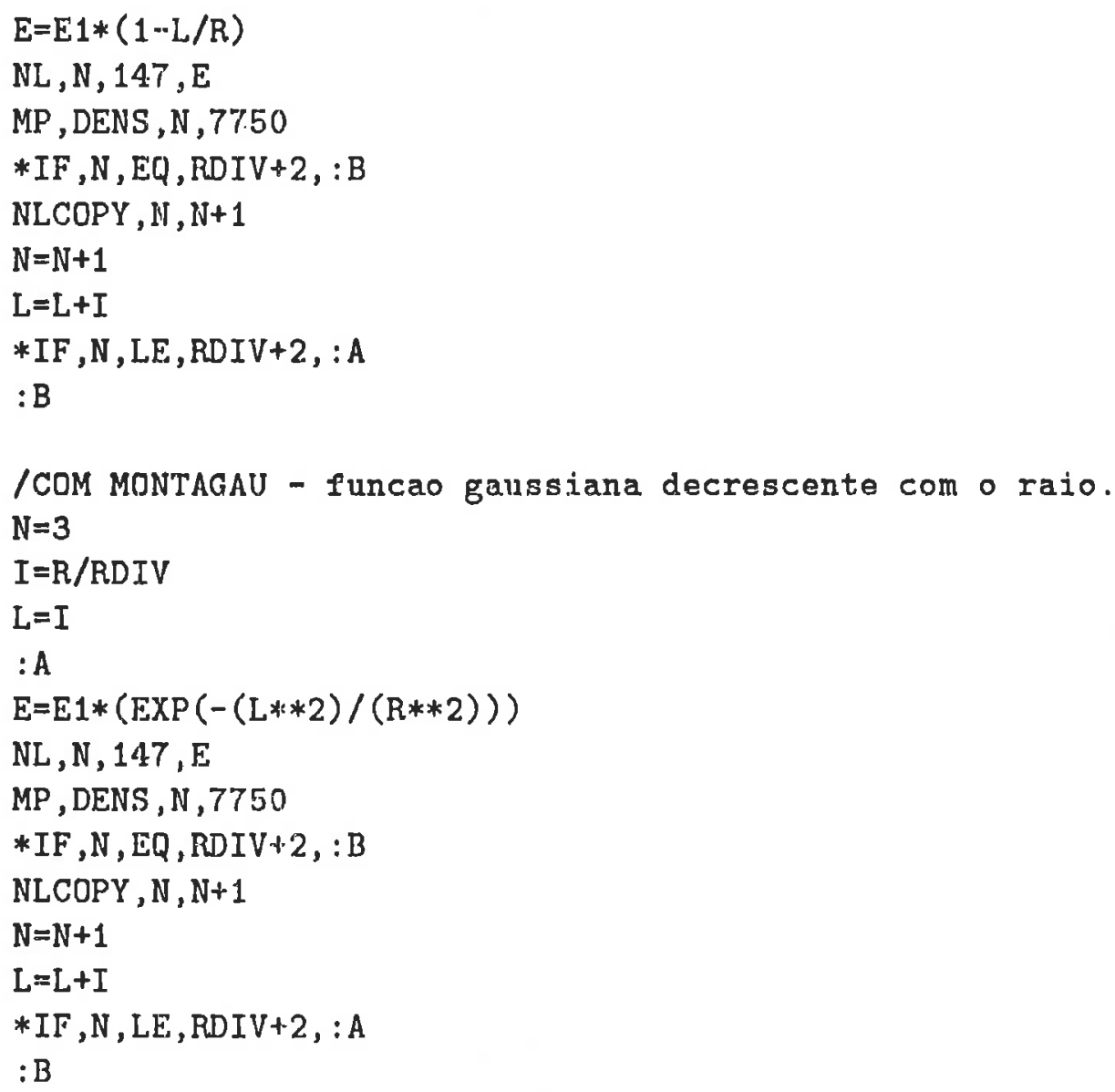

\section{Curva de Admitância.}

\section{Rotina RANGE}

/COM RANGE - Essa rotina monta uma tabela de frequencias /COM distribuidas exponencialmente em torno das frequencias de /COM ressonancia ( 6 a direita e 6 a esquerda). Essa tabela /COM otimiza o calculo da curva de admitancia. $N$ e o numero de /COM frequencias de ressonancia a serem lidas no arquivo file40.dat. /COM RANGE deve ser usada no PREPG.

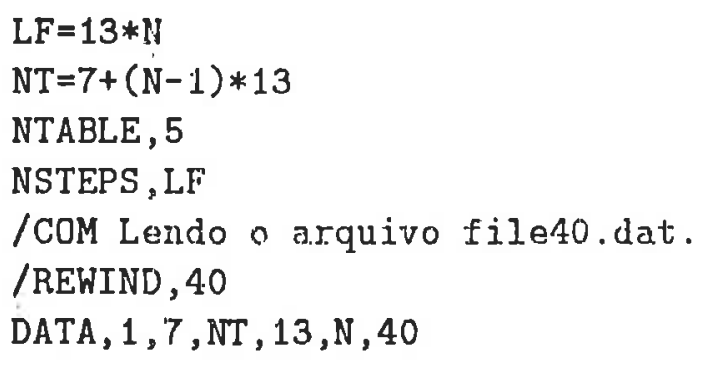


APÊNDICE D.

(1E6)

/REHIND, 40

$\mathrm{L}=1$

$\mathrm{N} 5=7$

/COM Montando a tabela com NT termos.

:A

COPY $1,1, N 5, N 5, L, 6$

$\mathrm{L}=\mathrm{L}+7$

COPY $, 1,1, N 5, N 5, L$,

$\mathrm{N} 5=\mathrm{N} 5+13$

$\mathrm{L}=\mathrm{L}+6$

$* \mathrm{IF}, \mathrm{N} 5, \mathrm{LE}, \mathrm{NT},: \mathrm{A}$

EXP, 2,1,6,1,1E4,-.5,.5 /COM Distribuindo exponencialmente as frequencias.

$\mathrm{L}=1$

$\mathrm{N} 5=\mathrm{L}+12$

$: \mathrm{C}$

COPY $, 2,2, \mathrm{~L}, \mathrm{~L}, \mathrm{~N} 5,1$

$\mathrm{L}=\mathrm{L}+1$

$\mathrm{N} 5=\mathrm{N} 5-1$

$*$ IF , L , LE , $6,: \mathrm{C}$

FILL, $2,7,7,1,-100$

$\mathrm{L}=14$

COPY, $2,2,1,13,14, \mathrm{~N}$

FILL, $3,1,6,1,-1$

FILL, $3,7,13,1,1$

COPY $, 3,3,1,13,14, N$

MULT, $2,2,3$

COMBIN , $4,1,2$

/COM Comandos com o intuito de reduzir o arquivo de saida file12.dat.

LGR1,PODISP, ,-1 /COM Nao gravar os deslocamentos.

LGR1,POSTR, ,-1 /COM Nao gravar o vetor de tensoes mecanicas.

LGR1, NPRINT, , 0 /COM Nao imprimir.

/COM Associam as frequencias com o comando HARFREQ do PREP7.

LGR1, FRQB , 4

LGR1, FRQE, 4

\section{Rotinas ADMIT e ADMIT1}

/COM ADMIT - Essa rotina calcula e plota a curva de admitancia, dado /COM o numero $N 1$ do no mestre do eletrodo (definido nas rotinas /COM TCHE3, TCHE6 e ATCHE6), e F=180/A, onde A e o angulo de abertura /COM do setor cjlindrico. ADMIT deve ser usada no POST26.

RFORCE, 2,N1, AMPS /COM Lendo as cargas eletricas do vetor de reacoes nodais. 
PI2 $=(3,1.4159 * 2)$

PROD, 3, 2,1, ,MHOS, , ,PI2 /COM Multiplicando pela frequencia.

ABS $, 4,3$, , MMHOS, , , $-F * 1000$ /COM Determinando o modulo da admitancia.

/COM Plotagem admitancia $X$ frequencia.

/GRAPH, GRID , 1

/TITLE, |ADMITANCIA| (MMHOS) X FREQUENCIA (KHz)

PROD , 2, 1., , , , ,.001

XVAR, 2

PLVAR, 4

/COM ADMIT1 - Calcula e plota a admitancia no caso em que ha /COM anortecimento (amplitude e fase). Parametros identicos a ADMIT. /COM ADMIT1 deve ser usada no POST26.

RFORCE , $2, N 1$, AMPS

$\mathrm{PI} 2=(3.14159 * 2)$

PROD , 4 , 2, 1, ,MMHOS , , , PI2*F*1000

/GRAPH, GRID , 1

/TITLE, |ADMITANCIA| (MMHOS) X FREQUENCIA（KHz)

PROD $, 3,1, \ldots, \ldots .001$

PLCPLX,0 /COM Plotagem somente da amplitude (fase - PLCPLX,1).

XVAR, 3

PLVAR, 4

/COM Plotagem em dB.

/TITLE, |ADMITANCIA| (dB) X FREQUENCIA ( $\mathrm{KHz}$ )

CLOG $, 5,4, \ldots,,, 1 / 800,2$

\section{D.5 Análise Transiente}

\section{Rotina TRANS}

/COM Essa rotina realiza uma analise transiente do transdutor, /COM excitando-o com uma funcao definida pela rotina DIRAC /COM (Pulso de banda retangular). Deve ser usada no PREP7.

/COM A sequencia de comandos e identico a TCHE3, diferindo apenas /COM na aplicacao da tensao eletrica. Deve ser usada no PREP7.

$\mathrm{KAY}, 5,2$

$\mathrm{KAY}, 9,0$

CSYS, 1

$K, 1, .00001,-A$

$K, 2, R,-A$

$\mathrm{K}, 3, \mathrm{R},-\mathrm{A}, \mathrm{H} / 2$ 


\section{APÊNDICE D.}

$\mathrm{K}, 4, .00001,-\mathrm{A}, \mathrm{H} / 2$

$\mathrm{KGEN}, 2,1,4,1,2 * \mathrm{~A}$

$\mathrm{L}, 2,3, \mathrm{HDIV} / 2$

$\mathrm{L}, 2,6,1$

$\mathrm{V}, 7,3,4,8,6,2,1,5$

MAT , 3

ELSIZ, , RDIV , 2

VMESH , 1

SYMBC $, 1,2,-A$

SYMBC , 1, 2,A

SYMBC $1,1,0$

SYMBC , $1,3,0$

NSEL, $Z, O$

NT , ALL , VOLT , 0

NALL

CPSIZE , 300

NSEL, $\mathrm{Z}, \mathrm{H} / 2$

CP, 3, VOLT, ALL

*GET, N1, NMIN

NALL

$\mathrm{KRF},-1$ /COM Nao calcular as reacoes nodais.

CP , 1, TEMP, ALL

$\mathrm{CP}, 2, \mathrm{MAG}, \mathrm{ALL}$

$\mathrm{B}=(\mathrm{R}-.00001) / \mathrm{RDIV}$

$W=0$

$\mathrm{N}=4$

$\mathrm{L}=\mathrm{B}+.00001$

$: A$

NSEL , $Z, W$

NRSEL , $X, L$

$C P, N, U X, A L L$

NALL

$\mathrm{N}=\mathrm{N}+1$

$\mathrm{L}=\mathrm{L}+\mathrm{B}$

$* I F, L, L E, R,: A$

$\mathrm{W}=\mathrm{W}+\mathrm{H} / \mathrm{HDIV}$

$L=B+.00001$

$* I F, W, L E, H / 2,: A$

$\mathrm{W}=\mathrm{H} / \mathrm{HDIV}$

$\mathrm{L}=.00001$

$: \mathrm{E}$

NSEL, $Z, W$

NRSEL , $X, L$

$C P, N, U Z, A L L$

NALL 
APÊNDICE' D.

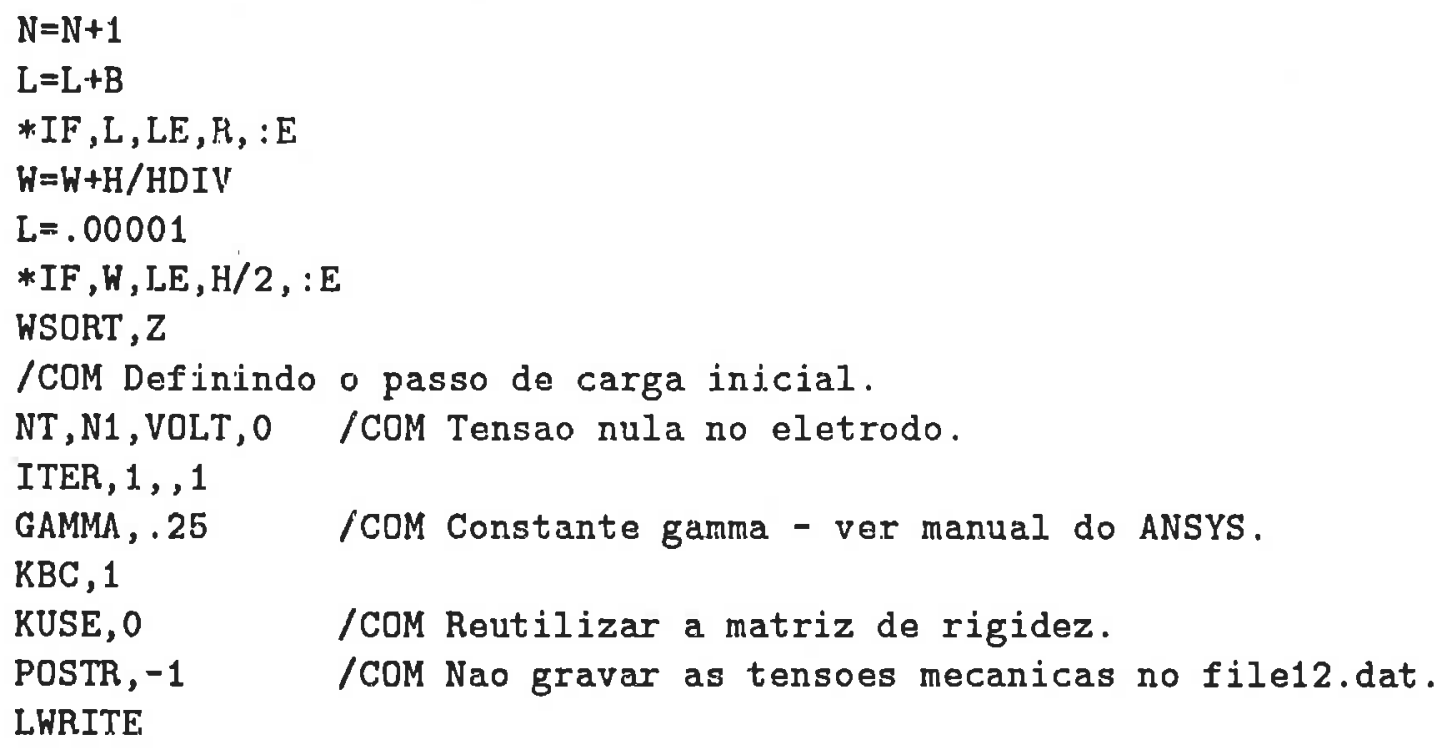

\section{Rotina DIRAC}

/COM Essa rotina monta a tabela tensao $\mathrm{X}$ tempo para um pulso de /COM banda retangular de largura $2 * F$. Deve ser usada no PREP6.

NTABLE, 6

NU=NMAX *1E7 /COM NMAX e o tempo maximo de analise.

NSTEPS, NU

/COM Montando a tabela.

$\mathrm{COS}, 2,1, \mathrm{NU}, 1,1,(360 * \mathrm{~F} * 1 \mathrm{E}-7), 90$

FILL , 3, 1, NU , 1, 1E-7, 1E-7

FILL $, 4,1$, NU $, 1,1 /(2 * F), 0$

COMBIN , $6,3,4,,,-1$

DIVIDE $, 5,2,6, .3183$

/COM Comandos destinados a reduzir o arquivo de saida file12.dat.

LGR1, NPRINT , , 0

LGR1, POSTR, , -1

LGR1, NITTER, , 1

LGR1, NPOST, , 1

LGR1,TIME,3 /COM Associa os incrementos de tempo com a tabela 3.

LGR1,KUSE,,0 /COM Determina a reutilizacao da matriz rigidez.

LGR2,VOLT,N1,5 /COM Associa a tensao eletrica aplicada no no1 com a tabela 


\section{D.6 Acoplamento fluido-estrutura}

\section{Rotina PP}

/COM Essa rotina cria um modelo que permite calcular o campo acustico /COM de um pistao plano circundado por um refletor rigido perfeito, excitado /COM em OC. Deve ser usada no PREP7.

MP,DENS,1,1000 /COM Definicao das propriedades do fluido (agua).

MP , VISC , 1,1500

$M P, M U, 1,0$

MP, DENS , 2, 1000

MP , VISC $, 2,1500$

MP , MU , 2,1

/COM Absorcao igual a 1.

CSYS, 1

/COM Construcao do Modelo.

$\mathrm{K}, 1, .00001,-\mathrm{A}$

/COM Definicao dos keypoints.

$\mathrm{K}, 2, \mathrm{R},-\Lambda$

$K, 4, .00001,-A, R$

$K, 5, R,-A, R$

$K, 3, R 1,-A$

$\mathrm{K}, 7, .00001,-\Lambda, \mathrm{R} 1$

CSYS, 2

$\mathrm{K}, 6, \mathrm{R} 1,-\mathrm{A}, 45$

$\mathrm{L}, 6,7, \mathrm{RDIV}$

$\mathrm{L}, 3,6, \mathrm{RDI}$.V

/COM Definicao das linhas.

CSYS, 1

L , 1,2, RDIV

L , 2,3, LDIV

L , 1,4, RDIV

$\mathrm{L}, 4,7, \mathrm{LDIV}$

$L, 2,5$, RDIV

$\mathrm{L}, 4,5, \mathrm{RDIV}$

L , 5,6, LDIV

A, $1,2,5,4$

CSYS, 2

/COl Definicao das areas.

$A, 5,2,3,6$

$A, 5,6,7,4$

CSYS 1

AGEN $, 2,1,3,1,2 * A,, 7$

ELSIZE , , 1,2

V, $12,5,4,11,9,2,1,8$ /COM Definicao dos volumes.

$\mathrm{V}, 13,6,7,14,12,5,4,11$

$\mathrm{V}, 13,6,5,12,10,3,2,9$

VATT,1,,1/COM Definicao dos elementos fluidos. 
APENNDICE D.

VMESH, ALL /COM Definicao da malha.

MERGE

NSEL , Z, O

/COM Definicao dos elementos de interface no plano $Z=0$.

ENODE

TYPE, 2

/COM Elemento de interface.

MAT, 1

EMOD, ALI.

EALL

NALL

CSYS, 2

NSEL , X , R1

/COM Definicao dos elementos de interface no raio $R 1$.

ENODE

TYPE, 2

MAT , 2

EMOD , ALL

EALL

NALL

$\mathrm{C} 1=(\mathrm{R}-.00001) / \mathrm{RDIV} / \mathrm{COM}$ Definindo os incrementos no espaco.

$\mathrm{C} 3=(\mathrm{R} 1-\mathrm{R}) / \mathrm{LDIV}$

CSYS, 1

NSEL, $Z, 0$

/COM Acoplando pressao e deslocamento no plano $\mathrm{Z}=0$.

PSF, ALL , , 1.0

$D, A L L, U X$

/COM Definindo o refletor rigido perfeito.

NRSEL , X, R, R1, C3

$D, A L L, U Z$,

NALL

CSYS, 2

NSEL , X, R1

/COM Acoplando pressao e deslocamento no raio R1.

PSF , ALL , , , 1.0

D,ALL,UX,,,,,UZ /COM Definindo a parede ficticia.

NALL

CSYS, 1

NSEL $, Z, 0$

NRSEL , $X, 0, R+0.01, C 1$

D,ALL,UZ,1E-6 /COM Definindo amplitude de vibracao do pistao.

NALL

D,ALL,UY /COM Definindo condicao de contorno.

/COM Acoplando GLs de pressao e deslocamento dos planos laterais.

$\mathrm{N}=1$

$\mathrm{C} 2=\mathrm{R} / \mathrm{RDIV}$

$\mathrm{W}=0$

$\mathrm{L}=0.00001+\mathrm{C} 1$

:D

NSEL , $Z, W$

NRSEL, $X, L$ 
APÊNDICE D.

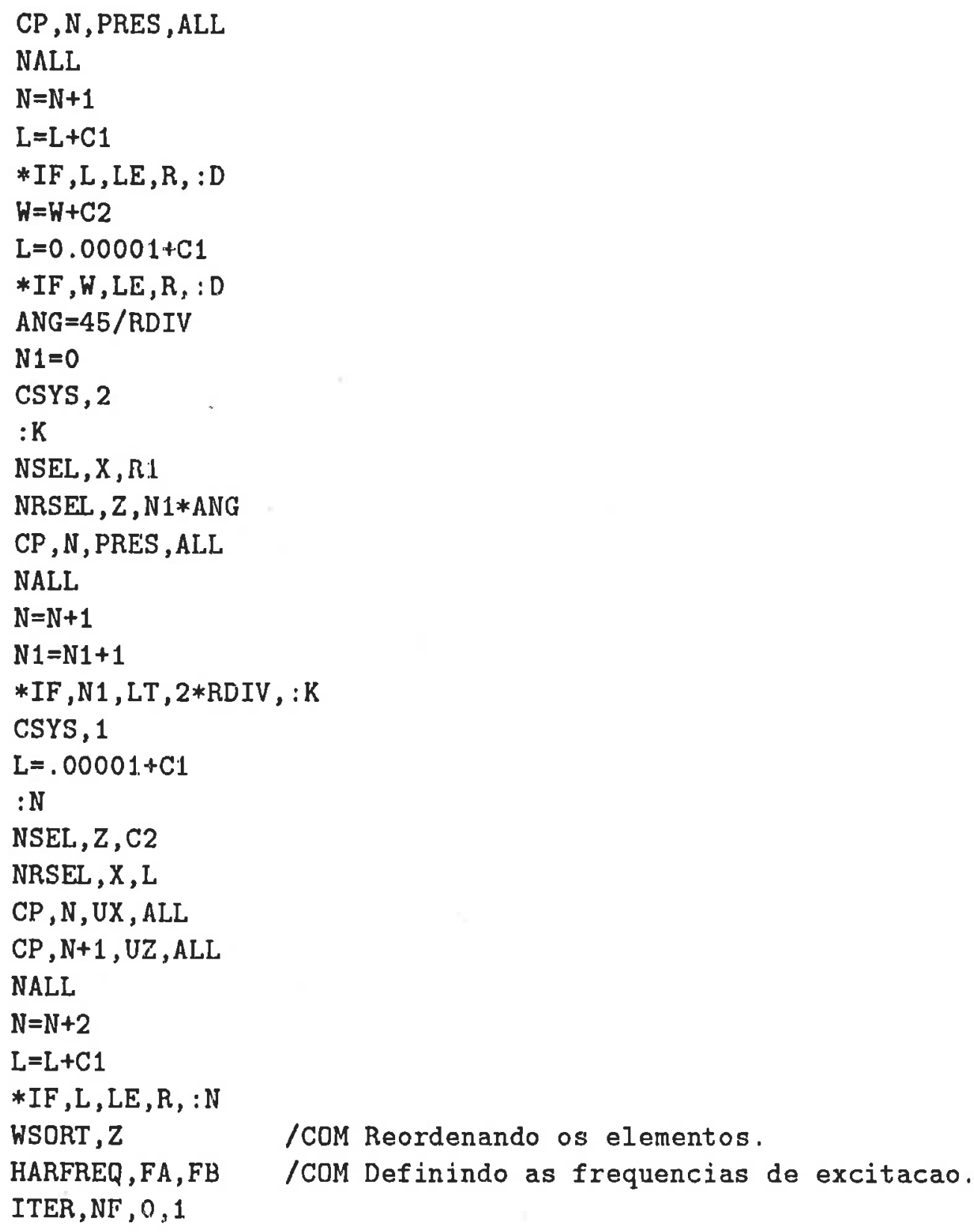

\section{Rotina TCP1}

/COM Essa roitina cria um modelo que permite calcular o campo acustico /COM de um transdutor cilindrico, circundado por um refletor rigido /COM pefeito, excitado em OC. A montagem do modelo segue o mesmo /COM procedimento que a rotina PP. Deve ser usada no PREP7.

MP , DENS , 1, 1000 /COM Definicao das propriedades do fluido. MP , VISC $, 1,1500$ $M P, M U, 1,0$ 


\section{APÊNDICE D.}

MP , DENS , 2, 1000

MP, VISC , 2,1500

MP, MU , 2,1

CSYS, 1

$\mathrm{K}, 1, .00001,-\mathrm{A},-\mathrm{H}$ /COM Construcao do modelo.

$K, 2, R,-A,-H$

$K, 3, .00001,-A$

$\mathrm{K}, 4, \mathrm{R},-\mathrm{A}$

$K, 6, .00001,-A, R$

$K, 7, R,-A, R$

$K, 5, R 1,-A$

$K, 9, .00001,-A, R 1$

CSYS, 2

$\mathrm{K}, 8, \mathrm{R} 1,-\mathrm{A}, 45$

$\mathrm{L}, 8,9, \mathrm{RDIV}$

$\mathrm{L}, 5,8, \mathrm{RDIV}$

CSYS, 1

$\mathrm{L}, 1,2, \mathrm{RDIV}$

$\mathrm{L}, 4,5, \mathrm{LDIV}$

$\mathrm{L}, 3,6, \mathrm{RDIV}$

$\mathrm{L}, 6,7, \mathrm{RDIV}$

$\mathrm{L}, 3,4, \mathrm{RDIV}$

$\mathrm{L}, 4,7, \mathrm{RDIV}$

L , 6,9 , LDIV

$\mathrm{L}, 7,8$, LDIV

$\mathrm{L}, 2,4, \mathrm{HDIV}$

$\mathrm{L}, 1,3, \mathrm{HDIV}$

L , 3, 4 , RDIV

A, $1,2,4,3$

$A, 3,4,7,6$

CSYS, 2

$A, 7,4,5,8$

$A, 7,8,9,6$

CSYS, 1

AGEN, $2,1,4,1,2 * A,, 9$

ELSIZE , , 1,2

$\mathrm{V}, 16,7,6,15,13,4,3,12$

$\mathrm{V}, 17,8,9,18,16,7,6,15$

$\mathrm{V}, 17,8,7,16,14,5,4,13$

$\mathrm{V}, 13,4,3,12,11,2,1,10$

VATT $, 1,, 1$

VMESH, ALL

/COM Definicao do elemento fluido.

NSEL , $Z, O$

/COM Construcao da malha.

ENODE

TYPE, 2 
APENNDICE D.

MAT, 1

EMOD, ALL

EALL

NALL

VLSEL, , 4

/COM Atribuicao das propriedades è elementos piezoeletric EVOLU

TYPE, 3

MAT, 3

EMOD, ALL

EALL

VLALL

CSYS, 2

NSEL , X, R1

/COM Definicao dos elementos de interface no raio $\mathrm{R} 1$.

ENODE

TYPE, 2

MAT, 2

EMOD, ALL

EALL

NALL

$\mathrm{B}=(\mathrm{R}-.00001) / \mathrm{RDIV} / \mathrm{COM}$ Definicao dos incrementos no espaco. $\mathrm{C} 3=(\mathrm{R} 1-\mathrm{R}) / \mathrm{LDIV}$

CSYS, 1

NSEL, $Z, 0$

PSF, ALL , , , 1.0

NRSEL, $X, R, R 1, C 3$

$D, A L L, U X,,,,, U Z$

NALL

NSEL, $X, .00001$

$D, A L L, U X$

NALL

CSYS, 2

NSEL, X, R1

/COM ao volume 4 .

PSF , ALL , ,, 1.0

$D, A L L, U X, \ldots$, UZ /COM Definindo a parede ficticia.

NALL

CSYS, 1

$D, A L L, U Y$

/COM Definindo condicao de contorno.

CPSIZE, 380

VLSEL , , 4

NVOLU, 1

/COM Acoplando os GLs de pressao e deslocamento no plano

/COM Definindo refletor rigido perfeito.

/COM Definindo condicao de contorno.

CP , 1, TEMP , ALL

/COM Acoplando os GLs desnecessarios, e os GLs de

CP , 2, MAG , ALL

/COM pressao e deslocamento dos planos laterais.

NALL

VLALL

$\mathrm{KBC}, 1$ 
APÊNDICE D.

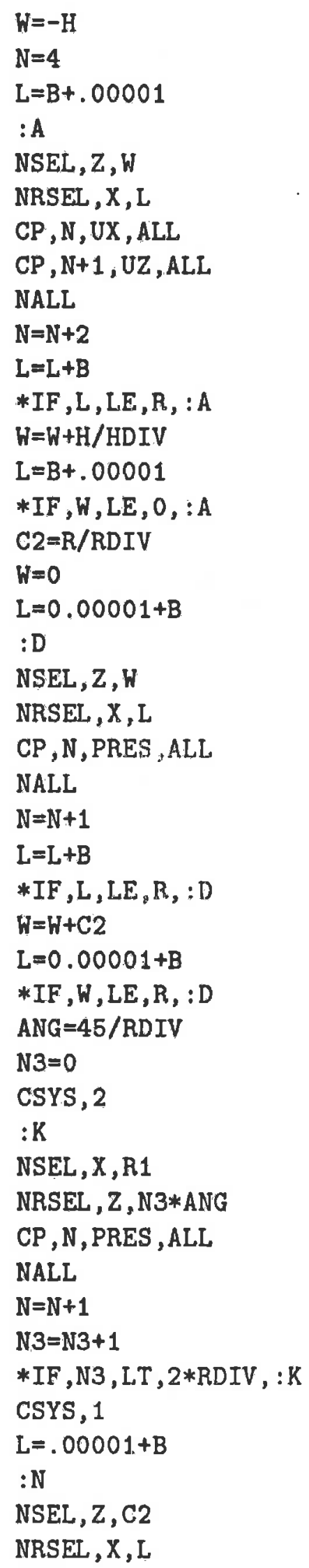


APENNDICE D.

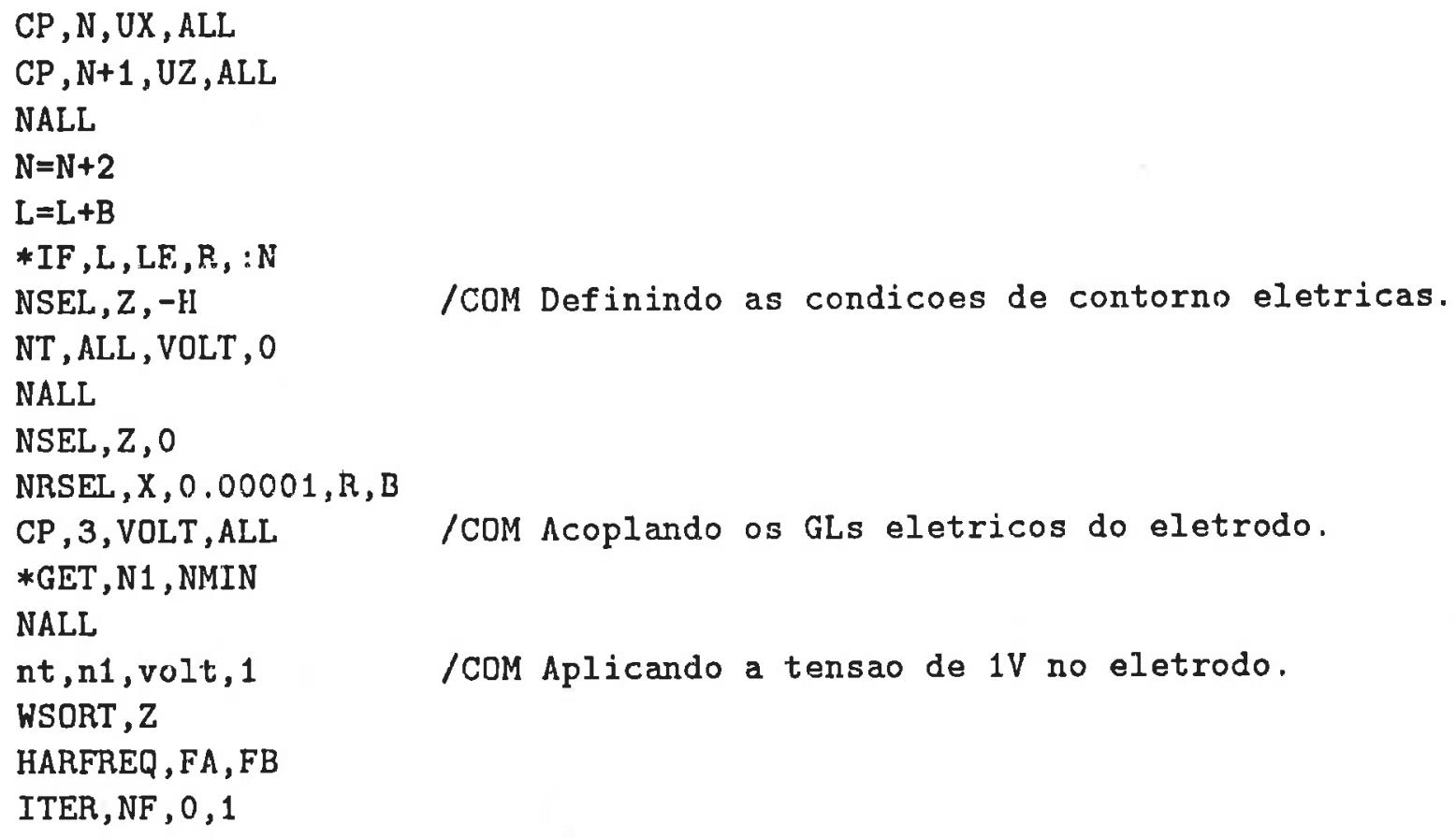

/COM Aplicando a tensao de $1 V$ no eletrodo.

\section{Rotina TCP2}

/COM Essa rotina cria um modelo que permite calcular o campo acustico /COM de um transdutor cilindrico totalmente imerso num fluido, excitado /COM em OC. A montagem do modelo segue o mesmo procedimento da rotina TCP 1. /COM Deve ser usada no PREP7.

MP,DENS,1,1000 /COM Definicao das propriedades do fluido.

MP , VISC , 1,1500

MP , MU , 1,0

MP , DENS , 2, 1000

MP, VISC , 2, 1500

MP , MU , 2,1

CSYS, 1

$K, 1,0.00001,-A$

/COM Construcao do modelo.

$K, 2, R,-A$

$\mathrm{K}, 3, \mathrm{R} 1,-\mathrm{A}$

$\mathrm{K}, 4,0.00001,-\mathrm{A}, \mathrm{H} / 2$

$\mathrm{K}, 5, \mathrm{R},-\mathrm{A}, \mathrm{H} / 2$

$\mathrm{K}, 7,0.00001,-\mathrm{A}, \mathrm{R}$

$K, 8, R,-A, R$

$K, 10,0.00001,-A, R 1$

CSYS, 2

$\mathrm{K}, 6, \mathrm{R} 1,-\mathrm{A}, \mathrm{HDIV} * 45 /(2 * \mathrm{RDIV})$

$\mathrm{K}, 9, \mathrm{R} 1,-\mathrm{A}, 45$ 
L , 9,10, RDIV

$\mathrm{L}, 6,9,(\mathrm{RDIV}-(\mathrm{HDIV} / 2))$

$\mathrm{L}, 3,6, \mathrm{HDIV} / 2$

CSYS 1

$\mathrm{L}, 1,2, \mathrm{RDIV}$

$\mathrm{L}, 2,3, \mathrm{LDIV}$

$\mathrm{L}, 4,7$, (RDIV-(HDIV/2))

$\mathrm{L}, 2,5, \mathrm{HDIV} / 2$

$\mathrm{L}, 1,4, \mathrm{HDIV} / 2$

$\mathrm{L}, 5,8,(\mathrm{RDIV}-(\mathrm{HDIV} / 2))$

$\mathrm{L}, 4,5, \mathrm{RDIV}$

$\mathrm{L}, 7,8, \mathrm{RDIV}$

$\mathrm{L}, 7,10$, LDIV

$\mathrm{L}, 8,9$, LDIV

$A, 1,2,5,4$.

$A, 4,5,8,7$

CSYS, 2

A , $5,2,3,6$

A , 5, 6, 9,8

$A, 8,9,10,7$

CSYS 1

AGEN , 2, 1, 5, 1, , 2*A, , 10

ELSIZE , , 1, 2

$\mathrm{V}, 18,8,7,17,15,5,4,14$

$\mathrm{V}, 19,9,10,20,18,8,7,17$

$\mathrm{V}, 19,9,8,18,16,6,5,15$

$\mathrm{V}, 16,6,5,15,13,3,2,12$

$\mathrm{V}, 15,5,4,14,12,2,1,11$

VATT $, 1,1$

VMESH, ALL

VLSEL , , 5

NVOLU, 1

ENODE

TYPE, 2

MAT, 1

/COM Definindo elementos de interface.

EMOD, ALI.

EALL

NALL

VLALL

VLSEL, , 5

EVOLU

/COM Atribuicao das propriedades e dos elementos

TYPE, 3

MAT, 3

EMOD, ALL

EALL 
APÊNDICE D.

VLALL

$\mathrm{C} 3=(\mathrm{R} 1-\mathrm{R}) / \mathrm{LDIV} / \mathrm{COM}$ Definjcao dos incrementos no espaco.

$B=(R-0.00001) / R D I V$

CSYS, 2

NSEL , X, R1

ENODE

TYPE, 2

MAT , 2

/COM Definicao dos elementos de interface no raio $\mathrm{R} 1$.

EMOD, ALL

EALL

NALL

CSYS, 1

NSEL , $\mathrm{Z}, \mathrm{H} / 2$

NRSEL, $X, 0.00001, R, B$

PSF, ALL , , 1.0

/COM Acoplando GLs de pressao e deslocamento nas

NALL

NSEL , $X, R$

NRSEL , Z, $0, H / 2, H / H D I V$

PSF, ALL, , , 1.0

NALL

CSYS , 2

NSEL, X, R1

PSF,ALI, , 1.0 /COM Definindo a parede ficticia.

$D, A L L, U X, \ldots, U Z$

/COM interfaces.

NALL

CSYS, 1

NSEL , $Z, 0$

$D, A L L, U Z$

NALL

NSEL, $X, 0.00001$

$D, A L L, U X$

NALL

$D, A L L, U Y$

CPSIZE , 380

VLSEL, , 5

NVOLU, 1

CP,1,TEMP,ALL /COM Acoplando os GLs desnecessarios es GLs de CP , 2, MAG, ALL

/COM Definicao das condicoes de contorno.

NALL

VLALL

$\mathrm{KBC}, 1$

$W=0$

$\mathrm{N}=4$

$\mathrm{L}=\mathrm{B}+0.00001$

$: A$ 
APÊNDICE D.

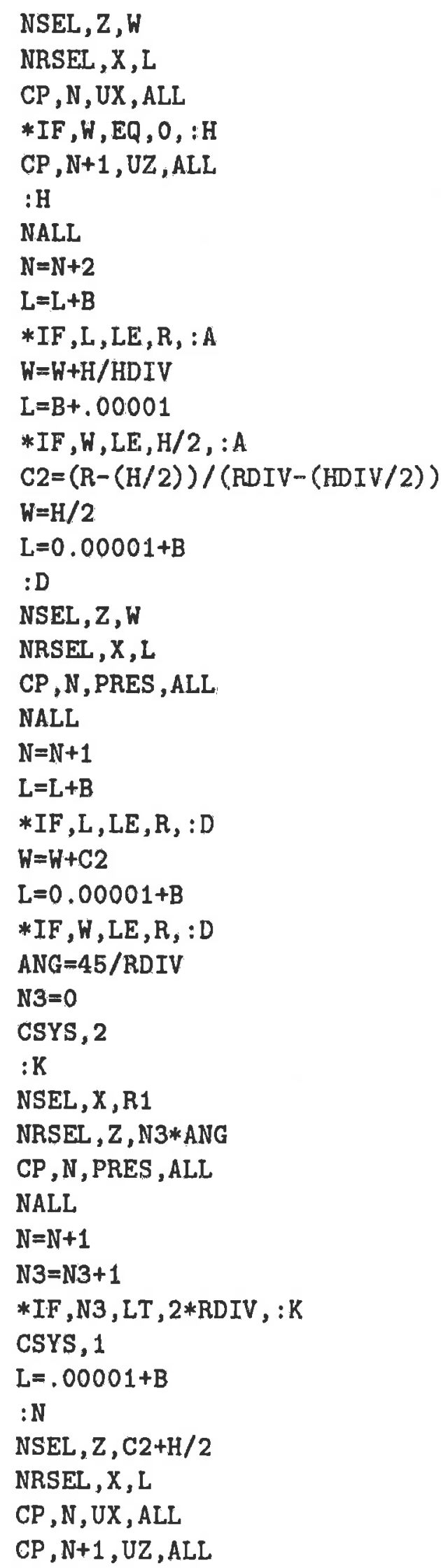




\section{APÊNDICE D.}

NALL

$\mathrm{N}=\mathrm{N}+2$

$\mathrm{L}=\mathrm{L}+\mathrm{B}$

$* I F, L, L E, R,: N$

NSEL , $Z, 0$

/COM Definindo as condicoes de contorno eletricas.

NRSEL , $X, 0.00001, R, B$

NT, ALL , VOLT , 0

NALL

NSEL , $\mathrm{Z}, \mathrm{H} / 2$

NRSEL , $X, 0.00001, R, B$

CP , 3, VDLT, ALL

/COM Acoplando os GLs eletricos do eletrodo.

*GET , N1, NMIN

NALL

NT,N1,VOLT,0.5 /COM Aplicando a tensao de $0,5 \mathrm{~V}$ no eletrodo.

WSORT, Z

HARFREQ , FA , FB

ITER, NF , 0,1

\section{Rotina TCPMB}

/COM Mesmo procedimento da rotina TCP1 levando em conta as camadas de /COM casamento e retaguarda. Deve ser usada no PREP7.

MP , DENS , 1,1000

/COM Definicao das propriedades do fluido.

MP , VISC , 1, 1500

$M P, M U, 1,0$

MP , DENS , 2,1000

MP , VISC $, 2,1500$

MP , MU , 2,1

MP, EX,4,7.03E10 /COM Definicao das propriedades da camada de

MP, NUXY, 4,.345 /COM casamento.

MP , DENS , 4,2690

MP,EX,5,7.03E10 /COM Definicao das propriedades da camada de

MP , NUXY , $5, .345$

MP , DENS , 5,2690

CSYS, 1 /COM retaguarda.

$\mathrm{K}, 1, .00001,-\mathrm{A},-(\mathrm{HM}+\mathrm{H}+\mathrm{HB})$

/COM Construcao do modelo.

$\mathrm{K}, 2, \mathrm{R},-\mathrm{A},-(\mathrm{HM}+\mathrm{H}+\mathrm{HB})$

$K, 3, .00001,-A,-(H M+H)$

$\mathrm{K}, 4, \mathrm{R},-\mathrm{A},-(\mathrm{HM}+\mathrm{H})$

$\mathrm{K}, 5, .00001,-\mathrm{A},-\mathrm{HM}$

$K, 6, R,-A,-H M$

$K, 7, .00001,-A$

$K, 8, R,-A$ 
APÊNDICE D.

$\mathrm{K}, 10, .00001,-\mathrm{A}, \mathrm{R}$
$\mathrm{K}, 11, \mathrm{R},-\mathrm{A}, \mathrm{R}$
$\mathrm{K}, 9, \mathrm{R} 1,-\mathrm{A}$
$\mathrm{K}, 13, .00001,-\mathrm{A}, \mathrm{R} 1$
$\mathrm{CSYS}, 2$

$\mathrm{K}, 12, \mathrm{R} 1,-\mathrm{A}, 45$

$\mathrm{L}, 12,13$, RDIV

L , 9,12 , RDIV

CSYS, 1

L, 8,9 , LDIV

L , 7, 10, RDIV

L, 10,11 , RDIV

$\mathrm{L}, 7,8, \mathrm{RDIV}$

$\mathrm{L}, 8,11$, RDIV

L, 10,13 , LDIV

$\mathrm{L}, 11,12$, LDIV

$\mathrm{L}, 1,2, \mathrm{RDIV}$

$\mathrm{L}, 3,4, \mathrm{RDIV}$

$\mathrm{L}, 5,6, \mathrm{RDIV}$

$L, 1,3$, HBDI

$\mathrm{L}, 2,4, \mathrm{HBDI}$

$\mathrm{L}, 3,5, \mathrm{HDIV}$

$L, 4,6, \mathrm{HDIV}$

$\mathrm{L}, 5,7, \mathrm{HMDI}$

$\mathrm{L}, 6,8, \mathrm{HMDI}$

A , 7,8,11,10

$A, 1,2,4,3$

$A, 3,4,6,5$

$A, 5,6,8,7$

CSYS, 2

A , $11,8,9,12$

$A, 11,12,13,10$

CSYS, 1

AGEN , $2,1,6,1,2 * A, 13$

ELSIZE , , 1,2

$\mathrm{V}, 24,11,10,23,21,8,7,20$

$\mathrm{V}, 25,12,13,26,24,11,10,23$

$\mathrm{V}, 25,12,11,24,22,9,8,21$

$\mathrm{V}, 21,8,7,20,19,6,5,18$

VATT $, 1, \ldots$

$\mathrm{V}, 19,6,5,18,17,4,3,16$

VLSEL, , 5

VATT,3,,3 /COM Definicao do transdutor piezoeletrico.

VLALL,

$v, 17,4,3,16,15,2,1,14$ 
APENDICED.

VLSEL , , 6

VATT, $5,, 4$ /COM Definicao da camada de retaguarda.

VLALL

VMESH, ALL /COM Construcas da malha.

NSEL , $Z, 0$

ENODE

TYPE, 2

/COM Definicao dos elementos de interface.

MAT, 1

EMOD, ALL

EALL

NALL

VLSEL, ,4 /COM Definicao da camada de casamento.

EVOLU

TYPE , 4

MAT, 4

EMOD , ALL

EALL

VLALL

CSYS, 2

NSEL , X, R1

ENODE

TYPE, 2

MAT , 2

/COM Definicao dos elementos de interface no raio $\mathrm{R} 1$.

EMOD , ALL

EALL

NALL

$\mathrm{B}=(\mathrm{R}-.00001) / \mathrm{RDIV} / \mathrm{COM}$ Definicao dos incrementos.

C3 $=(\mathrm{R} 1-\mathrm{R}) / \mathrm{LDIV}$

CSYS, 1

NSEL,Z,0 /COM Acoplando GLs de pressao e deslocamento no plano $\mathrm{Z}=0$.

PSF, ALL , , , 1.0

NRSEL, X,R,R1,C3 /COM Definindo o refletor rigido perfeito.

$D, A L L, U X,,,,,, U Z$

NALL

NSEL , X, .00001

$D, A L L, U X$ /COM Definicao das condicoes de contorno.

NALL.

CSYS, 2

NSEL $, X, R 1$

PSF,ALL,, ,1.0 /COM Definicao da parede ficticia.

$D, A L L, U X,,,,, U Z$

NALL

CSYS, 1

D,ALL,UY /COM Definicao das condicoes de contomo.

CPSIZE , 380 
VLSEL, , 5

NVOLU, 1

CP,1,TEMP,ALL /COM Acoplando os GLs desnecessarios.

CP , 2, MAG , ALL

NALL

VLALL

$\mathrm{KBC}, 1$

NSEL, Z, $-(H M+H) / C O M$ Definindo as condicoes de contorno eletricas.

NT , ALL , VOLT , 0

NALL

NSEL , Z, -HM

CP, 3,VOLT,ALL /COM Acoplando os GLs eletricos do eletrodo.

*GET, N1, NMIN

NALL

NT,N1, VOLT, 1 /COM Aplicando a tensao de $1 \mathrm{~V}$ no eletrodo.

WSORT, Z

HARFREQ , FA, FB

ITER, NF , 0,1

\section{Rotinas AMPL e VELOC}

/COM AMPL e VELOC sao destinadas ao pos-processamneto dos

/COM dados de pressao o veloc. do fluido. Devem ser usadas no POST1.

/COM AMPL - Plota o grafico de amplitudes de pressao.

STORE,DISP /COM Le as pressoes nodais.

/COM Calculando a amplitude.

LCLIM , 3

LCASE , 1

SET , 1, LS

LCASE , 2

SET, 1, LS , , 1

LCASE, 3 /COM Gravando no caso 3.

LCSRSS , $3,1,2$

LCASE, 3 /COM Torna o caso 3 corrente.

/COM VELOC - Plota a distribuicao das amplitudes dos vetores velocidade.

/COM Lendo as componentes dos vetores veloc.

STRESS , VLSUM , 30,7

STRESS , VLX $, 30,8$

STRESS, VLY $, 30,9$

STRESS , VLZ, 30,10 
APÊNDICE D.

STORE, STRES

/COM Calculando a amplitude

LCLIM , 3

LCASE , 1

SET $, 1,1$

LCASE , 2

SET $, 1,1,, 1$

LCASE, 3

LCSRSS $, 3,1,2$

LCASE, 3

\section{D.7 Análise Transiente Acústica}

\section{Rotina TRANPP}

/COM Essa rotina cria um modelo para o calculo do campo transiente /COM resultante da excitacao de um pistao plano (circundado por um refletor /COM rigido perfeito) por um pulso definido na macro EXCIT. Deve ser usada /COM no PREP7.

$\mathrm{KAY}, 5,2$

ET, 1,30, 1 /COM Definindo os elementos.

ET $, 2,30$

$\mathrm{MU}, 1,0$ /COM Definindo as propriedades do fluido.

VISC $, 1,1500$

DENS, 1,1000

CSYS 1 /COM Construindo o modelo - setor cilindrico de fluido.

$\mathrm{K}, 1,0.00001,-\mathrm{A}$

$\mathrm{K}, 2, \mathrm{R} 1,-\mathrm{A}$

$\mathrm{K}, 3,0.00001,-\mathrm{A}, \mathrm{H}$

$\mathrm{K}, 4, \mathrm{R} 1,-\mathrm{A}, \mathrm{H}$

$\mathrm{L}, 1,2,9 * \mathrm{KE}$

$\mathrm{L}, 3,4,9 * \mathrm{KE}$

$\mathrm{L}, 1,3,6 * \mathrm{KE}$

$\mathrm{L}, 2,4,6 * \mathrm{KE}$

A, $1,2,4,3$

AGEN $, 2,1,1,, 2 * A,, 4$

ELSIZE , , 1,2

$\mathrm{V}, 8,4,3,7,6,2,1,5$

VMESH, ALL

/COM Construindo a malha.

NSEL, $Z, 0$

/COM Definindo elementos de interface.

ENODE

TYPE, 2 
EMOD, ALL

EALL

NALL

NSEL $, Z, 0$ /COM Definindo o refletor rigido perfeito.

NRSEL , $X, R, R 1,(R 1-R) / 6 * K E$

$D, A L L, U Z,,,,, U X$

NALL

NSEL, $\mathrm{X}, 0.00001$ /COM Definindo as condicoes de contorno mecanicas.

$D, A L L, U X$

NALL

$\mathrm{C} 1=(\mathrm{R}-0.00001) /(3 * \mathrm{KE})$

$\mathrm{C} 2=\mathrm{H} /(6 * \mathrm{KE})$

NSEL , $Z, 0$

PSF,ALL, ,1.0/COM Acoplando os GLs de pressao e deslocamento.

NRSEL , $X, 0.00001, R, C 1$

$D, A L L, U X$

NALL

D,ALL, UY /COM Definindo condicoes de contorno mecanicas.

$\mathrm{KRF},-1$

ITER $, 1,, 1$

TIME, 1E-6/KT /COM Definindo o incremento de tempo.

GAMMA , . 25

$\mathrm{KBC}, 0$

$\mathrm{K}=(.25 * \operatorname{COS}(12.57 / \mathrm{KT})-\operatorname{COS}(6.28 / \mathrm{KT})+.75) * 1 \mathrm{E}-6$

NSEL, $\mathrm{Z}, 0$

NRSEL , $X, 0.00001, R, C 1$

$D, A L L, U Z, K$ /COM Definindo o deslocamento do pistao no primeiro incremen

NALL /COM de tempo.

NSEL , $Z, 0$

NRSEL , $X, 0.00001$

$D, A L L, U Z, K$

NALL

NSEL , $Z, 0$

NRSEL , $X, R$

$D, A L L, U Z, K$

NALL

LWRITE

\section{Rotina EXCIT}

/COM Essa rotina cria um pulso de excitacao em deslocamento, dado por /COM uma funcao definida no texto.

NTABLE , 5 
APÊNDICE D.

NSTEPS , KT"

FILL , 3, 1, KT-1, 1, .75E-6

$\mathrm{COS}, 1,1, \mathrm{KT}-1,1, .25 \mathrm{E}-6,720 / \mathrm{KT}, 720 / \mathrm{KT}$

$\mathrm{COS}, 2,1, \mathrm{KT}-1,1,-1 \mathrm{E}-6,360 / \mathrm{KT}, 360 / \mathrm{KT}$

COMBIN , 2, 1, 2, 3

FILL , $2, \mathrm{KT}, \mathrm{KT}, 1,0$

FILL $, 4,1, \mathrm{KT}-1,1,2 \mathrm{E}-6 / \mathrm{KT}, 1 \mathrm{E}-6 / \mathrm{KT}$

FILL $, 4, K T, K T, 1,(1 E-6)+(\operatorname{NMAX}-1) *(1 E-6)$

FILL , 3, 1, KT-1, 1, 1

FILL , 5, 1, KT-1, 1, 1

FILL , 3,KT , , , (NMAX-1)*KT

FILL , $5, \mathrm{KT},,, 3$

LGR1, NPRINT, ,0 /CDM Comandos destinados a reduzir 0 arquivo de

LGR1,POSTR, ,-1 /COM pos-processamento file12.dat.

LGR1, NITTER, 3

LGR1, NPOST , 5

LGR1,KUSE, , 1 /COM Determina a reutilizacao da matriz de rigidez LGR1, TIME 4 /COM no calculo.

LGR2,UZ,183,2, 201,1 /COM Associa a excitacao com os nos do pistao. $\mathrm{LGR} 2, \mathrm{UZ}, 2163,2,2180,1$

LGR2, UZ, 2127,2 